\title{
ANÁLISE ESTRUTURAL DE PAINÉIS DE CONCRETO PRÉ-MOLDADO CONSIDERANDO A INTERAÇÃO COM A ESTRUTURA PRINCIPAL
}

\author{
VANESSA CRISTINA DE CASTILHO
}

Dissertação apresentada à Escola de Engenharia de São Carlos, da Universidade de São Paulo, como parte dos requisitos para a obtenção do Título de Mestre em Engenharia de Estruturas.

ORIENTADOR: Prof. Dr. Mounir Khalil El Debs

São Carlos

1998 


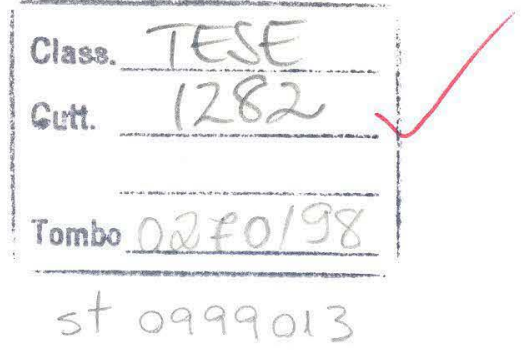

Ficha catalográfica preparada pela Seção de Tratamento da Inform ação do Serviço de Biblioteca - EESC-USP

Castilho, Vanessa Cristina de
Análise estrutural de painéis de concreto
pré-moldado considerando a interação com a
estrutura principal / Vanessa Cristina de
Castilho. -- são Carlos, 1998.
Dissertação (Mestrado) -- Escola de Engenharia
de São Carlos-Universidade de São Paulo, 1998.
Área: Engenharia de Estruturas.
Orientador: Prof. Dr. Mounir Khalil El Debs.
1. Painéis pré-moldados. 2. Deformabilidade das
ligaços. 3. Interaço do fechamento com a
estrutura principal. I. Título.




\section{FOLHA DE APROVACÃO}

Candidata: Engenheira VANESSA CRISTINA DE CASTILHO

Dissertação defendida e aprovada em 25.09.1998 pela Comissão Julgadora:

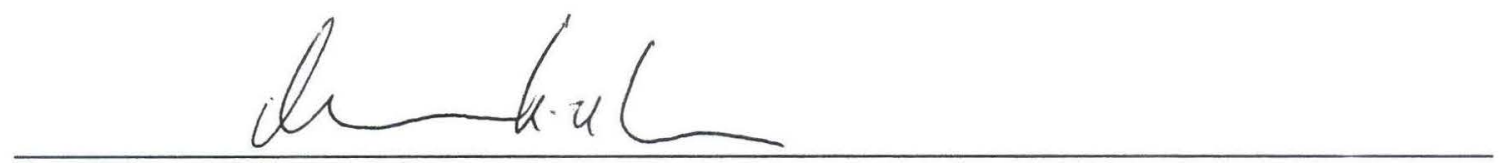

Prof. Assoc. MOUNIR KHALIL EL DEBS (Orientador)

(Escola de Engenharia de São Carlos - Universidade de São Paulo)

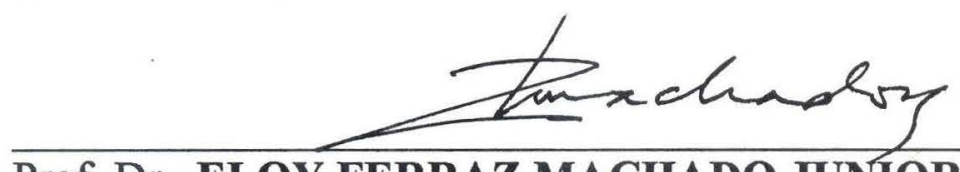

Prof. Dr. ELOY FERRAZ MACHADO JUNIOR

(Escola de Engenharia de São Carlos - Universidade de São Paulo)

$\frac{\text { Aloisio \&, Arsan }}{\text { Prof. Liv.Doc. ALOÍSIO ERNESTO ASSAN }}$

(Universidade Estadual de Campinas - UNICAMP)

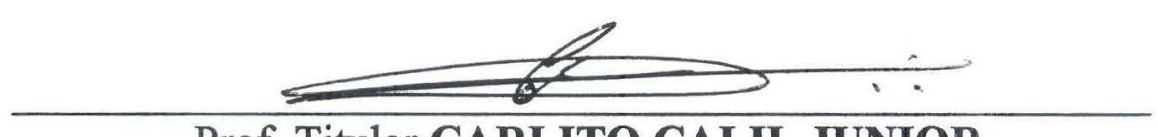

Prof. Titular CARLITO CALIL JUNIOR

Coordenador da Área de Engenharia de Estruturas

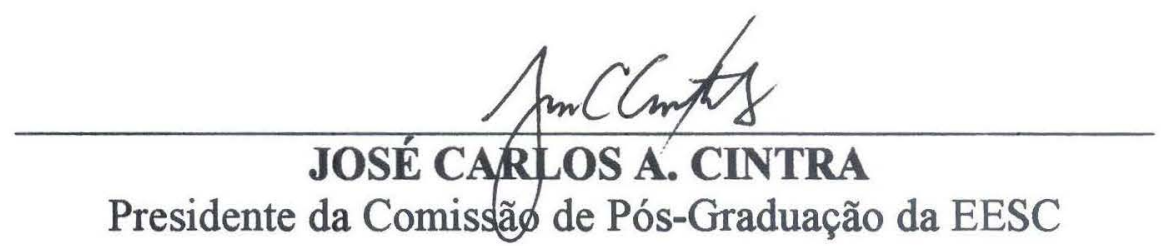


Aos meus pais,

Lucas e Elza

e aos meus irmãos,

Alessandra e Fabrício. 


\section{AGRADECIMENTOS}

Àquele que me deu forças para poder enfrentar as duras etapas da minha vida, dando-me a oportunidade de poder realizar este trabalho, ao meu Deus.

Ao Prof. Dr. Mounir Khalil El Debs, pela orientação, extrema paciência e interesses demostrados na elaboração do trabalho, e pela oportunidade de ter sido sua orientanda.

Ao Engenheiro Laércio Souza Gil, pelas sugestões e pela valiosa ajuda, sem a qual não seria possível a realização dos exemplos.

À grande amiga Kristiane Mattar Accetti, pelo grande carinho, companheirismo e apoio durante minha estada em São Carlos.

Aos inesquecíveis amigos do Departamento de Engenharia de Estruturas da Escola de Engenharia de São Carlos - USP.

A Anamaria Malachini Miotto Soares e Carlos Humberto Martins, pelos ensinamentos iniciais do "software" LUSAS.

A Suzana Campana Peleteiro e Arthur Dias Mesquita, pela grande ajuda e valiosas sugestões para o trabalho.

A Fernanda Telles pela paciência e pela brilhante ajuda na redação da dissertação.

Ao grande amigo Dr. João Ferreira Neto, pela disposição em me ouvir nos momentos difíceis.

A Maria Nadir Minatel, pelas orientações fornecidas na elaboração do trabalho.

Ao CNPQ, pelo apoio financeiro concedido no primeiro ano

À FAPESP, pelo apoio financeiro concedido no segundo ano. 


\section{SUMÁRIO}

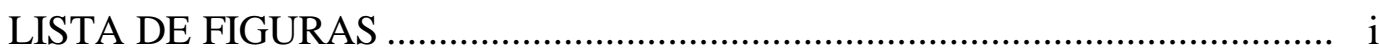

LISTA DE TABELAS …................................................................

LISTA DE SÍMBOLOS ........................................................................ vi

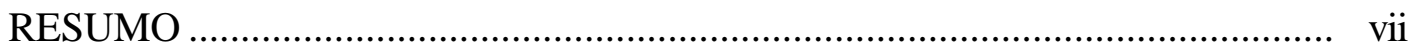

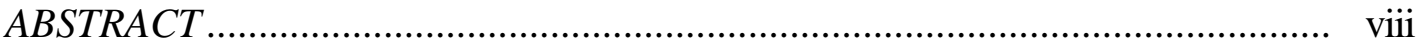

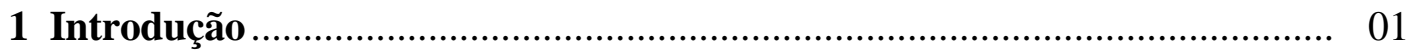



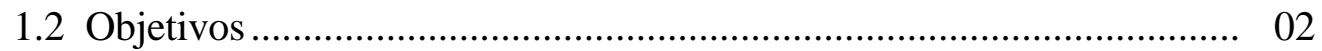

1.3 Organização do trabalho ............................................................. 02

2 Projeto estrutural do painel de fechamento .............................................. 04

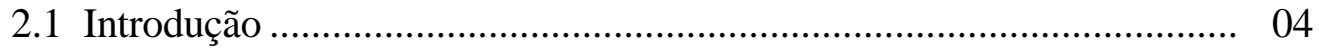

2.2 Tipos de painéis pré-moldados ........................................................ 12

2.2.1 Painéis não-estruturais........................................................ 12

2.2.2 Painéis portantes.................................................................. 13

2.2.3 Painéis usados como paredes de contraventamento ............... 13

2.2.4 Painéis usados como fôrmas para o concreto moldado no local 17

2.3 Projeto do painel de fechamento ........................................................ 18

2.3.1 Preliminares .................................................................... 18

2.3.2 Fases transitórias ............................................................... 20

2.3.3 Situações definitivas ............................................................ 29

2.4 Ligaç̧̃̃es ..................................................................................... 31

2.4.1 Preliminares ..................................................................... 31

2.4.2 Considerações do projeto de ligações...................................... 33

2.4.3 Tipos de ligações .................................................................. 35

2.4.4 Deformabilidade das ligações................................................. 40

3 Modelos de análise da interação painel de fechamento $x$ estrutura

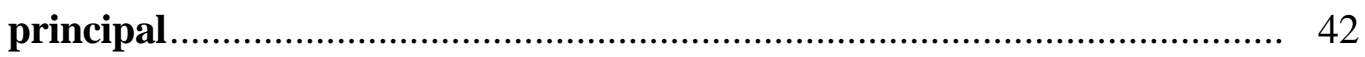

3.1 Estudos anteriores realizados ................................................... 42

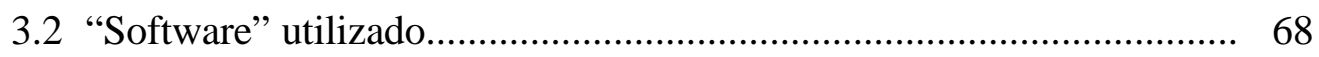


3.2.1 Informações gerais.................................................................... 68



3.3 Modelagem utilizada para painéis e ligações......................................... 74

3.3.1 Modelagem para o caso plano ……………………………........ 74

3.3.2 Modelagem para o caso fora do plano....................................... 74

4 Analise da interação painéis $\mathbf{x}$ estrutura principal de situações típicas..... 77

4.1 Painel isolado ................................................................................ 77

4.1.1 Preliminares ............................................................................ 77

4.1.2 Análise dos deslocamentos................................................... 79

4.1.3 Análise dos resultados dos esforços nos painéis e ligações ..... 90

4.1.3.1 Análise das tensões nos painéis ................................. 90

4.1.3.2 Análise dos esforços nas ligações .............................. 94

4.2 Exemplo de estrutura de um único pavimento...................................... 96

4.2.1 Descrição da estrutura ……………………………………..... 96

4.2.2 Análise dos deslocamentos................................................ 102

4.2.3 Análise dos resultados dos esforços nos painéis e ligações ..... 108

4.2.3.1 Análise de tensões..................................................... 108

4.2.3.2 Esforços resultantes nas ligações.............................. 110

4.3 Exemplo de estrutura de vários pavimentos ………………………..... 112

4.3.1 Descrição da estrutura e painéis ............................................... 112

4.3.2 Análise dos deslocamentos................................................... 117

4.3.3 Análise dos resultados dos esforços nos painéis e ligações ..... 120

4.3.3.1 Tensões nos painéis ............................................... 120

4.3.3.2 Esforços resultantes nas ligações............................... 122

5 Considerações finais e conclusões........................................................... 128

Referências Bibliográficas ........................................................................ 130 


\section{LISTA DE FIGURAS}

FIGURA 2.1 - Aplicações da pré-moldagem .................................................... 07

FIGURA 2.2- Réplica de Parthenon ................................................................... 09

FIGURA 2.3- Templo de Baha'i.................................................................... 09

FIGURA 2.4- Edificações com painéis de concreto pré-moldado ........................ 10

FIGURA 2.5- Disposição típica dos painéis de fechamento................................. 12

FIGURA 2.6- Exemplo de edificação com painel liso........................................... 14

FIGURA 2.7- Exemplo de edificação de painéis com aberturas .......................... 14

FIGURA 2.8- Exemplo de edificação com painel do tipo "spandrel” .................. 15

FIGURA 2.9- Exemplo de edificação com fasquia de divisão ............................. 15

FIGURA 2.10- Exemplo de edificação com painel "sandwich".......................... 16

FIGURA 2.11- Exemplo de edificação com painéis estruturais .......................... 16

FIGURA 2.12- Exemplo de edificação como paredes de contraventamento........ 17

FIGURA 2.13- Exemplo de edificação de painéis como fôrmas ........................... 18

FIGURA 2.14- Espessura mínima do painel........................................................... 19

FIGURA 2.15- Força unitária aplicada no painel ................................................ 21

FIGURA 2.16- Momentos referentes a algumas situações na desmoldagem em elementos lineares …....................................................... 25

FIGURA 2.17- Desmoldagem com o levantamento da peça ................................ 27

FIGURA 2.18- Transporte de painéis em forma de A ......................................... 27

FIGURA 2.19- Transporte de acordo com o peso do painel................................ 28

FIGURA 2.20- Momentos devido à montagem ...................................................... 29

FIGURA 2.21- Deformação do painel devido à temperatura................................. 30

FIGURA 2.22- Vinculação típica dos painéis com a indicação dos movimentos liberados pelas ligações .......................................................... 33

FIGURA 2.23- Tipos de ligações de apoio vertical fixo diretas ........................... 36

FIGURA 2.24- Tipos de ligações de apoio vertical fixo excêntricas.................... 37 
FIGURA 2.25- Tipos de ligações de apoio perpendicular ................................. 38

FIGURA 2.26- Tipos de ligações de alinhamento .............................................. 39

FIGURA 2.27- Representação da deformabilidade ........................................... 41

FIGURA 2.28- Barra embutida entre dois elementos de concreto....................... 41

FIGURA 3.1-Enchimento do tipo 1 ................................................................. 43

FIGURA 3.2-Enchimento do tipo 2 ….............................................................. 43

FIGURA 3.3-Enchimento do tipo 3 …............................................................. 43

FIGURA 3.4- Definição da largura da diagonal de enchimento ........................... 44

FIGURA 3.5- Modelo de enchimento................................................................ 44

FIGURA 3.6- Vistas do edifício de 25 andares................................................... 47

FIGURA 3.7- Deslocamentos para as faces de 1 a 4 ......................................... 48

FIGURA 3.8- Modelo de colapso incremental .................................................... 49

FIGURA 3.9- Deslocamento em função da altura do edifício ............................... 49

FIGURA 3.10- Modelo de histerese …................................................................. 50

FIGURA 3.11- Condições de suporte e relação força x deslocamento para $\mathrm{o}$ modelo de ligação .................................................................. 50

FIGURA 3.12- Modelo e ligações desenvolvido por HENRY e ROLL ............... 51

FIGURA 3.13- Edifício analisado ............................................................... 52

FIGURA 3.14- Deslocamentos laterais para a variação de peso dos painéis........ 52

FIGURA 3.15- Elemento de ligação do painel ................................................... 55

FIGURA 3.16- Estrutura analisada por CHARNEY E HARRIS ........................ 55

FIGURA 3.17- Planta baixa das análises realizadas ............................................ 58

FIGURA 3.18- Localização e tipo de ligações.................................................... 60

FIGURA 3.19- Dimensões dos pilares do edifício ............................................. 60

FIGURA 3.20- Deslocamentos em função dos andares para cada tipo de análise 61

FIGURA 3.21- Modelagem do painel isolado .................................................... 63

FIGURA 3.22- Deslocamentos para os casos de braços rígidos .......................... 67

FIGURA 3.23- Modelo para o caso plano ............................................................ 75

FIGURA 3.24- Modelo para o caso fora do plano............................................. 76 
FIGURA 4.1 - Malha utilizada nos painéis ...................................................... 78

FIGURA 4.2- Dimensões dos painéis ................................................................. 79

FIGURA 4.3- Situações de análises só para o painel........................................... 80

FIGURA 4.4- Situações de análises para o painel no plano ................................. 81

FIGURA 4.5- Situações de análises para o painel fora do plano .......................... 82

FIGURA 4.6- Ligações nos painéis .................................................................. 87

FIGURA 4.7- Deslocamentos em função do tipo de painel................................. 89

FIGURA 4.8- Pontos de análise das tensões e esforços ......................................... 90

FIGURA 4.9- Tensões principais para os 3 caso considerando os 4 tipos

FIGURA 4.10- Dimensões dos painéis pré-moldados .......................................... 97

FIGURA 4.11- Planta baixa do galpão .................................................................. 98

FIGURA 4.12- Disposição dos painéis no galpão pré-moldado ............................ 98

FIGURA 4.13- Detalhe da ligação ....................................................................... 99

FIGURA 4.14- Esquema da estrutura e painéis ................................................. 100

FIGURA 4.15- Ações devido ao vento na estrutura ......................................... 101

FIGURA 4.16- Pontos analisados para tensões e esforços ................................ 109

FIGURA 4.17-Tipos de painéis utilizados ao longo da estrutura ........................ 112

FIGURA 4.18 -Vista do painel de fechamento com o acabamento ..................... 113

FIGURA 4.19 - Disposição dos painéis na estrutura analisada .......................... 114

FIGURA 4.20-Tipo de ligação utilizada para interligar painéis e estrutura

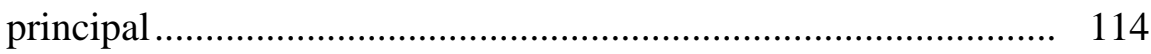

FIGURA 4.21 - Esquema de análise da estrutura e dos painéis......................... 115

FIGURA 4.22- Representação da excentricidade x deslocamento ..................... 117

FIGURA 4.23- Valores extremos de tensões principais em kPa para a aç pilares de seção $600 \times 600 \mathrm{~mm}^{2}$, comprimento de pino de $200 \mathrm{~mm} \quad 121$

FIGURA 4.24- Valores extremos de tensões principais em kPa para a ação 1; pilares de seção 500x500 $\mathrm{mm}^{2}$, comprimento de pino de 50mm. 121

FIGURA 4.25- Valores extremos de tensões principais em kPa para a ação 2; 
pilares de seção $500 \times 500 \mathrm{~mm}^{2}$, comprimento de pino de 50mm. 122

FIGURA 4.26- Esforços de cisalhamento em kN para a ação 1; pilares de seção $600 \times 600 \mathrm{~mm}^{2}$,comprimento de pino de $200 \mathrm{~mm}$

FIGURA 4.27- Esforços de cisalhamento em kN para a ação 1; pilares de seção $500 \times 500 \mathrm{~mm}^{2}$,comprimento de pino de $50 \mathrm{~mm}$

FIGURA 4.28- Esforços de cisalhamento em $\mathrm{kN}$ para a ação 2; pilares de seção $500 \times 500 \mathrm{~mm}^{2}$,comprimento de pino de $50 \mathrm{~mm}$ 


\section{LISTA DE TABELAS}

TABELA 2.1- Momentos na desmoldagem....................................................... 23

TABELA 2.2- Coeficientes dinâmicos .............................................................. 26

TABELA 2.3- Força e momento devido à gradientes térmicos............................ 32

TABELA 3.1- Tipos de enchimento e seus respectivos deslocamentos .............. 46

TABELA 3.2- Deslocamentos da estrutura em função da altura ........................ 56

TABELA 3.3- Deslocamentos obtidos das análises realizadas para o painel isolado.

TABELA 3.4- Modelo de escoras equivalentes com seus respectivos deslocamentos.

TABELA 3.5- Deslocamentos considerando a redução de inércia 67

TABELA 4.1- Deslocamentos e descrição da estrutura e painéis 83

TABELA 4.2- Deslocamentos e descrição da estrutura e painéis 84

TABELA 4.3- Deslocamentos e descrição da estrutura e painéis 85

TABELA 4.4- Deslocamentos e descrição da estrutura e painéis........................ 86

TABELA 4.5- Deslocamentos para as análises consideradas ............................. 88

TABELA 4.6- Tensões principais máximas ........................................................ 91

TABELA 4.7- Valores máximos e sentidos dos esforços ..................................... 95

TABELA 4.8- Deslocamentos no topo do pilar e a descrição para cada caso na direção y.....

TABELA 4.9- Deslocamentos no topo do pilar e a descrição para cada caso na direção $\mathrm{x}$

TABELA 4.10- Resumo dos deslocamentos para os casos analisados..... 105

TABELA 4.11- Valores máximos das tensões principais para a direção y 109

TABELA 4.12- Valores máximos dos esforços em $\mathrm{kN}$ para a direção y....

TABELA 4.13- Deslocamentos no topo do pilar com a descrição dos elementos utilizados para todos os casos.

TABELA 4.14- Resumo de tensões, deslocamentos e esforços nas ligações para os casos analisados 


\section{LISTA DE SÍMBOLOS}

a

$\mathrm{A}_{\mathrm{v}}$

b

E, $\mathrm{E}_{\mathrm{c}}$

$\mathrm{E}_{\mathrm{s}}$

$\mathrm{E}_{\mathrm{t}}$

$\mathrm{H}_{\text {dtotal }}$

I

$\mathrm{I}_{\mathrm{p}}$

$\mathrm{I}_{\mathrm{V}}$

k

$\ell$

W

v

$\theta$

Deslocamento no topo do pilar

Distância do apoio à aplicação da carga $\mathrm{P}$

Distância da parte superior do painel ao seu centro de gravidade

Deslocamento no topo do pilar devido à força lateral

Deslocamento no topo do pilar devido ao desaprumo

Área equivalente da escora

Área equivalente do pilar

Área equivalente da viga

Distância entre pontos de aplicação de forças para a montagem

Módulo de elasticidade do concreto

Módulo de elasticidade do aço

Módulo de elasticidade do concreto modificado para efeitos do tempo

Força horizontal total

Inércia do painel

Inércia do pilar

Inércia da viga

Rigidez

Comprimento do painel

carregamento uniformemente distríbuido

Coeficiente de poison

Ângulo entre a diagonal da escora e o eixo da viga 


\section{RESUMO}

CASTILHO. V. C. (1998) Análise estrutural de painéis de concreto pré-moldado considerando a interação com a estrutura principal. São Carlos. Dissertação (Mestrado) - Escola de Engenharia de são Carlos, Universidade de São Paulo.

No presente trabalho trata-se de um estudo da contribuição de painéis pré-moldados de fechamento no enrijecimento da estrutura principal, com relação às ações laterais. Inicialmente são apontados os critérios correntes de dimensionamento dos -moldados de fechamento sem a consideração da interação destes com a estrutura principal. Em seguida, são desenvolvidas simulações numéricas em três exemplos com o objetivo de avaliar tal efeito. Estes exemplos englobam as seguintes situações: painel isolado, estrutura de um pavimento e uma estrutura de vários pavimentos. Os principias parâmetros analisados são os deslocamentos na estrutura principal, os esforços nas ligações e as tensões nos painéis. Os resultados obtidos mostram a importância da contribuição dos painéis no enrijecimento da estrutura principal. Na estrutura de um único pavimento analisada, a consideração de interação possibilita a passagem de situação em que os efeitos globais de segunda ordem são relevantes para aquela em que tais efeitos são desprezíveis. Para a estrutura analisada de vários pavimentos, a consideração de interação resulta em significativas economias de materiais apontando para economia da ordem de $20 \%$ na estrutura principal. Com base nos resultados, conclui-se que os painéis de fechamento pode ser incorporados numa estratégia de projeto, possibilitando economia na estrutura principal.

Palavras-chaves: painéis pré-moldados, deformabilidades das ligações, interação do fechamento com a estrutura principal 


\begin{abstract}
CASTILHO. V. C. (1998) Structural analysis of precast concrete panels considering the interaction with the main frame. São Carlos. Master degree thesis - Escola de Engenharia de São Carlos, Universidade de São Paulo.
\end{abstract}

This work presents a study of the precast panels contribution in the main frame stiffness, subjected to lateral loads. At first, currents criteria of panels design are analyzed, without considering the interaction with the main frame. After that, three examples are calculated using numerical simulation to evaluate this effect. These examples include the following situations: a single panel, an one-story frame and a multi-story frame. The parameters are: the frame displacements, the connections efforts and the panels tensions. The results show the magnitude of the panels contribution. In fact, to the one-story frame, it was possible to pass from a flexible structure where the second-order effects must be taken into account to an other one where this effects could be neglected. For the multi-story frame analysis, the panels contribution produced an effective material economy of about 20\% (and consequent cost reduction). Basing on these results, one can conclude that the infill panels can be included in the design strategy with economy for the structural system.

Key-words: precast concrete panels, connections deformability, interaction of the infill with the frame 


\section{Introdução}

\subsection{Preliminares}

Atualmente, há uma grande tendência em utilizar elementos de concreto pré-moldado na construção das edificações. Isso se deve à economia de mão-de-obra, materiais e, principalmente, à maior rapidez na construção, alcançada quando o processo da prémoldagem é aplicado.

Um dos elementos de concreto pré-moldado, incorporado nas edificações e amplamente utilizado nos EUA e Europa é o painel de fechamento. Uma das vantagens do seu uso é a possibilidade de utilizar inúmeros recursos, combinados ou não, como: relevos, textura, cor, agregados expostos etc. para compor para compor as fachadas de edificações. Em geral, os mesmos são projetados para transferir o peso próprio e a ação do vento para a estrutura principal.

Neste trabalho são abordados sistemas de fechamento realizados por painéis de concreto pré-moldado, empregados como elementos de vedação de edifícios em estruturas de esqueleto, priorizando-se o efeito de rigidez adicional promovida pelo fechamento, quando é considerada a interação painéis de fechamento x estrutura principal. Esse travamento depende das propriedades do material envolvido e, principalmente, do tipo de sistema de ligação escolhido para conectar os painéis na estrutura principal. Desta forma, o projeto das ligações desempenha um importante papel no estudo da interação. 
$\mathrm{O}$ efeito de enrijecimento em elementos de fechamento tem sido, geralmente, desprezado no cálculo estrutural. Entretanto, devido à inúmeros estudos na área, pôde-se avaliar que tais elementos contribuem na rigidez lateral de edifícios, auxiliando a estrutura principal, na resistência às ações laterais.

Exemplos práticos citados em GAIOTTI (1994) comprovam tal efeito. O mais interessante deles é uma estrutura de 12 andares de concreto armado, localizada no México, que 1985, atingida por um grande terremoto, teve parcela significativa destruída. As fissuras ocorridas nos painéis, juntos aos pilares, verificaram-se nos pontos das ligações e nenhum deles chegou a cair. Um estudo minucioso comprova a eficácia de tais painéis no travamento da estrutura.

Por outro lado, a interação entre estrutura principal e elementos de fechamento acarreta o surgimento de solicitações adicionais nos painéis quando os mesmos são submetidos à ação lateral e, apesar do surgimento de esforços inconveniente nos painéis, o sistema pode ser projetado de forma a promover economia global, em virtude da diminuição dos esforços e deslocamentos da estrutura principal.

\subsection{Objetivos}

Os principais objetivos que se pretende atingir com esta dissertação são:

a) sintetizar as informações sobre o projeto de painéis de fechamento de concreto pré-moldado, enfatizando as ligações com a estrutura principal;

b) analisar a interação dos painéis de fechamento com a estrutura principal; e

c) quantificar o efeito desta interação para situações típicas.

\subsection{Organização do trabalho}

A dissertação está estruturada da forma apresentada a seguir: 
No capítulo 2 relata-se um breve histórico da pré-moldagem e citam-se algumas aplicações práticas do uso de painéis pré-moldados como elemento de fechamento, enfocando-se, ainda, critérios de projeto para as ligações.

No capítulo 3 abordam-se estudos interessantes realizados nesta linha bem como algumas características do "software" utilizado, além dos elementos finitos incorporados na análise e os modelos utilizados para estrutura e ligações.

No capítulo 4 estuda-se o comportamento de painéis e ligações para um painel isolado e de duas estruturas representativas para diferentes tipos de elementos de fechamento, interagindo com a estrutura principal, com relação às ações laterais e volumétricas. Este estudo é desenvolvido mediante simulação numérica, considerando as deformabilidades das ligações.

E finalmente, no capítulo 5 efetuam-se as conclusões e as considerações finais do trabalho. 


\section{Projeto estrutural do painel de fechamento sem considerar a interação}

\subsection{Introdução}

A pré-moldagem é definida como sendo um processo de execução em que a construção, ou parte dela, é moldada fora do seu local de utilização definitivo. O campo de aplicação das técnicas da pré-moldagem é amplo, abrangendo edificações, construções pesadas e diversas outras obras civis, como por exemplo, estádios e muros de arrimo.

O emprego do pré-moldado é bastante antigo, coincidindo com o aparecimento do concreto armado. As primeiras aplicações da pré-moldagem foram a construção do barco de Lambort, em 1848, e os vasos de Joseph Monier, em 1849. A primeira construção utilizando elementos pré-moldados foi em Paris, em 1891, com vigas do Cassino Biarritz.

Nos Estados Unidos surgem os primeiros elementos pré-moldados de grandes dimensões para coberturas, por volta de 1900. Neste país em 1907 foram feitos muitas experiências utilizando as técnicas da pré-moldagem [PHILLIPS \& SHEPPARD (1988)] e nesta mesma época, houve o surgimento do processo "tilt-up". Este processo consta da moldagem dos elementos na posição horizontal, perto do local definitivo, e de sua desmoldagem através do levantamento da peça.

Na Europa, em 1906, aparecem as vigas treliça "Visintini”". Após o fim da 2ª Guerra Mundial ocorre um grande impulso das aplicações da pré-moldagem, principalmente em construções de galpões e também devido à necessidade de reconstrução de escolas, hospitais, indústrias, pontes, etc 
No Brasil o emprego da pré-moldagem data de 1925, com a fabricação de estacas para a fundação do Jockey Clube do Rio de Janeiro [VASCONCELOS (1988)].

Atualmente a utilização da pré-moldagem tem avançado nos EUA e Europa, mas, no Brasil, seu emprego ainda é limitado, se restringindo as aplicações em grande escala no caso de construções de galpões e em elementos de laje, estacas e tubos de drenagem. A Figura 2.1 ilustra algumas belas e interessantes aplicações da pré-moldagem em edifícios e monumentos nos Estados Unidos e em toda Europa [PCI (1989)].

A pré-moldagem é um processo construtivo do qual se pode tirar proveito das seguintes características:

a) em produção em série há a possibilidade de grande reutilização das fôrmas; emprego da protensão com armadura pré-tracionada; emprego de seções com maiores rendimentos mecânicos; maior produtividade da mão de obra e controle de qualidade;

b) desmontabilidade da construção;

c) aumento da qualidade dos elementos através do controle constante na fabricação;

d) redução de materiais empregado, levando a uma diminuição do peso total do edifício;

e) a construção do pré-moldado independe das condições do tempo.

Apesar de tantas vantagens, deve-se salientar que o uso da pré-moldagem implica, também, na utilização de equipamentos de transporte e de montagem, além da dificuldade de se efetuar as ligações entre os elementos. Na escolha do processo construtivo mais adequado deve-se considerar todos os fatores envolvidos na execução do projeto, analisando vantagens e desvantagens do concreto moldado no local e do concreto pré-moldado.

Uma das aplicações do concreto pré-moldado que tem sido atualmente bastante explorada são os painéis de fechamento empregados tanto para estruturas principais em concreto pré-moldado, como em combinação com estruturas de concreto moldado no local e em estruturas de aço. 
Normalmente, os painéis de fechamento têm um importante papel arquitetônico, principalmente nas fachadas de edificações, sendo geralmente denominados painéis prémoldados arquitetônicos.

$\mathrm{Na}$ verdade, o termo concreto arquitetônico é mais amplo e refere-se a qualquer elemento de forma especial ou padronizada que, mediante acabamento, forma, cor ou textura, contribui na forma arquitetônica ou no efeito de acabamento da construção.

Em decorrência da grande diversidade de tipos de acabamento, forma, cor, textura, que justifica, em parte, seu emprego, podem-se ter variações de cor e de tamanho dos agregados, além dos diversos processos de acabamento e profundidade de exposição.

O PCI(1989) traz exemplos clássicos que utilizam painéis pré-moldados encontrados em Nashville, Tennesse (Figura 2.2), e em Wilmette, Illinois (Figura 2.3). O primeiro corresponde à réplica de Parthenon grego construído entre 1920 e 1931, projetado pelo arquiteto canadense Louis Bourgeois, e o segundo, o templo de Baha'i, iniciado em 1920 com término em 1953. O PCI (1989) mostra algumas aplicações do uso de painéis de concreto pré-moldado, aplicado em edificações (Figura 2.4).

O fechamento, como mostrado pelas figuras, pode ser usado limitando apenas a estrutura exterior, ou ajudando o edifício a resistir a carregamentos laterais.

Os painéis, usualmente, podem ser dispostos ao longo da estrutura cobrindo o vão entre pilares (Figura 2.5.a), com diversos painéis cobrindo o vão para estruturas de vários pavimentos (Figura 2.5.b), ou com diversos painéis cobrindo o vão para estrutura de um pavimento (Figura 2.5.c). 

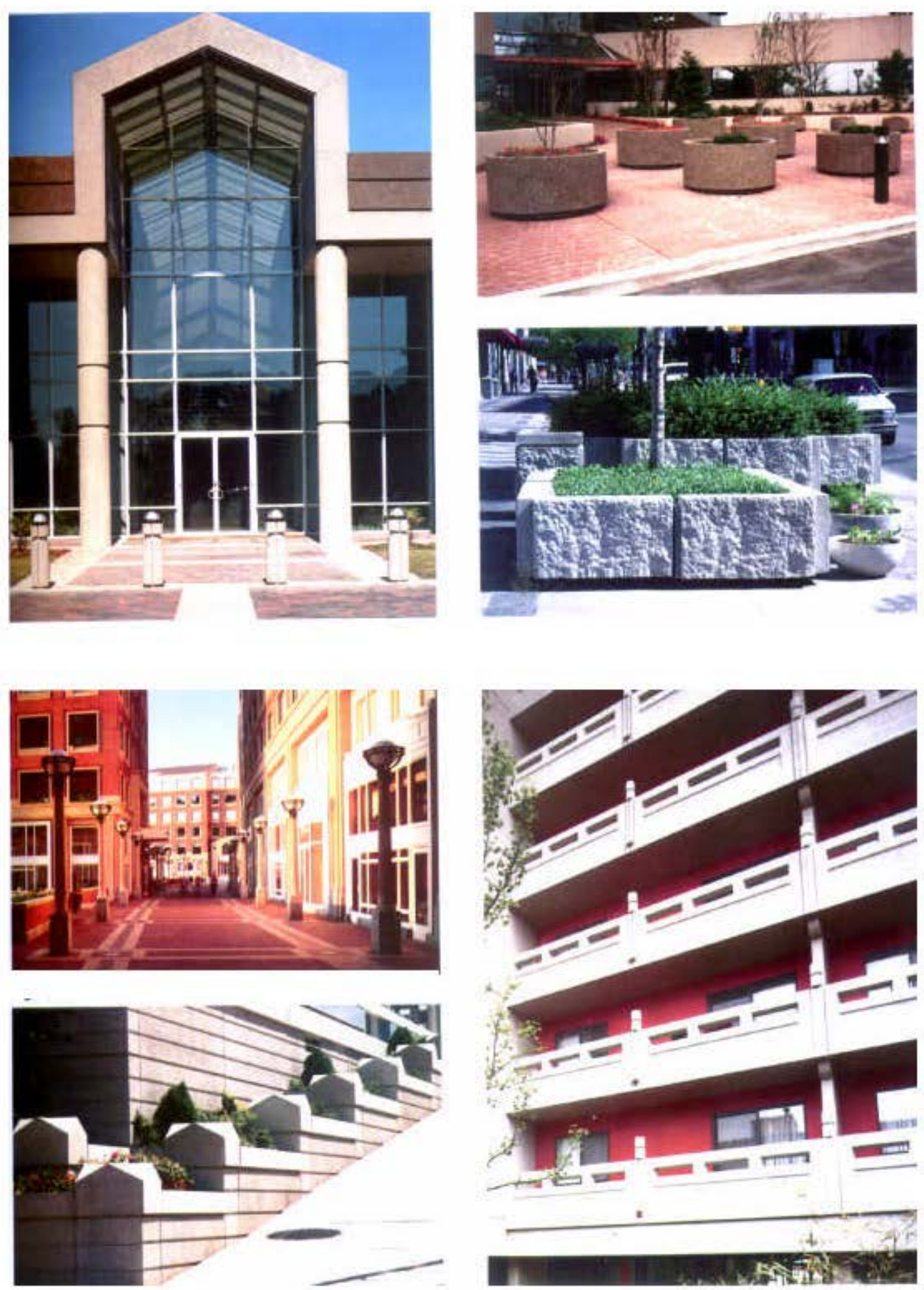

Figura 2.1- Aplicações da pré-moldagem [PCI(1989)] 

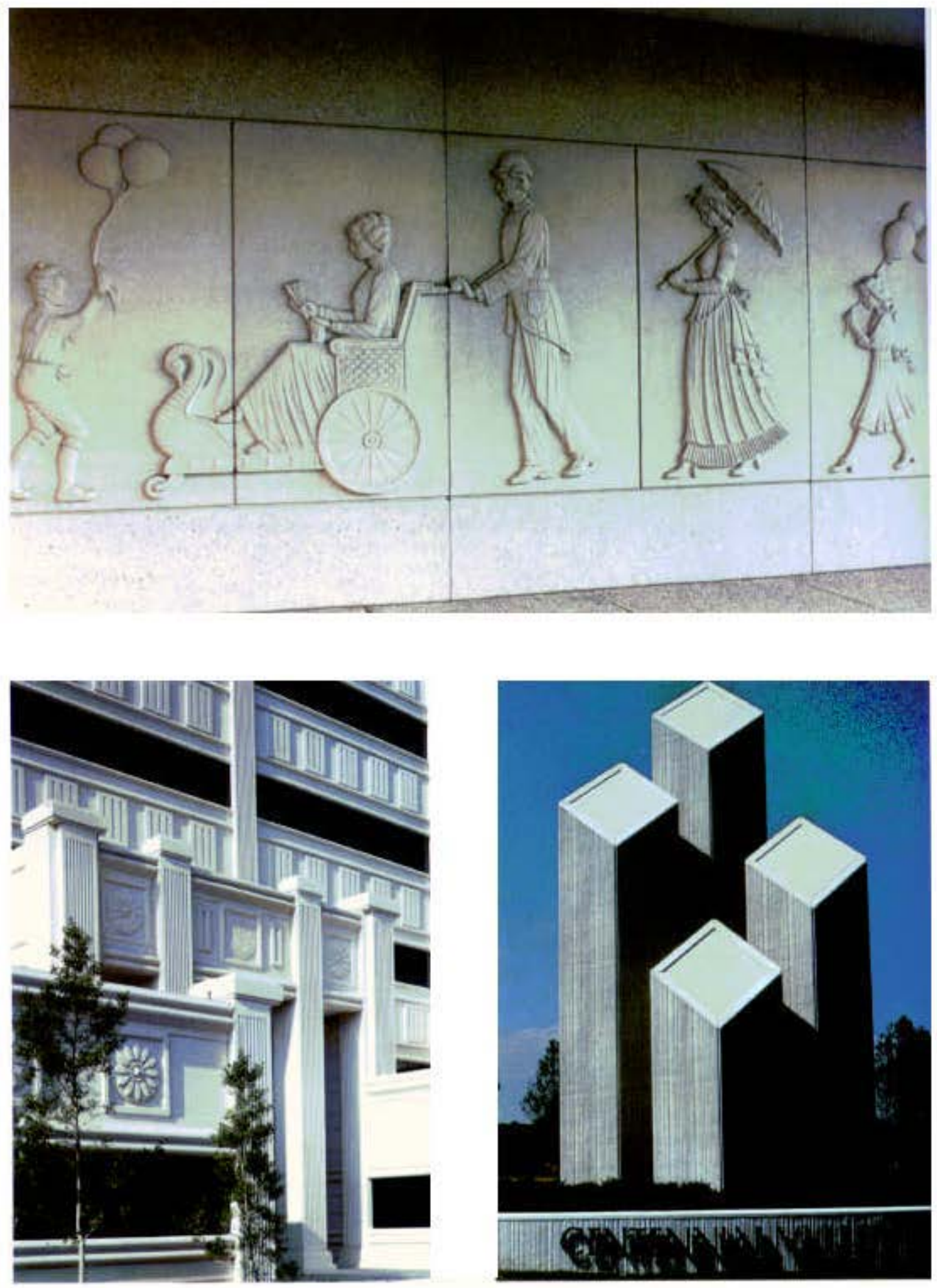

Figura 2.1- Aplicações da pré-moldagem [PCI(1989)](cont.) 


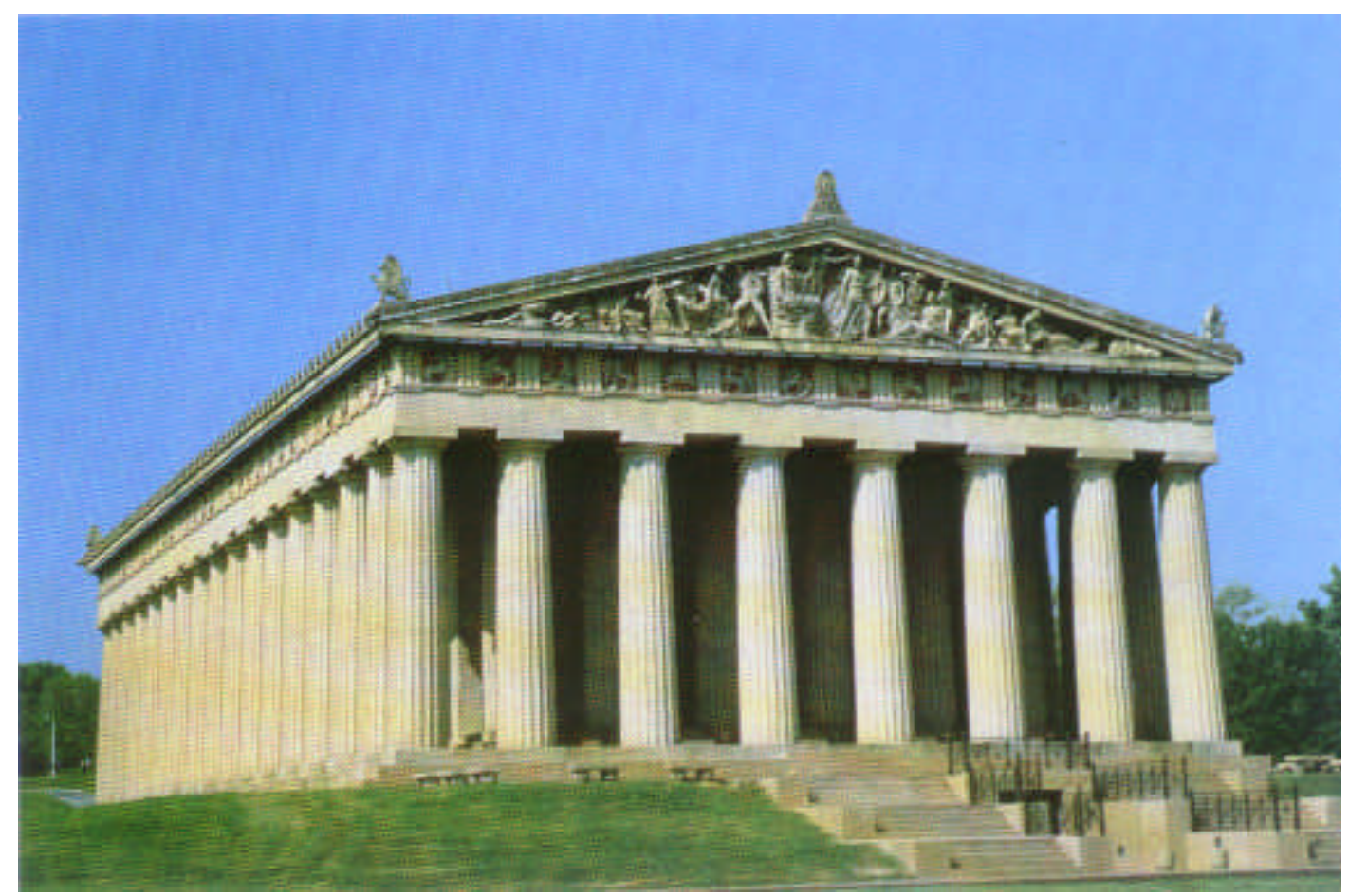

Figura 2.2- Réplica de Parthenon [PCI(1989)]

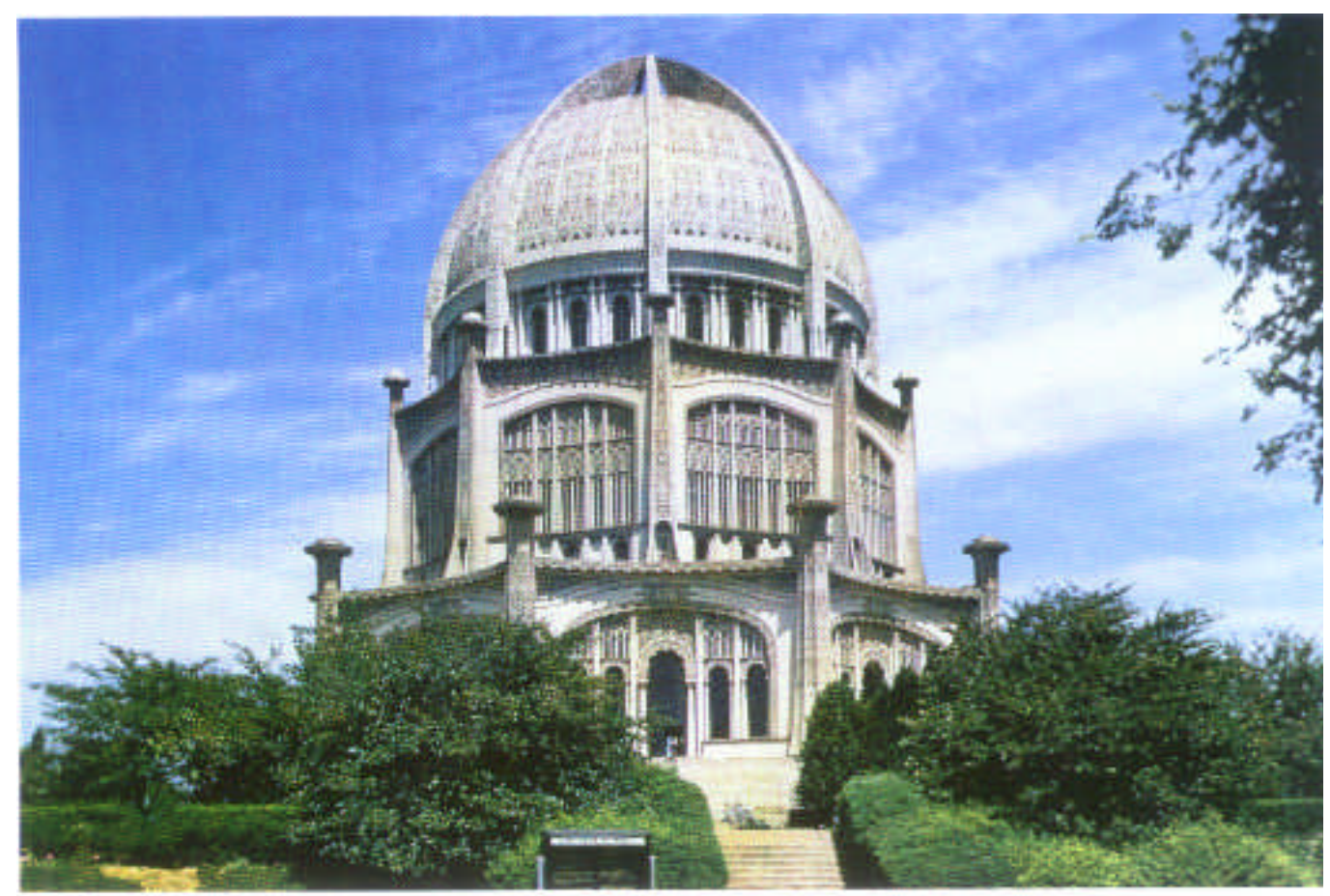

Figura 2.3- Templo de Baha'i [PCI(1989)] 

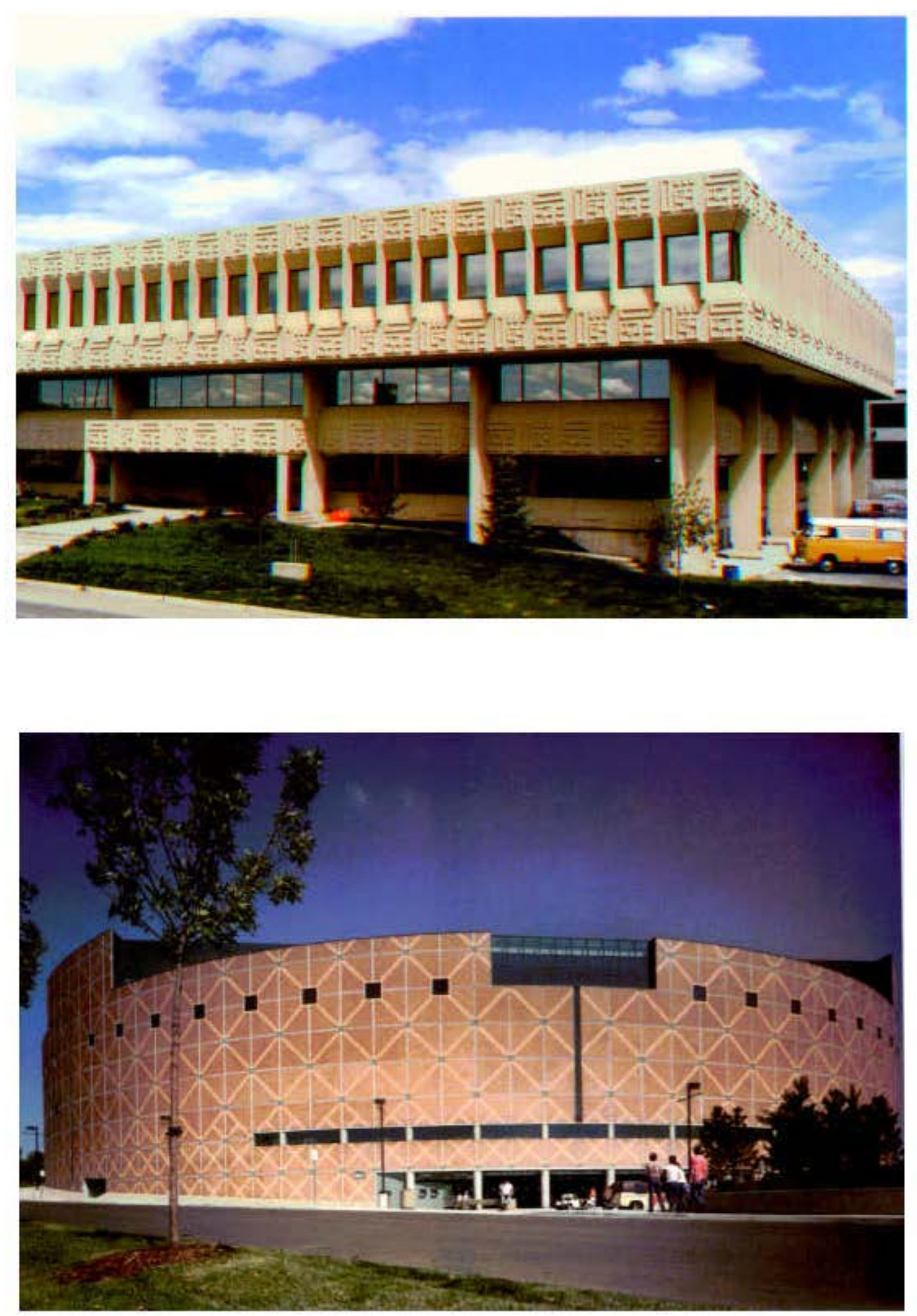

Figura 2.4- Edificações com painéis de concreto pré-moldado [PCI(1989)] 



Figura 2.4- Edificações com painéis de concreto pré-moldado [PCI(1989)] (cont.) 


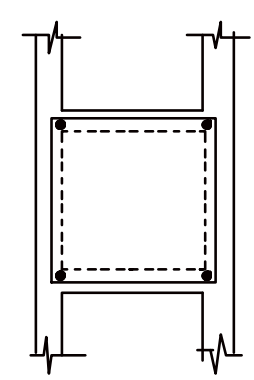

a) painel cobrindo o vão entre pilares

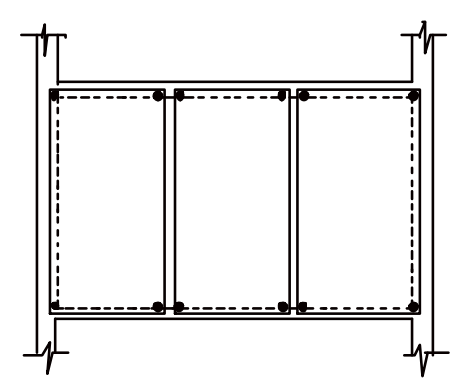

b) diversos painéis cobrindo o vão para estruturas de vários pavimentos

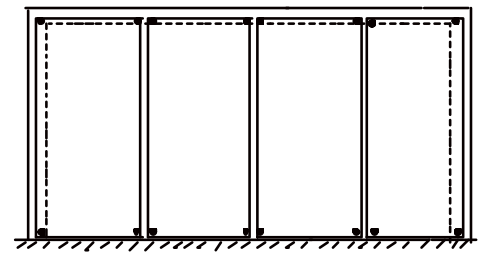

c) diversos painéis cobrindo o vão para estrutura de um pavimento

Figura 2.5- Disposições típicas dos painéis de fechamento

Os tipos de fechamentos existentes são mostrados com maiores detalhes, a seguir.

\subsection{Tipos de painéis pré-moldados}

\subsubsection{Painéis não-estruturais}

Os painéis não-estruturais são amplamente utilizados em sistemas arquitetônicos e projetados apenas para resistir a forças de vento e a seu próprio peso. Incluem painéis maciços, com aberturas, com nervuras ou "sandwich" .

Os painéis maciços permitem uma maior flexibilidade de projeto e variedades na aparência. Na Figura 2.6, a superfície dos painéis pré-moldados foi levemente jateada com areia. Na sua borda foi feito um escurecimento deixando-a áspera a fim de obter um visual de relevo. Podem-se ter, ainda, vigas de grande altura, denominados painéis "spandrel" , que resistem às lajes e servem para compor a fachada. Na Figura 2.8 nota-se a utilização de vidros dispostos horizontalmente.

Os painéis com aberturas são planos e podem ser esculpidos quando necessário. Podem conter uma única janela ou várias. Observa-se, na Figura 2.7, a utilização de unidades de painéis com apenas uma abertura simples abrangendo todo o pilar. Ainda têm-se elementos que "correm" verticalmente toda a estrutura, com divisões de caixilhos nas janelas, algumas vezes utilizados para ocultar os pilares ou apenas circundá-los. Esses painéis são projetados para terem fasquias de divisão a fim de se colocarem janelas ao 
longo do mesmo. Nota-se, na Figura 2.9, que os painéis são bastante leves, preenchidos por vidros e cobrem todos os pilares da estrutura.

Os painéis "sandwiches" são elementos com peso reduzido, possuindo vazios no centro, para serem preenchidos com material leve, constituídos por duas camadas de concreto e cujo vazio central pode ou não ser preenchido por uma camada de isolamento ou estar justaposta à camada exterior (Figura 2.10).

Podem suportar apenas seu peso próprio, transferir cargas verticais para o suporte da estrutura e atuar como paredes de contraventamento e painéis portantes.

Estudos feitos com painéis de fechamento mostram que esses elementos contribuem efetivamente no enrijecimento da estrutura. Geralmente, esse efeito é desprezado pelo fato de o processo de interação painel/estrutura ser desconhecido. Além disso, a consideração do efeito nos cálculos acarreta esforços adicionais no fechamento, os quais não foram projetados.

\subsubsection{Painéis portantes}

Esses painéis, usados com finalidade estrutural, freqüentemente mais econômicos que os anteriores, são projetados para transferir os esforços verticais.

Podem-se ter elementos estruturais que abrangem os listados anteriormente (sistemas maciços, "spandrel”, etc.). Na Figura 2.11 têm-se painéis estruturais com uma unidade representando quatro andares.

\subsubsection{Painéis pré-moldados usados como paredes de contraventamento}

Painéis paredes, incorporando resistência e rigidez, são mais econômicos, se projetados para resistir à ação do vento, combinados com o efeito do diafragma dos pisos do edifício. Tais painéis resistem ao carregamento lateral e transferem-no ao plano da parede ou a um paralelo a ele e destes para a fundação. Na Figura 2.12 os painéis com aberturas transferem as cargas para a fundação, enquanto que os painéis das extremidades, funcionam como paredes de contraventamento. 


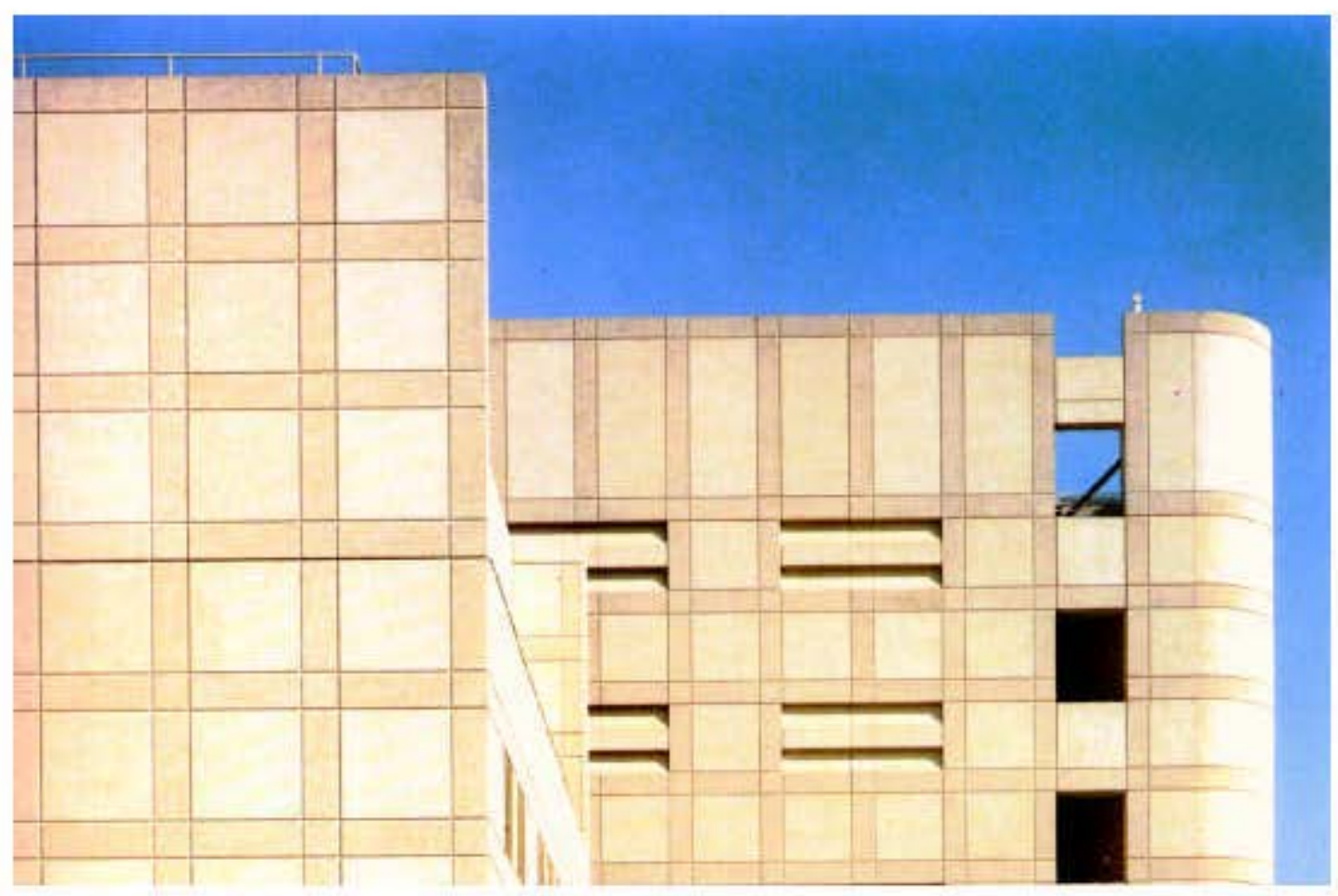

Figura 2.6- Exemplo de edificação com painel liso [PCI(1989)]

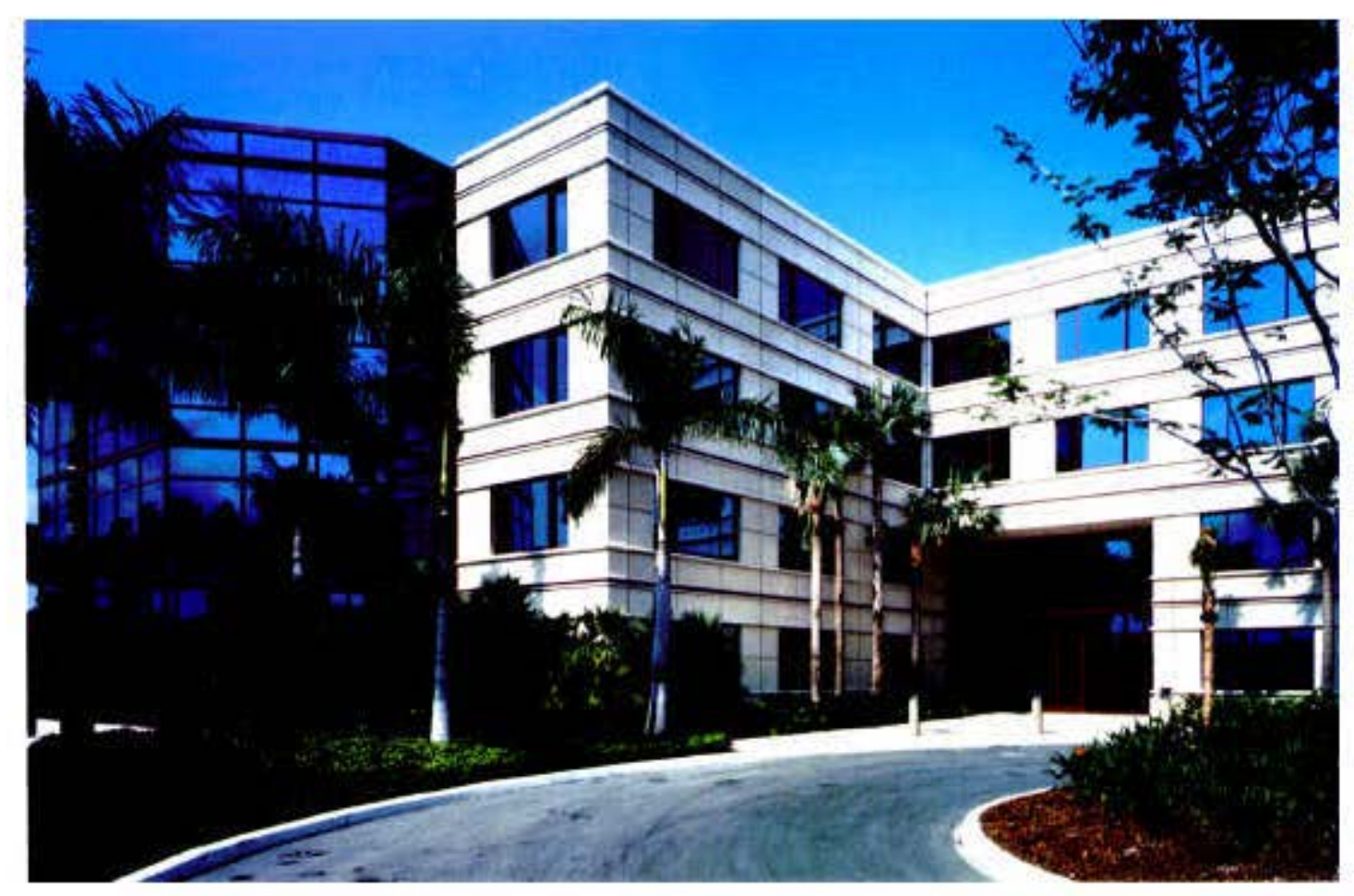

Figura 2.7- Exemplo de edificação de painéis com aberturas [PCI(1989)] 


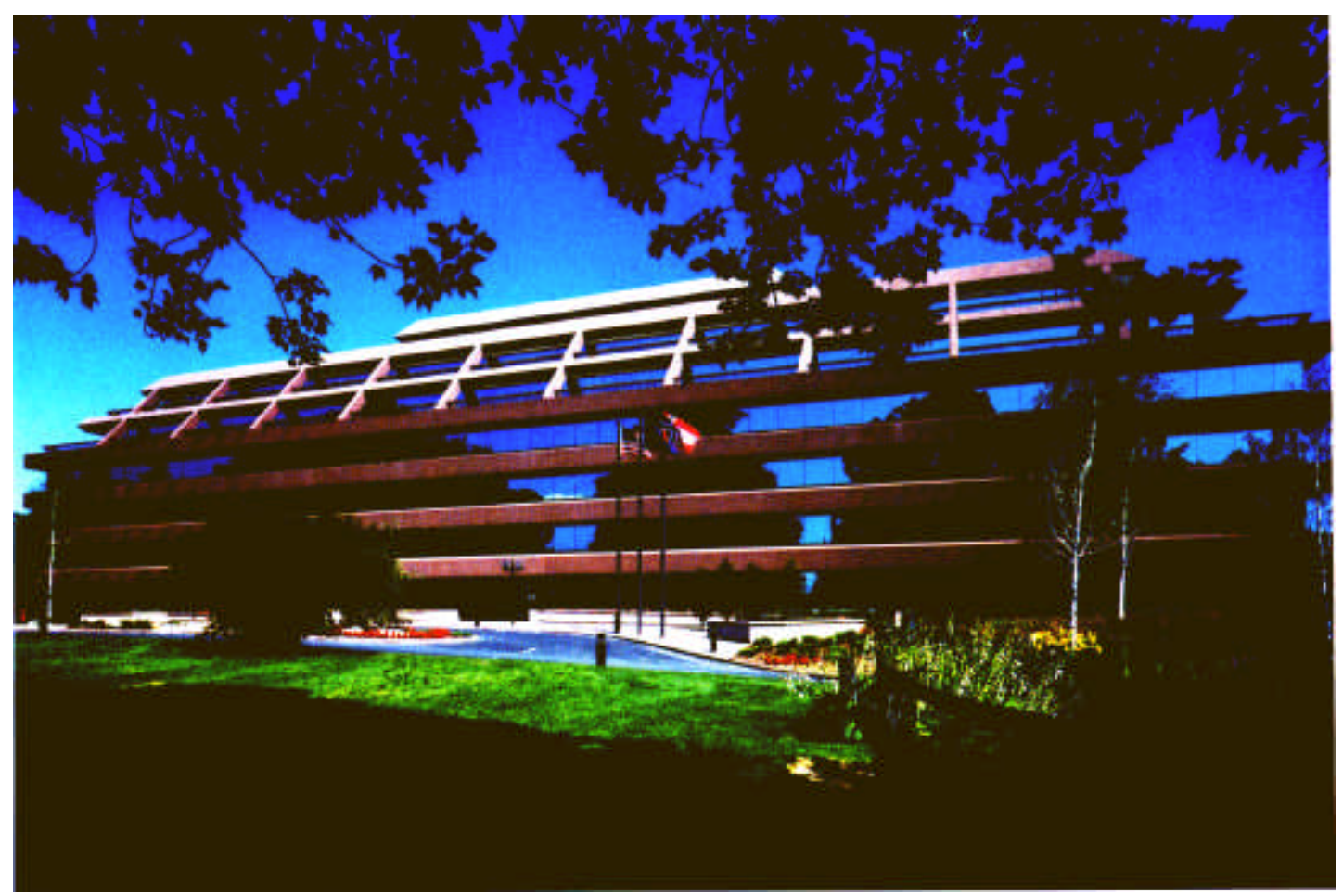

Figura 2.8- Exemplo de edificação com painel do tipo "spandrel” [PCI(1989)]

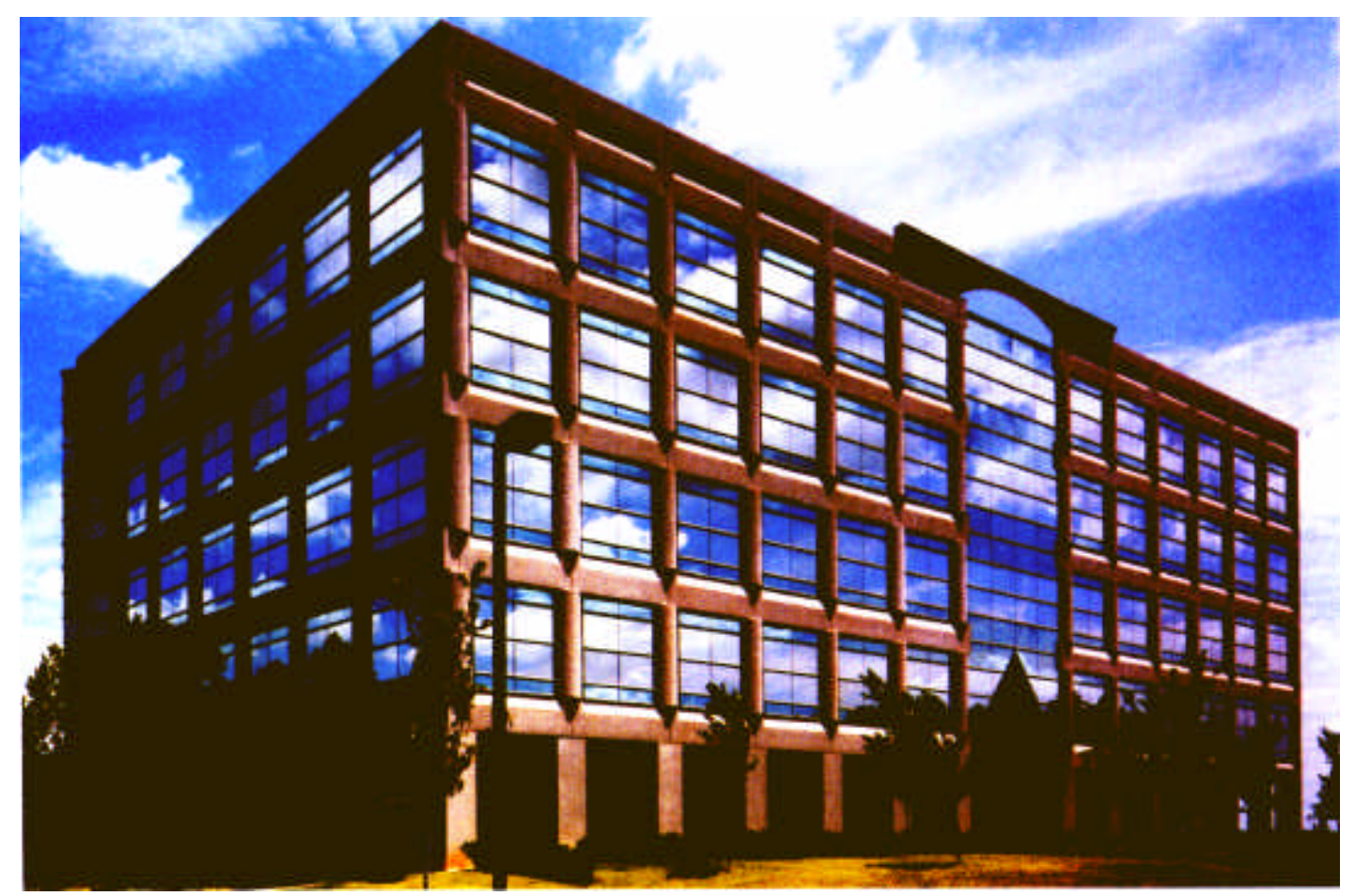

Figura 2.9- Exemplo de edificação com fasquia de divisão [PCI(1989)] 

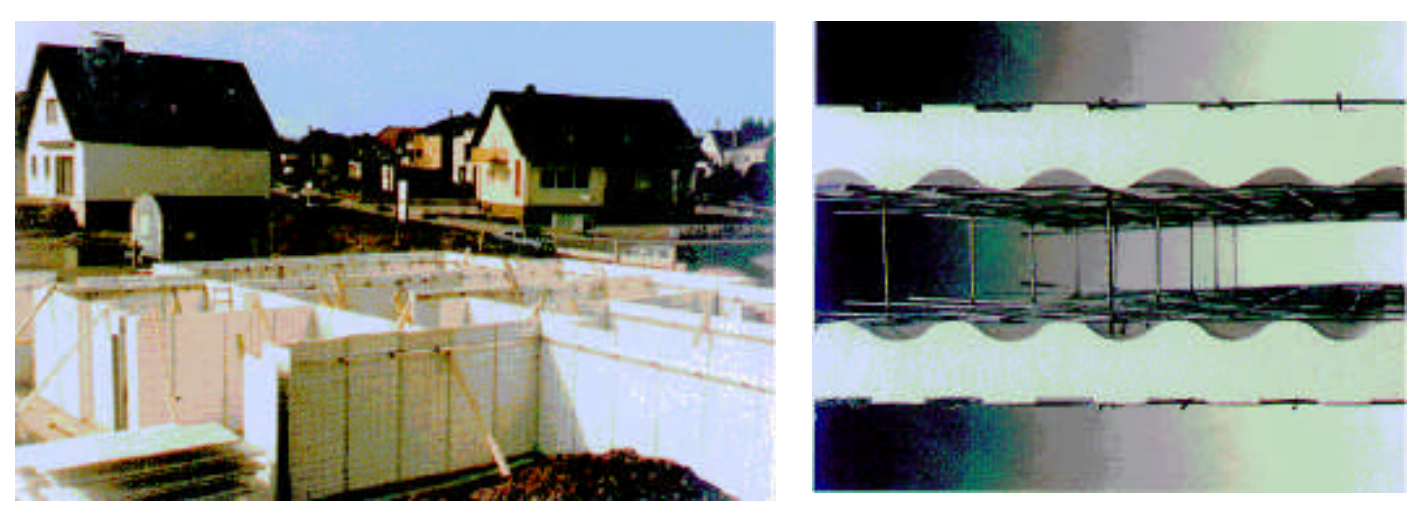

Figura 2.10- Exemplo de edificação com painéis "sandwich"

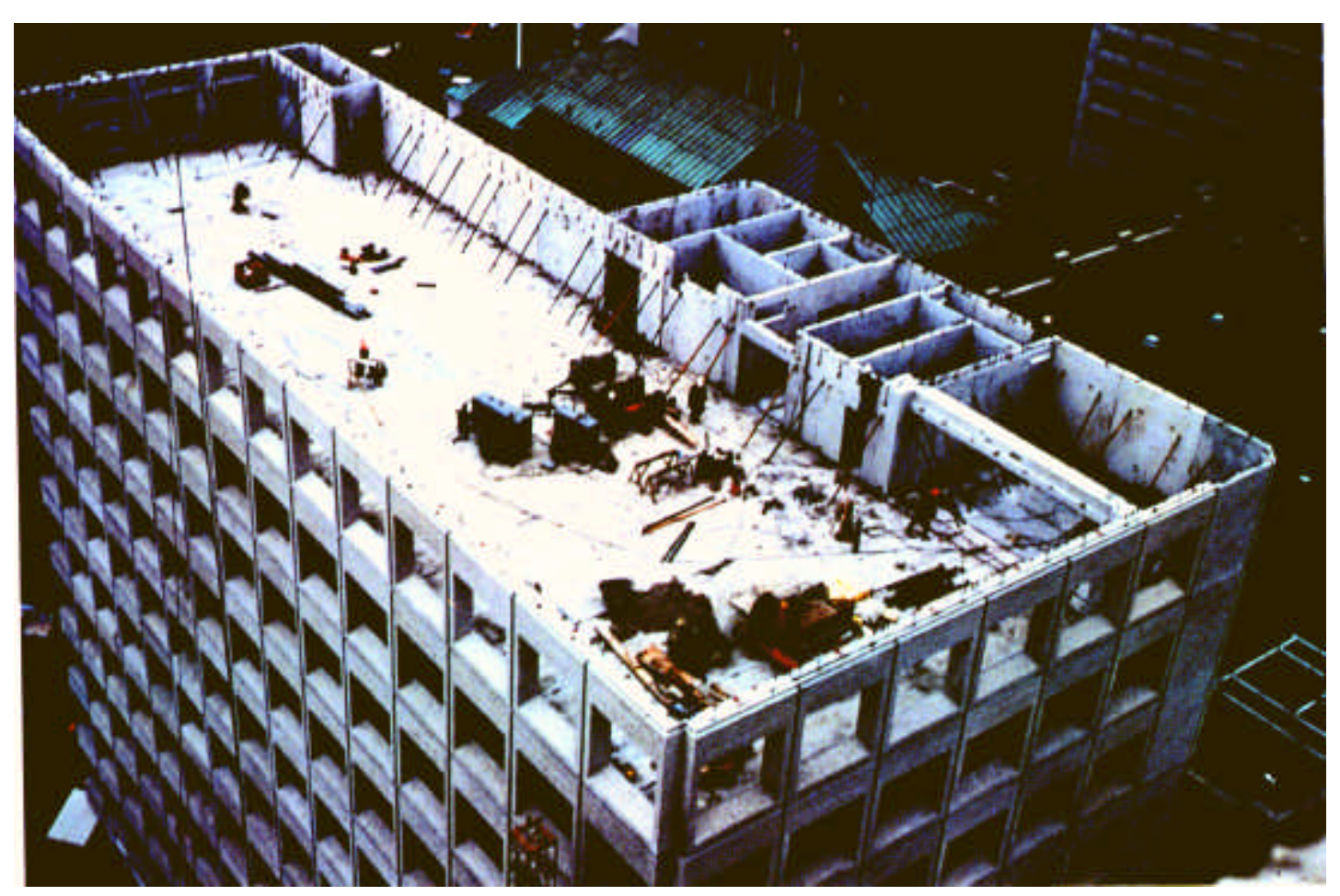

Figura 2.11- Exemplo de edificação com painéis estruturais [PCI(1989)] 


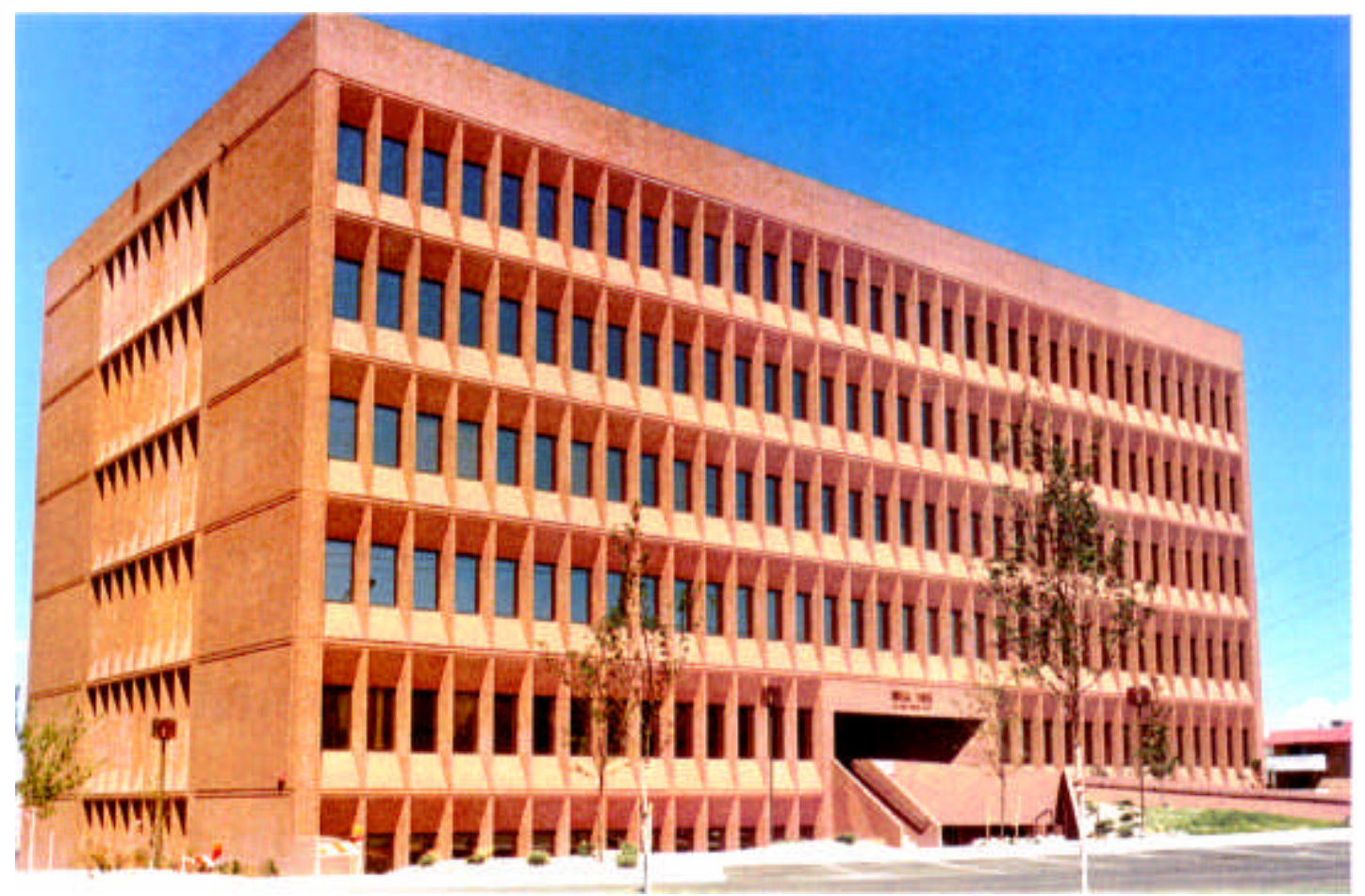

Figura 2.12- Exemplo de edificação de painéis como parede de contraventamento [PCI(1989)]

\subsubsection{Painéis usados como fôrmas para concreto moldado no local}

São painéis usados como fôrmas para concreto moldado no local, conforme ilustrado pela Figura 2.13. 

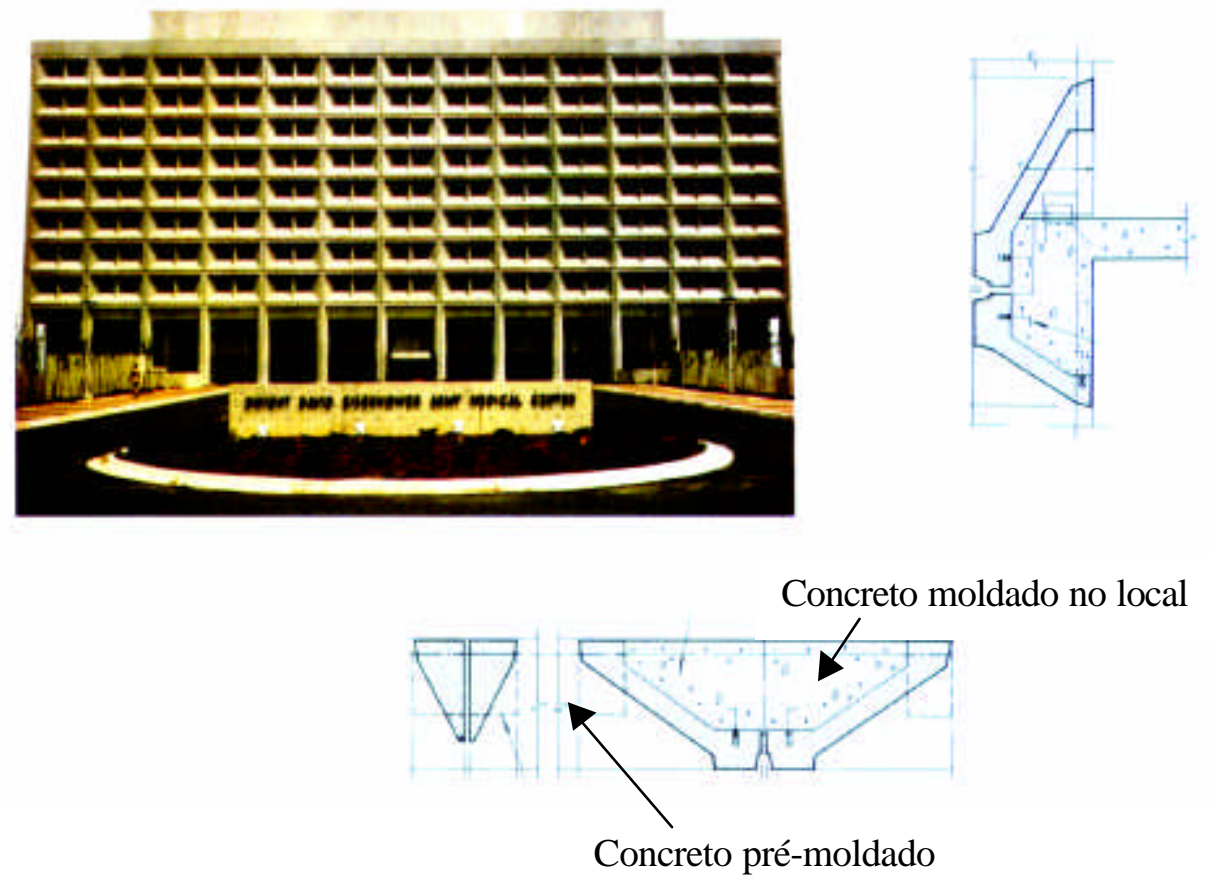

Figura 2.13- Exemplo de edificação de painéis como fôrmas [PCI(1989)]

\subsection{Projeto do painel de fechamento}

\subsubsection{Preliminares}

O projeto de concreto pré-moldado é similar ao projeto de um edifício moldado no local. A diferença é que elementos pré-moldados são projetados também para as fases transitórias (desmoldagem, transporte e montagem).

A seguir, encontra-se a seqüência de projeto de um painel não estrutural de fechamento [PHILLIPS e SHEPPARD (1988) ], desprezando a interação da estrutura.

a) Inicialmente, define-se o tamanho preliminar do painel, analisando-se a viabilidade de acesso de caminhões e guindastes ao local da obra;

b) Definem-se as ações às quais a estrutura está submetida, considerando-se que, em geral, os painéis pré-moldados estão sujeitos às seguintes: 
vertical : ações permanentes (peso próprio);

lateral : ações devido ao vento;

volumétrico : ações devido à temperatura;

manuseio : ações devidas à desmoldagem, ao transporte e à montagem;

c) define-se a resistência do concreto, bem como o tipo de armadura a ser utilizada;

d) determina-se a espessura do painel, levando-se em consideração tanto a condição de carregamento anteriormente calculada, quanto o manuseio do mesmo, respeitando as dimensões mínimas dadas em normas;

Os valores mínimos da espessura do painel, segundo FIP (1982), são funções da maior dimensão do painel (Figura 2.14). A Figura não é aplicável a painéis usados como fôrmas para concreto moldado no local.

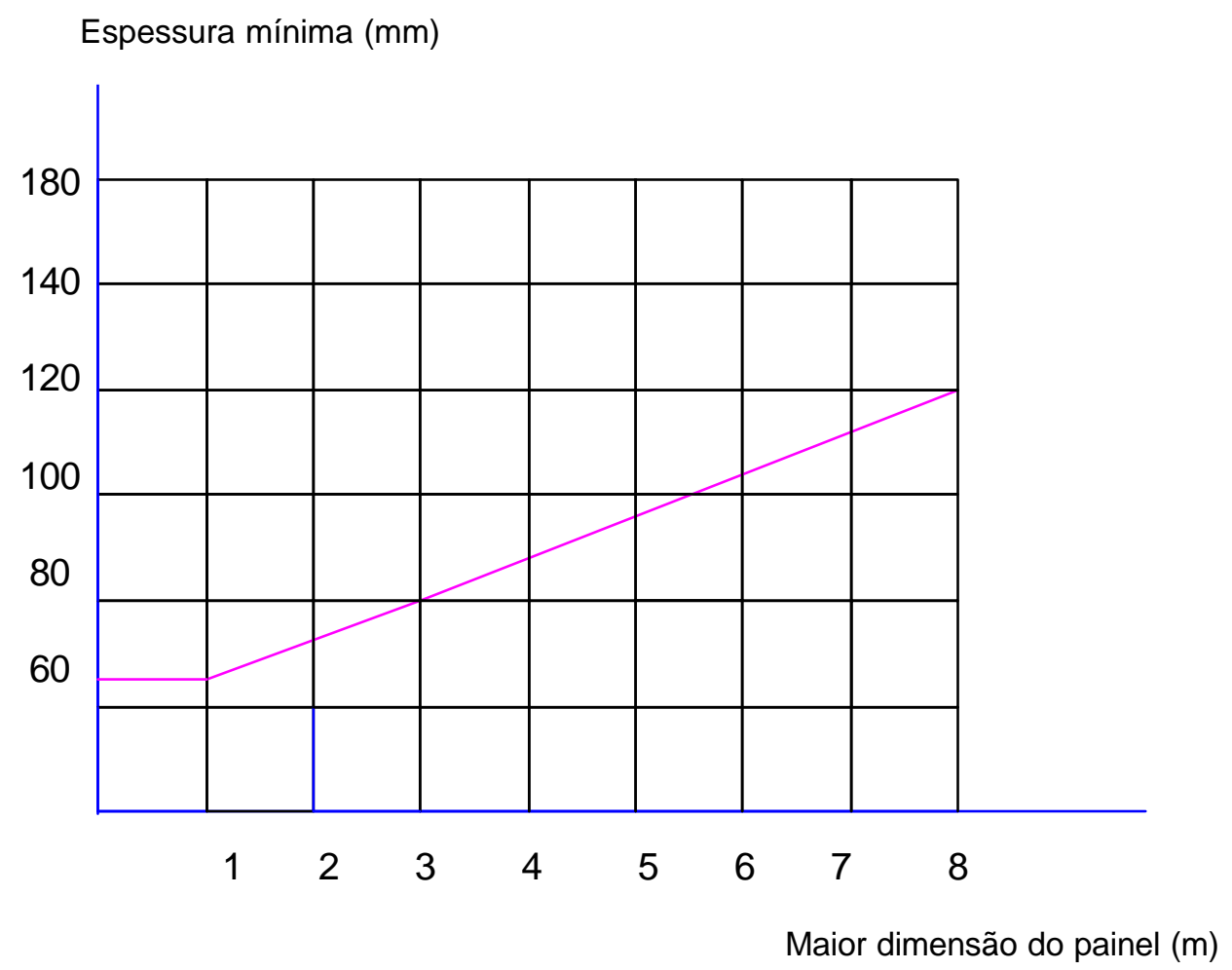

Figura 2.14- Espessura mínima fornecida pela FIP (1982) 
e) calcula-se a armadura de flexão do painel, verificando-a para a desmoldagem, o transporte e a montagem;

f) localizam-se os pontos de ligação a fim de que resistam às forças laterais e verticais, para a condição de carregamento, bem como definem-se os tipos de ligações utilizados;

Utilizando ações laterais e verticais, PHILLIPS \& SHEPPARD (1989) analisam a distribuição de um unidade de carga $\left(1^{\mathrm{k}}\right)$ aplicada no centro de gravidade do painel (Figura 2.15).

g) projetam-se as ligações do painel, nos pontos anteriormente localizados, com uma força unitária aplicada em qualquer direção no elemento; e

h) finalmente se verifica se o movimento causado pelas ações está sendo acomodado pelas ligações.

\subsubsection{Fases transitórias}

Os painéis, durante as fases transitórias (produção, transporte, montagem), necessitam de uma análise isolada verificando a resistência do concreto na situação final. Para cada fase, consideram-se os seguintes itens que afetam o projeto.

- Desmoldagem:

orientação do elemento;

coeficientes de impacto;

número e localização dos equipamentos de manuseio;

peso do elemento. 

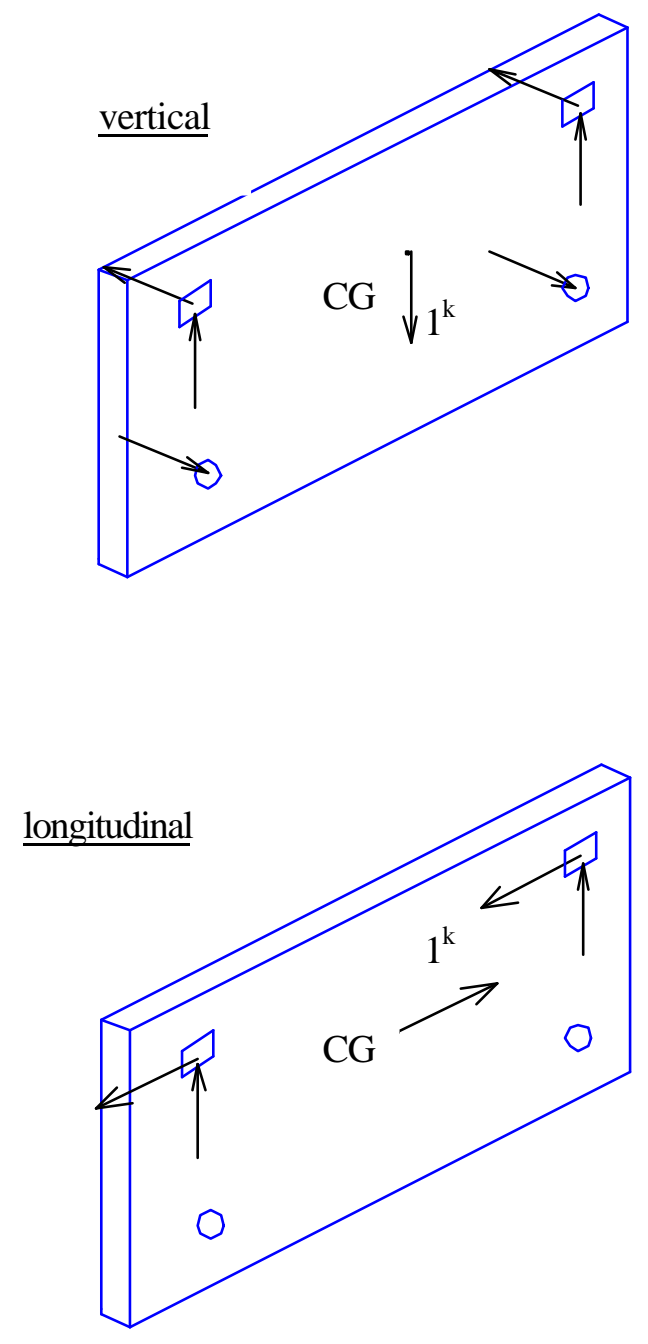

Ligação suporte

Ligação lateral

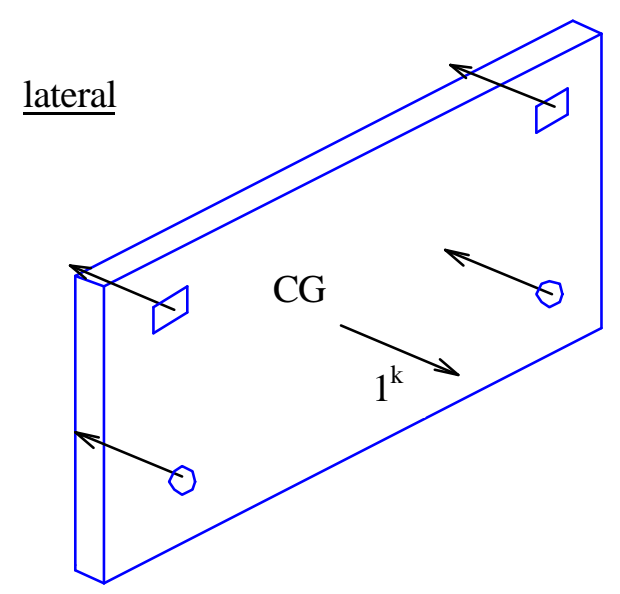

Figura 2.15- Força unitária para o painel [PHILLIPS e SHEPPARD(1989)] 
- Transporte:

localização de suporte vertical e horizontal;

escolha do veículo de transporte e seu estado de utilização;

considerações dinâmicas durante o transporte.

- Montagem:

número e localização dos pontos de elevação;

carregamentos temporários;

localização de suportes temporários.

A seguir, estão listadas algumas considerações de projeto para cada fase.

a) Desmoldagem

Os painéis desmoldados pela borda estão sujeitos aos momentos fletores mostrados pela Figura 2.16. Os momentos decorrentes da desmoldagem feita no próprio plano do painel visualizam-se pela Tabela 2.1 .

Os valores dos coeficientes dinâmicos usados para cada fase são dados pela Tabela 2.2, da acordo com o PCI (1992).

Usualmente são utilizadas mesas inclinadas a fim de diminuir as tensões nessa fase utilizando o processo com mesa de tombamento (Figura 2.17).

b) Transporte

A escolha do tipo de transporte depende basicamente do peso e do tamanho dos painéis. Podem ser transportados em forma de A com painéis horizontais (Figura 2.18.a) ou verticais (Figura 2.18.b) dependendo do tamanho de cada unidade.

As dimensões máximas permitidas para o transporte são representadas pela Figura 2.19 [FIP (1982)]. 
Tabela 2.1- Momentos na desmoldagem [PCI (1992)]

\begin{tabular}{|c|c|}
\hline \multicolumn{2}{|c|}{ momentos na desmoldagem considerando uma borda } \\
\hline Momento resistente &  \\
\hline Momento resistente & $\begin{array}{l}\text { quatro pontos de içamento } \\
\mathrm{M}_{\mathrm{x}}=\frac{\mathrm{g} \cdot \mathrm{a}^{2}}{8} \\
-\mathrm{M}_{\mathrm{y}}=+\mathrm{M}_{\mathrm{y}}=0,0027 \cdot \mathrm{g} \cdot \mathrm{a} \cdot \mathrm{b}^{2} \\
(\text { resistido pela seção de espessura } \\
\mathrm{g}=\text { anidade de força por área }\end{array}$ \\
\hline
\end{tabular}


Tabela 2.1- Momentos na desmoldagem [PCI (1992)] (cont.)

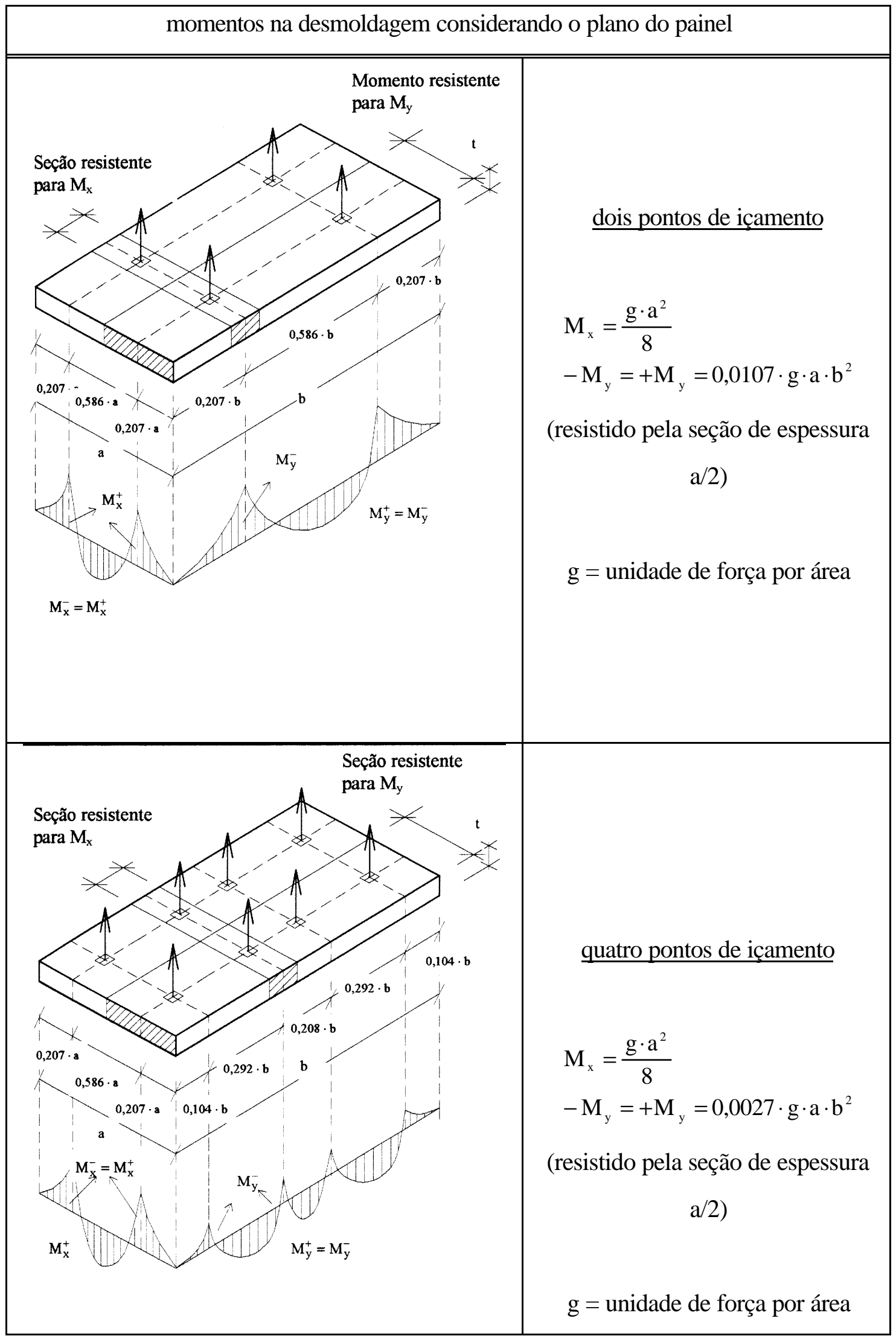






dois pontos para desmoldagem:

$$
\begin{aligned}
& M^{+}=(2 c-1) \frac{w \ell^{2}}{8} \\
& M^{-}=0,5 b^{2} w \ell^{2}
\end{aligned}
$$

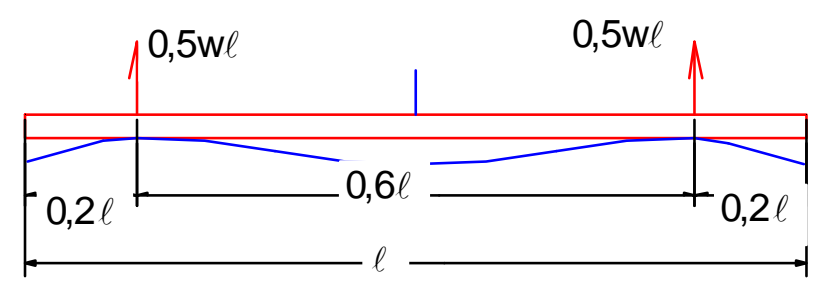

dois pontos para desmoldagem e dois pontos para o transporte:

$$
\mathrm{M}^{+}=\mathrm{M}^{-}=0,025 \mathrm{w} \ell^{2}
$$

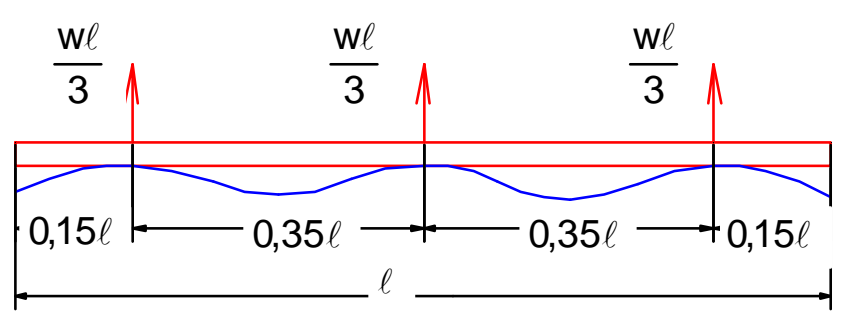

três pontos para desmoldagem:

$$
M^{+}=M^{-}=0,025 w \ell^{2}
$$

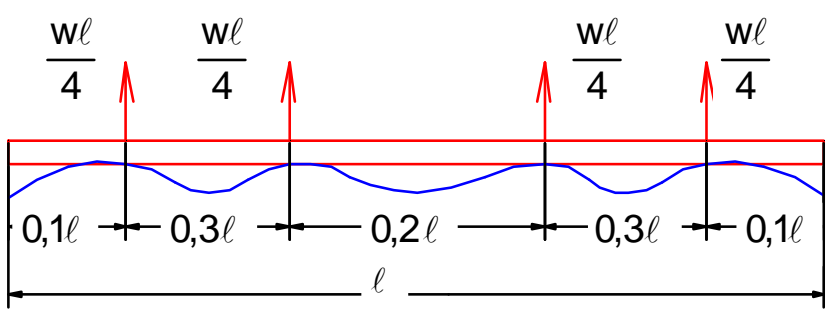

$$
\begin{gathered}
\underline{\text { quatro pontos para }} \\
\underline{\text { desmoldagem: }} \\
\mathrm{M}^{+}=\mathrm{M}^{-}=0,056 \mathrm{w} \ell^{2}
\end{gathered}
$$

Figura 2.16- Momentos referentes a algumas situações lineares de desmoldagem

$$
\text { [PCI (1992)] }
$$


Tabela 2.2- Coeficientes dinâmicos

\begin{tabular}{|c|c|c|}
\hline & \multicolumn{2}{|c|}{ DESMOLDAGEM } \\
\hline & \multicolumn{2}{|c|}{ Tipo de acabamento } \\
\hline Tipo do produto & $\begin{array}{l}\text { agregado exposto com } \\
\text { retardador }\end{array}$ & $\begin{array}{c}\text { molde liso (apenas } \\
\text { desmoldante) }\end{array}$ \\
\hline $\begin{array}{c}\text { plano, com lateral removível, sem } \\
\text { junta falsa }\end{array}$ & 1,2 & 1,3 \\
\hline plano, com falsa junta & 1,3 & 1,4 \\
\hline fôrma com inclinação apropriada & 1,4 & 1,6 \\
\hline \multirow[t]{2}{*}{ fôrma complexa } & 1,4 & 1,7 \\
\hline & \multicolumn{2}{|c|}{ MANUSEIO E MONTAGEM } \\
\hline \multirow[t]{2}{*}{ todos os produtos } & \multicolumn{2}{|c|}{1,2} \\
\hline & \multicolumn{2}{|c|}{ TRANSPORTE } \\
\hline todos os produtos & \multicolumn{2}{|c|}{1,5} \\
\hline
\end{tabular}

c) Montagem

Durante a montagem surgem momentos cujos valores são influenciados pelo posicionamento dos pontos de levantamento (Figura 2.20). 

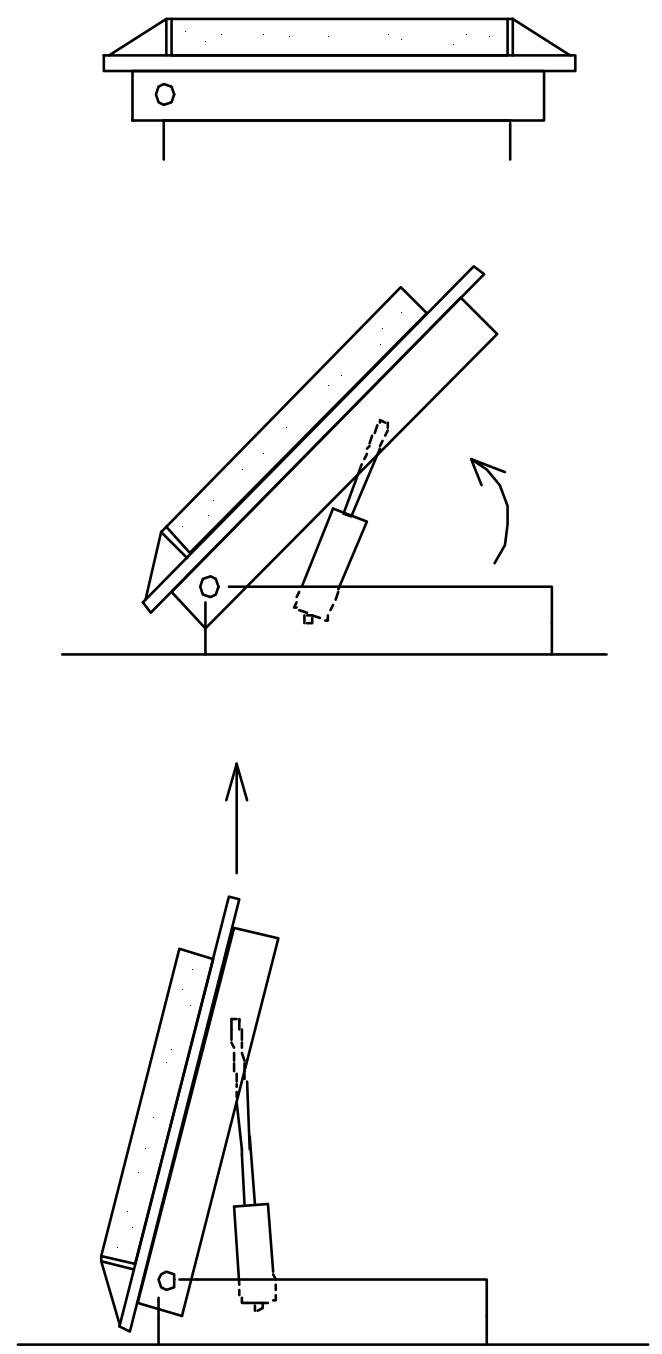

Figura 2.17- Desmoldagem com o levantamento da mesa

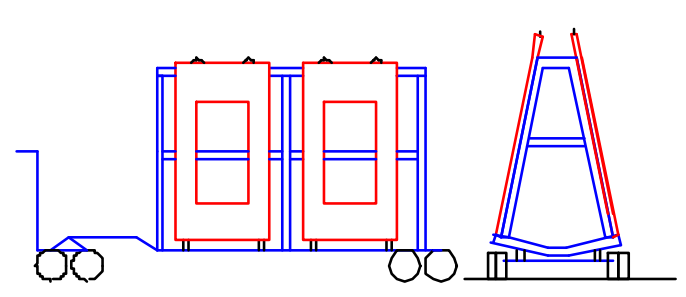

a)

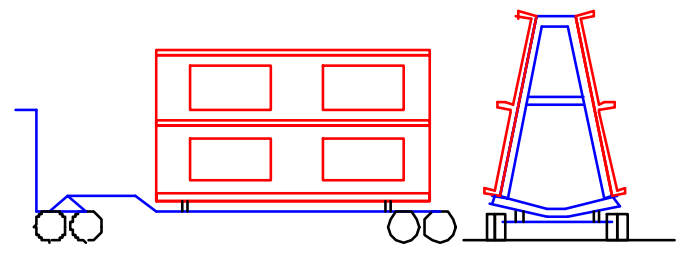

b)

Figura 2.18- Transporte de painéis em forma de A [PCI (1992)] 

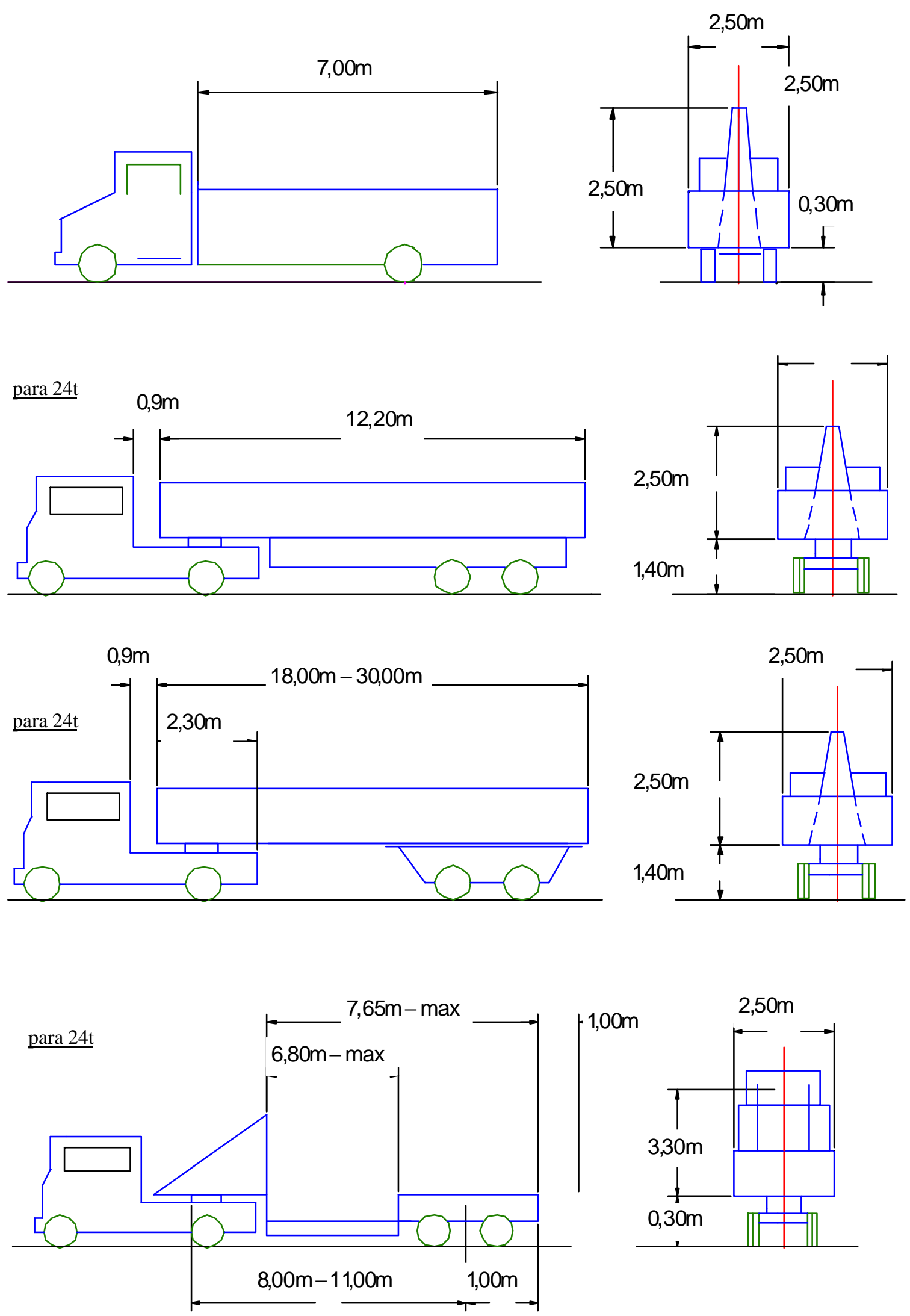

Figura 2.19- Transporte de acordo com o peso do painel [FIP (1982)]. 


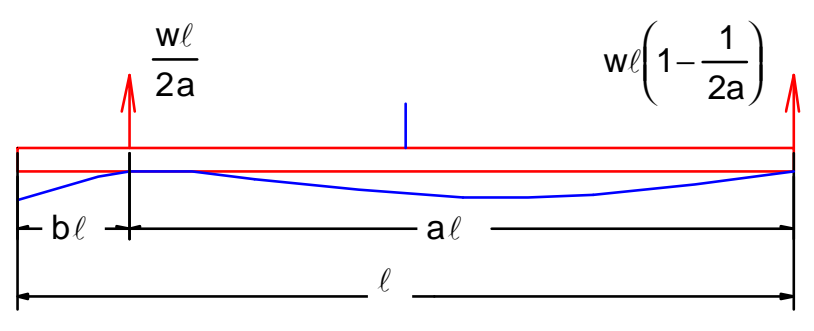

dois pontos para montagem:

$$
\begin{aligned}
& \mathrm{M}^{-}=0,56 \mathrm{~b}^{2} \mathrm{w} \ell^{2} \\
& \mathrm{M}^{+}=\left(1-\frac{1}{2 \mathrm{a}}\right)^{2} \frac{\mathrm{w} \ell^{2}}{2}
\end{aligned}
$$

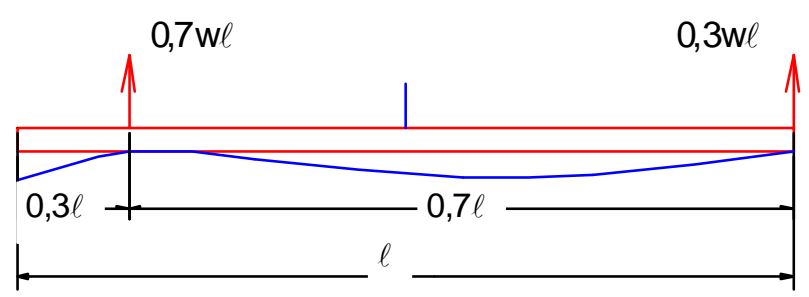

dois pontos para montagem:

$$
M^{+}=M^{-}=0,043 w \ell^{2}
$$

Figura 2.20- Momentos devido à montagem [PHILLIPS e SHEPPARD (1992)]

\subsubsection{Situações definitivas}

Além das fases transitórias, os painéis são projetados para as situações definitivas com ações atuando na estrutura, tais como, ações do vento, de variação volumétrica, do solo e de efeitos sísmicos, sendo algumas delas relacionadas abaixo.

Os painéis podem sofrer uma deformação devido a gradientes de temperatura (Figura 2.21), cujo valor teórico, dado por $\Delta$, é determinado, segundo PCI (1992), pela equação 2.1 .

$$
\Delta=\alpha \cdot\left(\mathrm{T}_{1}-\mathrm{T}_{2}\right) \cdot \frac{\ell^{2}}{8 \cdot \mathrm{h}}
$$

onde

$\alpha$ - coeficiente de dilatação térmica

$T_{1}$ e $T_{2}$ - temperatura externa e de interna do painel

$\ell$ - distância entre suportes

$h$ - espessura do elemento 


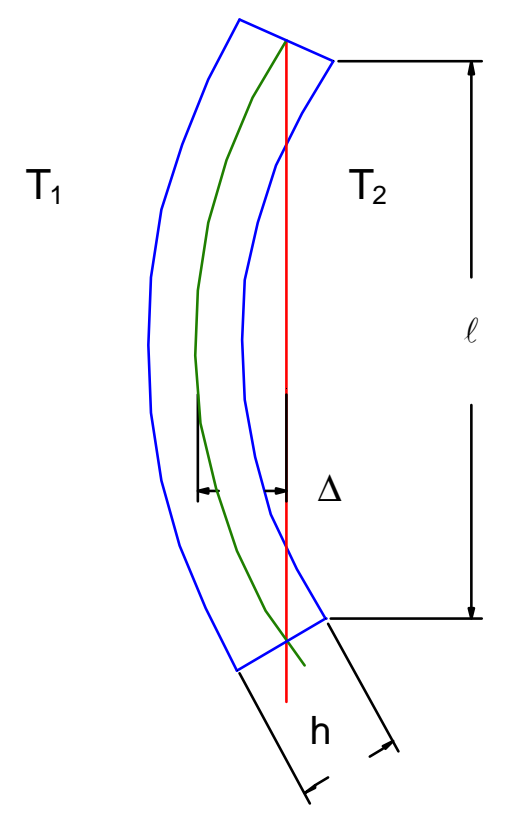

Figura 2.21- Deformação do painel devido a temperatura.

A diferença de umidade também causa o "estufamento" do elemento. Isto é, quando o ambiente está quente, a camada externa absorve a umidade da atmosfera e das chuvas, enquanto a interna permanece seca, provocando a deformação do painel para dentro.

A Tabela 2.3 representa algumas situações utilizadas devido a diferença de temperatura [PCI(1992)].

Pode haver ainda, situações em que os painéis de fechamento estão em contato com o solo, sendo importante nesse caso, a consideração do empuxo de terra no local.

Em alguns países, efeitos como terremoto devem ser considerados, pois geram forças laterais bastante significativas. Independentemente da intensidade sísmica, um projeto detalhado das ligações e dos painéis deve ser utilizado para assegurar a estabilidade da estrutura e acomodação do efeito pelas ligações. 
Tabela 2.3- Forças e momentos no painel devido à gradiente térmico






\subsection{Ligações}

\subsubsection{Preliminares}

A necessidade de se efetuarem as ligações entre elementos pré-moldados representa um dos principais problemas enfrentados na utilização da prémoldagem. Portanto, as ligações representam parte importante no projeto das estruturas pré-moldadas, tanto na produção, como no comportamento.

A finalidade das ligações é suportar e restringir os painéis pré-moldados contra ações atuantes. Isto é, suportar seu peso e restringir movimentos causados pela aplicação das cargas.

Normalmente, os painéis são projetados para transferir seu peso e a ação do vento para a estrutura principal. Para que isto ocorra, a escolha dos movimentos liberados e o posicionamento das ligações entre o elemento de fechamento e a estrutura principal são de fundamental importância no comportamento, tanto dos painéis, como da estrutura.

Nesse sentido, procuram-se projetar as ligações tendo em vista as seguintes recomendações: a) o sistema de ligações deve ser de forma a resultar em um sistema estaticamente determinado e b) as ligações devem acomodar as variações volumétricas e as deformações da estrutura principal. Na Figura 2.22 estão mostradas algumas vinculações típicas dos painéis com os movimentos liberados na estrutura principal. 

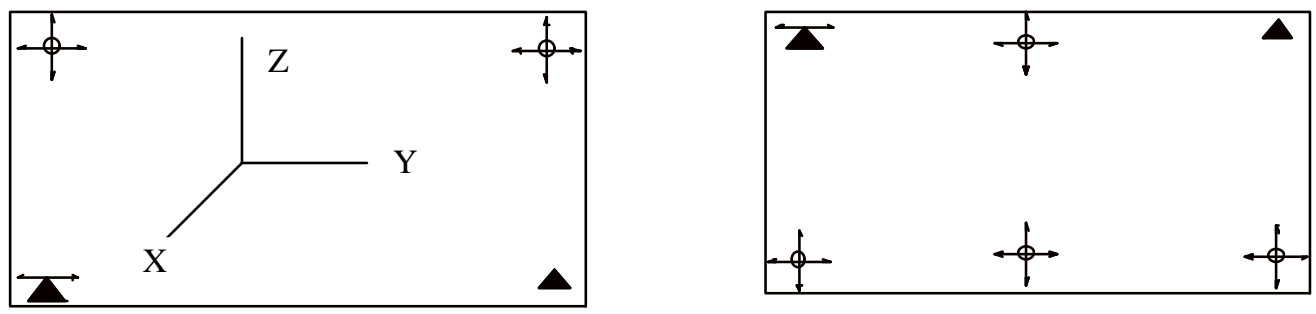

\begin{tabular}{|c|c|c|c|c|}
\hline \multirow[t]{2}{*}{ Símbolo } & \multicolumn{3}{|c|}{$\begin{array}{c}\text { Deformações impedidas } \\
\text { pelas ligações }\end{array}$} & \multirow[t]{2}{*}{ Ligação } \\
\hline & $\mathbf{X}$ & $\mathbf{Y}$ & $\mathbf{Z}$ & \\
\hline & $\bullet$ & $\bullet$ & $\bullet$ & $\begin{array}{l}\text { apoio vertical fixo: } \\
\text { esforços em X, Y e Z }\end{array}$ \\
\hline & $\bullet$ & & $\bullet$ & $\begin{array}{l}\text { apoio vertical móvel: } \\
\text { esforços em X e Z }\end{array}$ \\
\hline - & $\bullet$ & & & $\begin{array}{l}\text { apoio perpendicular: } \\
\text { esforços em X }\end{array}$ \\
\hline
\end{tabular}

Figura 2.22 - Vinculação típica dos painéis com a indicação dos movimentos liberados pelas ligações.

\subsubsection{Consideração de projeto de ligações}

O projeto das ligações é de fundamental importância no cálculo do elemento prémoldado. De acordo com o PCI (1988), uma boa ligação combina praticidade com resistência, produção, durabilidade, construção, durabilidade e economia.

As ações mais usuais, levadas em conta durante o cálculo das ligações, são aquelas decorrentes do peso próprio, vento e solo, e, em alguns casos, as decorrentes de variação volumétrica. 
No projeto e execução das ligações devem ser consideradas ainda algumas recomendações importantes quanto à produção e à montagem, indicadas no PCI (1988), a fim de levar à projetos com maior economia e trabalhabilidade.

Com relação a produção, têm-se que seu conhecimento é essencial para o projeto das ligações e seu entendimento acarreta diminuição dos custos. As recomendações são as seguintes:

a) a padronização das ligações, para melhorar a qualidade e a economia de produção;

b) evitar o congestionamento da armadura e dos dispositivos metálicos;

c) estar ciente das limitações e das dimensões reais dos elementos;

d) considerar folgas e tolerâncias;

e) reduzir os trabalhos após a desforma;

f) evitar tolerâncias de execução e montagem não padronizadas;

g) usar repetição dos detalhes;

h) padronizar os dispositivos e usar poucas variações deles;e

i) usar materiais de ligações simétricas.

As ligações serão projetadas seguindo também algumas indicações, tendo em vista à montagem:

a) tentar diminuir o tempo em que os elementos ficam suspensos;

b) prever ajustes no campo;

c) dar acessibilidade à ligação; e

d) evitar elementos salientes que possam danificar durante o transporte e montagem.

Para o projeto das ligações aplicam-se os mesmos princípios do dimensionamento do concreto armado. Ainda, segundo o PCI (1992), podem-se empregar coeficientes de ajustes para prever as incertezas no comportamento das ligações. Esses coeficientes que variam de 1,0 a 1,33, consideram a forma de ruína, conseqüências da ruína, sensibilidade da ligação aos desvios e relação das ações permanente e acidental. 
São utilizados ainda nos painéis, insertos soldados ou inseridos no concreto. Esses insertos são projetados para resistir basicamente à tração e ao cisalhamento ou à combinação dos dois. Além de insertos, podem-se ter ligações com solda e ligações com cantoneiras. As ligações com solda são muito utilizadas, resistindo a momentos fletores e de torção criados por cargas excêntricas.

\subsubsection{Tipos de ligações}

Os tipos de ligações a serem usadas, dependem da forma, do tamanho e do peso dos painéis. Podem-se ter ligações soldadas e/ou parafusadas.

Preferencialmente, o número de ligações entre pré-moldados arquitetônicos e estrutura principal são projetadas a fim de obter um menor número possível de pontos de interligação. O PCI(1988) recomenda que não mais que duas ligações de apoio vertical fixo ("load-bearing") suportem o peso de painéis.

As ligações, conforme PCI(1988), podem ser divididas nos seguintes tipos:

a)ligações de apoio vertical fixo ("load-bearing"):

Essas ligações transferem cargas verticais para o suporte de estrutura ou fundação, feito por dois pontos apenas. Podem ser aplicadas diretamente no plano do painel (ligações diretas) ou com uma certa excentricidade (ligações excêntricas) fora do plano do painel, conforme listadas nas Figuras 2.23 e 2.24 respectivamente.

b)ligações de apoio perpendicular (“tie-back”):

Tais ligações suportam ações devidas ao vento proporcionando reações perpendiculares ao plano do painel, suportando forças de tração e/ou compressão. São projetados para permitir movimentos verticais e horizontais (Figura 2.25).

c)ligações de alinhamento:

São usadas, como o próprio nome indica, para alinhar o posicionamento entre painéis (Figura 2.26), impedindo deslocamentos relativos entre eles. 

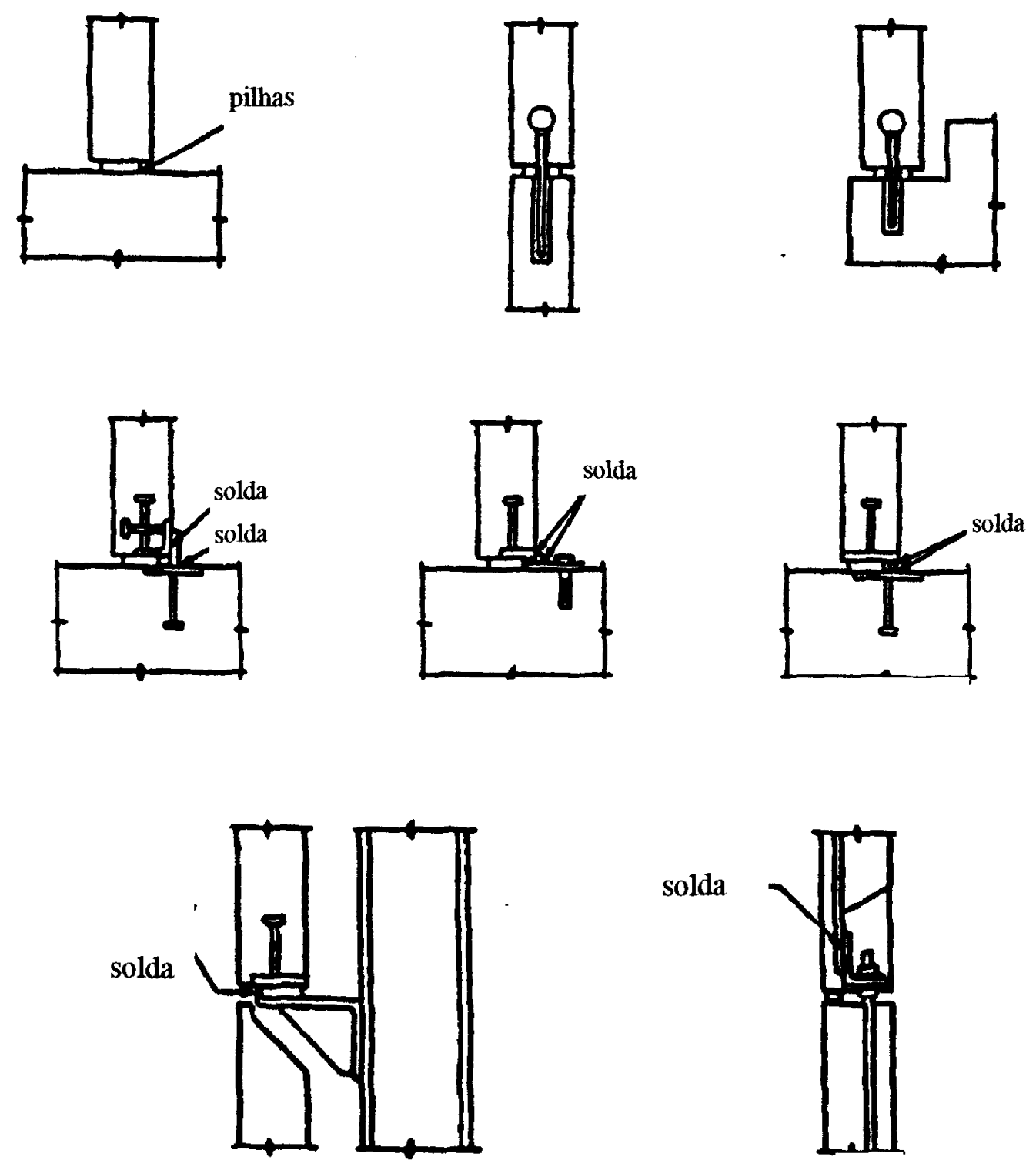

Figura 2.23- Tipos de ligações de apoio vertical fixo diretas [GAIOTTI(1994)] 

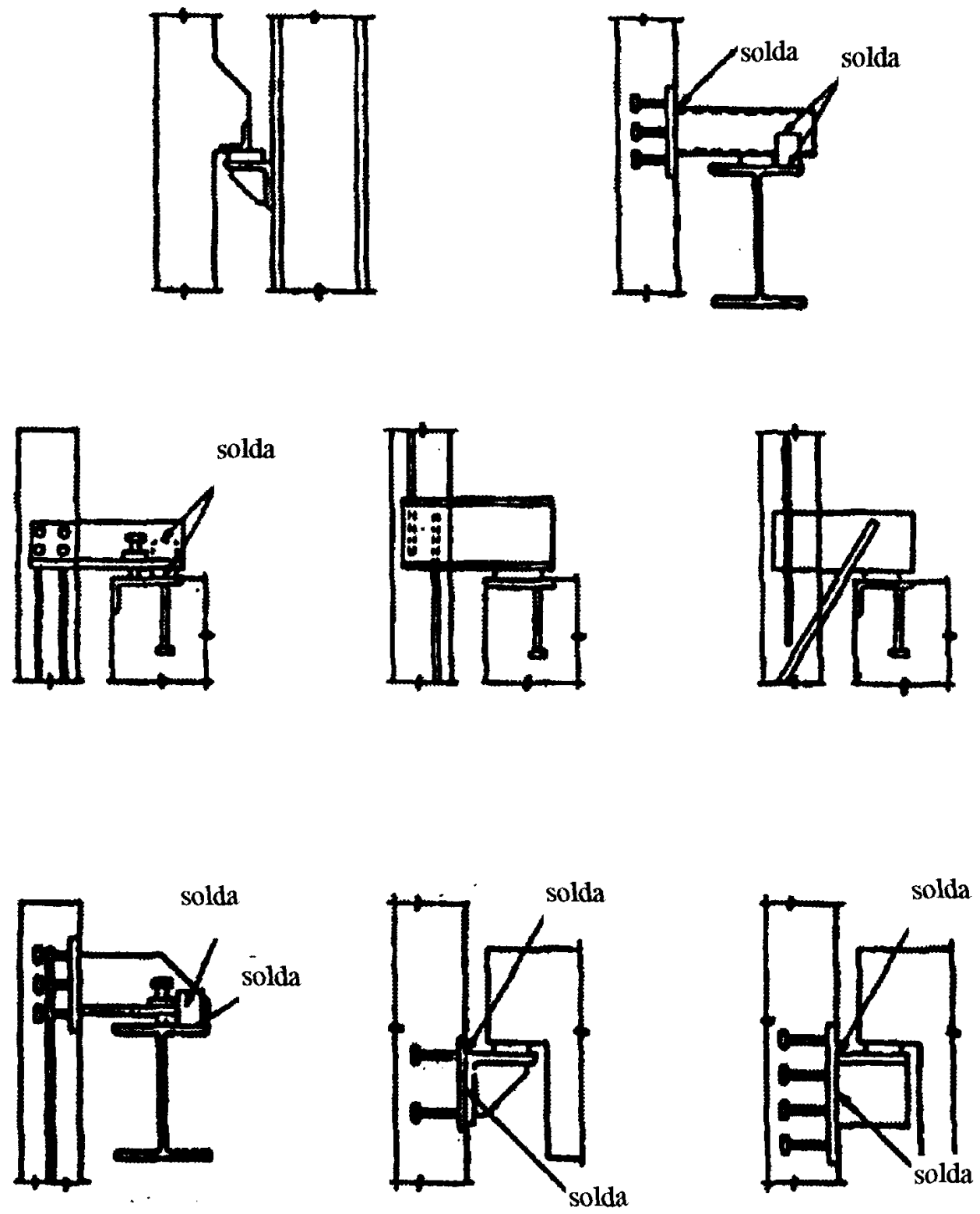

Figura 2.24- Tipos de ligações de apoio vertical fixo excêntricas [GAIOTTI(1994)] 

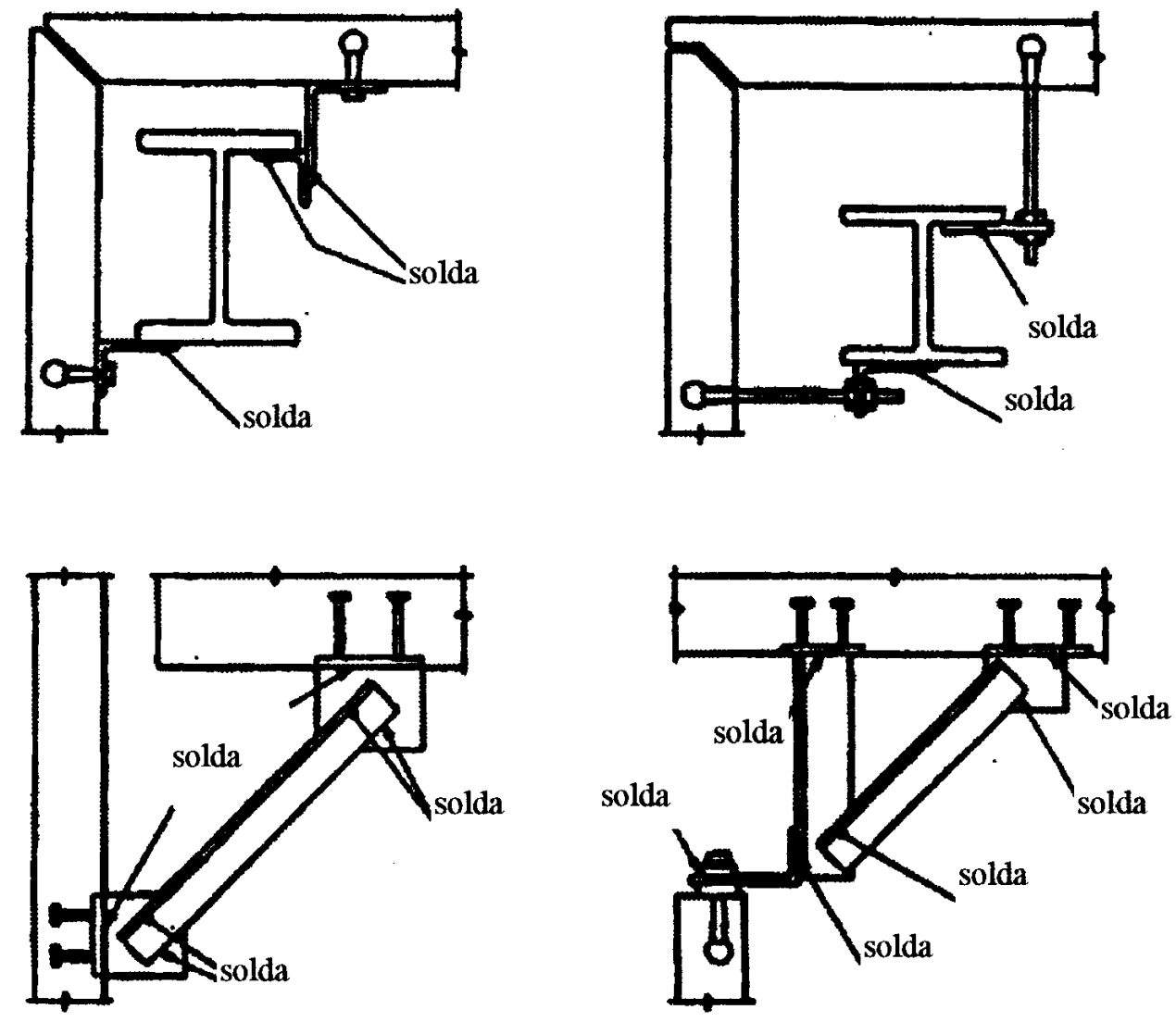

a) Ligações soldadas
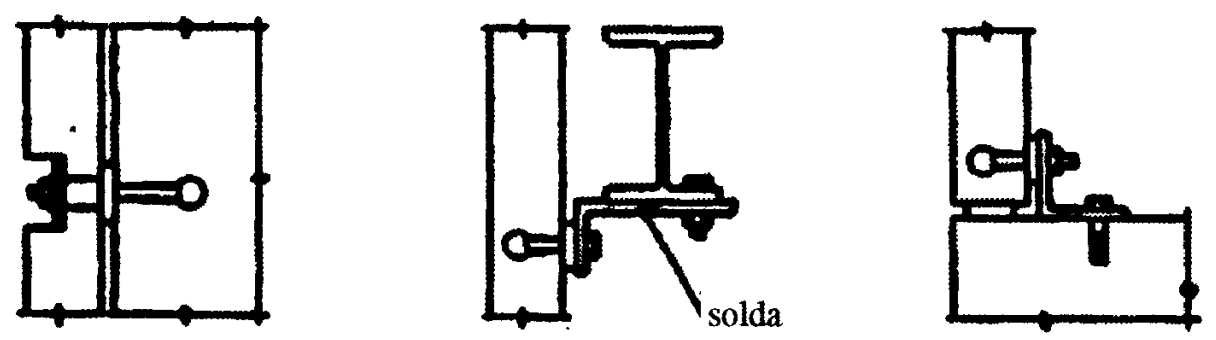

b) Ligações parafusadas

Figura 2.25- Tipos de ligações apoio perpendicular [GAIOTTI(1994)] 


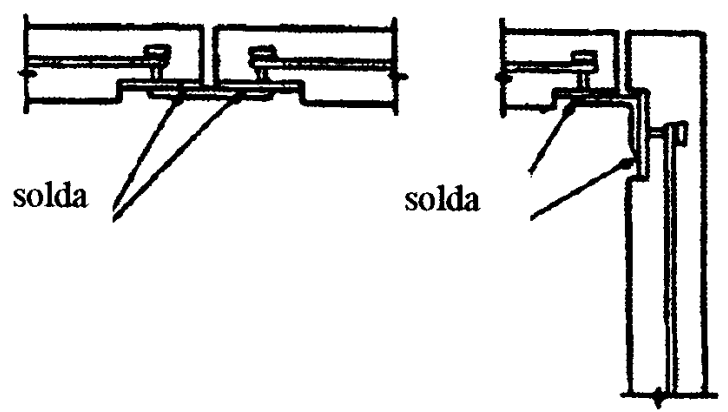

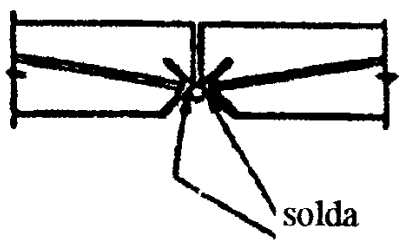

a) Ligações soldadas
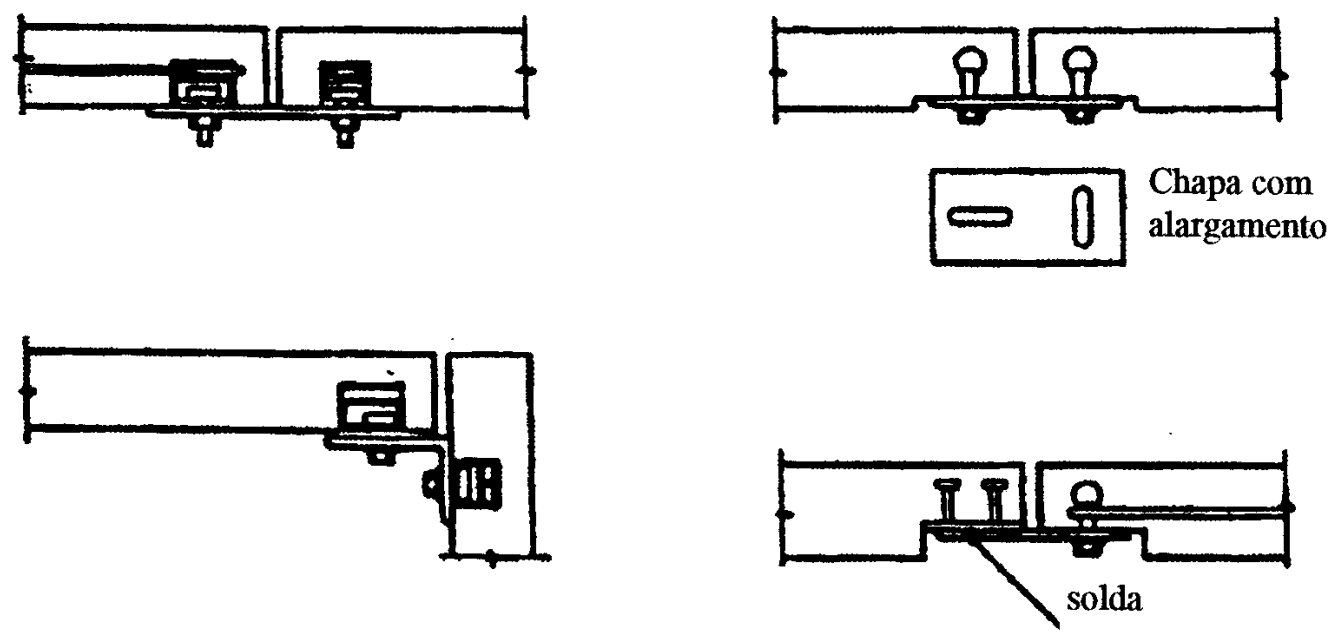

b) Ligações parafusadas

Figura 2.26- Tipos de ligações de alinhamento [GAIOTTI(1994)] 


\subsubsection{Deformabilidade das ligações}

As ligações entre elementos pré-moldados comumente são analisadas como perfeitamente rígidas ou como perfeitamente articuladas. Em geral, essas ligações não comportam como tais, apresentando uma certa deformabilidade quando solicitadas, denominadas ligações semi-rígidas.

A deformabilidade das ligações pode ser determinada tanto por ensaios experimentais como por avaliação analítica. Utilizando-se um procedimento analítico, pode-se idealizar a ligação mediante mecanismos básicos de deformação os quais correspondem à deformação específica de um componente de ligação.

As deformabilidades destas ligações são representadas pelo esquema de molas nas duas direções, como ilustrado pela Figura 2.27 e cuja deformabilidade será calculada adiante.

A consideração da deformabilidade da ligação entre elementos pré-moldados é tratada em FERREIRA(1993), que incorpora tal efeito segundo mecanismos básicos de deformação.

Limitou-se neste trabalho, a utilização da deformabilidade de uma barra embutida entre dois elementos de concreto (Figura 2.28), cuja equação 2.2 é dada abaixo.

$$
\lambda_{\mathrm{tb}}=\frac{16\left(\mathrm{~h}_{\ell}+2 \mathrm{~d}_{\mathrm{b}}\right)^{3}}{3 \pi \mathrm{E}_{\mathrm{s}} \mathrm{d}_{\mathrm{b}}^{4}}
$$

onde:

$$
\begin{aligned}
& \mathrm{E}_{\mathrm{S}}=\text { módulo de elasticidade da barra } \\
& \mathrm{h}_{\ell}=\text { altura livre dos elementos } \\
& \mathrm{d}_{\mathrm{b}}=\text { diâmetro da barra }
\end{aligned}
$$



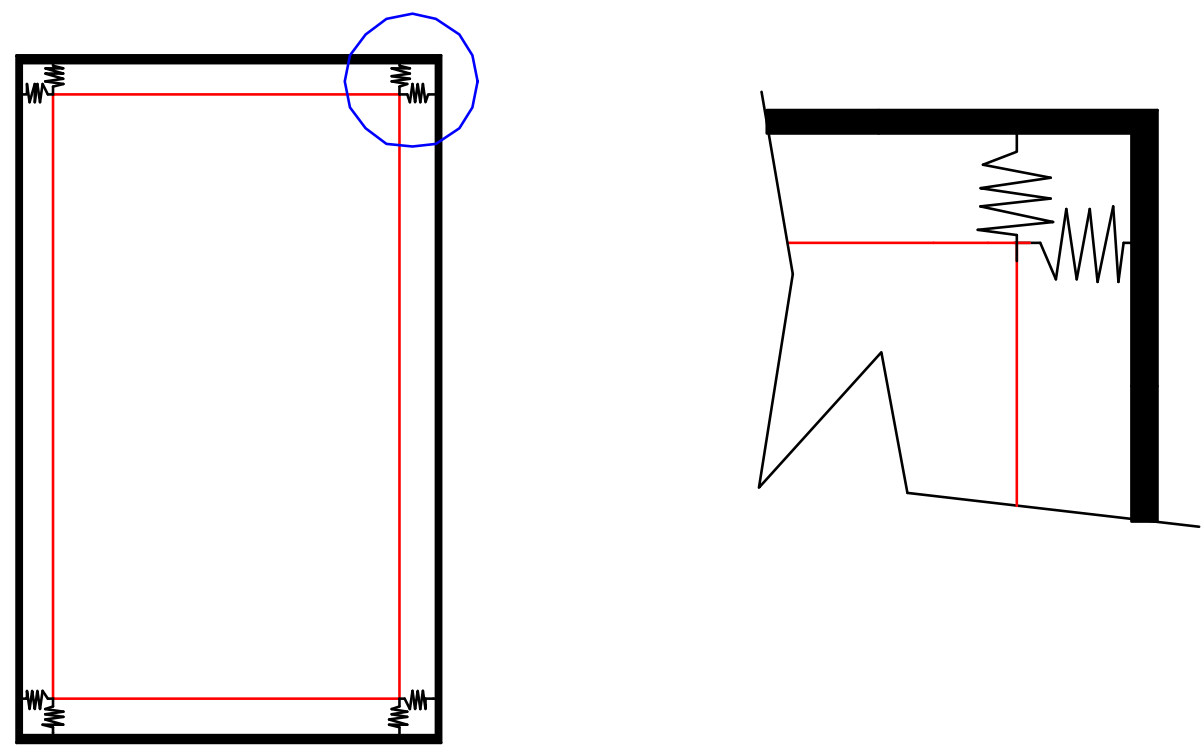

Figura 2.27- Representação da deformabilidade
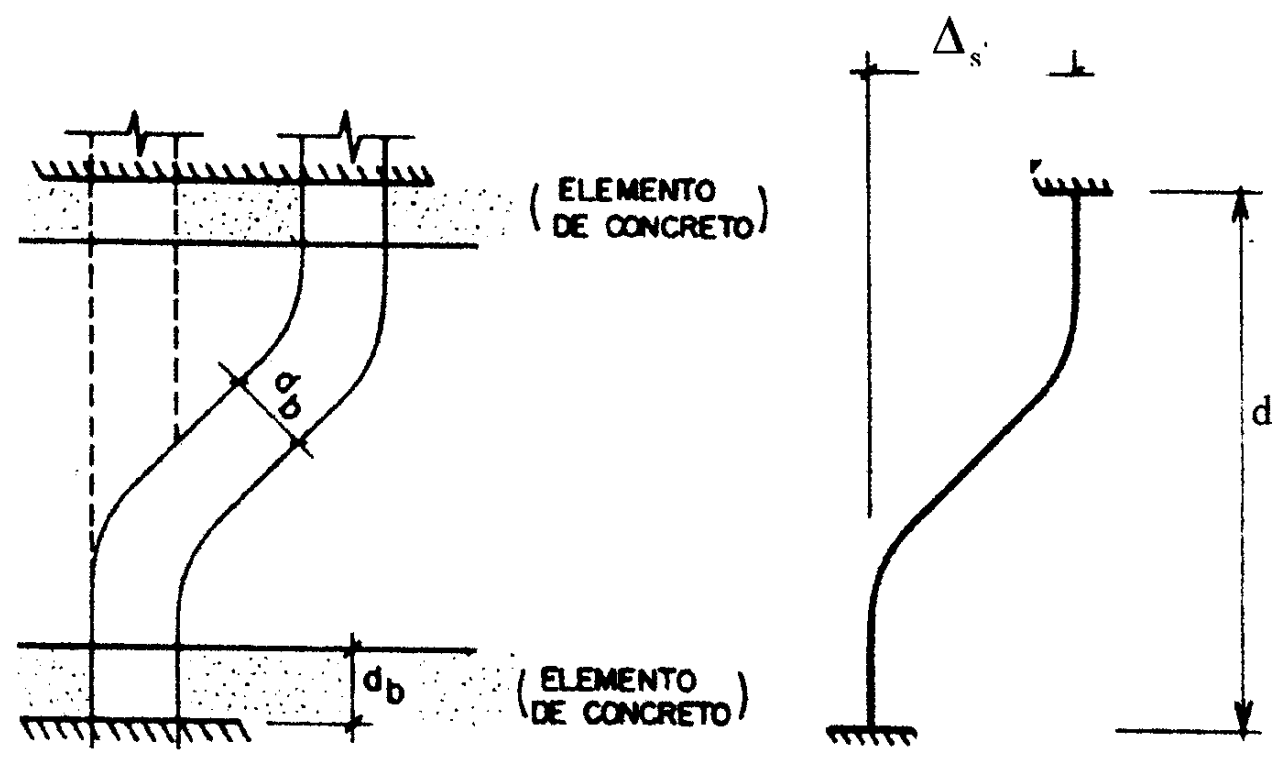

Figura 2.28- Barra embutida entre dois elementos de concreto [FERREIRA(1993)] 


\section{Modelos de análise da interação painel de 3 fechamento $x$ estrutura principal}

\subsection{Estudos anteriores realizados}

Estuda-se, em PUBAL ${ }^{1}$ (1988), o comportamento de um sistema de pórtico com painéis e paredes de enrijecimento interagindo com a estrutura principal. $\mathrm{O}$ trabalho trata da solução estática para esse sistema e mostra o esquema estrutural de um pórtico de vários andares. Além disso, o enchimento utilizado é substituído por hastes conectadas nos cantos dos pórticos.

O trabalho define, ainda, três tipos diferentes de paredes de enchimento, bem como o comprimento equivalente da diagonal da parede, utilizando a teoria elástica da faixa ou o modelo de elemento do enchimento. A seguir, estão listadas as características de cada tipo de enchimento.

TIPO 1: Parede monolítica ligada ao pórtico entre pilares e vigas. A parede é conectada nos mesmos, através de armaduras dentro do pórtico (Figura 3.1).

TIPO 2: Paredes pré-fabricadas inseridas dentro do pórtico, não ligadas rigidamente ao pilares e vigas e sim, conectadas nos cantos dos andares do pórtico (Figura 3.2).

TIPO 3: Enchimento de alvenaria (Figura 3.3).

\footnotetext{
${ }^{1}$ Está sendo feita uma inversão cronológica, justificada pelo trabalho geral sobre a interação de fechamento proposta pelo referido autor.
} 


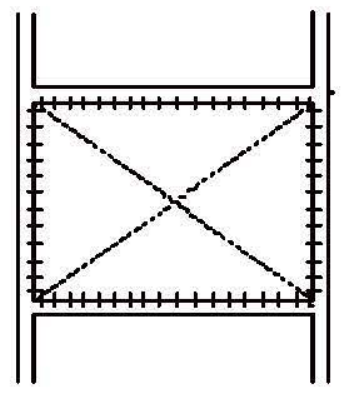

Figura 3.1- Enchimento do tipo 1 [PUBAL(1988)]
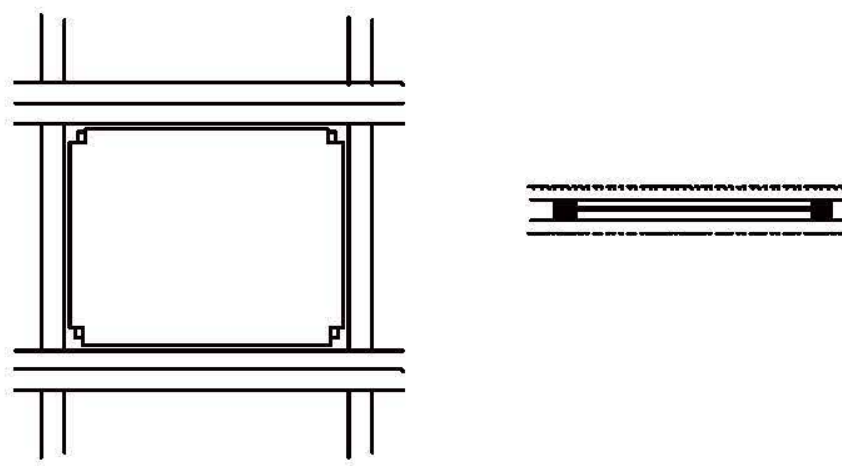

Figura 3.2- Enchimento do tipo 2 [PUBAL(1988)]

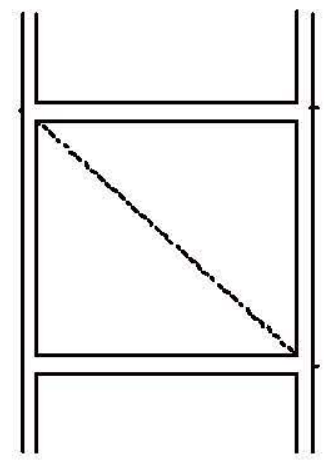

Figura 3.3- Enchimento do tipo 3 [PUBAL(1988)]

De acordo com o autor, determinam-se as espessuras equivalentes de pórtico, $\mathrm{h}_{\mathrm{x}}$ e $\mathrm{h}_{\mathrm{y}}$ definindo a largura da diagonal do enchimento (Figura 3.4). 

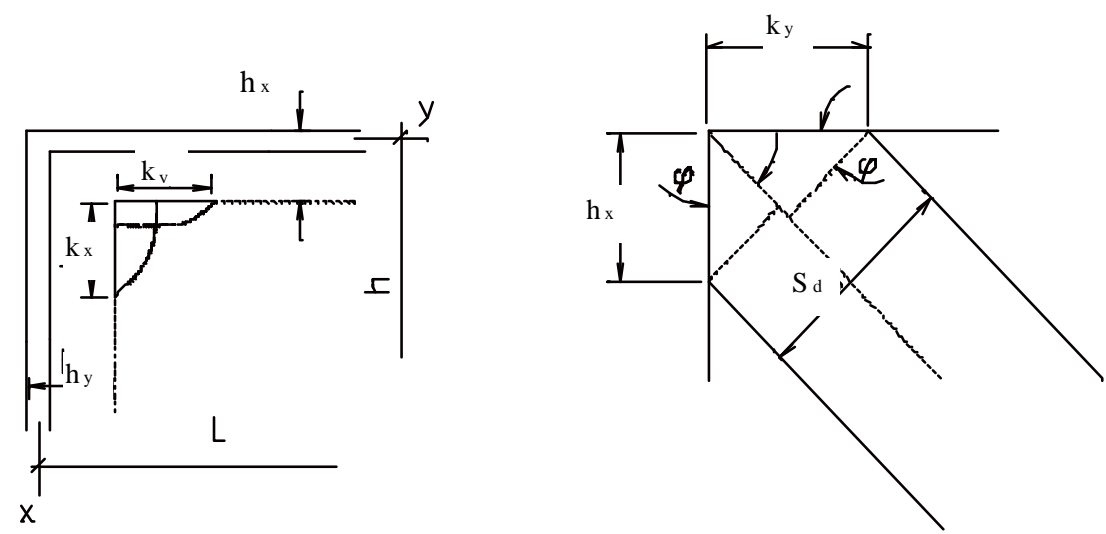

Figura 3.4- Definição da largura da diagonal de enchimento [PUBAL(1988)]

onde

$$
\begin{aligned}
& \mathrm{h}_{\mathrm{x}}=\text { largura equivalente da estrutura na direção } \mathrm{x} \\
& \mathrm{h}_{\mathrm{y}}=\text { largura equivalente da estrutura na direção y } \\
& \mathrm{k}_{\mathrm{x}}=\text { comprimento de contato na direção } \mathrm{x} \\
& \mathrm{k}_{\mathrm{y}}=\text { comprimento de contato na direção y } \\
& \mathrm{L}=\text { vão entre pilares } \\
& \mathrm{h}=\text { altura do andar } \\
& \mathrm{S}_{\mathrm{d}}=\text { largura equivalente da diagonal } \\
& \varphi=\text { ângulo da diagonal }
\end{aligned}
$$

O modelo para o enchimento define a ligação da parede ao pórtico apenas nos cantos, a partir das quais se obtém o comprimento equivalente da diagonal do enchimento (Figura 3.5).



$$
\begin{aligned}
& \mathrm{S}_{\mathrm{T}}=\text { componente cisalhante } \\
& \mathrm{S}_{\mathrm{Z}}=\text { componente normal }
\end{aligned}
$$

Figura 3.5- Modelo de enchimento [PUBAL(1988)] 
Através de equações diferenciais e integrações, é determinado em PUBAL (1988), o deslocamento do edifício em função da altura e os esforços atuantes no mesmo, levando em consideração o enchimento. A seguir, na Tabela 3.1, estão relacionados os tipos de enchimento, juntamente com os deslocamentos e esforços, quando submetidos à ação horizontal.

Todos os cálculos realizados consideram o fechamento como um elemento estrutural, interagindo com a estrutura de pórtico. No trabalho, verifica-se que os momentos fletores reduzem-se e que a transferência do carregamento tornou-se mais econômica devido à redistribuição do mesmo, tanto para a estrutura principal como para o fechamento.

Em GOODNO e PALSON (1986) são apresentados estudos dos efeitos do fechamento utilizando um edifício de 25 andares, com painéis pré-moldados, conforme ilustrado pela Figura 3.6.

Para tanto, os autores desenvolveram estudos com quatro modelos, representando o efeito dos painéis na rigidez lateral da estrutura principal de edifícios de vários pavimentos. Um breve comentário de cada modelo foi listado, a seguir, levando-se em conta a influência dos painéis de fechamento na resposta sísmica, em edifício medianamente alto, com movimento de terra moderado. Consideram-se também as lajes de piso rígidas no seu próprio plano e a rigidez lateral de cada um dos quatros pórticos que suportam o fechamento incluídas na modelação.

- Modelo enrijecedor ao cisalhamento entre andares: utiliza-se um parâmetro V (constante de rigidez ao cisalhamento), definido como a rigidez lateral da fila de painéis e suas ligações entre níveis de andares em cada face do edifício, para formar a matriz de rigidez, no fechamento de cada face, adicionada a esse parâmetro para formar a matriz de rigidez total de toda a estrutura. Variou-se $\mathrm{V}$ de $1,1.10^{5} \mathrm{kN} / \mathrm{m}$ a $1,4 \cdot 10^{5} \mathrm{kN} / \mathrm{m}$, obtendo-se o resultado, ilustrado pela Figura 3.7. 
Tabela 3.1- Tipos de enchimento e seus respectivos deslocamentos [PUBAL(1988)]

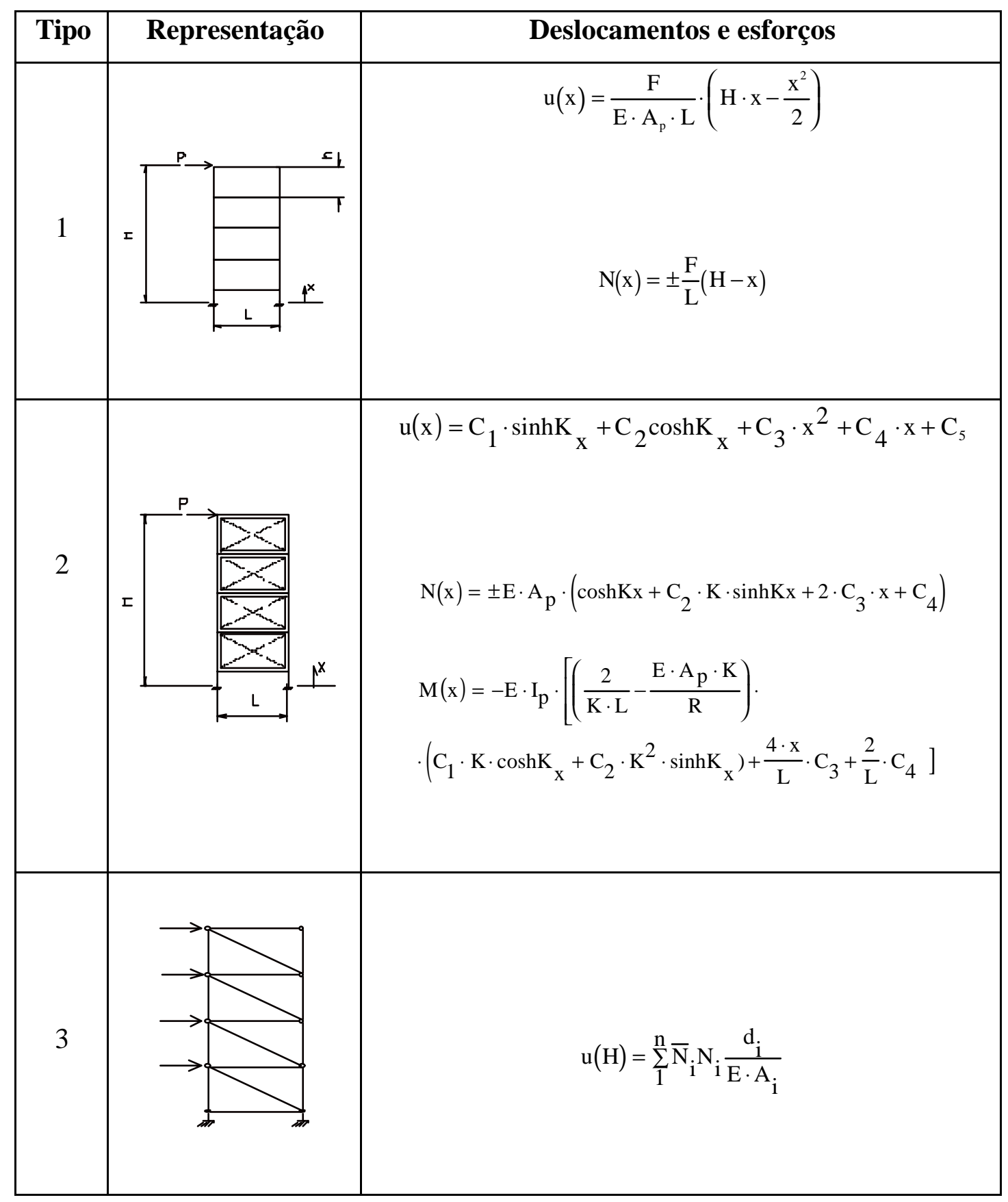

onde:

$\mathrm{u}=$ deslocamento da estrutura em função da altura

$\mathrm{F}=$ força aplicada no topo

$\mathrm{E}=$ módulo de elasticidade do pórtico ou parede

$\mathrm{A}_{\mathrm{p}}=$ área do pilar 

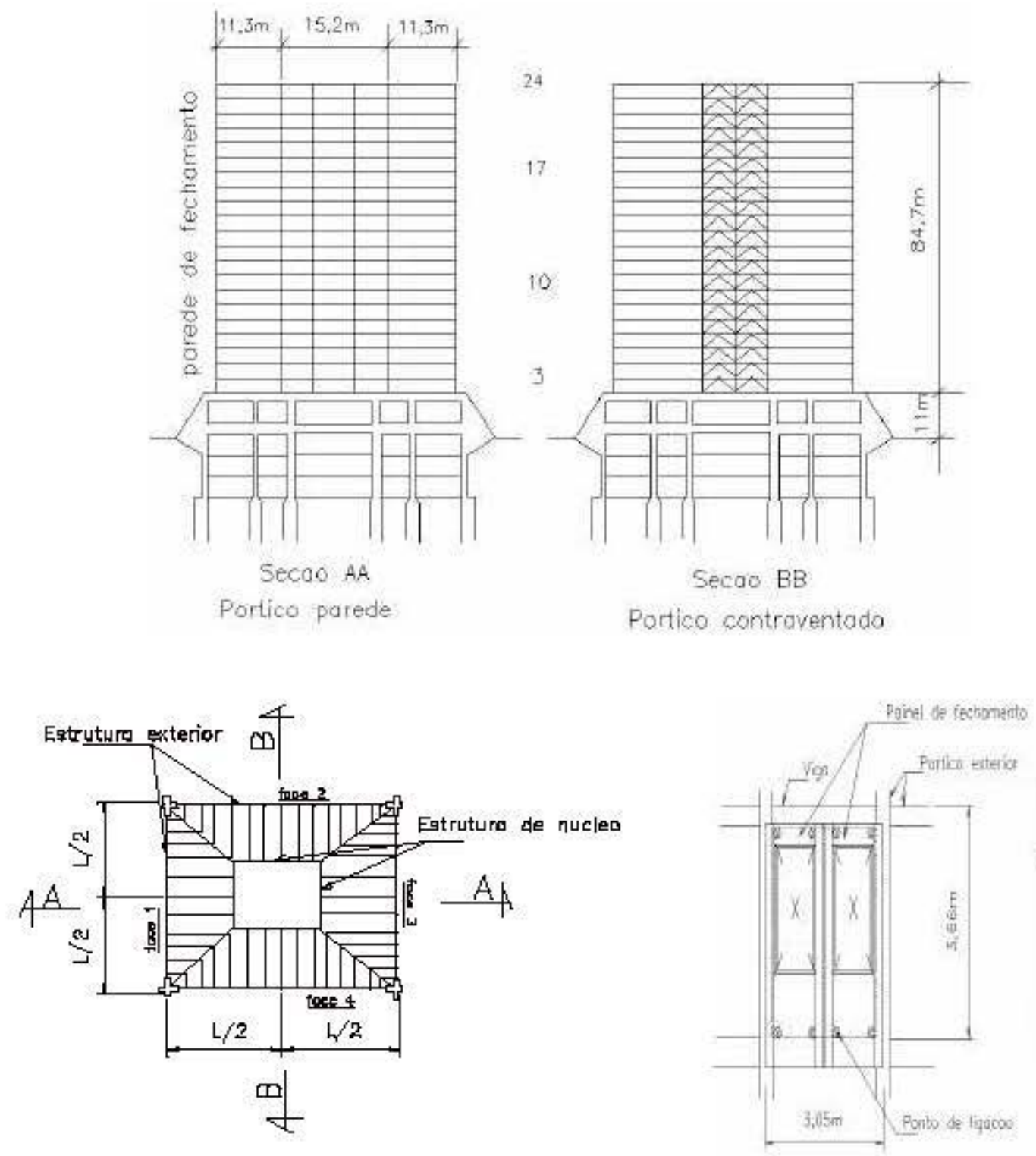

Planta baika

Figura 3.6- Vistas do edifício de 25 andares [ GOODNO e PALSON (1986)] 
$\mathrm{L}=$ distância entre eixos de pilares

$\mathrm{H}=$ altura do edifício

$\mathrm{K}$ = parâmetro de rigidez

$\mathrm{C}_{1}, \mathrm{C}_{2}, \mathrm{C}_{3}, \mathrm{C}_{4}, \mathrm{C}_{5}=$ constantes de integração

$\mathrm{I}_{\mathrm{p}}=$ momento de inércia do pilar

$\mathrm{R}=$ rigidez ao cisalhamento

$\overline{\mathrm{N}}_{\mathrm{i}}=$ força axial no tirante devida à ação de uma força unitária

$\mathrm{N}_{\mathrm{i}}=$ força axial no tirante devida às cargas horizontais

$\mathrm{d}_{\mathrm{i}}=$ comprimento do tirante

$\mathrm{A}_{\mathrm{i}}=$ área do tirante

- Modelo de colapso incremental: adota-se um modelo de fechamento simplificado, como mostra a Figura 3.8. Reduzindo-se gradativamente o parâmetro $\mathrm{V}$ à medida que se aumentava o deslocamento do andar, para qualquer face, durante um determinado tempo de análise dinâmica, reduziu-se V pela metade, em cada face da estrutura, adotando-se para $\delta$ valores equivalentes a $9 \mathrm{~mm}$ ou $18 \mathrm{~mm}$. A partir de $\mathrm{V}=0$, todo o fechamento da estrutura é considerado no colapso.

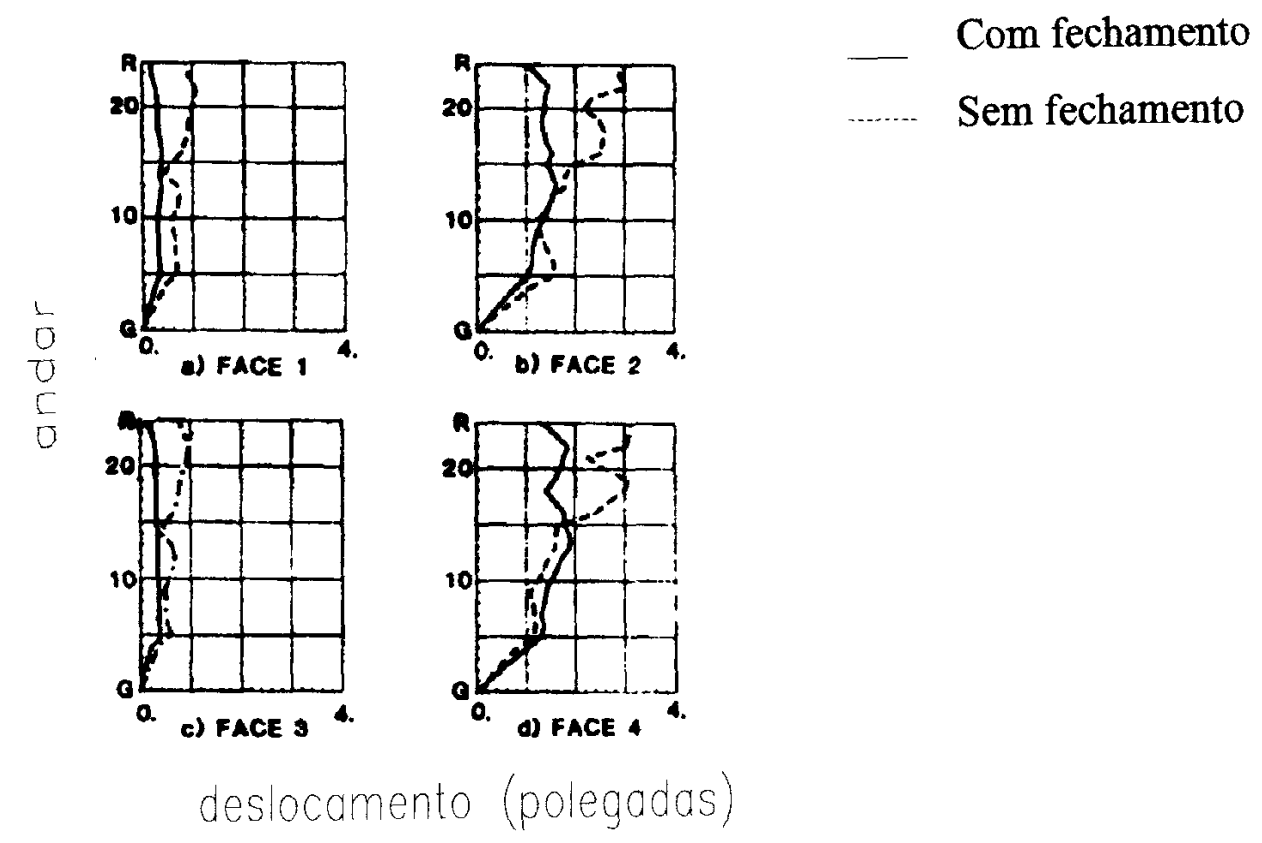

Figura 3.7- Deslocamentos para faces de 1 a 4 


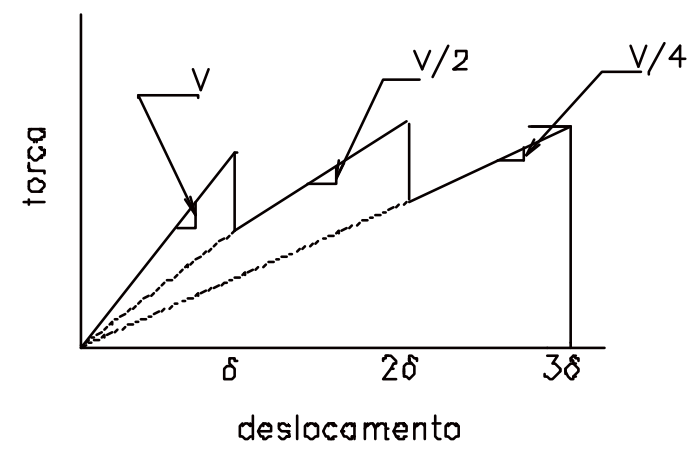

Figura 3.8- Modelo de colapso incremental

A Figura 3.9 mostra os casos do edifício com e sem fechamento e com colapso.

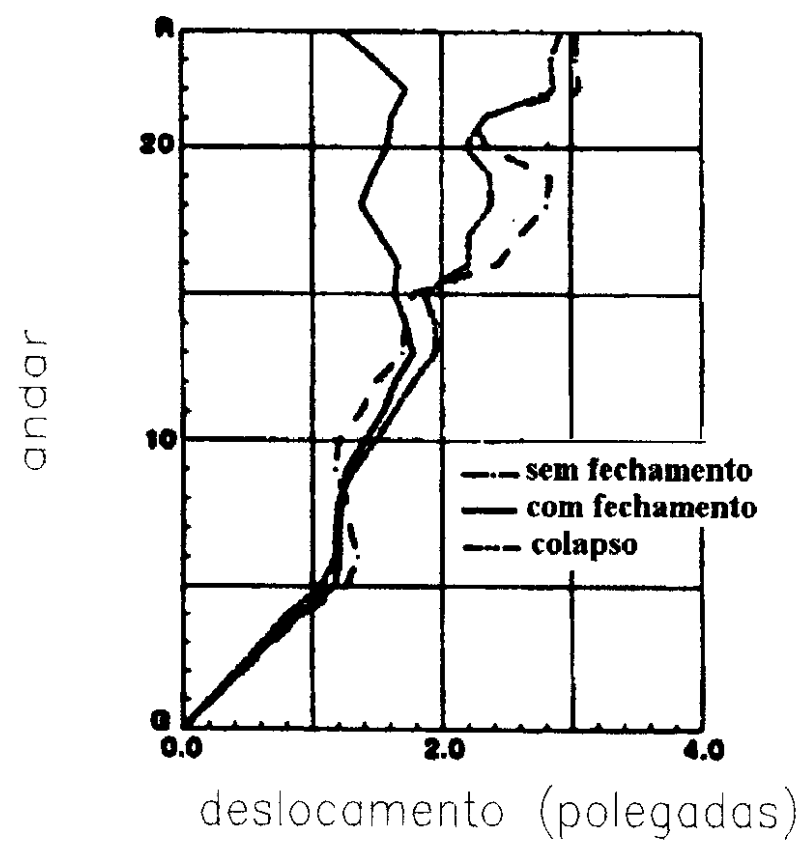

Figura 3.9- Deslocamento em função da altura do edifício

- Modelo de histerese: definiu-se um modelo (Figura 3.10) para representar a rigidez lateral variável, para uma fila de painéis de fechamento. 


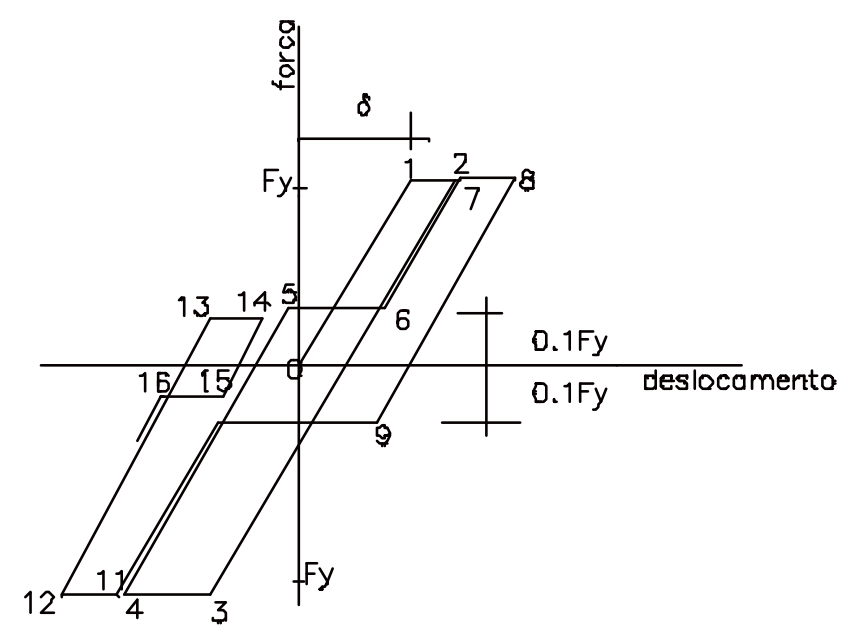

Figura 3.10- Modelo de histerese[ GOODNO e PALSON (1986)]

- Modelo de ligação com fraca rigidez inicial: adotam-se ligações com fraca rigidez inicial nos painéis de fechamento, a fim de acomodar deslocamentos e movimentos térmicos. Na Figura 3.11 foi representado o sistema de suporte utilizado no estudo, bem como o modelo de ligação para a relação força e deslocamento.

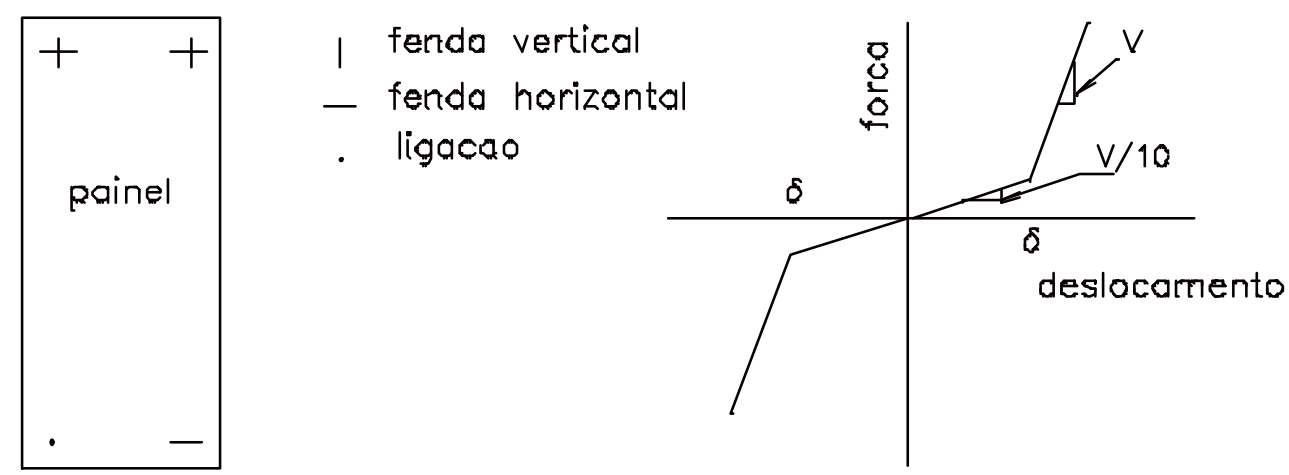

Figura 3.11- Condições de suporte e relação força x deslocamento para o modelo de ligação[ GOODNO e PALSON (1986)]

Os resultados obtidos mostram que os painéis de fechamento contribuem significativamente para enrijecer a estrutura com relação às ações laterais estáticas e dinâmicas. 
Em outro estudo, HENRY e ROLL (1986) analisam a interação de painéis pré-moldados de fechamento, modelados por meio de elementos finitos, utilizando-se um elemento com 12 graus de liberdade. As deformabilidades das ligações são incorporadas, durante a análise da estrutura e modeladas como elementos de viga, com 3 graus de liberdade em cada nó.

É desenvolvida a análise de um modelo típico do painel de fechamento com as ligações e a estrutura principal, como mostrado na Figura 3.12.

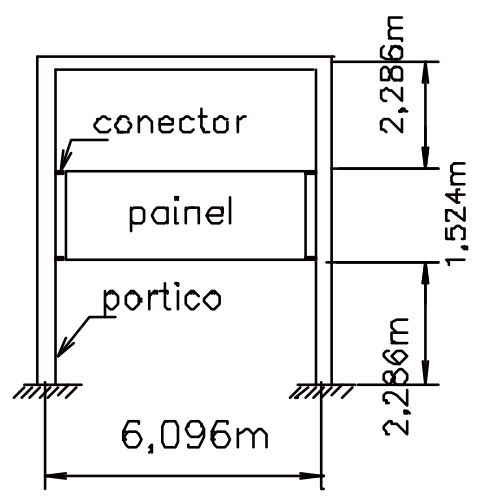

Figura 3.12- Modelo e ligações desenvolvido por HENRY e ROLL (1986)

Estuda-se um sistema de edifício (Figura 3.13), com o intuito de avaliar o efeito dos deslocamentos laterais, quando se considera o painel de fechamento como um elemento estrutural.

Utilizando-se como altura constante de cada andar 3,05m e espessura do painel $12,7 \mathrm{~cm}$, desenvolvem-se 3 análises com variações do vão do edifício, definidas pelas seguintes dimensões: 10,68m, 7,63m e 4,56m, utilizando-se, ainda, dois tipos de painéis com variação de peso e altura.

A Figura 3.14 representa os deslocamentos obtidos para cada peso do painel. 


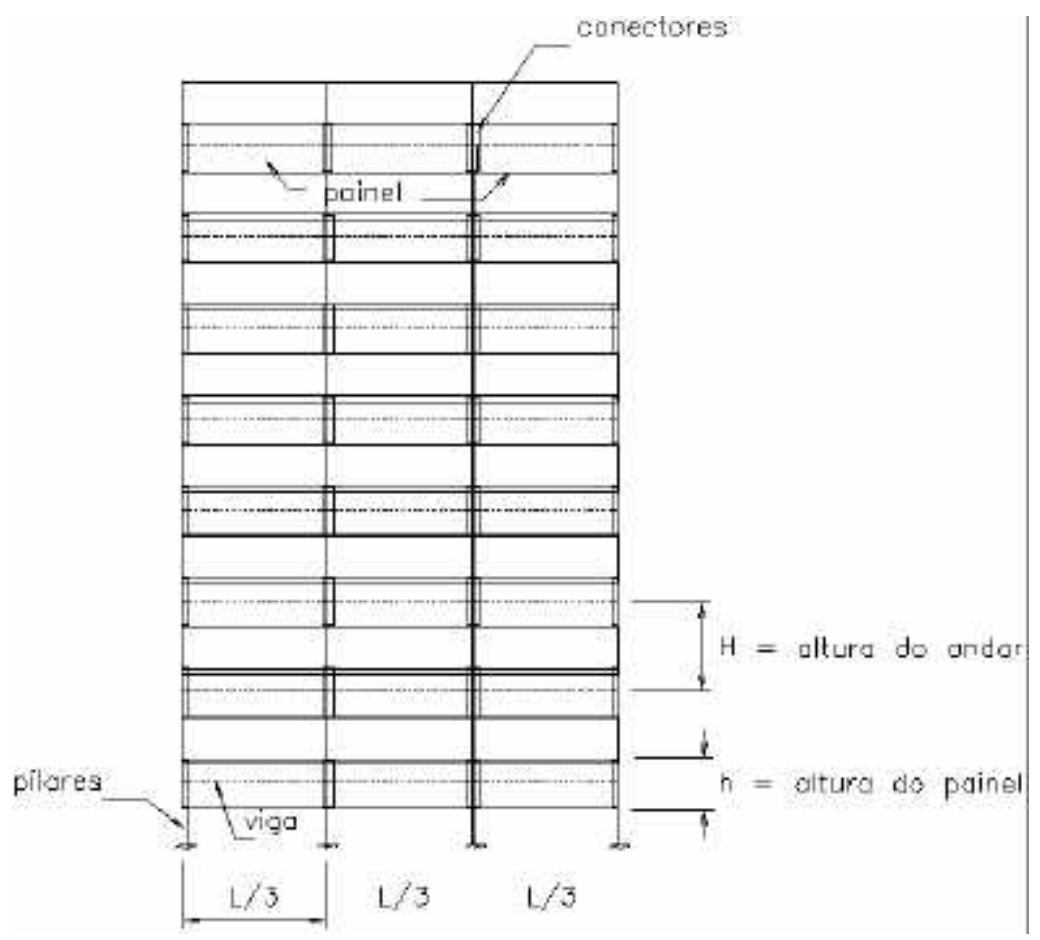

Figura 3.13- Edifício analisado [ HENRY e ROLL (1986)]

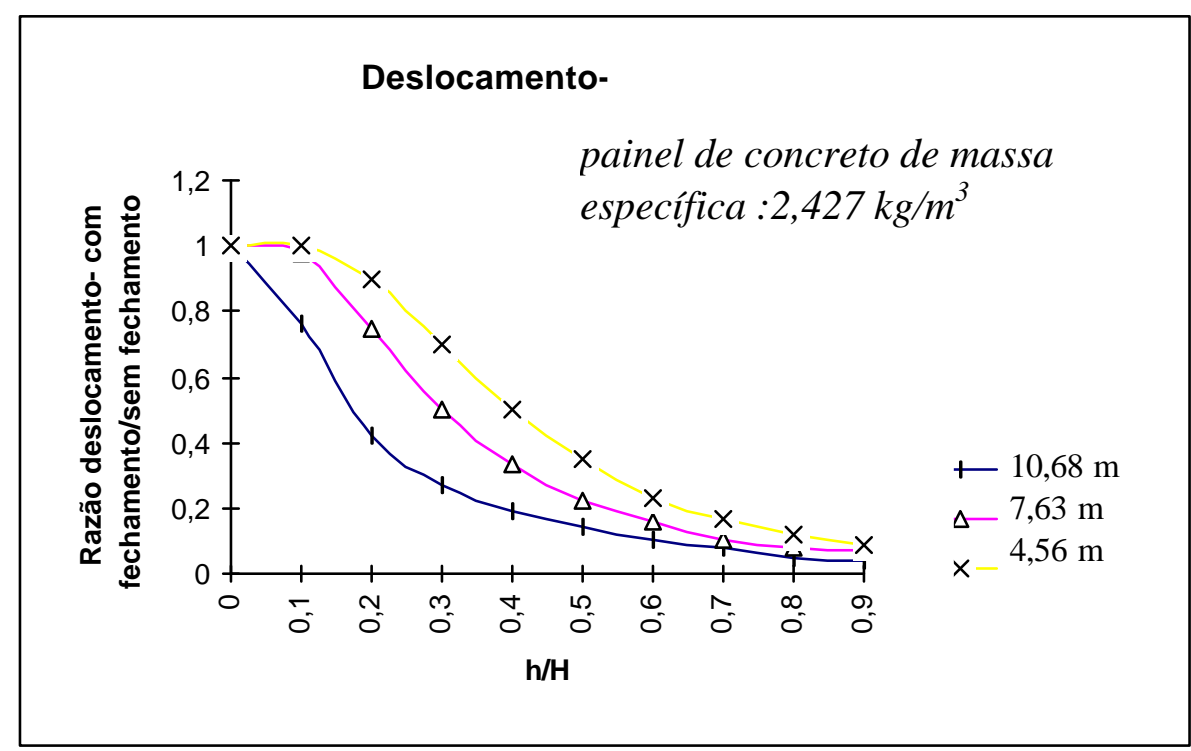

a) painel de massa específica igual a $2,427 \mathrm{~kg} / \mathrm{m}^{3}$

Figura 3.14- Deslocamentos laterais para a variação de massa específica dos painéis [HENRY e ROLL (1986)] 


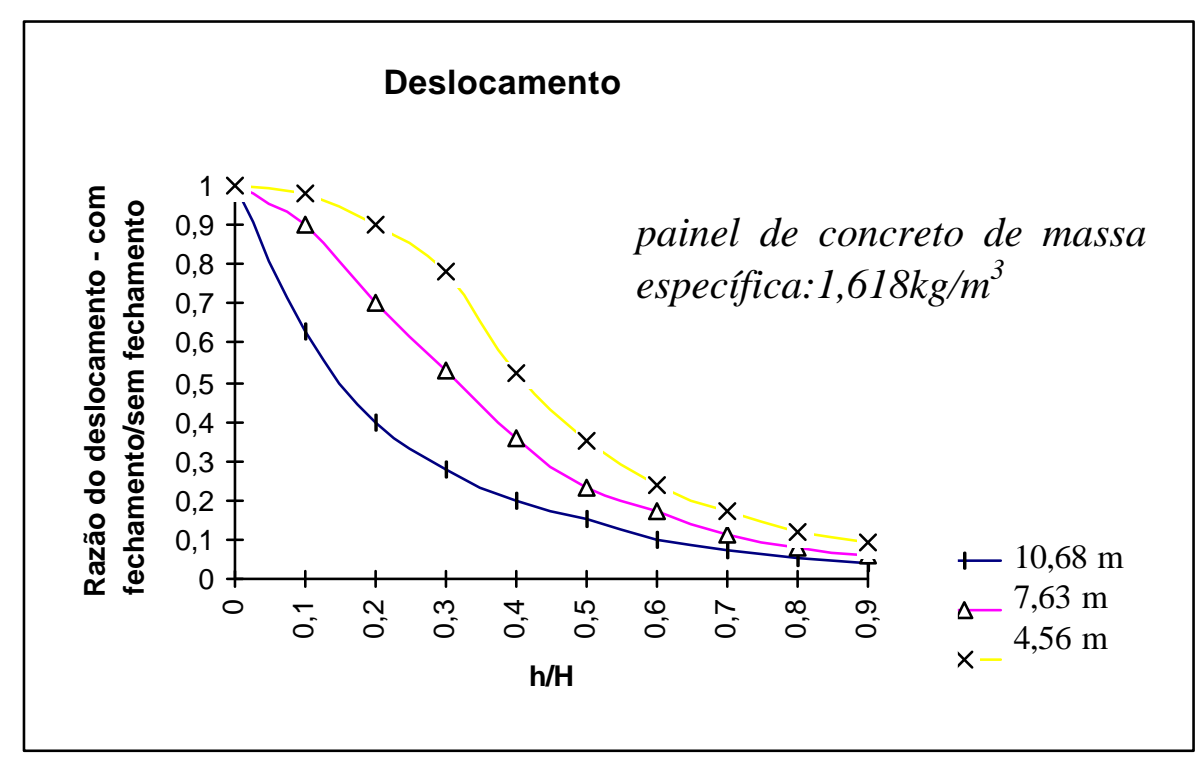

b)painel de massa específica igual a $1,618 \mathrm{~kg} / \mathrm{m}^{3}$

Figura 3.14- Deslocamentos laterais para a variação de massa específica dos painéis [HENRY e ROLL (1986)] (cont.)

Chega-se a importantes conclusões com o exemplo proposto por HENRY e ROLL (1986), representado pela Figura 3.14:

- os aspectos estruturais do fechamento são desprezados durante a análise da estrutura; entretanto devem ser consideradas as vantagens da interação fechamento/pórtico tais como: deslocamento lateral menor, esforços menores nas vigas e redução dos momentos nos pilares que levam a dimensões menores, reduzindo custos e tempo de construção;

- o projeto e o tipo de ligações devem ser adequados, a fim de evitar falhas durante a execução.

Em CHARNEY e HARRIS (1989) avalia-se o efeito do fechamento na resistência do edifício. A análise estrutural realizada inclui 4 tipos de rigidezes, representadas pela eq. 3.1 . 


$$
\mathrm{K}=\mathrm{K}_{\mathrm{S}}+\mathrm{K}_{\mathrm{NS}}+\mathrm{K}_{\mathrm{PC}}+\mathrm{K}_{\mathrm{G}}
$$

onde

$$
\begin{aligned}
\mathrm{K}= & \text { rigidez global do sistema de edifício } \\
\mathrm{K}_{\mathrm{S}}= & \text { rigidez à ação lateral da estrutura principal } \\
\mathrm{K}_{\mathrm{NS}}= & \text { rigidez das partes da estrutura que não são consideradas para } \\
& \text { resistir à ação lateral } \\
\mathrm{K}_{\mathrm{PC}}= & \text { rigidez dos elementos não estruturais, incluindo fechamentos } \\
& \text { exterior e interior } \\
\mathrm{K}_{\mathrm{G}}= & \text { rigidez que leva em conta o efeito P-Delta }
\end{aligned}
$$

Desenvolveram uma equação empírica (eq. 3.2) que relaciona deslocamentos laterais de estruturas com e sem fechamento, dada abaixo.

$$
a_{\text {clad }}=a_{\text {unclad }} \cdot\left[1-\alpha \cdot\left|\frac{A_{\text {clad }}}{A_{\text {total }}}\right|\right]
$$

onde

$$
\begin{aligned}
\mathrm{a}_{\text {clad }}= & \text { deslocamento da estrutura com fechamento } \\
\mathrm{a}_{\text {unclad }}= & \text { deslocamento da estrutura sem fechamento } \\
\alpha= & \text { fator empírico dependente do sistema estrutural, dos tipos de } \\
& \text { ligações, dos tipos de fechamento, da razão altura e espessura } \\
& \text { da edificação (o autor não fornece valores de cálculo) } \\
\mathrm{A}_{\text {clad }}= & \text { área total da superfície de fechamento }
\end{aligned}
$$

CHARNEY e HARRIS (1989) afirmam que a equação acima não é muito aplicável devido às incertezas envolvidas, mas que o deslocamento pode ser encontrado com mais precisão, através da análise detalhada de painéis e ligações, utilizando-se o Método dos Elementos Finitos. 
Os autores analisam as ligações separadamente com 3 graus de liberdade, utilizando um elemento de mola de comprimento zero, localizado entre o painel e a estrutura (Figura 3.15).

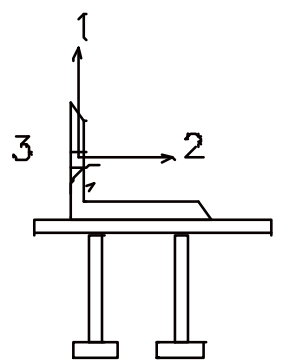

Real

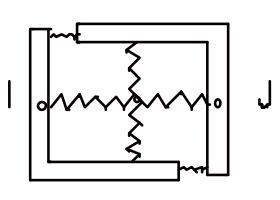

Idealizado $\begin{array}{lll}k 11 & k 12 & k 13 \\ k 21 & k 22 & k 23 \\ k 31 & k 32 & k 33\end{array}$

Rigidez

Figura 3.15- Elemento de ligação do painel CHARNEY e HARRIS (1989)

Através de um exemplo mostrado pela Figura 3.16, CHARNEY e HARRIS (1989) chega-se aos seguintes resultados, indicados na Tabela 3.2.

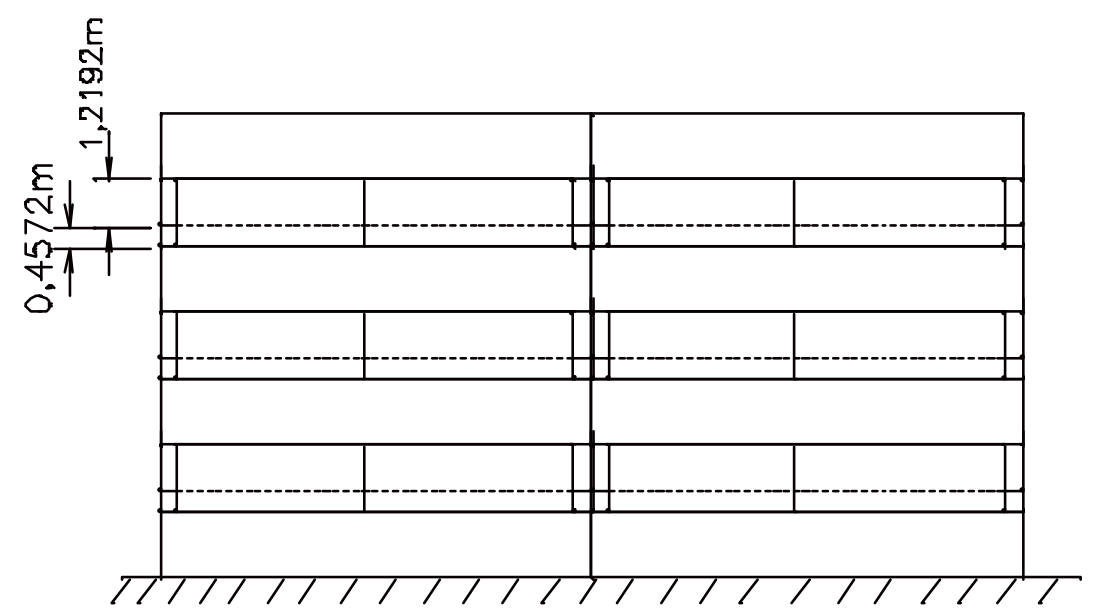

Figura 3.16- Estrutura analisada por CHARNEY e HARRIS (1989) 
Tabela 3.2- Deslocamento da estrutura em função da altura CHARNEY e HARRIS (1989)

\begin{tabular}{|c|c|}
\hline Espessura do painel $(\mathbf{c m})$ & Deslocamento (cm) \\
\hline \hline 0,00 & 1,1481 \\
\hline 5,08 & 0,8253 \\
\hline 10,16 & 0,7877 \\
\hline 15,24 & 0,7727 \\
\hline 152,40 & 0,7419 \\
\hline
\end{tabular}

Em CHARNEY e HARRIS (1989) conclui-se que os painéis enrijecem a estrutura principal, ressaltando a falta de informações adequadas para a elaboração de um projeto racional, sugerindo pesquisas analítico-experimentais para sua consecução, a fim de avaliar racionalmente as técnicas de projeto.

É feita uma revisão de estudos analíticos, em GOODNO e CRAIG (1989), envolvendo a contribuição do fechamento na resistência lateral de edifícios e citações de resultados experimentais desenvolvidos desde o período de 1970 até os dias atuais mostrando, ao final, direções futuras do emprego do fechamento nas edificações e complementando que a interação aumenta a complexidade e a análise do projeto, ou seja, o fechamento será projetado tanto para especificações estruturais, quanto para requisitos de arquitetura, de tempo etc.. Ainda prevêem futuros programas computacionais que considerem o fechamento no desempenho da estrutura.

Finalmente, salientam que os métodos de projeto das ligações devem incorporar propriedades de resistência, rigidez e ductilidade, para permitir a integração do fechamento com o sistema estrutural. Com isso, têm-se, no final, estruturas mais seguras e econômicas.

Em GAIOTTI (1990), estuda-se a interação do painel de fechamento com a estrutura principal, considerando as deformabilidades das ligações e dos painéis. Para tanto, são desenvolvidos dois exemplos de estrutura de 20 andares, com e sem os painéis, a fim de avaliar quantitativamente o efeito do enrijecimento dos painéis submetidos a um carregamento lateral de $9,1614 \mathrm{kN} / \mathrm{m}$. 
A primeira análise representa uma estrutura do tipo que associa parede e pórtico (deformável por momento fletor e por força cortante) e a segunda, corresponde a uma estrutura de pórtico (deformável por força cortante e extremamente rígido ao momento fletor), sendo ambas apresentadas pela Figura 3.17 .

Para cada andar são utilizados dois painéis de fechamento na fachada, com espessura de $125 \mathrm{~mm}$ e duas aberturas para janelas. Adota-se, ainda, a localização e o tipo das ligações dos painéis, conforme ilustrado na Figura 3.18. Referindo-se à Figura 3.18, o painel está ligado à estrutura por duas ligações do tipo apoio vertical fixo ("load-bearing"), 1 e 5, e quatro ligações do tipo apoio perpendicular ("tie-back"), 2, $3,4,6$, mais bem exemplificadas no capítulo 2.

O pórtico foi discretizado por elementos de barra e o painel, por elementos de chapa. A Figura 3.19 representa as dimensões dos pilares, utilizadas para o desenvolvimento do projeto.

Os resultados obtidos, considerando $1 / 4$ da estrutura e 1/4 do carregamento aplicado, são mostrados na Figura 3.20.

Para estimar o efeito de enrijecimento lateral resultante, considerando os seguintes critérios, GAIOTTI(1990) utiliza uma modelagem de uma unidade de painel, conforme ilustrado pela Figura 3.21, levando em conta a interação do painel e da viga:

- o pilar no lado esquerdo tem a metade da inércia, isto é, $\mathrm{I}=2,8125.10^{6} \mathrm{~cm}^{4}$;

- o pilar no lado direito tem sua inércia total, isto é, $\mathrm{I}=3,741.10^{5} \mathrm{~cm}^{4}$;

- a viga na parte inferior terá braços rígidos, para representar zona rígida de união dos pilares;

- são desprezadas as deformações axiais dos elementos de pórtico. 


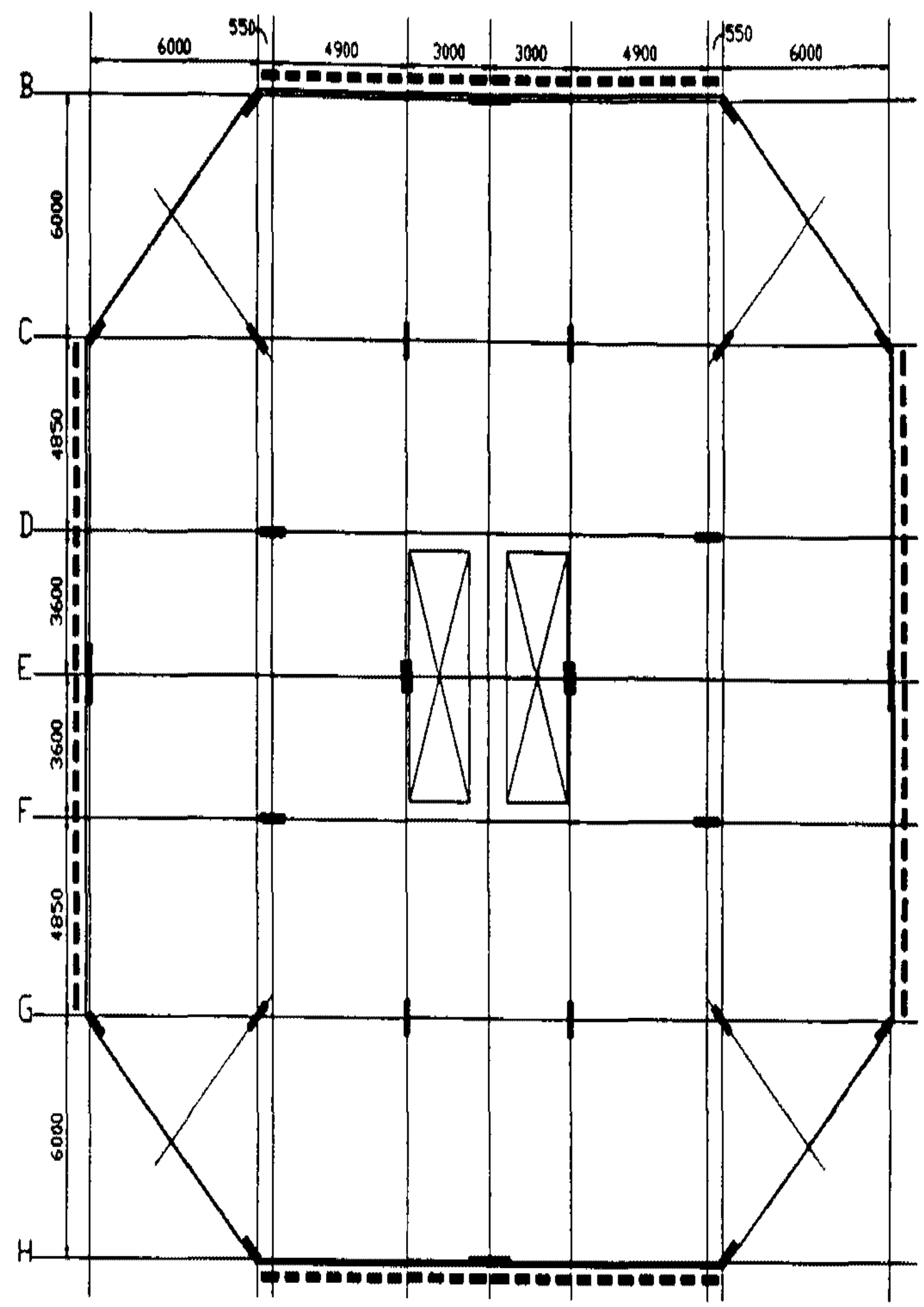

a) Estrutura de pórtico

Figura 3.17 - Planta baixa das análises realizadas GAIOTTI(1990) 


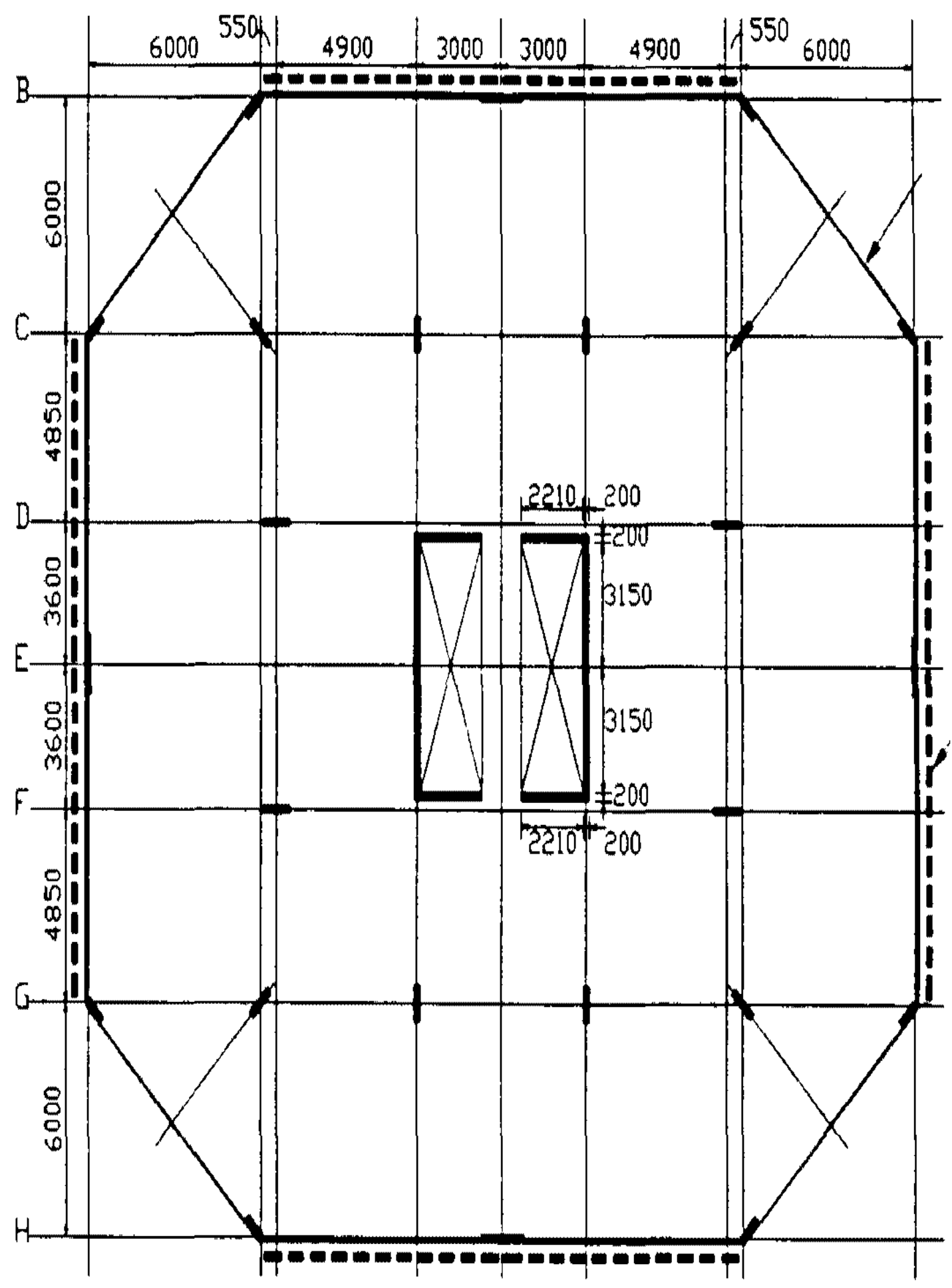

b) Estrutura de associação pórtico-parede

Figura 3.17 - Planta baixa das análises realizadas GAIOTTI(1990) (cont.) 


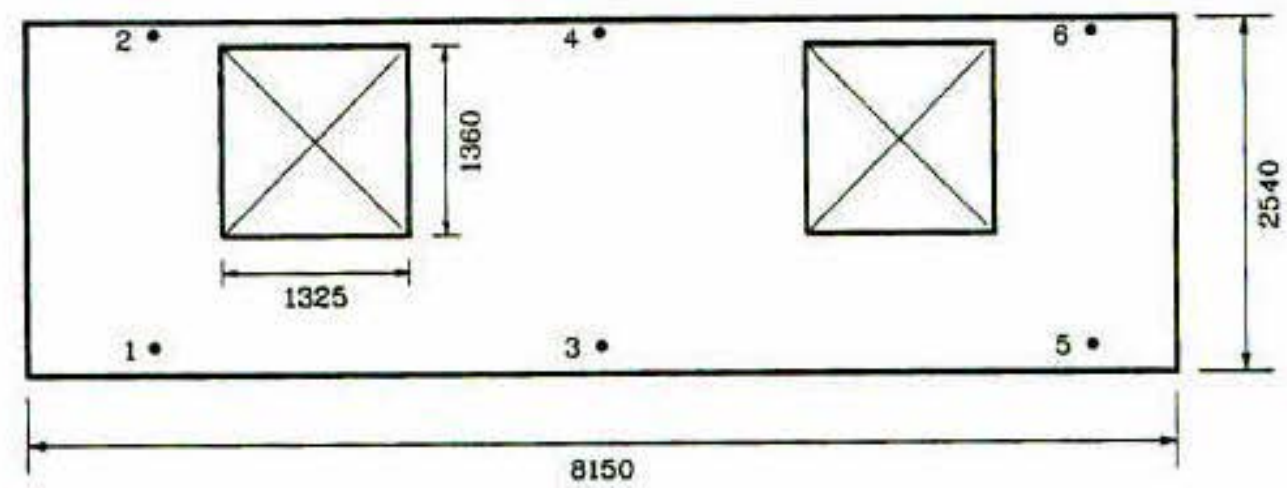

Figura 3.18 - Localização e tipo de ligações

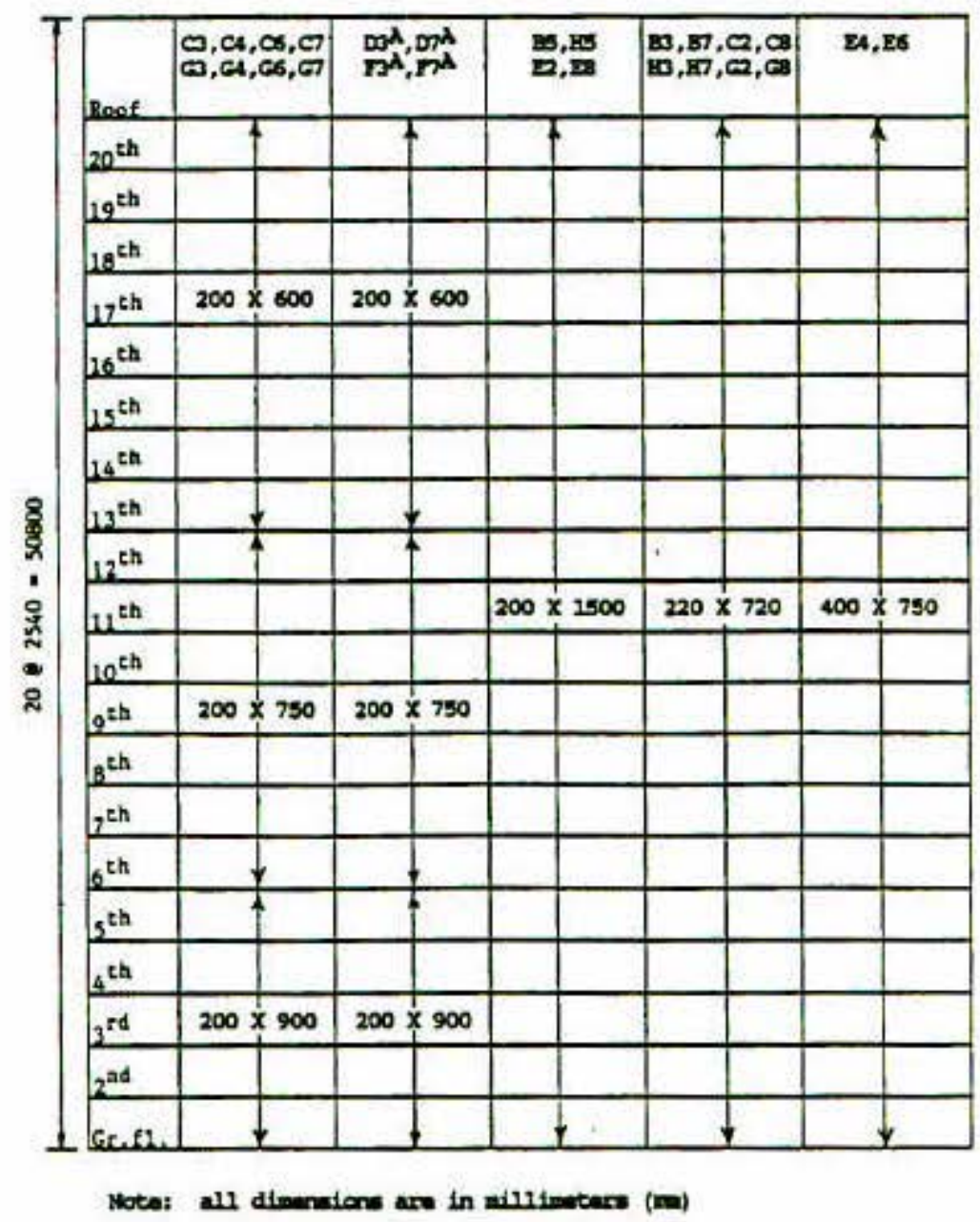

Figura 3.19- Dimensões dos pilares do edifício (em mm) [GAIOTTI (1990)] 


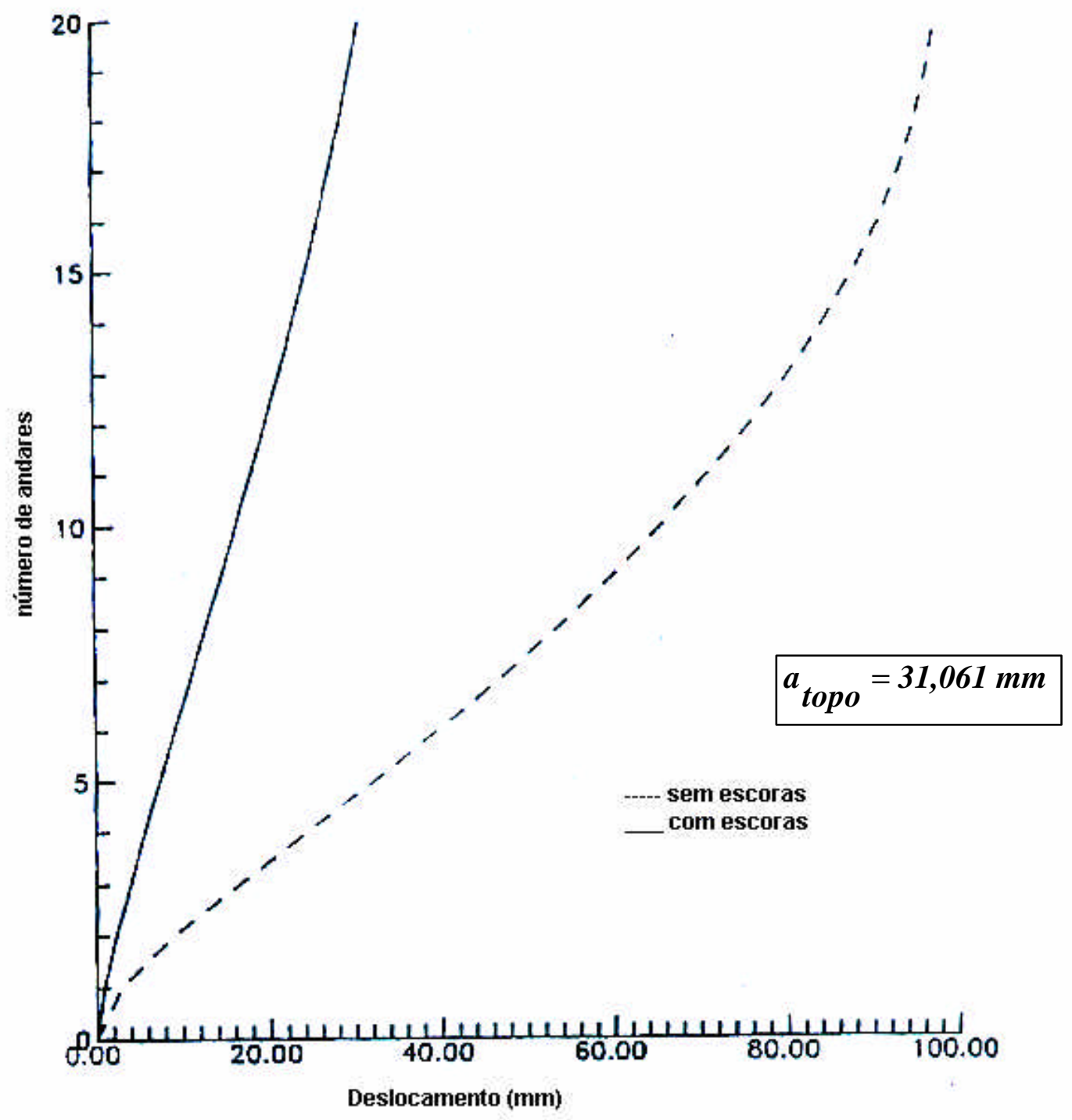

a) Estrutura do tipo pórtico

Figura 3.20- Deslocamentos em função dos andares para cada tipo de análise GAIOTTI(1990) 


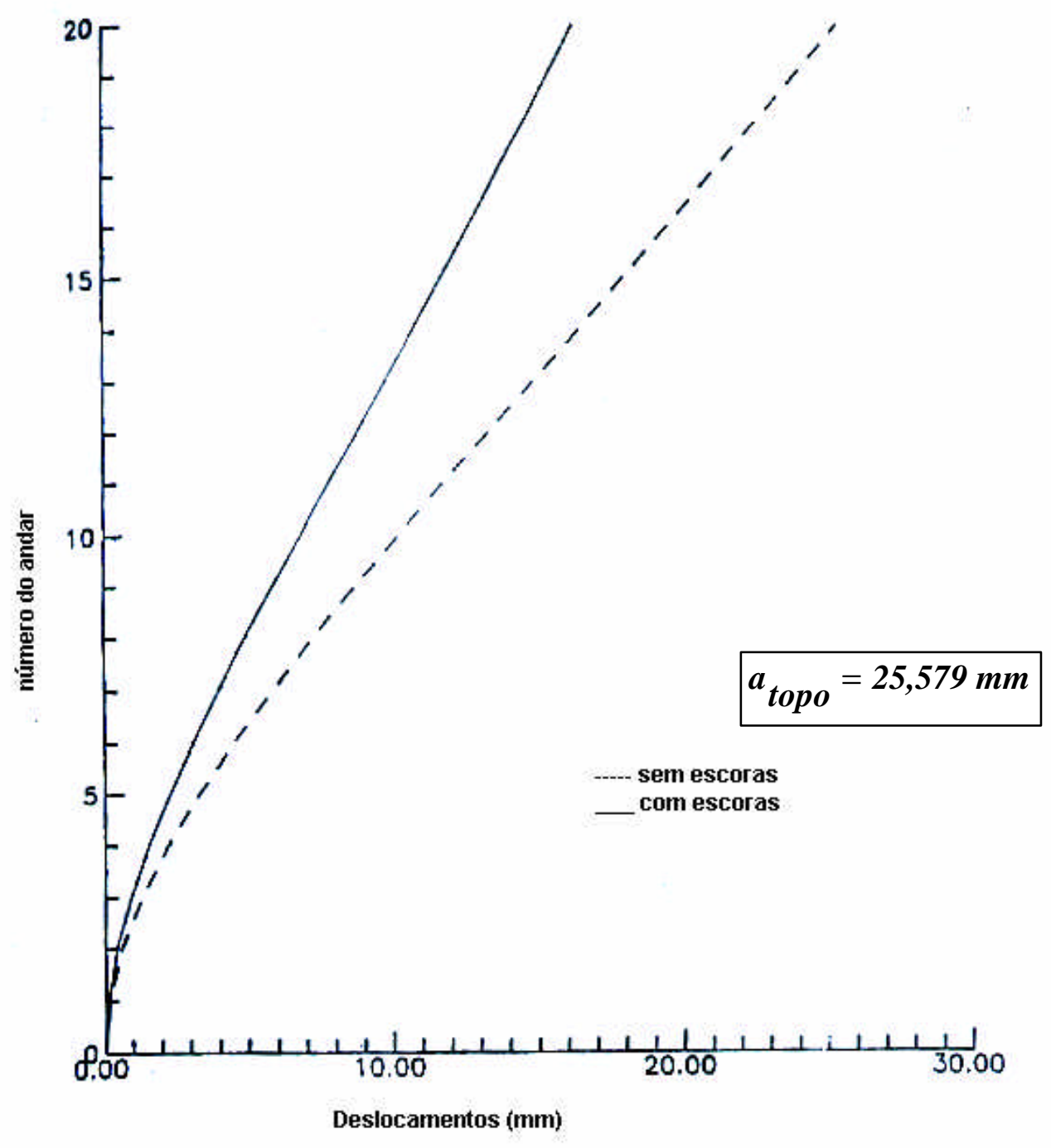

b)Estrutura do tipo associação pórtico-parede

Figura 3.20- Deslocamentos em função dos andares para cada tipo de análise GAIOTTI(1990) (cont.) 
Os elementos de pórtico são analisados para o módulo de elasticidade do concreto de $20 \mathrm{GPa}$ e os painéis, modelados para uma malha de 240 elementos de mesmo módulo de elasticidade.

A rigidez das ligações foi calculada em cada direção restringida. Para cada tipo de ligação são definidos os seguintes valores:

$\Rightarrow$ rigidez vertical para as ligações 1 e $5: \mathrm{k}=4500 \mathrm{kN} / \mathrm{cm}$;

$\Rightarrow$ rigidez horizontal para a ligação $1: \mathrm{k}=2000 \mathrm{kN} / \mathrm{cm}$;

$\Rightarrow$ rigidez horizontal para as ligações $2,3,4: \mathrm{k}=11670 \mathrm{kN} / \mathrm{cm}$.

A partir das rigidezes, analisou-se o comportamento do painel para diversas situações, conforme Tabela 3.3.

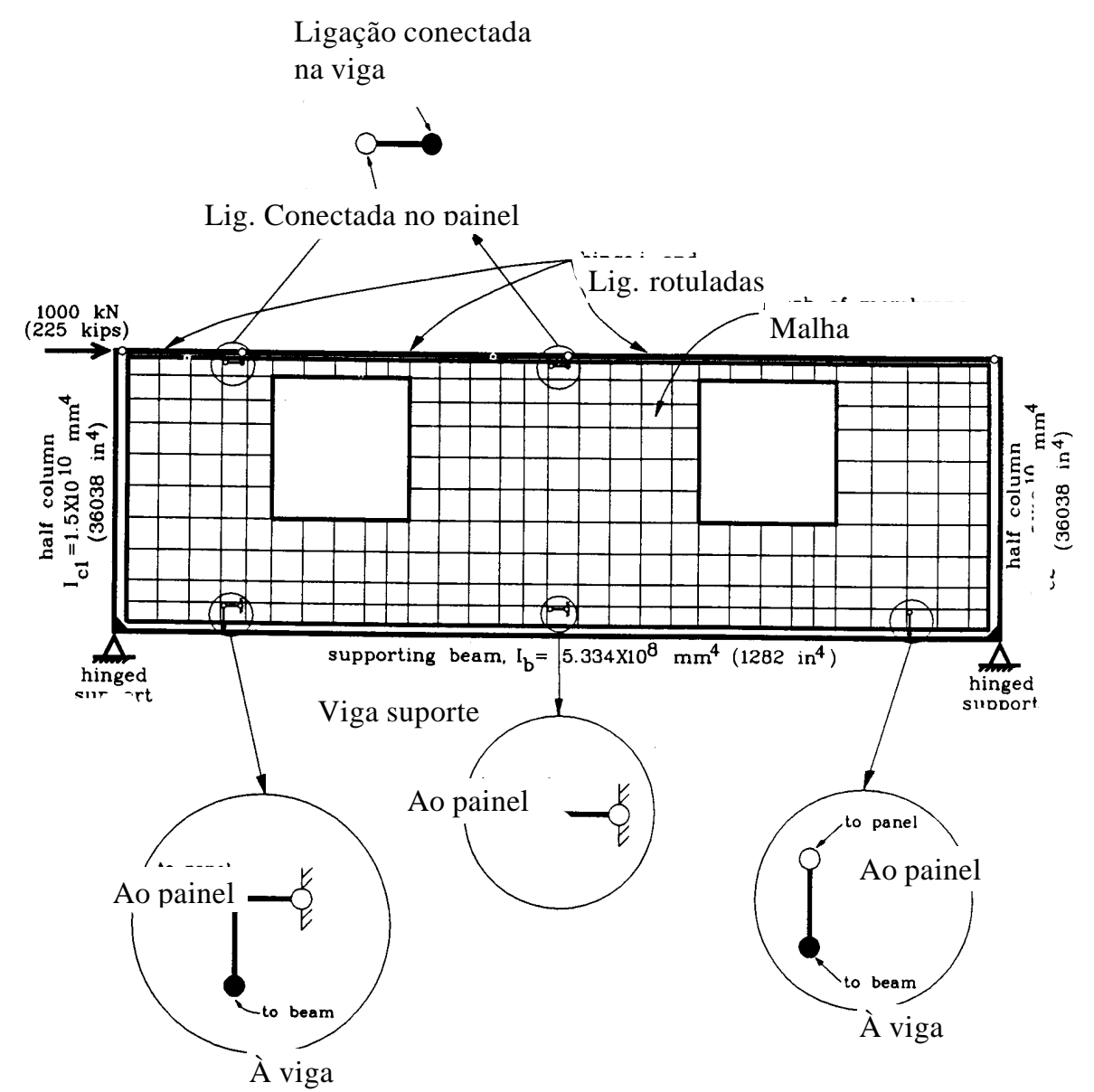

Figura 3.21- Modelagem do painel isolado [GAIOTTI (1990)]

Apresentam-se em GAIOTTI (1990), vários modelos de escoras equivalentes, que consistem na substituição dos painéis por barras fictícias de rigidez equivalente, 
para a análise da estrutura de esqueleto, a fim de representar o comportamento da interação de painéis e ligações na estrutura principal. Os modelos utilizados, bem como seus respectivos deslocamentos, estão descritos na Tabela 3.4.

Neste estudo existem, ainda, indicações referentes ao posicionamento das barras equivalentes.

A área equivalente da escora foi determinada pela equação 3.3 fornecida a seguir:

$$
\mathrm{A}=\frac{\mathrm{k} \cdot \ell}{\mathrm{E} \cdot \cos ^{2} \theta}
$$

A autora realiza um estudo da variação de rigidez da ligação para o mesmo modelo da Figura 3.21 reduzindo-a de um décimo e os resultados obtidos estão visualizados na Tabela 3.5.

De acordo com a tabela, vê-se que, com a redução da inércia, a flexibilidade da estrutura fica mais evidente.

GAIOTTI (1990) analisa, ainda, o efeito de casos distintos de braços rígidos nas vigas para o modelo de painel isolado, conforme Figura 3.22. Todos os casos foram realizados considerando a estrutura e painéis completos, sem desprezá-los no cálculo.

Da análise detalhada do modelo, concluiu-se que os painéis de fechamento contribuem significativamente na rigidez lateral do edifício, enrijecendo-o, tornando-se, portanto, interessante considerá-los no projeto estrutural. 
Tabela 3.3- Deslocamentos obtidos das análises realizadas para o painel isolado [GAIOTTI (1990)]

\begin{tabular}{|c|c|c|}
\hline Análise $\mathrm{n}^{\mathrm{O}}$ & "Descrição & "Deslocamento (mm) \\
\hline 1 & Pórtico sem fechamento & 126,35 \\
\hline 2 & Módulo completo (painel + estrutura) & 3,62 \\
\hline 3 & $\begin{array}{c}\text { Painéis e ligações sustentados pelas } \\
\text { ligações horizontais }\end{array}$ & 4,17 \\
\hline 4 & $\begin{array}{l}\text { Painéis e ligações sustentados pela viga } \\
\text { inferior }\left(\mathrm{I}_{\mathrm{pilar}}=0 \text { e } \mathrm{I}_{\mathrm{viga}}=\propto\right)\end{array}$ & 4,71 \\
\hline 5 & Módulo completo sem pilares & 17,08 \\
\hline 6 & $\begin{array}{l}\text { Módulo completo com pilares e painéis } \\
\text { efetivamente rígidos }\end{array}$ & 0,52 \\
\hline 7 & Módulo completo com viga inferior rígida & 1,51 \\
\hline
\end{tabular}


Tabela 3.4- Modelo de escoras equivalentes com seus respectivos deslocamentos para o painel isolado [GAIOTTI (1990)]

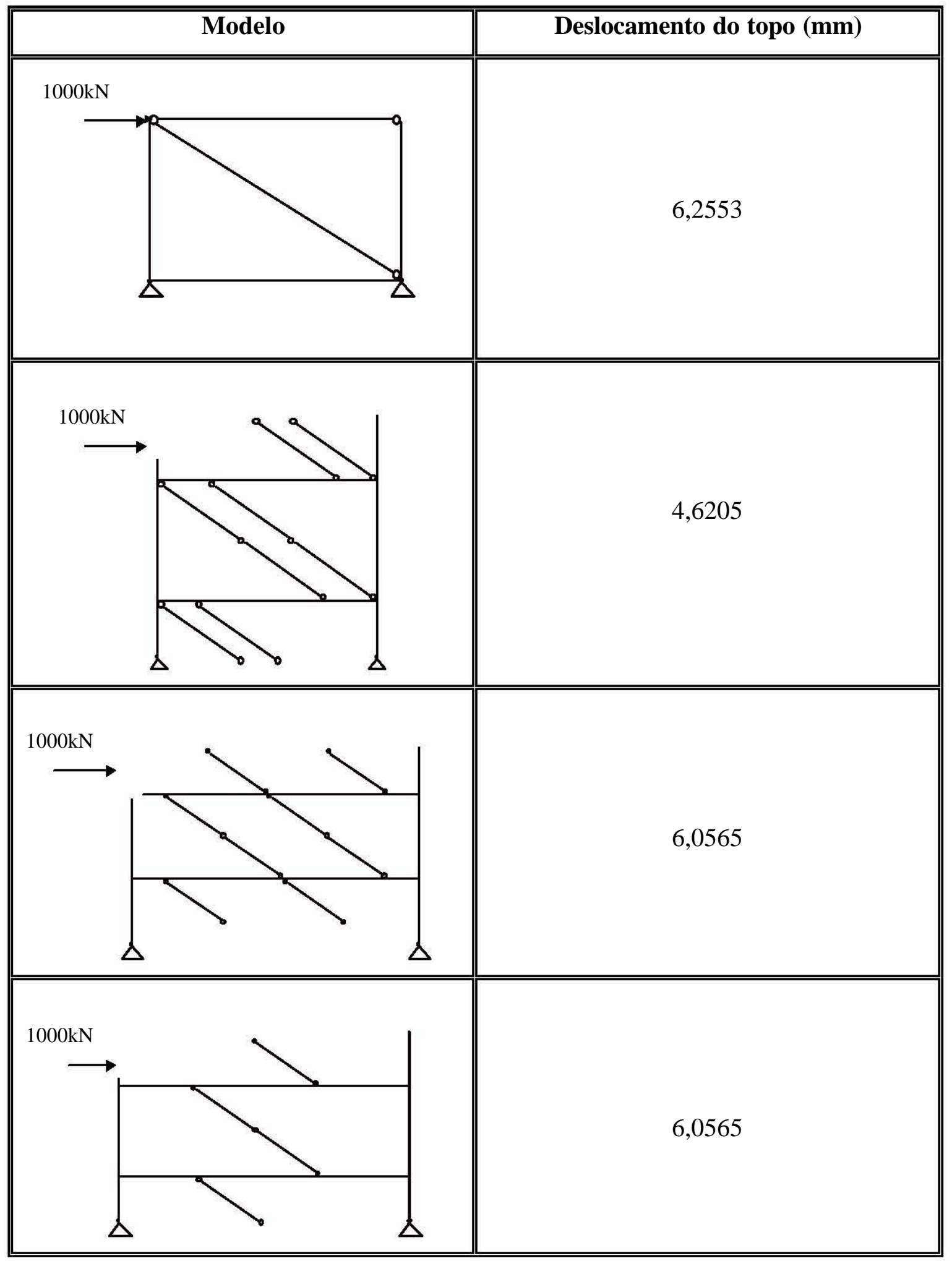


Tabela 3.5- Deslocamentos considerando redução de inércia [GAIOTTI (1990)]

\begin{tabular}{||c||c||c||c||}
\hline Análise & $\begin{array}{c}\text { Deslocamento com } \\
\text { redução da inércia } \\
(\mathrm{mm})\end{array}$ & $\begin{array}{c}\text { Deslocamento sem } \\
\text { redução da inércia } \\
(\mathrm{mm})\end{array}$ & $\begin{array}{c}\text { Deslocamento sem a } \\
\text { consideração do } \\
\text { fechamento (mm) }\end{array}$ \\
\hline \hline análise 2 & 13,31 & 3,62 & 126 \\
\hline \hline $\begin{array}{c}\text { análise da estrutura } \\
\text { de edifício }\end{array}$ & 49,166 & 31,061 & 98,377 \\
\hline
\end{tabular}
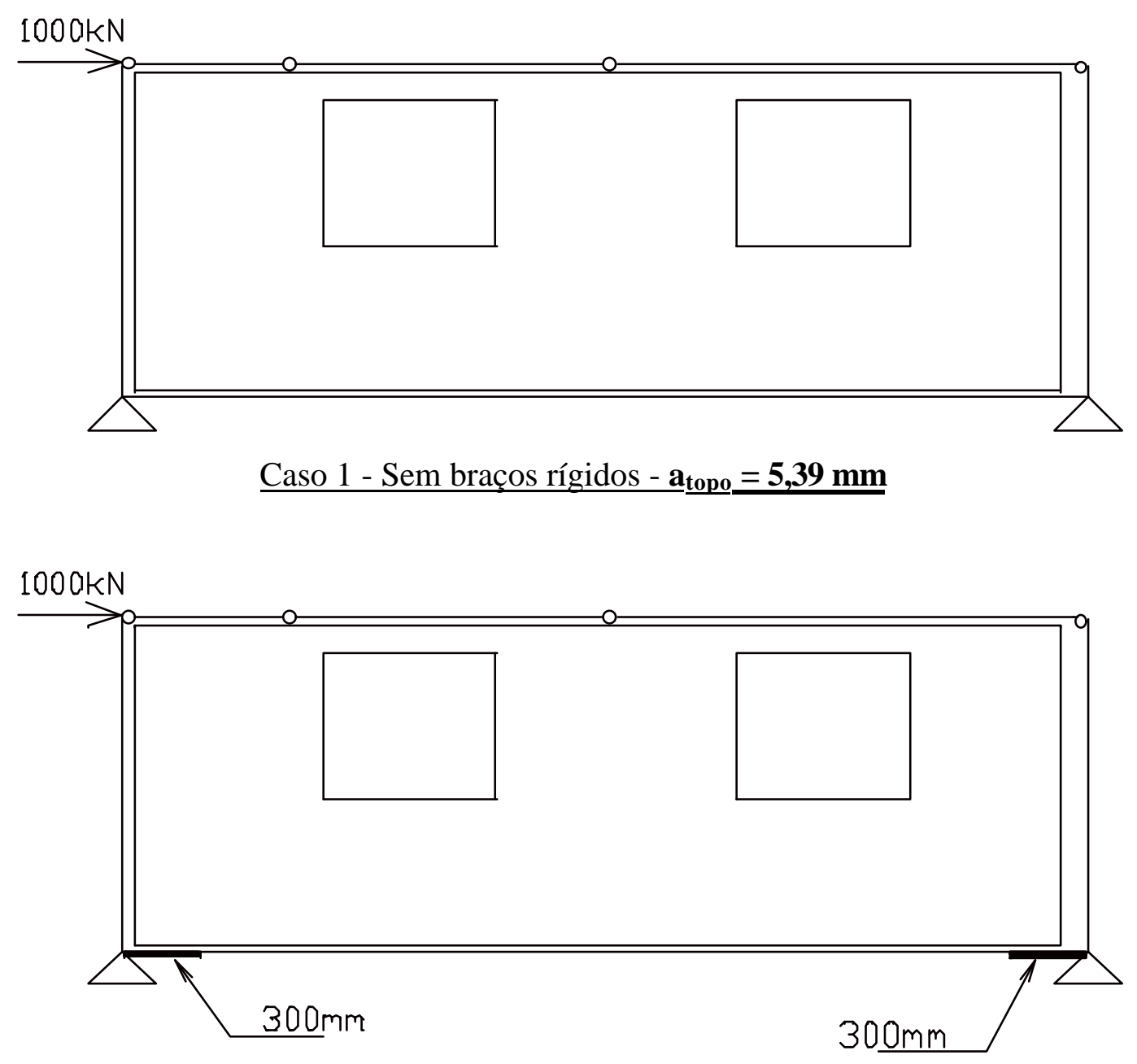

Caso 2- Com braços rígidos $(300 \mathrm{~mm})-\mathbf{a}$ topo $\underline{\mathbf{3 , 7 9} \mathbf{~ m m}}$

Figura 3.22- Deslocamentos para os casos de braços rígidos [GAIOTTI (1990)] 


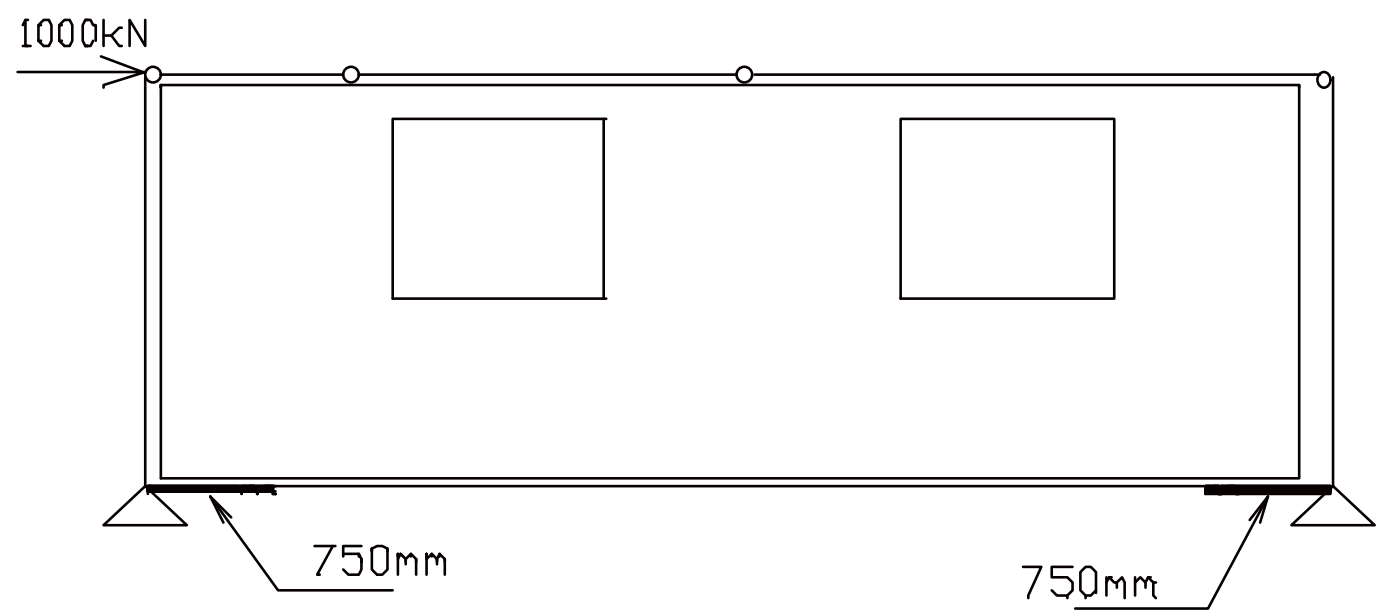

Caso 3- Com braços rígidos $(750 \mathrm{~mm})-\mathbf{a}$ topo $=\mathbf{3 , 2 2} \mathbf{~ m m}$

Figura 3.22- Deslocamentos para os casos de braços rígidos [GAIOTTI (1990)] (cont.)

\subsection{Descrição do software utilizado}

Para a realização de todos os exemplos propostos no capítulo 4 foram utilizados os recursos disponíveis pelo "software" LUSAS. Os elementos finitos e o próprio programa estão explicados a seguir.

\subsubsection{Informações gerais}

O "software" LUSAS é um programa para análise estrutural, através do método dos elementos finitos, que incorpora as análises estruturais (estática linear, estática não linear, dinâmica linear, dinâmica não linear, e outras).

Além disso, são também analisados os modelos constitutivos lineares e não lineares tais como: linear isótropo, ortótropo e anisótropo, elastoplástico, isótropo e anisótropo com encruamento, concreto não-linear, além de outros.

O sistema "LUSAS “ possui uma biblioteca de mais de 100 tipos de elementos finitos aplicados na engenharia sendo capaz de analisar os elementos de barras, vigas, superfícies 2-D e 3-D, placas, chapas, membranas e ligações. 
As condições de contorno que podem ser aplicadas aos elementos finitos são as restrições de vínculos, valores prescritos em vínculos e molas. Inclui, ainda, uma variedade de carregamentos, que podem ser aplicados a eles tais como: deslocamentos prescritos, cargas concentradas, cargas distribuídas, cargas por unidade de volume, tensões residuais, carregamento devido à temperatura, tensões e deformações iniciais.

O arquivo de entrada é feito através de seções com palavras-chaves, ou utilizando-se seu pré-processador gráfico, MYSTRO.

Os resultados podem também ser mais bem analisados no seu pósprocessador o qual realiza gráficos coloridos de iso-tensões, deslocamentos, deformações etc., ou na utilização de seu arquivo de saída de dados.

\subsubsection{Elementos finitos utilizados}

Os elementos finitos utilizados, durante a análise de exemplos, estão listados a seguir:

\section{Elementos para pórtico plano:}

\section{BEAM}
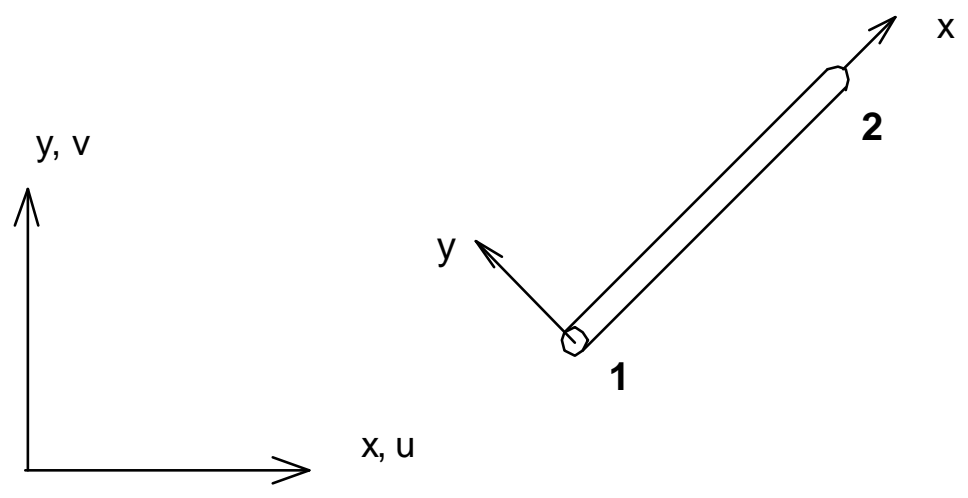

- Descrição do elemento: suas deformações ao cisalhamento podem ser incluídas e as propriedades geométricas são constantes ao longo do comprimento.

- Número de nós: 2 pontos nodais. 
- liberdade de movimento: $\mathrm{u}, \mathrm{v}, \theta_{\mathrm{z}}$ : para cada nó.

- coordenadas nodais: x, y: para cada nó.

- propriedades geométricas: A (área da seção), $\mathrm{I}_{\mathrm{zz}}$ (inércia para o eixo local z), $A_{s}$ (área cisalhante efetiva) : por elemento.

- carregamento: cargas concentradas $-\mathrm{P}_{\mathrm{x}}, \mathrm{P}_{\mathrm{y}}, \mathrm{M}$ : nos nós globais.

- arquivo de saída: para cada elemento têm-se as forças nas direções locais - $F_{x}, F_{y}$ , $\mathrm{M}_{\mathrm{z}}$

\section{Elementos para pórtico espacial:}

\section{BMS3}
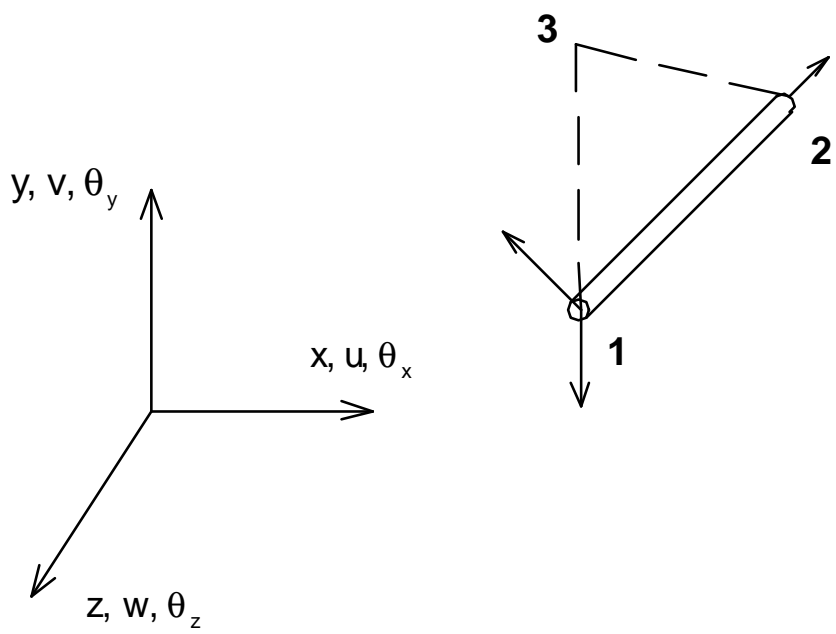

- Descrição do elemento: suas deformações ao cisalhamento podem ser incluídas, e as propriedades geométricas são constantes ao longo do comprimento.

- Número de nós: 3 pontos nodais, sendo o terceiro nó usado para definir o plano xy (local).

- liberdade de movimento: $\mathrm{u}, \mathrm{v}, \mathrm{w}, \theta_{\mathrm{y}}, \theta_{\mathrm{y}}, \theta_{\mathrm{z}}$ : para os nós extremos.

- coordenadas nodais: $\mathrm{x}, \mathrm{y}, \mathrm{z}$ : para cada nó.

- propriedades geométricas: A (área da seção), Iyy , Izz (inércia para o eixo local y e $\mathrm{z}$ respectivamente), $\mathrm{J}_{\mathrm{xx}}$ (inércia a torção), $\mathrm{A}_{\mathrm{sz}}, \mathrm{A}_{\mathrm{sy}}$ (áreas cisalhantes efetivas nas direções $\mathrm{z}$ e $\mathrm{y}$ ), $\mathrm{e}_{\mathrm{z}}$ (excentricidade da viga no plano $\mathrm{xy}$ ) : por elemento. 
- carregamento: cargas concentradas - $\mathrm{P}_{\mathrm{x}}, \mathrm{P}_{\mathrm{y}}, \mathrm{P}_{\mathrm{z}}, \mathrm{M}_{\mathrm{x}}, \mathrm{M}_{\mathrm{y}}, \mathrm{M}_{\mathrm{z}}$ : nos nós globais.

- arquivo de saída: para cada elemento têm-se as forças nas direções locais - $F_{x}, F_{y}$ $, \mathrm{F}_{\mathrm{z}}, \mathrm{M}_{\mathrm{x}}, \mathrm{M}_{\mathrm{y}}, \mathrm{M}_{\mathrm{z}}$

\section{Elemento de chapa:}

QPM4

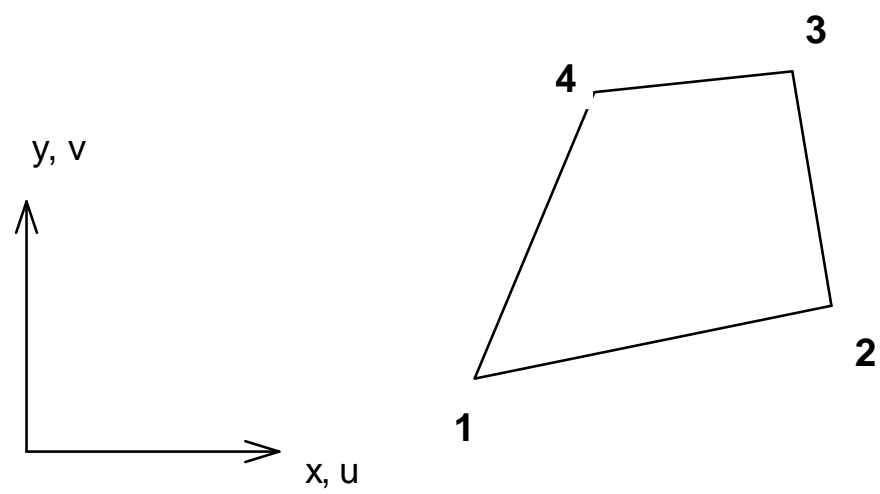

- Descrição do elemento: isoparamétricos bidimensionais.

- Número de nós: 4 pontos nodais.

- liberdade de movimento: u, v: para cada nó.

- coordenadas nodais: $\mathrm{x}, \mathrm{y}, \mathrm{z}$ : para cada nó.

- propriedades geométricas: $\mathrm{t}_{1} \ldots \mathrm{t}_{\mathrm{n}}$ : espessura para cada nó.

- carregamento: cargas concentradas $-\mathrm{P}_{\mathrm{x}}, \mathrm{P}_{\mathrm{y}}$ : nos nós.

- arquivo de saída: para cada elemento têm-se tensões e deformações

$$
\begin{aligned}
& N_{x}, N_{y}, N_{x y}, N_{\text {max }}, N_{\text {min }} \\
& \sigma_{x}, \sigma_{y}, \sigma_{x y}, \sigma_{\text {max }}, \sigma_{\text {min }}
\end{aligned}
$$




\section{Elemento de casca}

QSI4

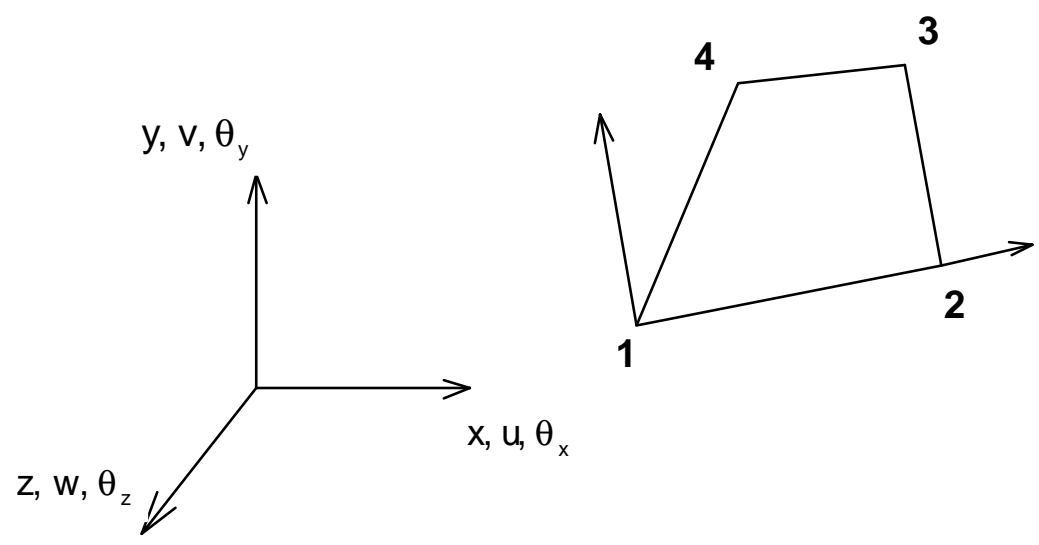

- Descrição do elemento: dotados de deformações na membrana e flexão, desprezando-se aquela por cisalhamento.

- Número de nós: 4 pontos nodais.

- liberdade de movimento: $\mathrm{u}, \mathrm{v}, \mathrm{w}, \theta_{\mathrm{y}}, \theta_{\mathrm{y}}, \theta_{\mathrm{z}}$ : para cada nó.

- coordenadas nodais: $\mathrm{x}, \mathrm{y}, \mathrm{z}$ : para cada nó.

- propriedades geométricas: $\mathrm{e}_{\mathrm{z}}, \mathrm{t}_{1} \ldots . \mathrm{t}_{\mathrm{n}}$ : excentricidade e espessura para cada nó.

- carregamento: cargas concentradas - $\mathrm{P}_{\mathrm{x}}, \mathrm{P}_{\mathrm{y}}, \mathrm{P}_{\mathrm{z}}, \mathrm{M}_{\mathrm{x}}, \mathrm{M}_{\mathrm{y}}, \mathrm{M}_{\mathrm{z}}$ : nos nós.

- arquivo de saída: para cada elemento têm-se tensões e deformações

$N_{x}, N_{y}, N_{x y}, M_{x}, M_{y}, M_{x y}-\quad$ forças e momentos / unidade de comprimento

$\sigma_{x}, \sigma_{y}, \sigma_{x y}, \sigma_{\max }, \sigma_{\min }-$ direção local 


\section{$\underline{\text { Elemento de ligação }}$}

JNT3

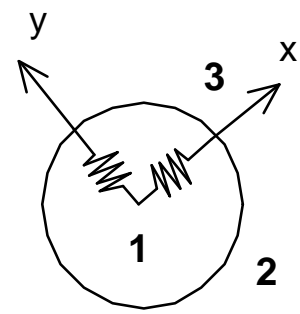

- Descrição do elemento: dotado de ligação bidimensional o qual conecta dois nós, por meio de molas, nas direções locais x e y.

- Número de nós: 3 pontos nodais. O terceiro é usado para definir a direção local x.

- liberdade de movimento: u, v : para cada nó.

- coordenadas nodais: $\mathrm{x}, \mathrm{y}$ : para cada nó.

- arquivo de saída: para cada elemento têm-se as forças nas molas nas direções locais $-\mathrm{F}_{\mathrm{x}}, \mathrm{F}_{\mathrm{y}}$

JNT4

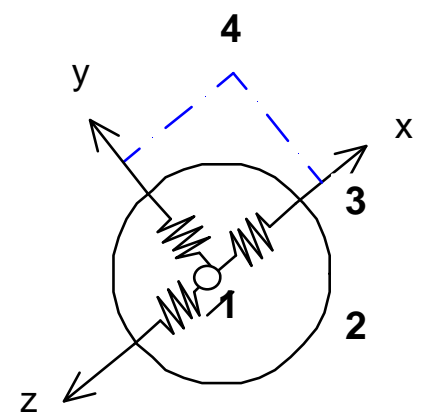

- Descrição do elemento: dotado de ligação tridimensional o qual conecta três nós por meio de molas nas direções locais x, y e z. 
- Número de nós: 4 pontos nodais sendo os dois últimos usados para definir a direção local x e o plano xy, respectivamente.

- liberdade de movimento: u, v, w : para cada nó.

- coordenadas nodais: $\mathrm{x}, \mathrm{y}, \mathrm{z}$ : para cada nó.

- arquivo de saída: para cada elemento têm-se as forças nas molas, nas direções locais $-\mathrm{F}_{\mathrm{x}}, \mathrm{F}_{\mathrm{y}}, \mathrm{F}_{\mathrm{z}}$.

\subsection{Modelagem proposta para painéis e ligações}

As ligações dos exemplos do capítulo 4 são feitas por meio de parafusos. Além disso, foram feitas análises de deslocamentos e de tensões, utilizando-se o "software" LUSAS.

\subsubsection{Modelagem para o caso plano}

A fim de avaliar a contribuição do painel no plano, considerou-se um elemento de ligação, por meio de molas, que represente sua deformabilidade. $\mathrm{O}$ modelo utilizado para os exemplos está apresentado pela Figura 3.23.

A deformabilidade da ligação, calculada conforme visto no capítulo 2, está apresentada a seguir, pela equação 3.4.

$$
\lambda_{\tau b}=\frac{16(d)^{3}}{3 \pi \mathrm{E}_{\mathrm{s}} \mathrm{d}_{\mathrm{b}}^{4}}
$$

\subsubsection{Modelagem para o caso fora do plano}

Para esse caso, adota-se uma excentricidade da ligação cujo esquema da modelação, está representado pela Figura 3.24 e, para simular o efeito da deformabilidade, adotou-se uma barra que represente a ligação em questão. 

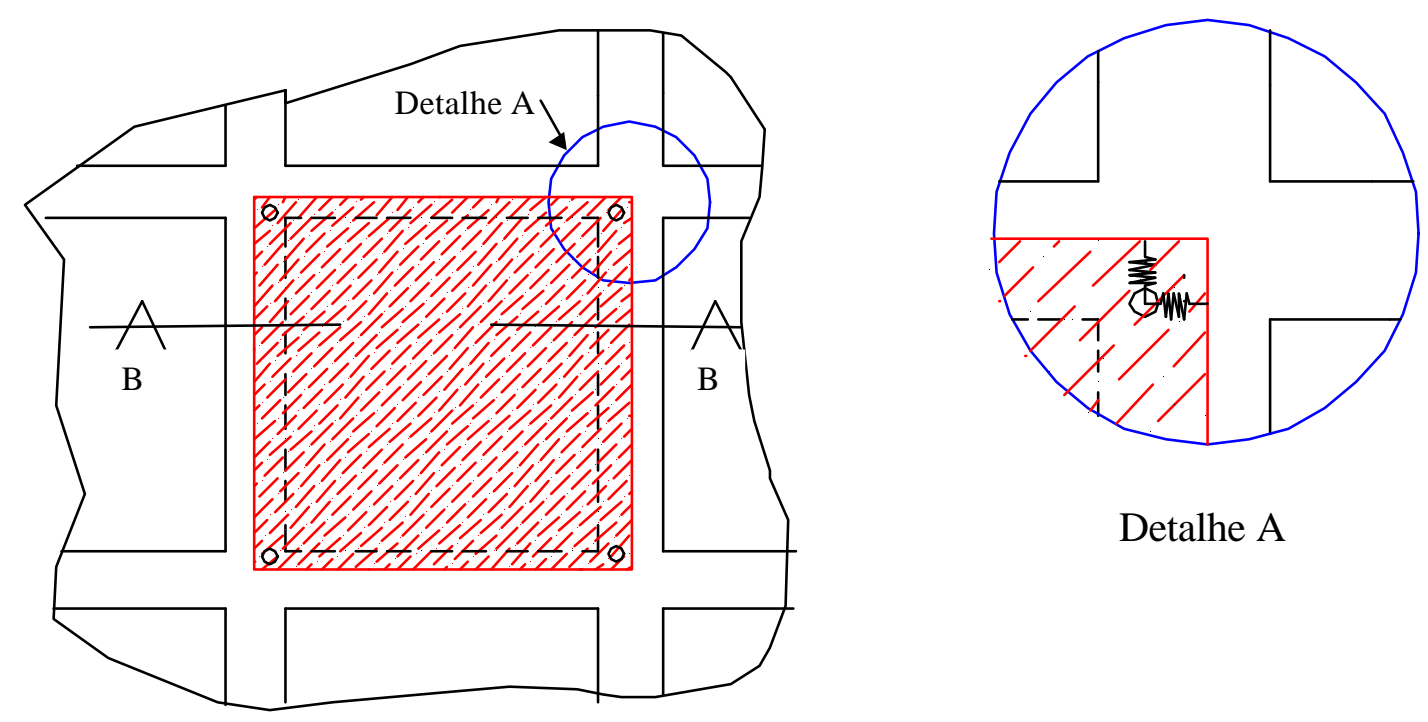

Detalhe A

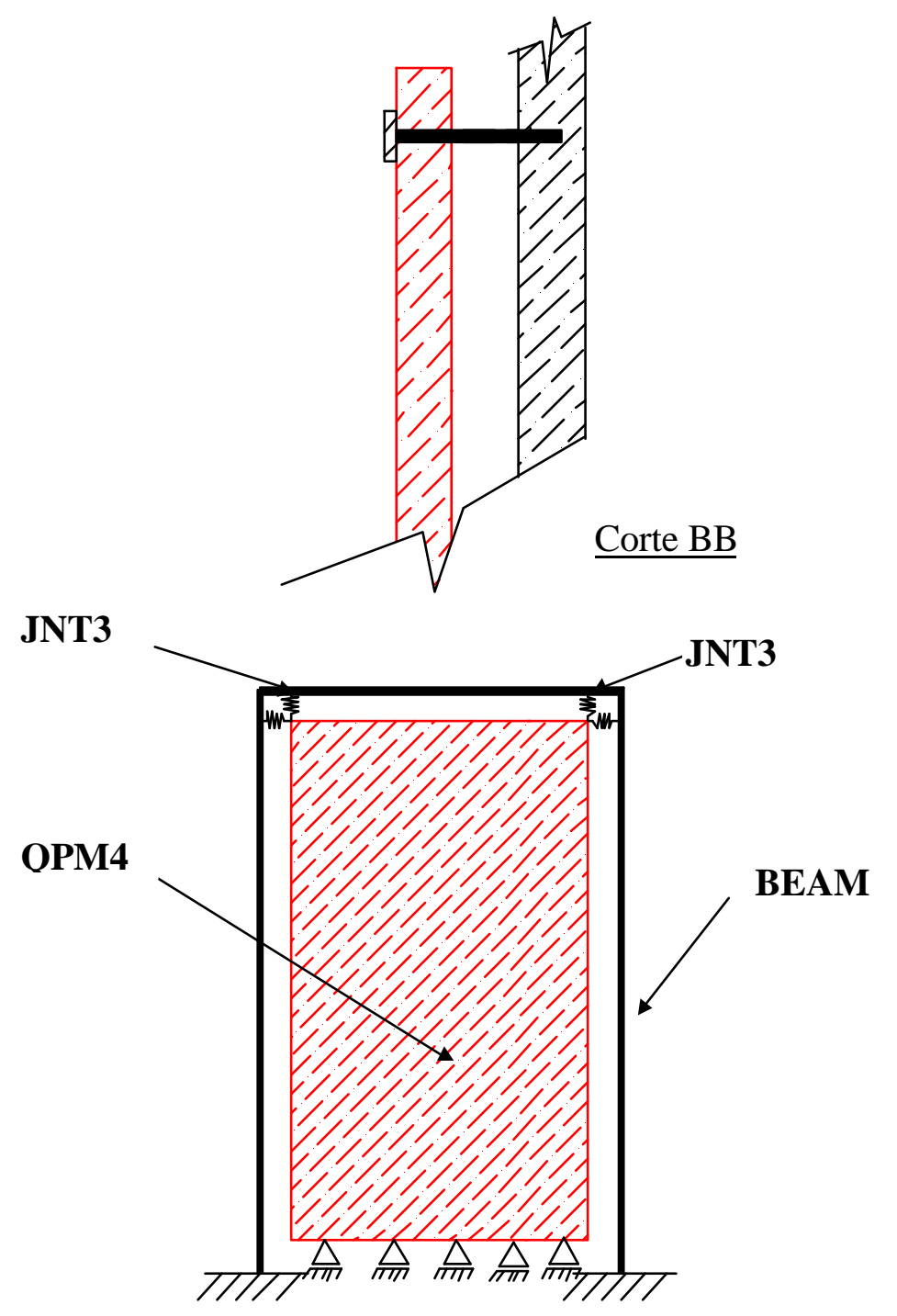

Figura 3.23- Modelo para o caso plano 

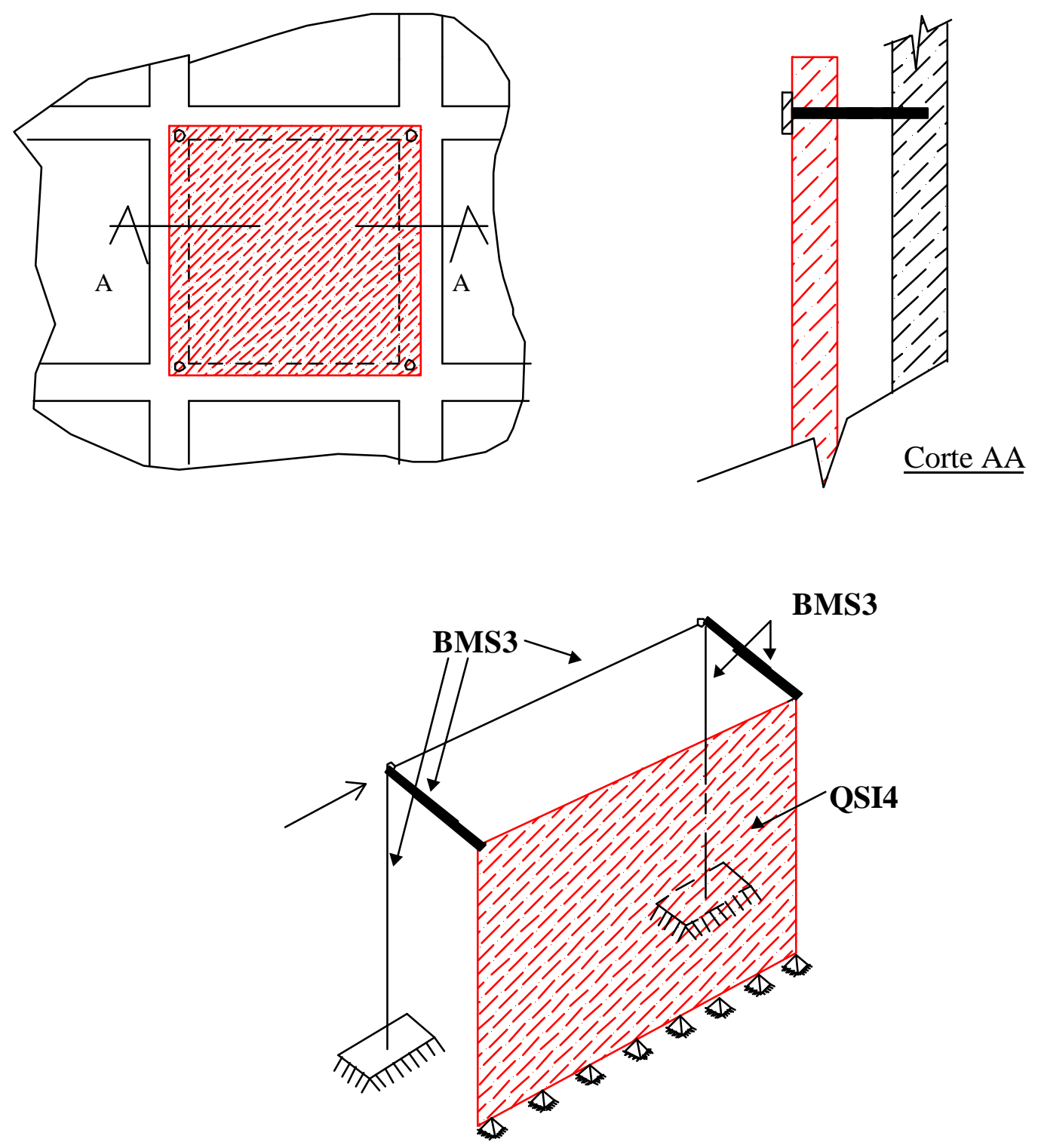

Figura 3.24- Modelagem para o caso fora do plano 


\section{Análise da interação painéis de \\ 4 fechamento x estrutura principal de situações típicas}

Este capítulo consta de três exemplos numéricos com a consideração da interação dos painéis. No primeiro, apresenta-se uma simulação numérica para um painel isolado; no segundo, apresenta-se uma aplicação para um caso de um galpão pré-moldado constituído por vários painéis com um único pavimento; e, no terceiro, apresenta-se um caso de vários painéis em estrutura com vários pavimentos.

\subsection{Exemplo de um painel isolado}

\subsubsection{Preliminares}

Neste exemplo serão feitas simulações numéricas de um único painel apresentando as seguintes variações: maciço, maciço com aberturas, maciço com nervuras (painéis $\pi$ ) e maciço com nervuras e aberturas. Através dessas, pôde-se analisar o comportamento das tensões e dos esforços nos painéis e ligações, além de avaliar a contribuição das nervuras ou aberturas no enrijecimento da estrutura.

Para as análises, foram considerados painéis ligados nas extremidades com a estrutura principal, sendo as ligações efetuadas com uma distância de $100 \mathrm{~mm}$ da estrutura, utilizando parafusos de 11/4" . Foi considerada uma força lateral unitária atuando na estrutura.

As simulações englobam análises no plano e fora dele. Para o caso plano, o modelo da ligação é feito por meio de molas, cujas rigidezes vertical e horizontal são 
calculadas de acordo com a eq. 3.4. Através dela, tem-se a representação da deformabilidade da ligação.

$$
\begin{array}{ll}
\mathrm{d}=100 \mathrm{~mm} & \lambda_{\tau \mathrm{b}}=7,96 \cdot 10^{-4} \mathrm{~cm} / \mathrm{kN} \\
\mathrm{E}_{\mathrm{c}}=2000 \mathrm{kN} / \mathrm{cm}^{2} & \mathrm{k}=1256 \mathrm{kN} / \mathrm{cm} \\
\mathrm{E}_{\mathrm{s}}=21000 \mathrm{kN} / \mathrm{cm}^{2} & \\
\mathrm{~d}_{\mathrm{b}}=31,75 \mathrm{~mm} &
\end{array}
$$

Primeiramente, analisa-se somente o painel isolado, com a força unitária para todos os casos, e, em seguida, só a estrutura principal. A partir daí, acrescentam-se os painéis e efetuam-se as avaliações para os casos no plano e fora dele, incluindo deslocamentos, tensões e esforços. Além disso, os painéis foram modelados utilizando elementos já mencionados no capítulo 3, cuja malha está ilustrada na Figura 4.1.

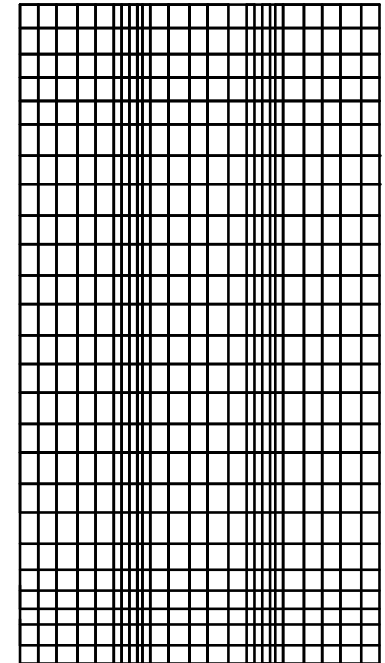

$\underline{625 \text { elementos }}$

a) painéis maciços e nervurados

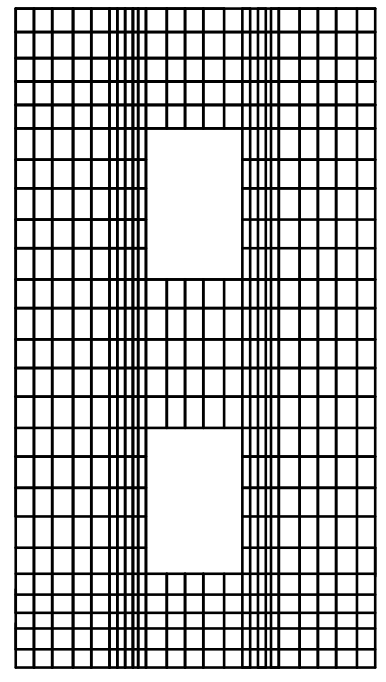

$\underline{575 \text { elementos }}$

b) painéis com aberturas

Figura 4.1- Malha utilizada nos painéis

As características de um único painel e as da estrutura principal adotadas para as simulações estão ilustradas pela Figura 4.2. 


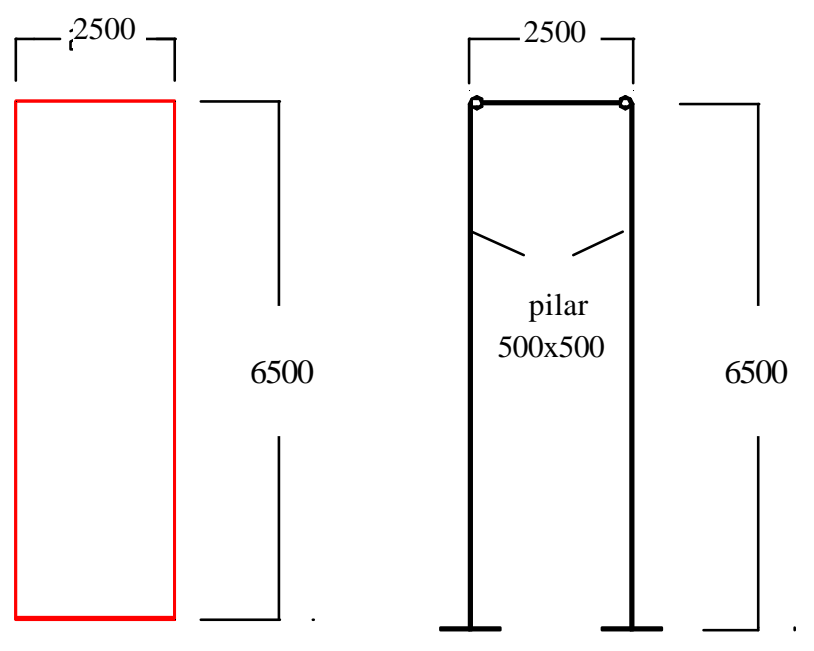

$$
\begin{aligned}
& \mathrm{A}_{\mathrm{V}}=0,2900 \mathrm{~m}^{2} \\
& \mathrm{I}_{\mathrm{v}}=0,0432 \mathrm{~m}^{4} \\
& \mathrm{~A}_{\mathrm{p}}=0,2500 \mathrm{~m}^{2} \\
& \mathrm{I}_{\mathrm{p}}=0,00521 \mathrm{~m}^{4} \\
& \mathrm{E}_{\mathrm{c}}=20000 \mathrm{MPa} \\
& \mathrm{E}_{\mathrm{s}}=210000 \mathrm{MPa}
\end{aligned}
$$

a) Painel maciço
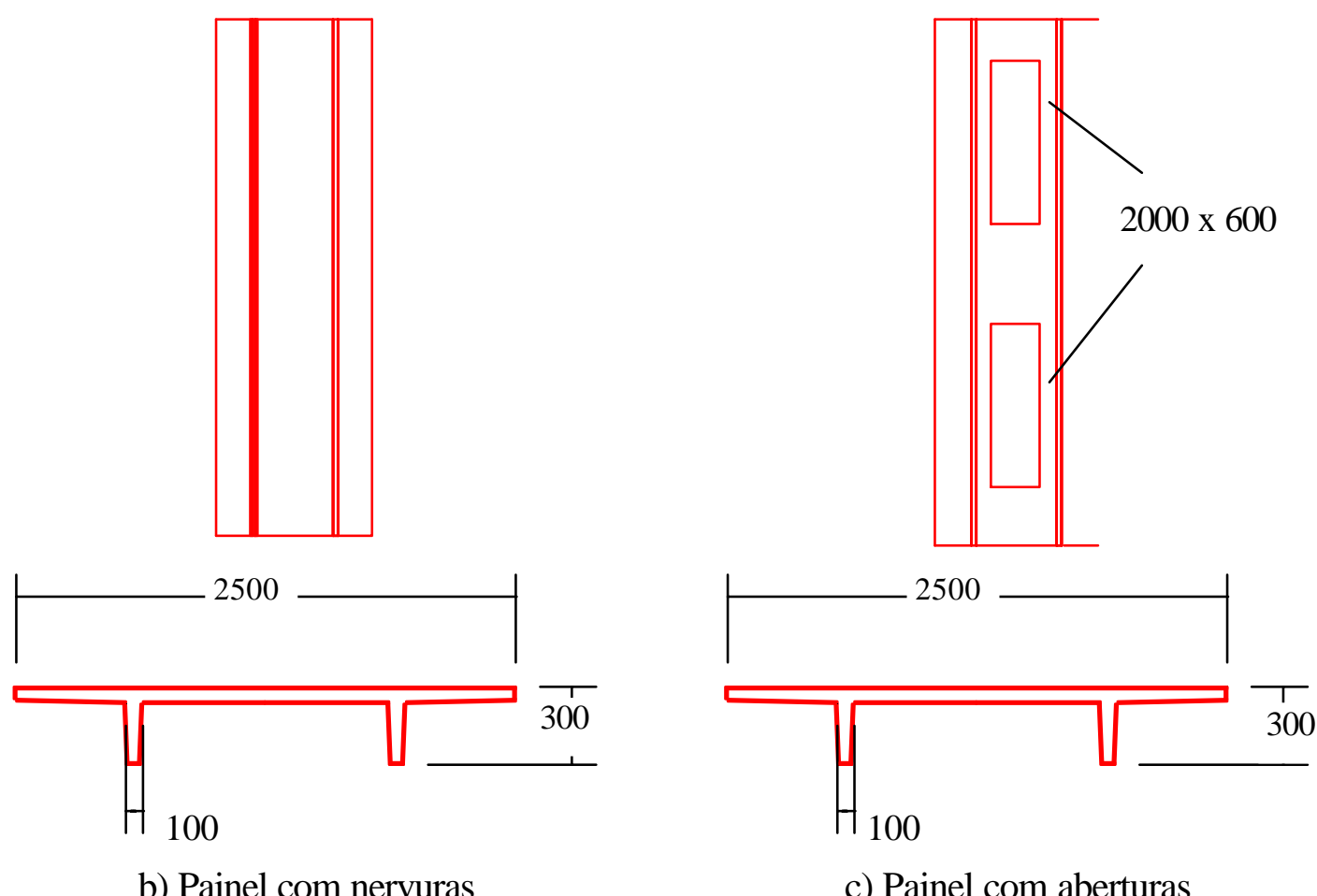

Figura 4.2- Dimensões dos painéis (medidas em mm)

\subsubsection{Análise dos deslocamentos}

O primeiro passo para avaliar a interação dos diferentes tipos de painéis foi a análise dos deslocamentos. Para tal, foram consideradas as situações ilustradas pelas 
Figuras 4.3 a 4.5, sendo as ligações efetuadas conforme visto no capitulo 3 (Figura 4.6). Os deslocamentos horizontais no topo dos painéis ou pilar, a, para as simulações, bem como os elementos finitos utilizados para cada caso, encontram-se nas tabelas a seguir.

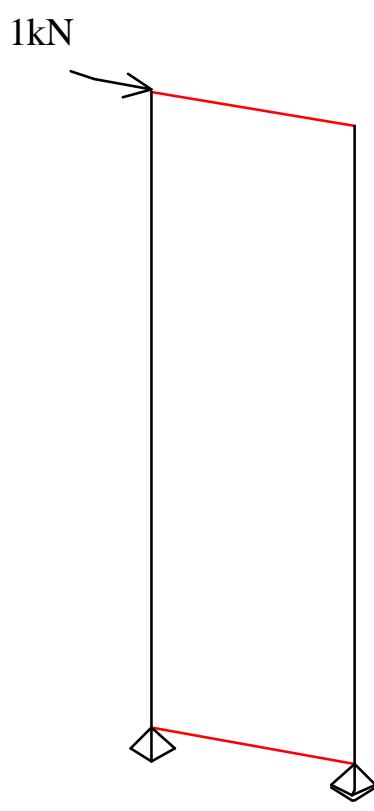

a) painel maciço

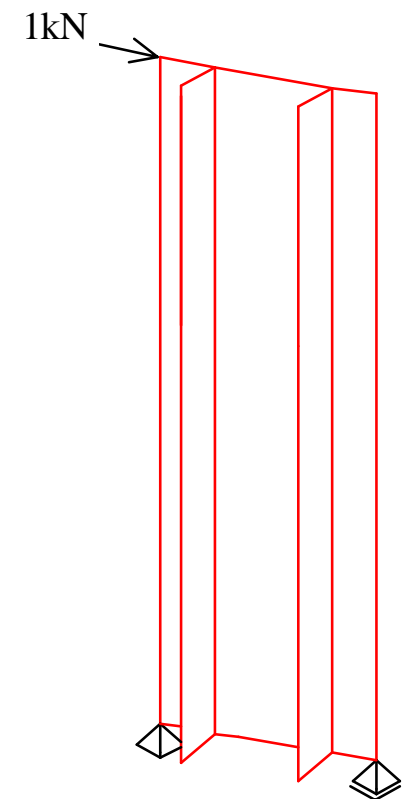

c) painel maciço com nervuras

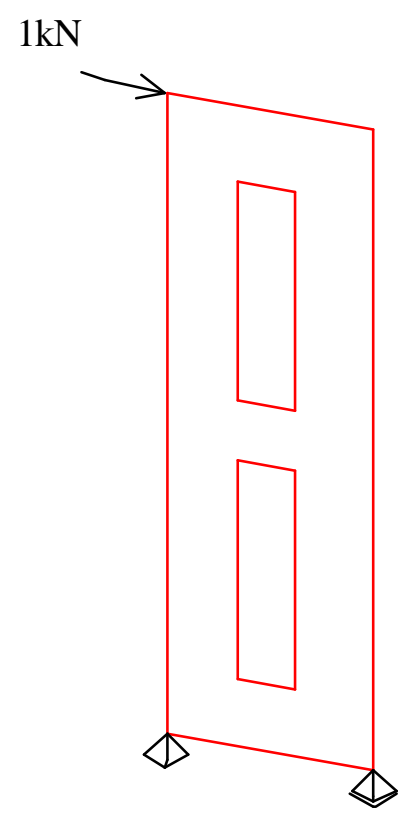

b) painel maciço com aberturas

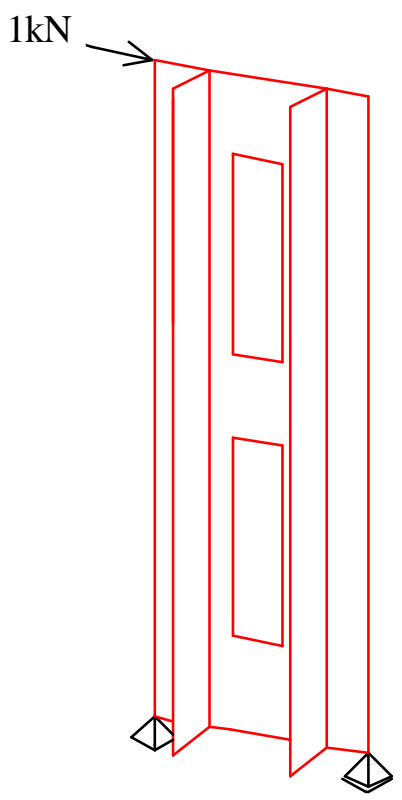

d) painel maciço com aberturas e nervuras

Figura 4.3- Situações de análises só para o painel 


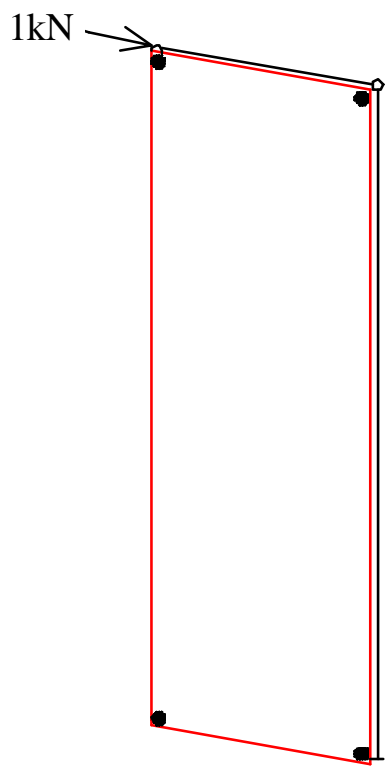

a) painel maciço

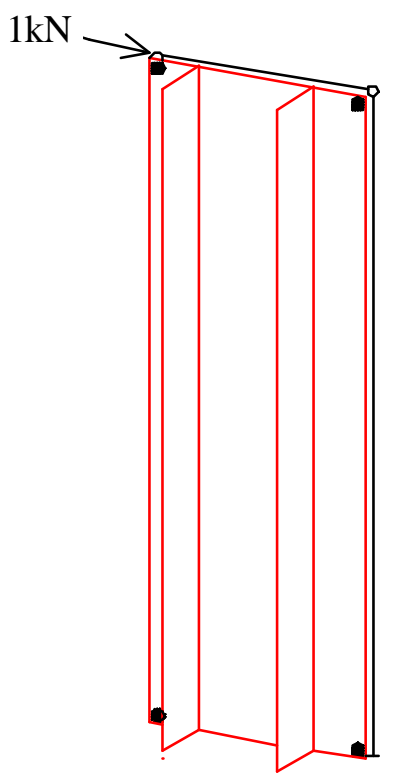

c) painel maciço com nervuras

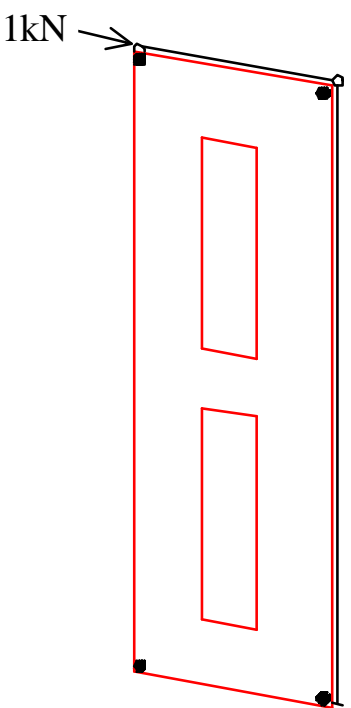

b) painel maciço com aberturas

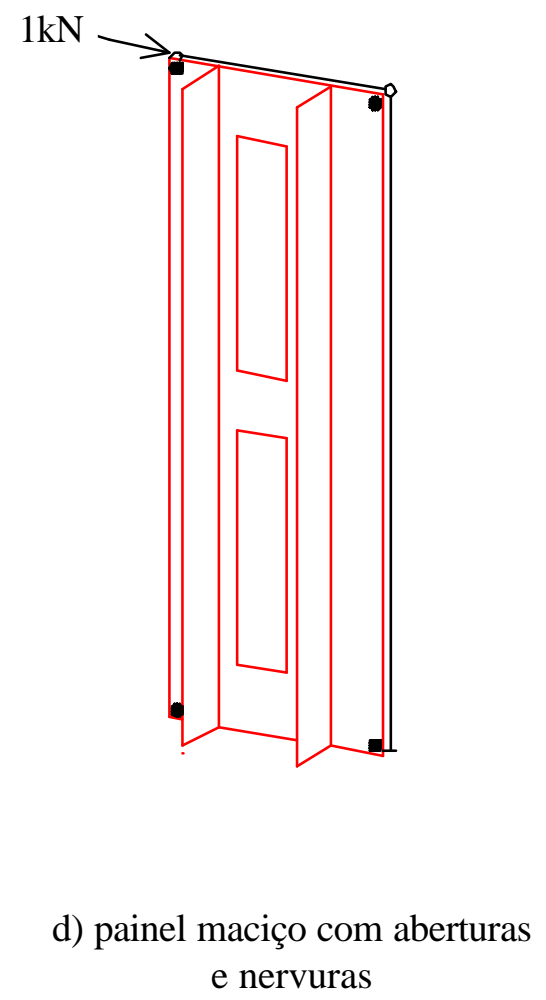

Figura 4.4- Situações de análises para o painel no plano 
$1 \mathrm{kN}$

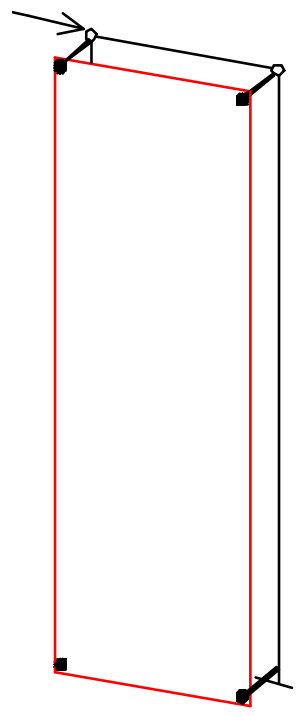

a) painel maciço

$1 \mathrm{kN}$

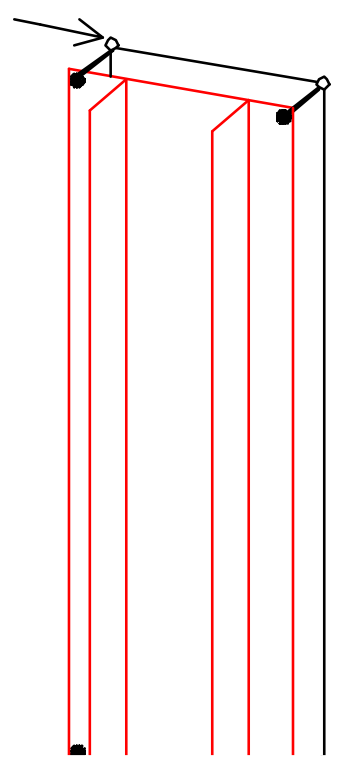

c) painel maciço com nervuras
$1 \mathrm{kN}$

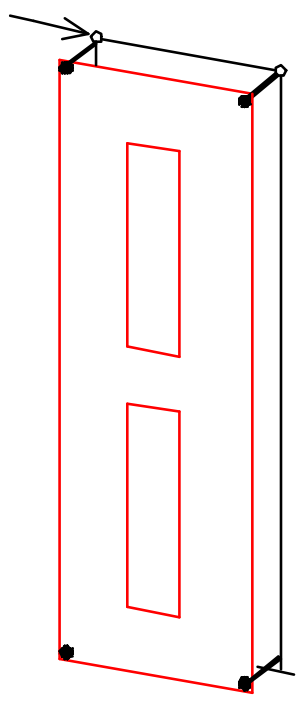

b) painel maciço com aberturas

$1 \mathrm{kN}$

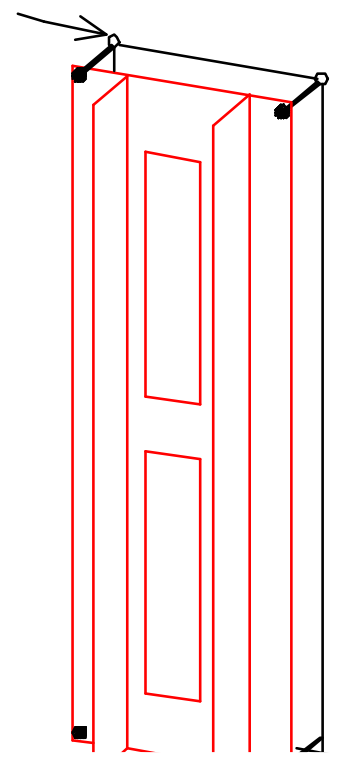

d) painel maciço com aberturas e nervuras

Figura 4.5- Situações de análises para o painel fora do plano 
a) Consideração do painel maciço

Nesta simulação, adotou-se o painel maciço de espessura de $125 \mathrm{~mm}$.

Tabela 4.1- Deslocamentos e descrição da estrutura e painéis

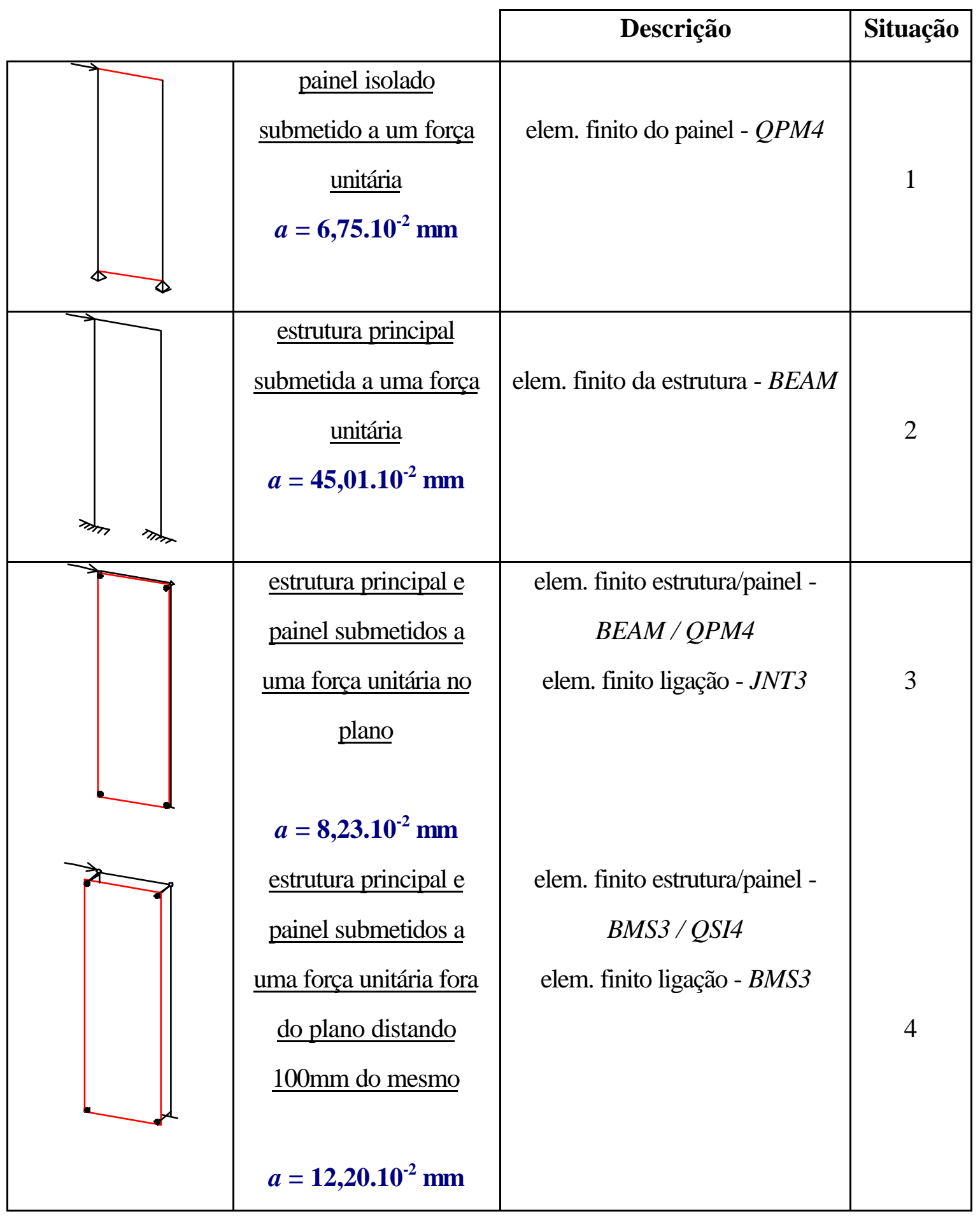


b) Consideração do painel maciço com abertura

Nesta simulação, adotou-se o painel de $125 \mathrm{~mm}$ de espessura com janela de $600 \mathrm{~mm} \times 2000 \mathrm{~mm}$.

Tabela 4.2- Deslocamentos e descrição da estrutura e painéis

\begin{tabular}{|c|c|c|c|}
\hline & & Descrição & Situação \\
\hline$\sqrt{1}$ & $\begin{array}{c}\frac{\text { painel isolado }}{\underline{\text { submetido a uma força }}} \\
\underline{\text { unitária }} \\
a=\mathbf{8 , 9 0 . 1 0 ^ { - 2 }} \mathrm{mm}\end{array}$ & elem. finito do painel - $Q P M 4$ & 1 \\
\hline & $\begin{array}{c}\frac{\text { estrutura principal }}{\underline{\text { submetida a uma força }}} \\
\underline{\text { unitária }} \\
a=\mathbf{4 5 , 0 1 . 1 0 ^ { - 2 }} \mathrm{mm}\end{array}$ & $\begin{array}{l}\text { elem. finito da estrutura - } \\
\qquad B E A M\end{array}$ & 2 \\
\hline & $\begin{array}{l}\frac{\text { estrutura principal e }}{\text { painel submetidos a }} \\
\frac{\text { uma força unitária no }}{\text { plano }} \\
a=\mathbf{9 , 3 2 . 1 0 ^ { - 2 }} \mathrm{mm}\end{array}$ & $\begin{array}{c}\text { elem. finito estrutura/painel - } \\
B E A M \text { / QPM4 } \\
\text { elem. finito ligação - JNT3 }\end{array}$ & 3 \\
\hline & $\begin{array}{l}\begin{array}{c}\text { estrutura principal e } \\
\text { painel submetidos a }\end{array} \\
\frac{\text { uma força unitária fora }}{\underline{\text { do plano distando }}} \\
\underline{100 \mathrm{~mm} \text { do mesmo }} \\
a=\mathbf{1 3 , 0 4 . 1 0 ^ { - 2 }} \mathbf{m m}\end{array}$ & $\begin{array}{l}\text { elem. finito estrutura/painel - } \\
\text { BMS3 / QSI4 } \\
\text { elem. finito ligação - BMS3 }\end{array}$ & 4 \\
\hline
\end{tabular}


c) Consideração do painel com nervuras

Nesta simulação, adotou-se o painel com mesa de 50mm e nervuras de $300 \mathrm{~mm}$.

Tabela 4.3- Deslocamentos e descrição da estrutura e painéis

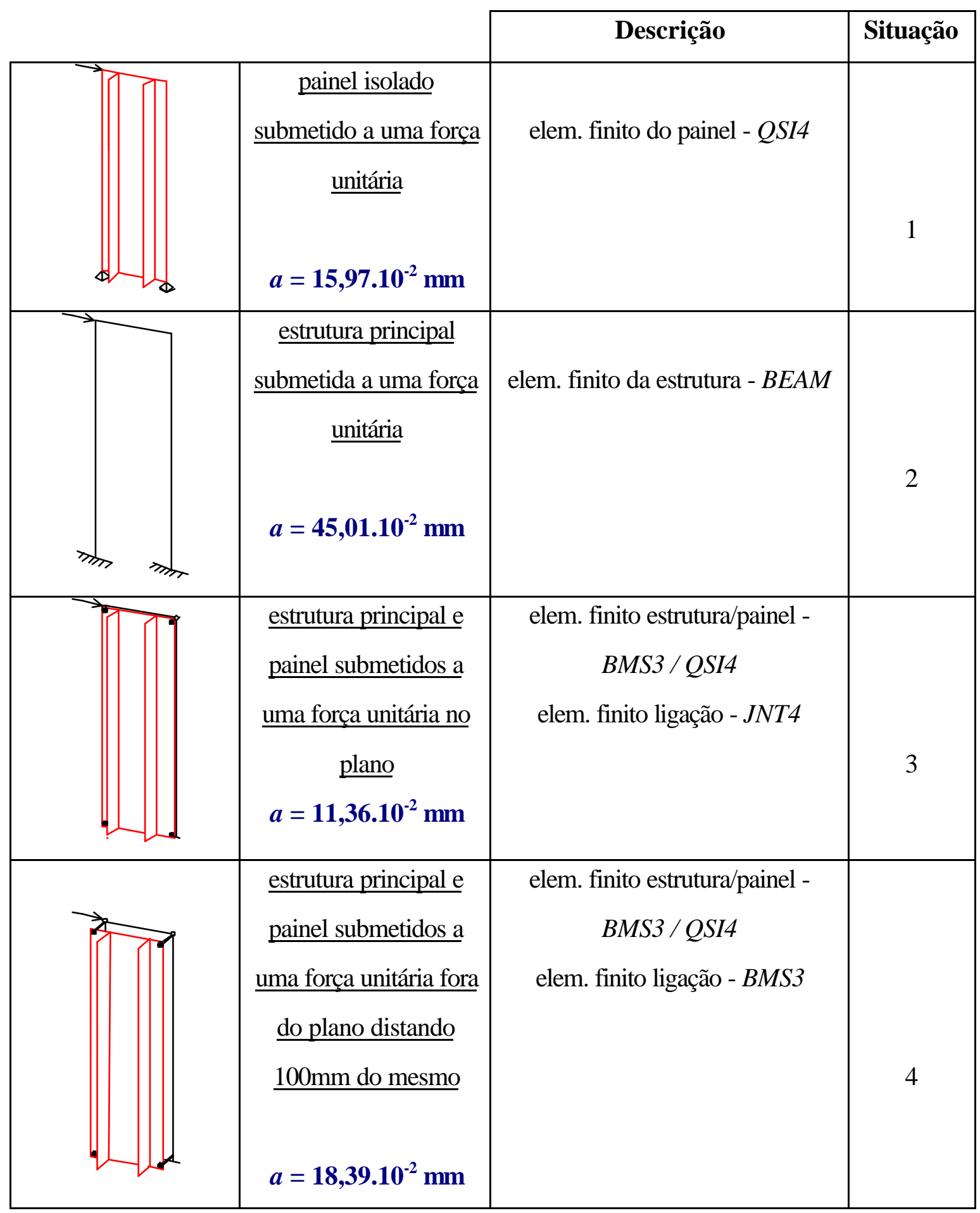


d) Consideração do painel com nervuras e abertura

Nesta simulação, adotou-se o painel com mesa de $50 \mathrm{~mm}$ e nervuras de $300 \mathrm{~mm}$ com janela de $600 \mathrm{~mm}$ x $2000 \mathrm{~mm}$.

Tabela 4.4- Deslocamentos e descrição da estrutura e painéis

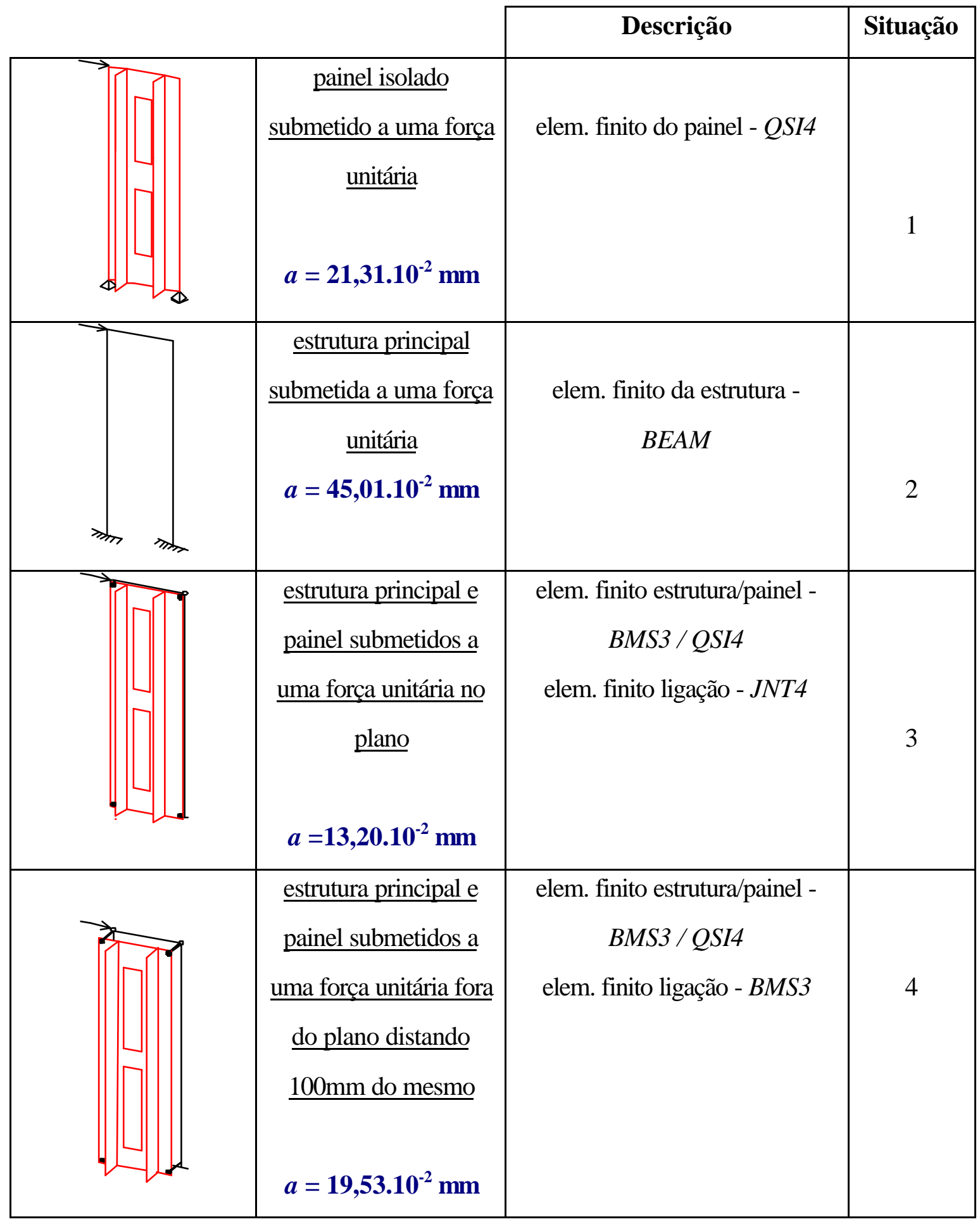




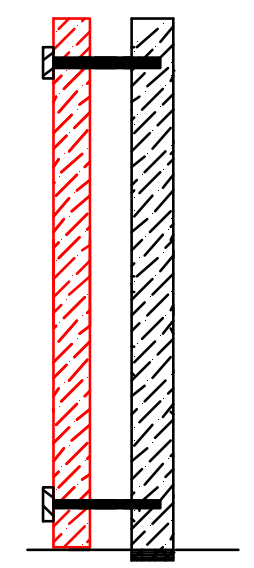

Figura 4.6- Ligações dos painéis

Um resumo dos deslocamentos está melhor representado pela Tabela 4.5 e pela Figura 4.7:

A partir dos itens acima relacionados, pode-se concluir que com a consideração de nervuras (situação 1), o deslocamento aumentou, fato previsível, já que os painéis com nervuras, pela própria dimensão, são menos rígidos que os maciços. Geralmente, a fim de aproveitar o efeito das nervuras, tais painéis são apoiados nas mesmas, as quais proporcionam tanto um aumento do enrijecimento quanto uma diminuição das tensões atuantes. Para este trabalho, não se efetuou tal consideração a fim de manter a mesma linha para comparação

Quando se consideram aberturas nos painéis nervurados e maciços, o deslocamento aumenta 1,32vezes, pois uma parte (abertura) não contribuirá para o deslocamento. Acrescentando-se somente as nervuras, nota-se que os descolamentos são aproximadamente, 2,37 vezes maiores e painéis com nervuras e aberturas os descolamentos são aproximadamente, 3,16 vezes maiores. 
Tabela 4.5 - Deslocamentos para as análises consideradas, em mm.

\begin{tabular}{|c|c|c|c|c|}
\hline & painel maciço & $\begin{array}{c}\text { painel com } \\
\text { nervuras }\end{array}$ & $\begin{array}{l}\text { painel com } \\
\text { nervuras e } \\
\text { aberturas }\end{array}$ & $\begin{array}{l}\text { painel maciço } \\
\text { com aberturas }\end{array}$ \\
\hline $\begin{array}{l}\frac{\text { painel isolado }}{\text { submetido a uma }} \\
\frac{\text { força unitária }}{(\mathrm{mm})}\end{array}$ & $6,75.10^{-2}$ & $15,97.10^{-2}$ & $21,31.10^{-2}$ & $8,90.10^{-2}$ \\
\hline $\begin{array}{l}\frac{\text { estrutura principal }}{\text { submetida a uma }} \\
\frac{\text { força unitária }}{(\mathrm{mm})}\end{array}$ & $45,01.10^{-2}$ & $45,01.10^{-2}$ & $45,01.10^{-2}$ & $45,01 \cdot 10^{-2}$ \\
\hline $\begin{array}{c}\frac{\text { estrutura principal e }}{\text { painel submetidos a }} \\
\frac{\text { uma força unitária }}{\text { no plano }} \\
(\mathrm{mm})\end{array}$ & $8,20.10^{-2}$ & $9,32.10^{-2}$ & $11,36.10^{-2}$ & $13,20.10^{-2}$ \\
\hline $\begin{array}{c}\text { estrutura principal e } \\
\text { painel submetidos a } \\
\frac{\text { uma força unitária }}{\text { fora do plano }} \\
\frac{\text { distando } 100 \mathrm{~mm} \text { do }}{\underline{\text { mesmo }}} \\
(\mathrm{mm})\end{array}$ & $12,20.10^{-2}$ & $13,04.10^{-2}$ & $18,39.10^{-2}$ & $19,53 \cdot 10^{-2}$ \\
\hline
\end{tabular}




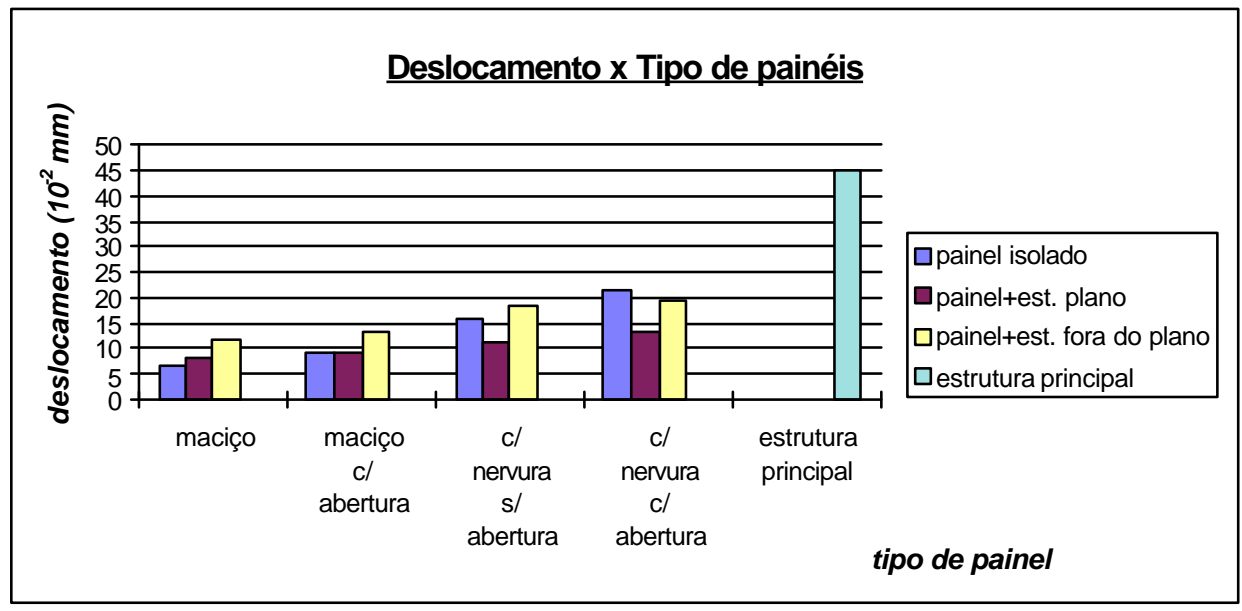

Figura 4.7- Deslocamentos em função do tipo de painel

Pelo gráfico da figura, podem-se visualizar melhor os deslocamentos de todas as situações, a partir do painel maciço, referência para análises.

Pelos resultados apresentados, percebe-se que, dentre os tipos de painéis existentes, a estrutura mais rígida é aquela cuja consideração da interação é realizada pelos painéis maciços. Adotando-se uma ordem de enrijecimento para os demais, têm-se painéis com aberturas, mais rígidos, posteriormente, nervuras, e por último, painéis com abertura e nervuras simultaneamente, que enrijecem menos. $\ddot{E}$ interessante salientar que a escolha dos tipos de painéis não é demarcada pelo maior ou menor enrijecimento da estrutura devendo, para cada situação de projeto, incorporar o mais adequado.

Os deslocamentos obtidos, referentes à análise da estrutura no plano e fora dele, são sensivelmente diferentes. Essa discrepância deve-se principalmente, à uma acentuada flexão do painel, não considerada durante as análises no plano.

Quanto ao enrijecimento, nota-se que o deslocamento diminui sensivelmente quando os painéis, maciços ou não, são considerados ligados à estrutura principal: 5,5 vezes para o painel maciço, 4,0 para o painel com nervuras, 3,4 para o painel com nervuras e aberturas e 4,8 para o painel maciço com aberturas. Além disso, vê-se que, mesmo com grandes aberturas, o painel contribui significativamente para diminuir os deslocamentos finais. Portanto observa-se que a consideração do efeito de enrijecimento torna-se benéfica ao conjunto, embora acarrete esforços nos painéis não considerados no cálculo, cujos valores serão vistos a seguir. 


\subsubsection{Análise dos resultados dos esforços nos painéis e ligações}

Em seguida à análise dos deslocamentos, realizaram-se as análises das tensões nos painéis e esforços nas ligações, utilizando o software LUSAS, para três casos distintos, nos quatro tipos de painéis:

- $1^{\circ}$ caso - análise utilizando só o painel;

- $2^{2}$ caso - análise utilizando o painel e a estrutura no plano; e

- $3^{\circ}$ caso - análise utilizando o painel e a estrutura fora do plano.

\subsubsection{Análise das tensões nos painéis}

Para os casos anteriores, analisaram-se os valores máximos das tensões principais, nos pontos escolhidos, conforme Figura 4.8, que representam as extremidades tanto do painel como das aberturas. A partir da Tabela 4.6, têm-se as tensões principais encontradas para os três casos analisados, para os painéis maciço e com nervura. A Figura 4.9 ilustra um resumo das tensões para os pontos de análise, nos três casos descritos.

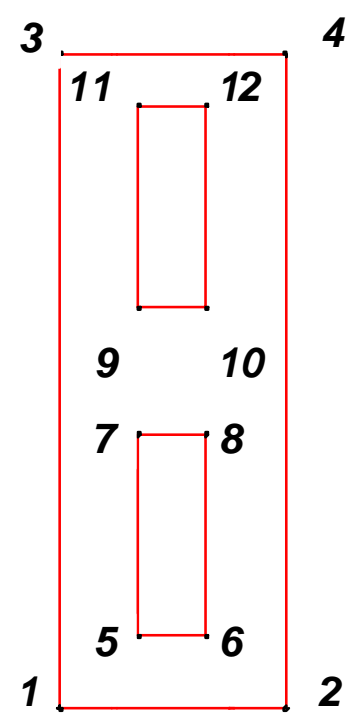

Figura 4.8 - Pontos de análise das tensões e esforços 
Tabela 4.6- Tensões principais máximas

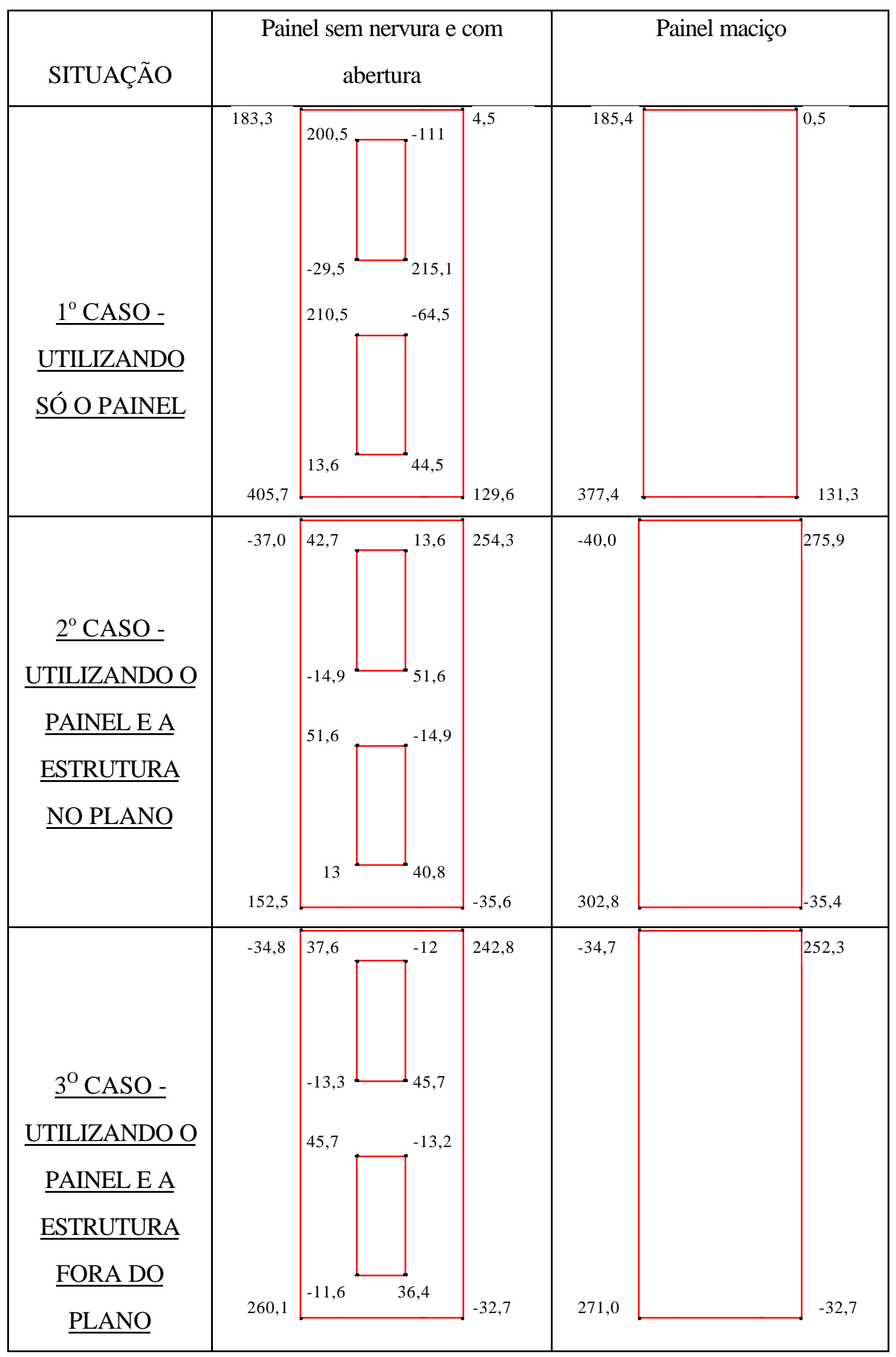



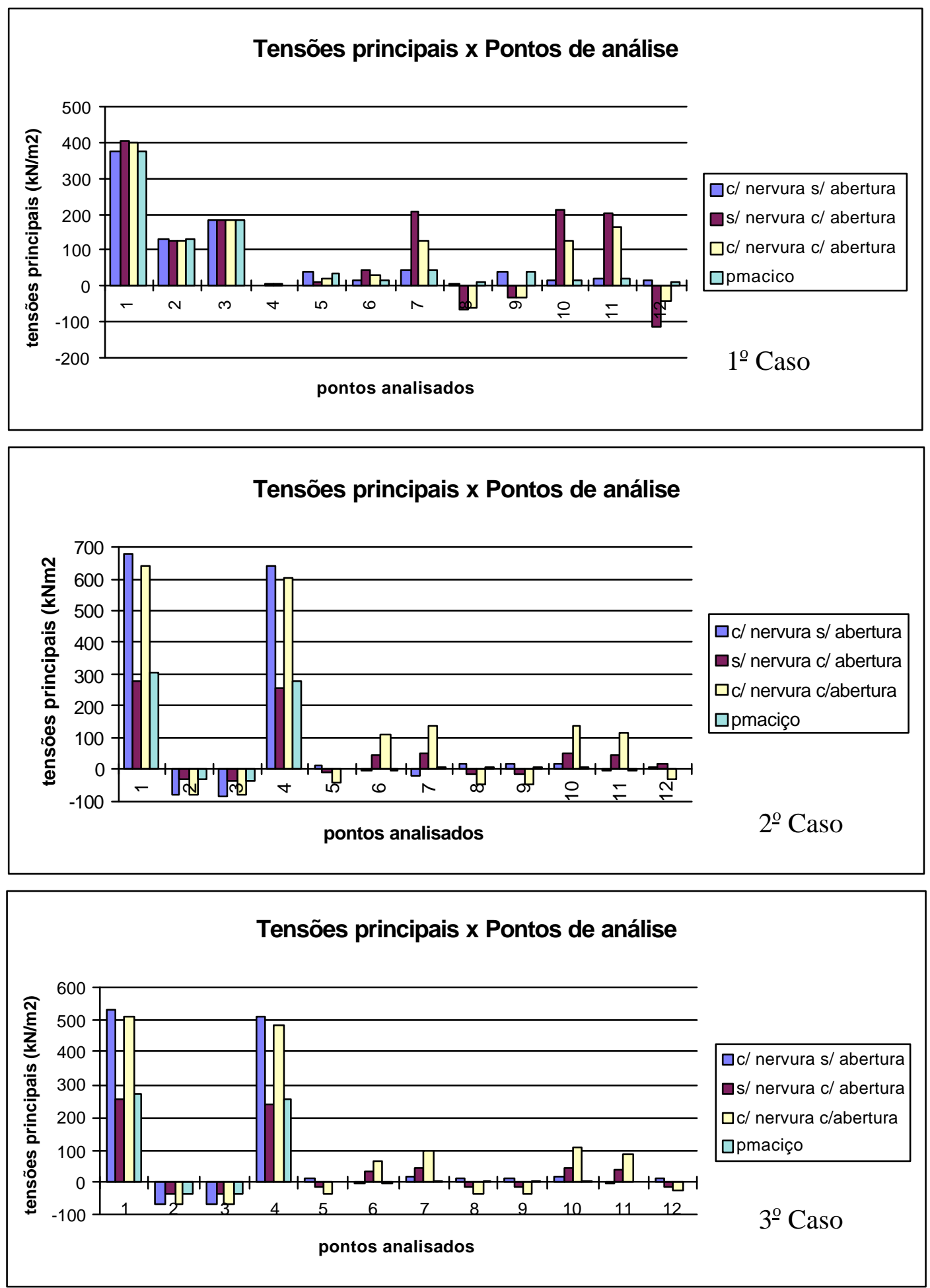

Figura 4.9- Tensões principais para os 3 casos considerando os 4 tipos de painéis em $\mathrm{kN} / \mathrm{m}^{2}$ 
Estão listados, ainda, no apêndice, a distribuição das tensões principais máximas e mínimas fornecidas pelo software.

A partir do gráfico exposto acima, pode-se relacionar as seguintes conclusões para os três casos.

\section{$\underline{1^{\circ} \mathrm{CASO}-\text { UTILIZANDO SÓ O PAINEL }}$}

No $1^{\circ}$ caso, tem-se que a consideração de aberturas no painel mantém as tensões praticamente iguais nas extremidades.

Nas situações em que o painel possui nervuras ou aberturas, observa-se que, para o ponto extremo, não há muita diferença nos valores encontrados, se comparado com o painel maciço.

Analisando, ainda, os painéis nervurados, pode-se perceber que comparando painéis com nervuras sem e com aberturas, chega-se à conclusão de que painéis nervurados sem aberturas possuem tensões similares. Algumas diferenças podem ser encontradas nos pontos extremos das aberturas.

\section{$\underline{2^{\circ} \text { CASO - UTILIZANDO O PAINEL E A ESTRUTURA NO PLANO }}$}

Para a análise do $2^{\circ}$ caso, tem-se que a consideração de aberturas no painel mantém as tensões praticamente iguais nas extremidades, aumentando, de maneira significativa, no caso de painéis com nervuras. Nota-se, ainda, que, nas extremidades das aberturas as maiores tensões ocorrem em painéis com nervuras.

$\mathrm{Na}$ situação em que o painel possui nervuras sem nenhuma abertura, observa-se que, para o valor extremo, a tensão aumenta 2,25 vezes, se comparado com o painel maciço. Para o caso do painel nervurado com aberturas, as tensões aumentam 2,13 vezes.

Analisando-se, ainda, os painéis nervurados, pode-se perceber que, comparando painéis nervurados sem e com aberturas, chega-se à conclusão de que painéis nervurados sem aberturas possuem tensões praticamente iguais. 


\section{$\underline{3^{\circ} \text { CASO - UTILIZANDO O PAINEL E A ESTRUTURA FORA DO PLANO }}$}

Finalmente, para a análise do $3^{0}$ caso, observa-se que valem as mesmas considerações feitas para o $2^{\underline{2}}$ :

$\Rightarrow$ as tensões se equiparam nas extremidades quando há a consideração de aberturas, aumentando para o caso de painéis nervurados;

$\Rightarrow$ painéis nervurados sem aberturas possuem tensões aumentadas para o valor extremo de 1,95 vezes; com aberturas, esse valor cai para 1,86 vezes;

$\Rightarrow$ analisando painéis nervurados, percebe-se que painéis sem aberturas possuem tensões praticamente iguais;

$\Rightarrow$ analisando painéis com aberturas, nota-se que as maiores tensões ocorrem nos painéis nervurados.

A partir das análises das distribuições das tensões principais dos três casos acima descritos, pode-se avaliar que as maiores tensões ocorrem nos painéis com aberturas, com tensões de tração nos cantos da diagonal principal. Ainda se percebe que a concentração de tensões ocorre nos cantos das aberturas e nos pontos de concentração de carga, enquanto, fora desta, as tensões são bem menores.

\subsubsection{Análise dos esforços nas ligações}

Avaliando os esforços nos painéis provenientes das ligações têm-se, a partir da Tabela 4.7, os valores máximos dos esforços nos quatro pontos de ligação. Deve-se salientar que esses esforços correspondem à resultante da soma vetorial das duas componentes na direção do plano. 
Tabela 4.7- Valores máximos e sentidos dos esforços

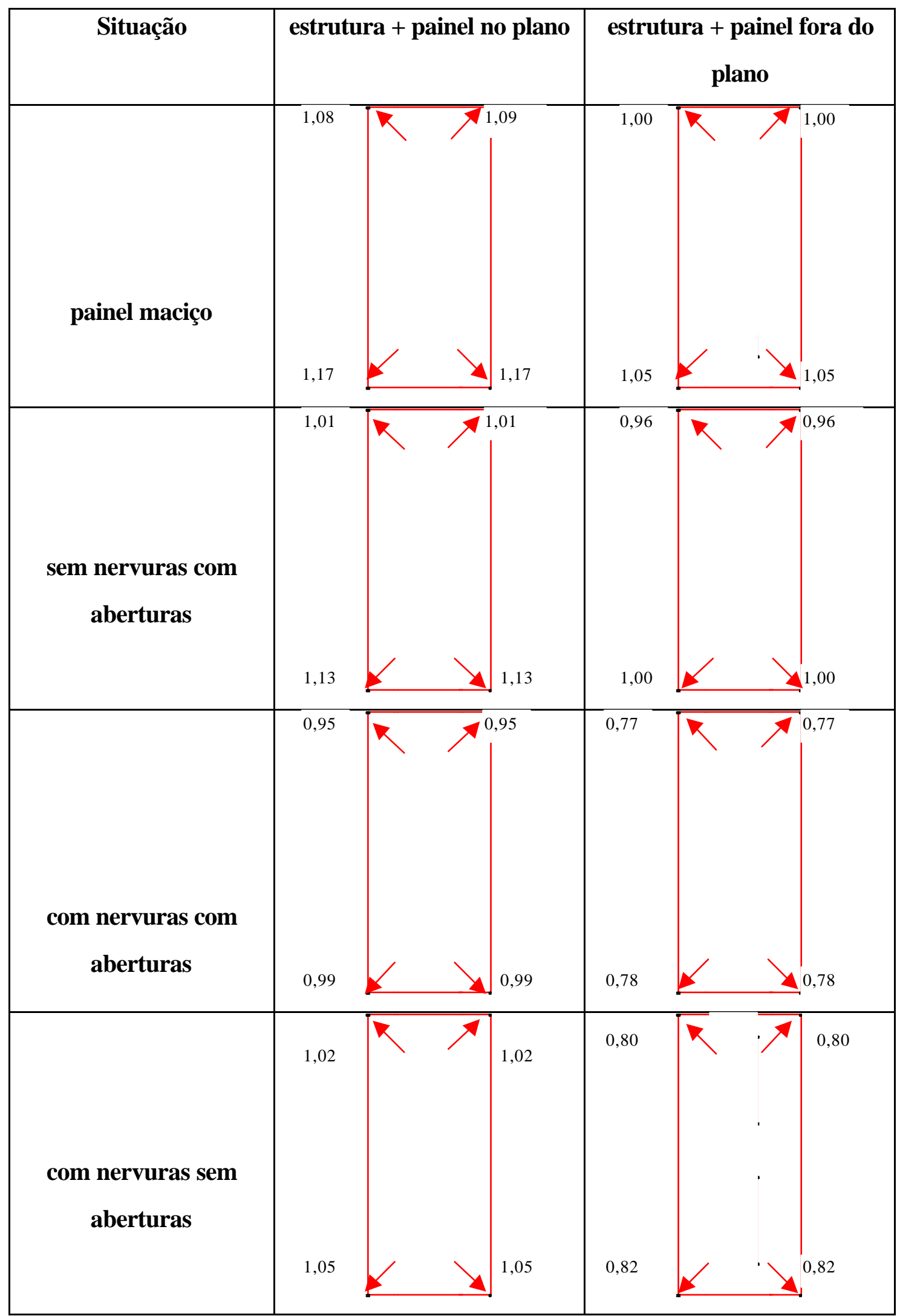


A partir da tabela, pode-se chegar às seguintes conclusões:

$\Rightarrow$ os esforços nas ligações não diferem muito quando há aberturas nos painéis;

$\Rightarrow$ quando se acrescentam nervuras e aberturas os esforços diminuem em média $12 \%$, para o caso da estrutura no plano e $23 \%$ fora dele; para o painel nervurado sem nenhuma abertura, os esforços diminuem $4 \%$ para o caso plano e $20 \%$ fora dele;

$\Rightarrow$ comparando painéis nervurados entre si, percebe-se que aqueles sem aberturas possuem valores maiores.

Pode-se ainda analisar, pelos resultados, que o uso de painéis maciços acarreta um bom desempenho quanto ao enrijecimento da estrutura, proporcionando tensões maiores nos painéis.

Todavia, de acordo com a Tabela 4.7, os esforços nas ligações são maiores para o caso do painel maciço, podendo, em alguns casos, sobrepor-se seu bom desempenho com relação ao enrijecimento.

Painéis nervurados $(\pi)$ dotados de aberturas para janelas ou portas, possuem menores esforços nas ligações com relação aos demais por outro lado, agregam valores de tensões elevados, o que pode necessitar de armadura adicional nos painéis.

\subsection{Exemplo de estrutura de um único pavimento}

\subsubsection{Descrição da estrutura}

Este exemplo apresenta uma aplicação para o caso de um galpão pré-moldado constituído por vários painéis com um único pavimento.

A estrutura principal a ser analisada corresponde a uma adaptação ao galpão do Laboratório de Estruturas do Departamento de Engenharia de Estruturas, sendo que, para este cálculo, considerou-se todo o fechamento realizado por painéis pré-moldados. Foi considerado o fechamento realizado por painéis em $\pi$ pré-moldados, com altura de $7500 \mathrm{~mm}$ e largura de $2500 \mathrm{~mm}$ conforme ilustrado na Figura 4.10, em substituição ao de alvenaria existente. Propositadamente para a análise do efeito de segunda ordem, fez-se 
uma alteração da dimensão transversal dos pilares de 500mm x 500mm para a ilustrada na Figura 4.11.

Basicamente, a estrutura do galpão é composta por pilares pré-moldados de seção transversal quadrada, dispondo de três consolos trapezoidais sobre os quais se apoiam as vigas calhas e as vigas-rolantes. Os painéis, por sua vez, são travados na extremidade superior por tirantes galvanizados, parafusados na viga calha. Na parte inferior, os mesmos são apenas apoiados. As dimensões, bem como a disposição dos painéis nas direções de análise x e y, estão melhor representados na Figura 4.12.

Consideram-se os painéis apoiados em uma viga que, por sua vez, apoia-se na fundação, sendo a estrutura principal perfeitamente engastada no solo. Foram analisados, ainda, tantos os casos em que se consideram as ligações entre painéis quanto aqueles que os desprezam. Foi considerada uma força lateral devida ao vento e a ponte rolante atuando na estrutura.
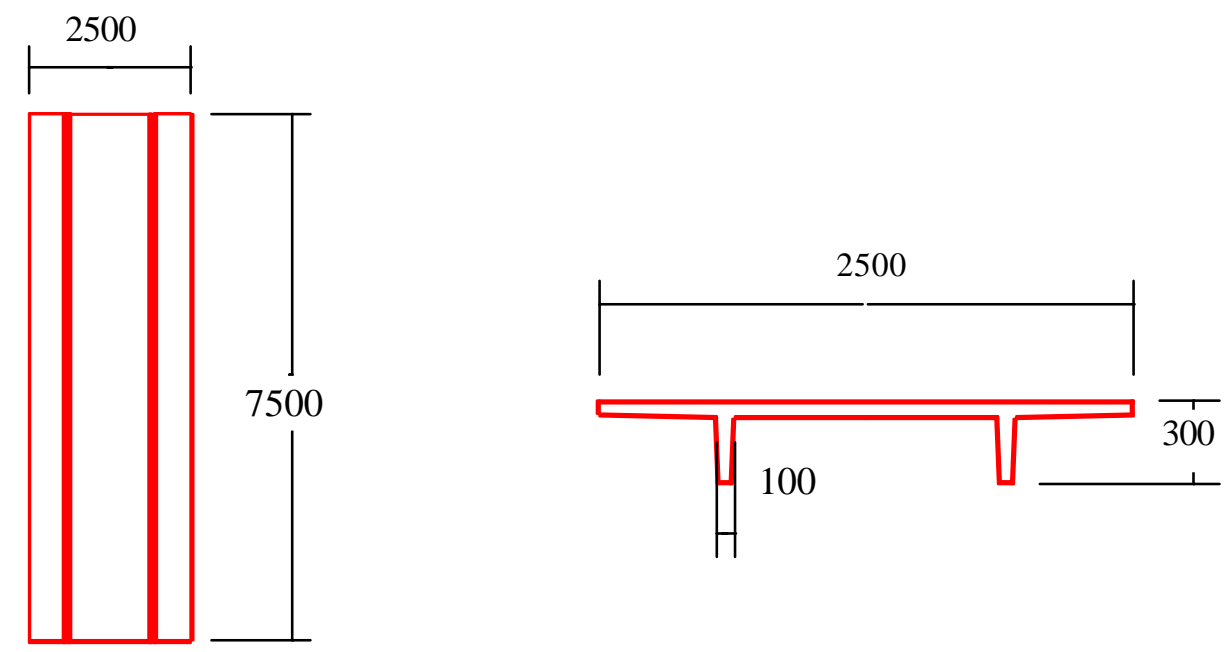

Figura 4.10- Dimensões dos painéis pré-moldados 


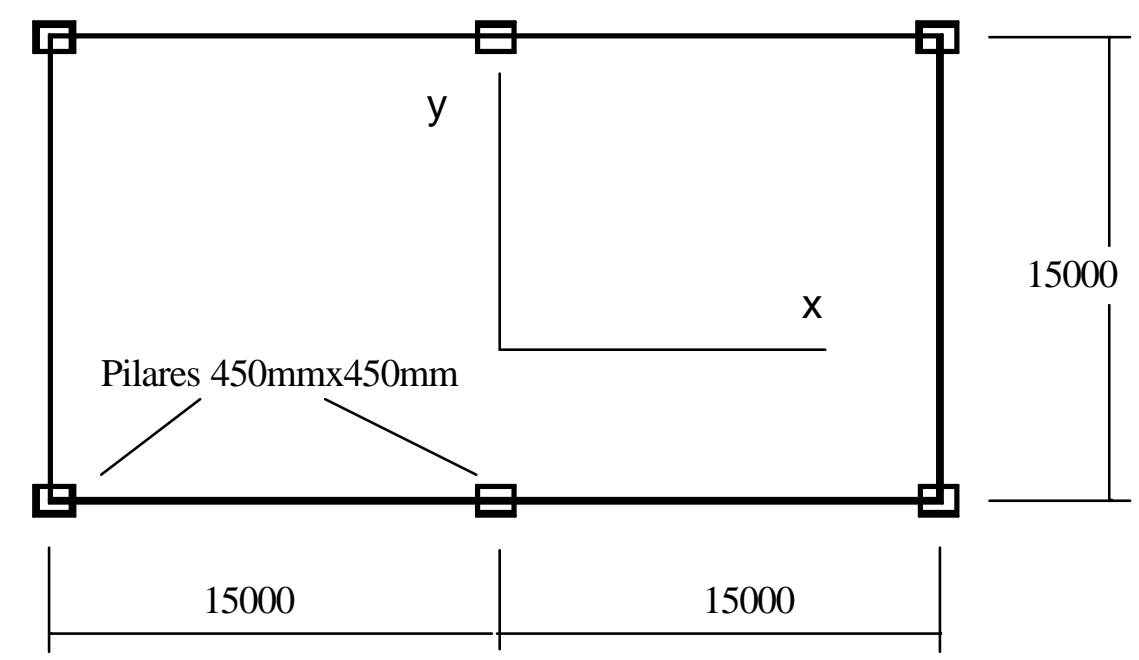

Figura 4.11- Planta baixa do galpão (dimensões em mm)



a) elevação na direção y

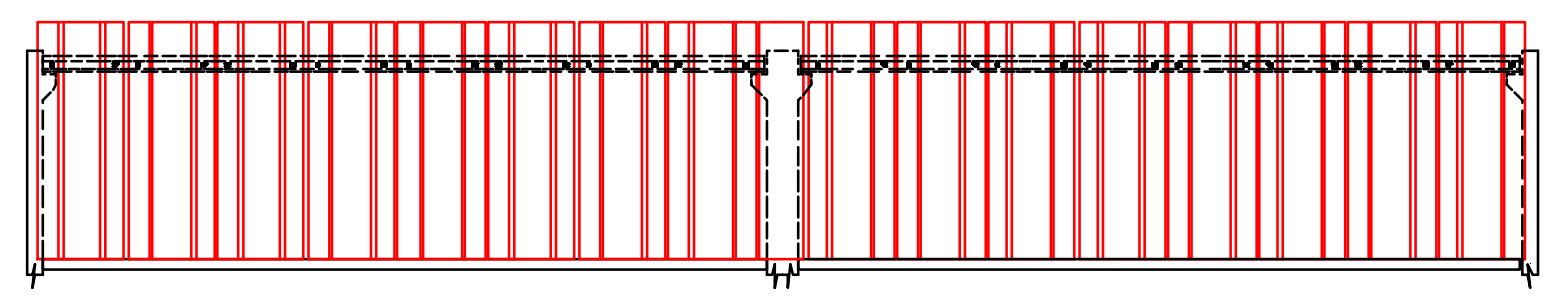

b) elevação na direção $x$

Figura 4.12- Disposição dos painéis no galpão pré-moldado 

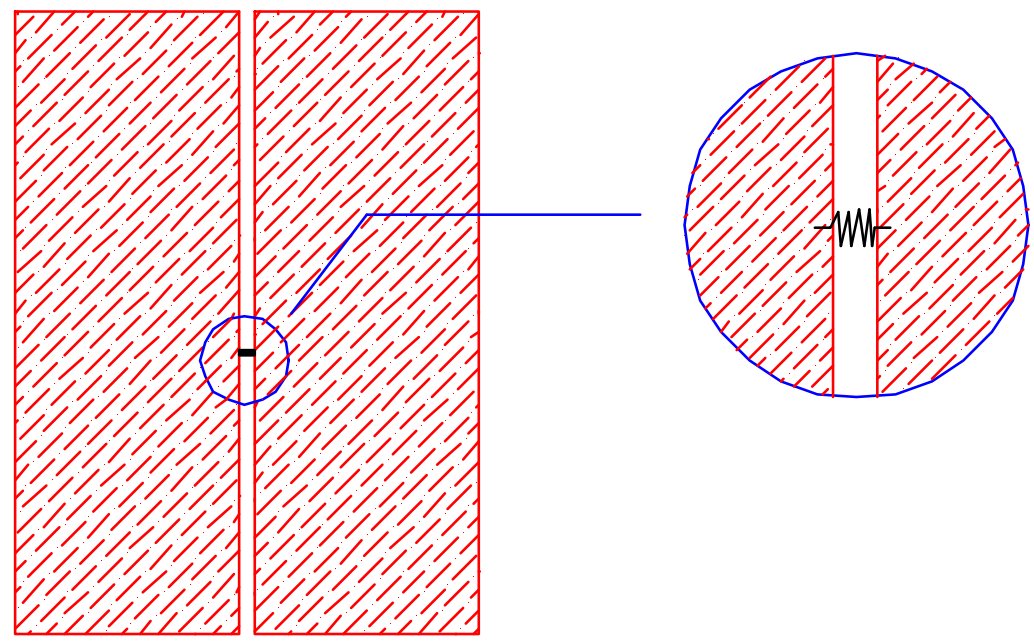

c) consideração da ligação entre painéis

Figura 4.12- Disposição dos painéis no galpão pré-moldado (cont.)

A ligação dos painéis na estrutura principal é feita por meio de parafusos ASTM A-307 de diâmetro 25,4mm (1") de comprimento 80mm, cujo detalhe está ilustrado pela Figura 4.13.

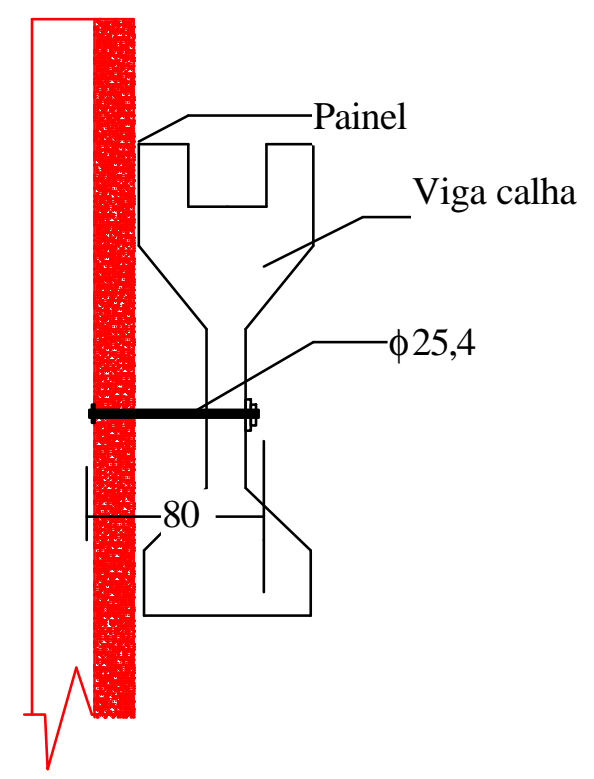

Figura 4.13- Detalhe da ligação (dimensões em mm)

Considerou-se a ligação por meio de molas cujas rigidezes verticais e horizontais correspondem àquelas calculadas de acordo com a eq. 3.1. Para o caso de ligação entre painéis, considerou-se a mesma rigidez calculada pela eq. 3.1. 


$$
\begin{aligned}
& \mathrm{d}=8 \mathrm{~cm} \\
& \mathrm{E}_{\mathrm{c}}=3000 \mathrm{kN} / \mathrm{cm}^{2} \\
& \mathrm{E}_{\mathrm{s}}=21000 \mathrm{kN} / \mathrm{cm}^{2} \\
& \mathrm{~d}_{\mathrm{b}}=2,54 \mathrm{~cm}
\end{aligned}
$$

$$
\begin{aligned}
& \lambda_{\tau \mathrm{b}}=9,94 \cdot 10^{-4} \mathrm{~cm} / \mathrm{kN} \\
& \mathrm{k}=1005 \mathrm{kN} / \mathrm{cm}
\end{aligned}
$$

Definido o modelo do galpão, analisou-se a interação da estrutura com os painéis e as ligações. O esquema da estrutura e do painel estão ilustrados pela Figura 4.14. Os painéis foram modelados utilizando um elemento de casca, o QSI4, com 220 elementos, os pilares e as vigas utilizando um elemento de viga, o BMS3, e as ligações ora JNT4, ora BMS3, dependendo do caso.

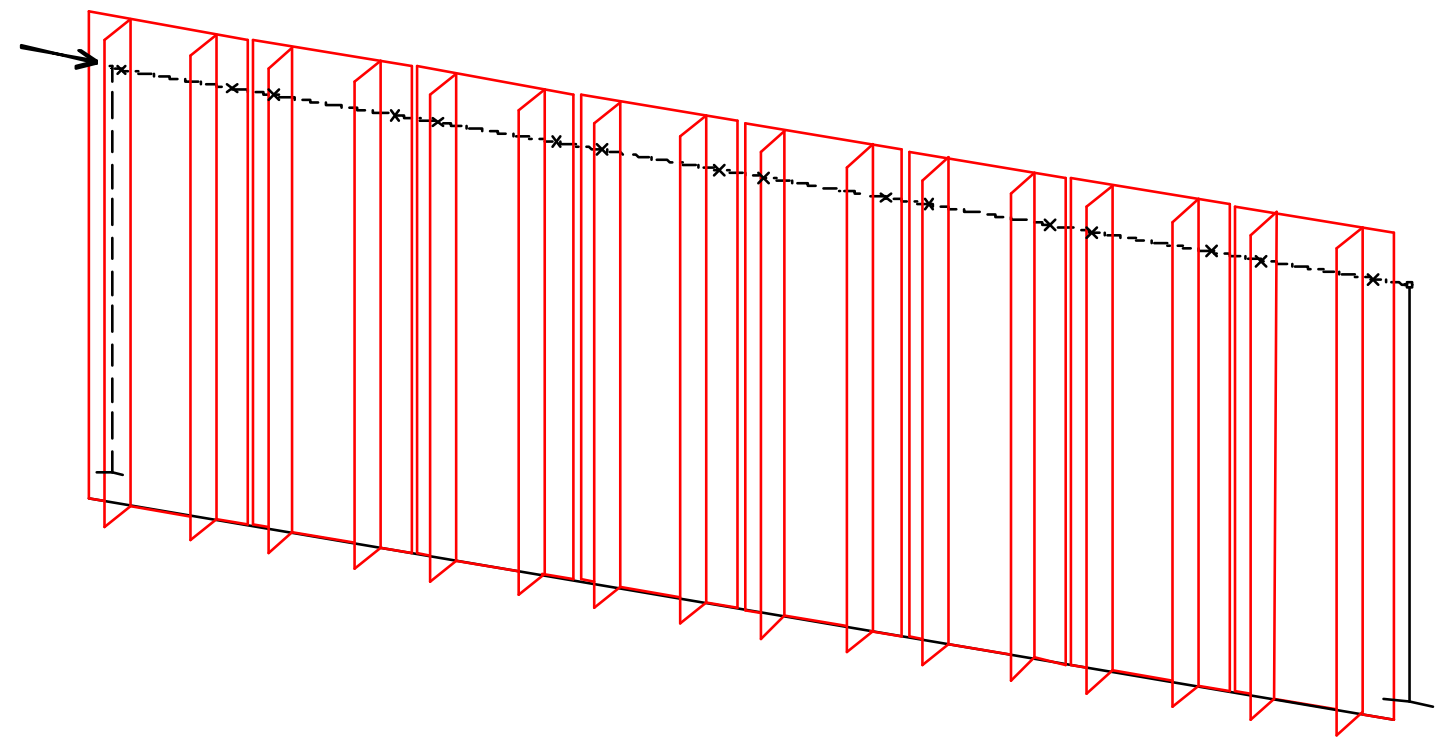

a) Esquema da estrutura na direção y

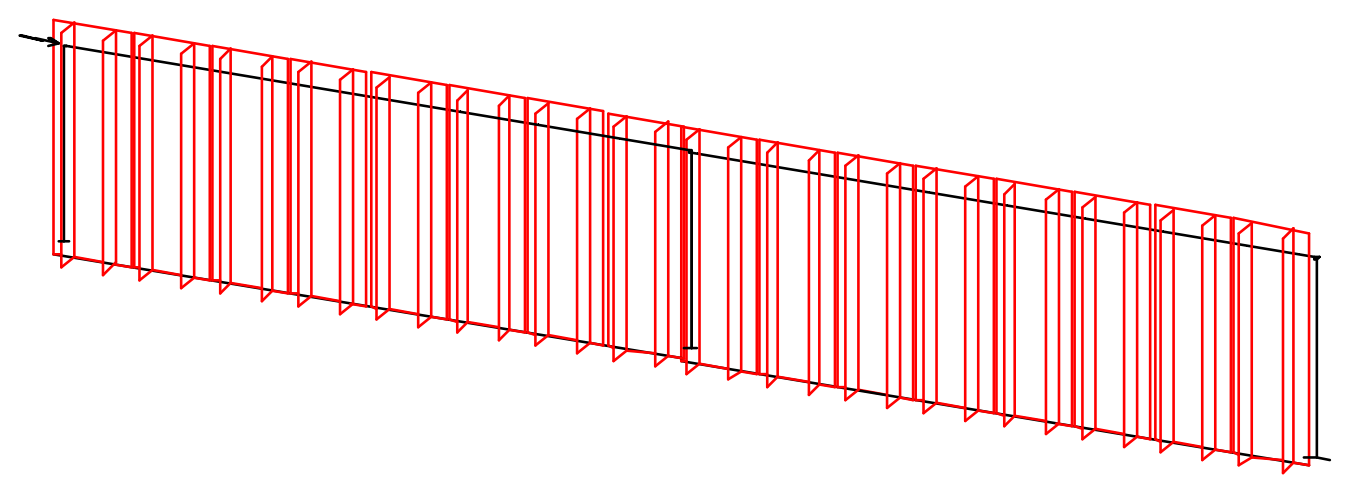

b) Esquema da estrutura na direção $x$

Figura 4.14- Esquema da estrutura e painéis 


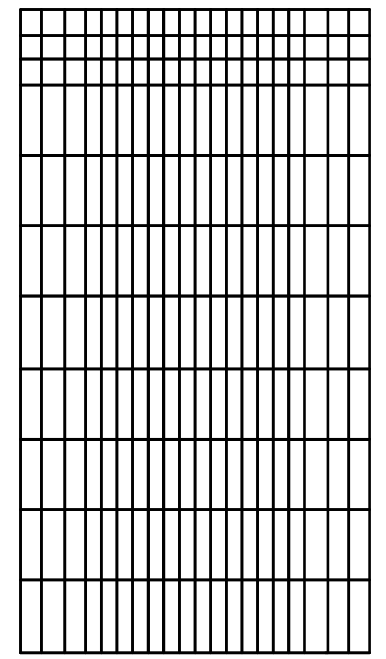

220 elementos

c)malha para os painéis

Figura 4.14- Esquema da estrutura e painéis (cont.)

Como passo preliminar na análise do galpão, determinou-se o deslocamento máximo da estrutura com e sem painéis de fechamento. Nos deslocamentos obtidos, ora foi desprezada a contribuição do enrijecimento das ligações entre painéis, ora considerada. Em seguida, acrescentam-se os painéis e efetuam-se as avaliações para os casos no plano e fora dele, incluindo tensões e esforços. Para as análises das tensões e deslocamentos, consideram-se atuando na estrutura, dois tipos de ações: a primeira corresponde ao efeito lateral (vento e frenagem) e a segunda ao efeito das variações volumétricas (fluência, retração e temperatura).

Para a ação 1, a força de cálculo atuando no topo do pilar para as duas direções (Figura 4.15), é: $\mathrm{H}_{\text {dtotal }}=45,25 \mathrm{kN}$.

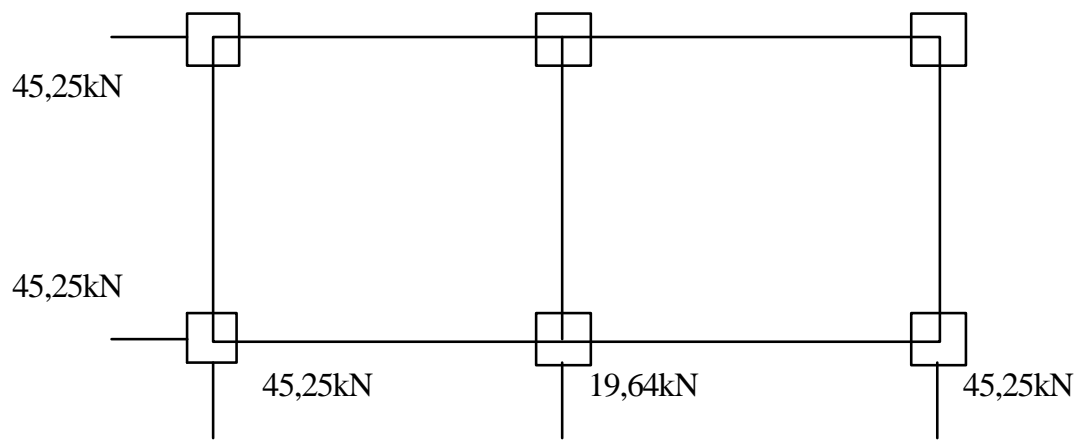

Figura 4.15- Ações devido ao vento na estrutura 
Para a ação 2, adotou-se uma variação térmica de $-35^{\circ} \mathrm{C}$. Embora a NB-1 recomende valores compreendidos entre $\pm 10^{\circ} \mathrm{C}$ e $\pm 15^{\circ} \mathrm{C}$, devido à variação de temperatura da atmosfera, adotou-se, para o presente trabalho, uma variação de $\pm 20^{\circ} \mathrm{C}$. Achou-se justificável tal valor, para elementos de fachada, em decorrência da grande variação térmica da atmosfera a que estão sujeitos.

A fim de englobar o efeito das variações volumétricas, foi adotada uma variação de temperatura de $-15^{\circ} \mathrm{C}$ que considera a retração e a fluência. Ainda que acarrete altas deformações para a fluência, julgou-se o valor adotado razoável, pois, como se trata de elementos pré-moldados, tais deformações não são impostas imediatamente à sua montagem, apresentando-as mais elevadas, após a execução das peças. Quando se efetua a montagem, supõe-se que parte das deformações dos elementos sejam acomodadas pela estrutura.

Além das análises das ações em separado, fez-se a combinação desfavorável que possa atuar na estrutura.

\subsubsection{Análise dos deslocamentos}

Definida a estrutura de análise, avaliou-se o efeito do enrijecimento dos diferentes tipos de painéis, a partir dos deslocamentos no topo do pilar. Nas Tabelas 4.8 e 4.9 a seguir, encontram-se os deslocamentos, $\boldsymbol{a}$, referentes ao topo para todas as análises, bem como os elementos finitos utilizados para cada caso.

Foram consideradas, durante as análises, as seguintes características:

$\Rightarrow$ Módulo de elasticidade longitudinal do concreto: $\mathrm{E}_{\mathrm{c}}=30 \mathrm{GPa}$

$\Rightarrow$ Módulo de elasticidade longitudinal do aço: $\mathrm{E}_{\mathrm{c}}=210 \mathrm{GPa}$

$\Rightarrow$ Coeficiente de Poison do concreto: $v=0,2$

$\Rightarrow$ Coeficiente de Poison do aço: $v=0,3$

$\Rightarrow$ Áreas das seções transversais das vigas e pilares: $A_{v}=0,29 m 2 ; A_{p}=0,25 m^{2}$

$\Rightarrow$ Momento de inércia das vigas e pilares: $\mathrm{I}_{\mathrm{v}}=0,0432 \mathrm{~m}^{4} ; \mathrm{I}_{\mathrm{p}}=0,00521 \mathrm{~m}^{4}$ 
Tabela 4.8- Deslocamentos no topo do pilar e a descrição para cada caso na direção y

\begin{tabular}{|c|c|c|}
\hline \multicolumn{2}{|c|}{$\begin{array}{c}\text { GALPÃO (Direção y) } \\
\text { nenhuma ligação entre painéis }\end{array}$} & Descrição \\
\hline $\begin{array}{c}\text { estrutura principal e painéis } \\
\text { ambos no plano }\end{array}$ & $a=13,26 \mathrm{~mm}$ & elem. finito estrutura - $B E A M$ \\
\hline $\begin{array}{c}\text { estrutura principal e painéis } \\
\text { ambos no plano }\end{array}$ & $a=0,87 \mathrm{~mm}$ & $\begin{array}{l}\text { elem. finito estrutura/painel - } B M S 3 \\
\qquad / \text { QSI4 } \\
\text { elem. finito ligação - JNT4 } \\
\text { malha do painel: } \underline{625} \text { elementos }\end{array}$ \\
\hline $\begin{array}{l}\text { estrutura principal e painéis } \\
\text { fora do plano distando }\end{array}$ & $a=0,97 \mathrm{~mm}$ & $\begin{array}{c}\text { elem. finito estrutura/painel - } B M S 3 \\
\qquad / Q S I 4 \\
\text { elem. finito ligação - BMS3 } \\
\text { malha do painel: } \underline{625} \text { elementos }\end{array}$ \\
\hline \multicolumn{2}{|c|}{$\begin{array}{l}\text { GALPÃO (Direção y) } \\
\text { com ligação entre painéis } \\
\end{array}$} & $\overline{\text { Descrição }}$ \\
\hline $\begin{array}{c}\text { estrutura principal e } \\
\text { painéis ambos no plano }\end{array}$ & $a=13,26 \mathrm{~mm}$ & elem. finito estrutura - $B E A M$ \\
\hline $\begin{array}{c}\text { estrutura principal e } \\
\text { painéis ambos no plano }\end{array}$ & $a=0,46 \mathrm{~mm}$ & $\begin{array}{l}\text { elem. finito estrutura/painel - } B M S 3 \\
\qquad / \text { QSI4 } \\
\text { elem. finito ligação - JNT4 } \\
\text { malha do painel: } \underline{625} \text { elementos }\end{array}$ \\
\hline $\begin{array}{l}\text { estrutura principal e } \\
\text { painéis fora do plano } \\
\text { distando }\end{array}$ & $a=0,49 \mathrm{~mm}$ & $\begin{array}{c}\text { elem. finito estrutura/painel - } B M S 3 \\
\qquad / Q S I 4 \\
\text { elem. finito ligação - BMS3 } \\
\text { malha do painel: } \underline{625} \text { elementos }\end{array}$ \\
\hline
\end{tabular}


Tabela 4.9- Deslocamentos no topo do pilar e a descrição para cada caso na direção $\mathrm{x}$

\begin{tabular}{|c|c|c|}
\hline \multicolumn{2}{|c|}{$\begin{array}{c}\text { GALPÃO (Direção x) } \\
\text { nenhuma ligação entre .painéis }\end{array}$} & Descrição \\
\hline $\begin{array}{l}\text { estrutura principal e painéis } \\
\text { ambos no plano }\end{array}$ & $a=8,84 \mathrm{~mm}$ & elem. finito estrutura - $B E A M$ \\
\hline $\begin{array}{c}\text { estrutura principal e painéis } \\
\text { ambos no plano }\end{array}$ & $a=0,28 \mathrm{~mm}$ & $\begin{array}{l}\text { elem. finito estrutura/painel - } \\
\qquad B M S 3 \text { / QSI4 } \\
\text { elem. finito ligação - JNT4 } \\
\text { malha do painel: } \underline{625} \text { elementos }\end{array}$ \\
\hline $\begin{array}{l}\text { estrutura principal e painéis } \\
\text { fora do plano distando }\end{array}$ & $a=0,45 \mathrm{~mm}$ & $\begin{array}{c}\text { elem. finito estrutura/painel - } \\
\qquad B M S 3 \text { / QSI4 } \\
\text { elem. finito ligação - BMS3 } \\
\text { malha do painel: } \underline{625} \text { elementos }\end{array}$ \\
\hline
\end{tabular}

Um resumo dos deslocamentos está melhor representado pela Tabela 4.10: 
Tabela 4.10- Resumo dos deslocamentos para os casos analisados

\begin{tabular}{|c|c|c|c|c|c|c|}
\hline & \multicolumn{3}{|c|}{ Direção y (mm) } & \multicolumn{3}{|c|}{ Direção x (mm) } \\
\hline & $\begin{array}{c}\text { estr. sem } \\
\text { painel }\end{array}$ & $\begin{array}{l}\text { estr. no } \\
\text { plano }\end{array}$ & $\begin{array}{l}\text { estr. fora } \\
\text { do plano }\end{array}$ & $\begin{array}{c}\text { estr. sem } \\
\text { painel }\end{array}$ & $\begin{array}{l}\text { estr. no } \\
\text { plano }\end{array}$ & $\begin{array}{l}\text { estr. fora } \\
\text { do plano }\end{array}$ \\
\hline $\begin{array}{c}\text { Com } \\
\text { ligação } \\
\text { entre } \\
\text { painéis } \\
\text { (caso a) } \\
\text { (mm) }\end{array}$ & 13,26 & 0,46 & 0,49 & - & - & - \\
\hline $\begin{array}{c}\text { Sem } \\
\text { ligações } \\
\text { entre } \\
\text { painéis } \\
\text { (caso b) } \\
\text { (mm) }\end{array}$ & 13,26 & $\mathbf{0 , 8 7}$ & $\mathbf{0 , 9 7}$ & 8,84 & 0,28 & 0,45 \\
\hline
\end{tabular}

Com relação à interação entre painéis, verifica-se, pela tabela, que o painel enrijece a estrutura em aproximadamente 2 vezes, quando a interligação entre eles é considerada.

Observa-se, pelos resultados, que a resistência do conjunto completo (caso b) é 25 vezes maior que a do pórtico sem o painel confirmando o que foi dito anteriormente.

A utilização dos painéis de fechamento acarreta uma diminuição dos esforços de segunda ordem, que, em alguns casos, pode até ser desprezada. Para esta estrutura, a análise da estabilidade global, empregando o processo simplificado do coeficiente $\gamma_{z}$,é: 


$$
\begin{aligned}
& M_{d}=\gamma_{z} \cdot M_{1 d} \\
& \gamma_{z}=\frac{1}{1-\frac{\Delta M_{d}}{M_{1 d}}}
\end{aligned}
$$

onde:

$\gamma_{z}$ - coeficiente de majoração de esforços de primeira ordem para obtenção dos esforços finais

$\Delta \mathrm{M}_{\mathrm{d}}$ - primeira avaliação dos esforços de segunda ordem calculados com a estrutura deslocada pelos esforços de primeira ordem

$\mathrm{M}_{\mathrm{td}}-$ momentos de primeira ordem que tendem a produzir tombamento na estrutura

$M_{d}-$ momentos finais

Considera-se uma redução de $50 \%$ na rigidez (EI) da estrutura a fim de levar em conta a fissuração do concreto. Se $\gamma_{z}<1,1$, os esforços de primeira ordem são desprezados; se $1,1 \leq \gamma_{z} \leq 1,2$, os esforços de segunda ordem devem ser considerados; se $\gamma_{z}>1,2$, os esforços de segunda ordem devem ser calculados, utilizando-se um processo mais preciso.

Neste exemplo, achou-se interessante avaliar tal efeito para a direção x. Portanto, tem-se:

Desprezando os painéis de fechamento:

$\Rightarrow \mathrm{H}_{\text {dotal }}=45,25 \mathrm{kN}$

$\Rightarrow$ força vertical de cálculo devido ao peso próprio $\left(\mathrm{V}_{\mathrm{d} 1}\right)$ : considerou-se as reações das telhas, das vigas de coberturas e carga acidental $(\mathrm{q}=0,50 \mathrm{kN} / \mathrm{m})$

$\mathrm{V}_{\mathrm{d}}=1385,31 \mathrm{kN}$

$\Rightarrow$ desaprumo dos pilares: $2,5 \mathrm{~cm}$

$\Rightarrow$ rigidez da estrutura : 
$\mathrm{I}=\frac{0,45^{4}}{12}=3,42 \cdot 10^{-2} \mathrm{~m}^{4}$

$\mathrm{EI}=0,5 \cdot 3.10^{7} \cdot\left(3 \cdot 3,42 \cdot 10^{-3}\right)=102600 \mathrm{kN} \cdot \mathrm{m}^{2}$

$\Rightarrow \mathrm{M}_{1 \mathrm{~d}}=45,25 \cdot 6,5+1385,31 \cdot 0,025=328,76 \mathrm{kN} \cdot \mathrm{m}$

$\Rightarrow$ deslocamentos:

$\mathrm{a}_{1}=\frac{\mathrm{H}_{\text {dtotal }} \mathrm{h}^{3}}{3 \mathrm{EI}}=0,0404 \mathrm{~m}$

$\mathrm{a}_{2}=0,0048 \mathrm{~m}$

$\Rightarrow$ acréscimo de esforços devido ao deslocamento da estrutura

$\Delta \mathrm{M}_{\mathrm{d}}=\mathrm{V}_{\mathrm{d}} \cdot\left(\mathrm{a}_{1}+\mathrm{a}_{2}\right)=62,62 \mathrm{kN} \cdot \mathrm{m}$

Considerando os painéis de fechamento:

$\Rightarrow$ deslocamentos:

$\mathrm{a}_{1}=0,00082 \mathrm{~m}$

$\mathrm{a}_{2}=0,0048 \mathrm{~m}$

$\Rightarrow$ acréscimo de esforços:

$\Delta \mathrm{M}_{\mathrm{d}}=\mathrm{V}_{\mathrm{d}} \cdot\left(\mathrm{a}_{1}+\mathrm{a}_{2}\right)=7,85 \mathrm{kN}$.

Pela análise dos momentos de segunda ordem, nota-se que, para o caso da consideração do efeito de enrijecimento, o momento de segunda ordem diminui de 62,62 kN.m, para 7,85 kN.m, o que é uma grande vantagem. Avaliando o efeito da instabilidade, tem-se:

Desprezando os painéis de fechamento:

$\gamma_{\mathrm{z}}=\frac{1}{1-\frac{62,62}{328,76}}=1,23 \quad \therefore$ esforços de segunda ordem devem ser considerados!!!!! 


\section{Considerando os painéis de fechamento:}

$\gamma_{\mathrm{Z}}=\frac{1}{1-\frac{7,79}{328,76}}=1,02 \quad \therefore$ esforços de segunda ordem desprezados!!!!!

A partir dos resultados observa-se que o efeito de segunda ordem pode ser desprezado para o caso da estrutura que considera a interação de painéis de fechamento. Quando os painéis estão incorporados a estrutura, os esforços globais de segunda ordem tornam-se desprezíveis, se comparados com a estrutura sem painéis.

Portanto, a consideração do efeito de enrijecimento de painéis pode se tornar um aspecto positivo para a análise da estrutura, já que se tem uma acentuada redução dos efeitos de segunda ordem.

\subsubsection{Análise das tensões nos painéis e esforços nas ligações}

A partir dos deslocamentos acima, nota-se que há um enrijecimento adicional da estrutura principal quando se considera a interação dos painéis. Contudo esse enrijecimento acarreta, também, esforços nos painéis e nas ligações que geralmente não são analisados.

Aqui serão analisados os esforços nos painéis e nas ligações, para os dois carregamentos atuantes, utilizando o software LUSAS, verificando se estão dentro do limite aceitável.

\subsubsection{Análise de tensões}

Na Tabela 4.11, encontram-se os máximos valores (Figura 4.16) das tensões principais, para o painel mais crítico para a direção x. Está incorporada, ainda, no apêndice, a distribuição das tensões principais fornecida pelo software para os casos dos painéis no plano e fora dele. 


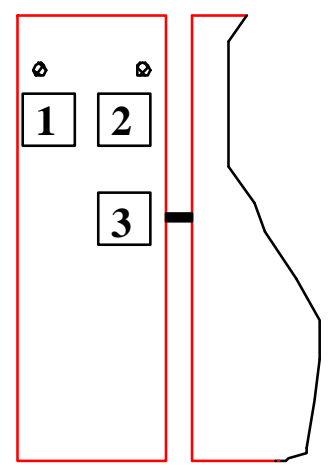

Figura 4.16- Pontos analisados para tensões e esforços

Tabela 4.11- Valores máximos de tensões principais em kPa para a direção y

\begin{tabular}{|c|c|c|}
\hline \multicolumn{3}{|c|}{ Estrutura no plano sem ligação entre painéis (DIREÇÃO Y) } \\
\hline "ação 1 & ação 2 & "combinação 1 e 2 \\
\hline 1) 473 & 1) 3841 & 1) 5082 \\
\hline 2) 328 & 2) 2035 & 2) 2770 \\
\hline \multicolumn{3}{|c|}{ Estrutura no plano com ligação entre painéis } \\
\hline ação 1 & ação 2 & combinação 1 e 2 \\
\hline 1) 412 & 1) 3318 & 1) 4394 \\
\hline 2) 173 & 2) 2361 & 2) 2833 \\
\hline 3) 1232 & 3) 8960 & 3) 11984 \\
\hline \multicolumn{3}{|c|}{ Estrutura fora do plano sem ligação entre painéis } \\
\hline ação 1 & ação 2 & " combinação 1 e 2 \\
\hline 1) 437 & 1) 3158 & 1) 4227 \\
\hline 2) 318 & 2) 1947 & 2) 2654 \\
\hline \multicolumn{3}{|c|}{ Estrutura fora do plano com ligação entre painéis } \\
\hline ação 1 & ação 2 & combinação 1 e 2 \\
\hline 1) 382 & 1) 2967 & 1) 3942 \\
\hline 2) 179 & 2) 2196 & 2) 2814 \\
\hline 3) 1226 & 3) 8647 & 3) 11602 \\
\hline
\end{tabular}


A tensão de tração do concreto é, de acordo com a NB1, de 2,2 MPa. Pelas tabelas apresentadas pode-se perceber que a maior tensão de tração, encontrada para todos os casos, está localizada nos pontos de ligações entre painéis e seu valor é de 12,2 $\mathrm{MPa}$, bem acima da norma.

\subsubsection{Esforços resultantes nas ligações}

Os maiores esforços resultantes obtidos, para a direção y, são os ilustrados na Tabela 4.12. Cabe salientar que os valores dos esforços na ligação correspondem à resultante da soma vetorial das duas componentes na direção do plano.

Para o máximo esforço resultante deve ser verificado se o mesmo ultrapassa a capacidade última da ligação. Portanto chega-se, adotando a ligação totalmente engastada, a uma estimativa de sua resistência [SALES \& etal (1994)]:

$\Rightarrow$ resistência ao cisalhamento:

$$
\mathrm{R}_{\mathrm{d}}=\phi_{\mathrm{v}} \cdot 0,60 \cdot \mathrm{A}_{\mathrm{p}} \cdot \mathrm{f}_{\mathrm{u}} \Rightarrow \mathrm{R}_{\mathrm{d}}=0,60 \cdot 0,60 \cdot 5,08 \cdot 41,5 \cdot 2=151,8 \mathrm{kN}
$$

onde

$\mathrm{R}_{\mathrm{d}}=$ resistência de cálculo

$\phi_{\mathrm{v}}=0,60$

$\mathrm{A}_{\mathrm{p}}=$ área bruta do pino

$\mathrm{f}_{\mathrm{u}}=$ tensão de escoamento do material

resistência à flexão: o máximo momento obtido nas análises é $15 \mathrm{kN} . \mathrm{cm}$. Portanto tem-se:

$$
\begin{aligned}
& \mathrm{f}=\frac{\mathrm{M}}{\mathrm{Z}} \leq 0,9 \cdot \mathrm{f}_{\mathrm{u}}=37,5 \mathrm{kN} / \mathrm{cm}^{2} \\
& \mathrm{f}=\frac{15}{1,61}=9,32 \mathrm{kN} / \mathrm{cm}^{2} \quad<37,5 \mathrm{OK}
\end{aligned}
$$


onde

$\mathrm{f}=$ tensão à flexão

$\mathrm{M}=$ momento no pino

$Z=$ momento estático dada por $\pi \cdot r^{3} / 4$

$\mathrm{f}_{\mathrm{u}}=$ tensão de escoamento do material

Tabela 4.12- Valores máximos dos esforços em $\mathrm{kN}$ para a direção y

Estrutura no plano sem ligação entre painéis (DIREÇÃO Y)

\begin{tabular}{|c|c|c|}
\hline $\begin{array}{c}\text { ação } 1 \\
\text { (coeficiente de segurança } \\
1,4)\end{array}$ & $\begin{array}{c}\text { ação } 2 \\
\text { (coeficiente de segurança } \\
1,2 \text { ) }\end{array}$ & combinação 1 e 2 \\
\hline 1) 4,3 & 1) 42,7 & 1) 55,4 \\
\hline 2) 1,7 & 2) 22,5 & 2) 29,0 \\
\hline \multicolumn{3}{|c|}{ Estrutura no plano com ligação entre painéis } \\
\hline ação 1 & ação 2 & combinação 1 e 2 \\
\hline 1) 3,8 & 1) 46,0 & 1) 59,0 \\
\hline 2) 3,2 & 2) 25,9 & 2) 34,3 \\
\hline 3) 13,8 & 3) 130,0 & 3) 169,8 \\
\hline \multicolumn{3}{|c|}{ Estrutura fora do plano sem ligação entre painéis } \\
\hline ação 1 & ação 2 & combinação 1 e 2 \\
\hline 1) 4,5 & 1) 34,2 & 1) 45,5 \\
\hline 2) 4,5 & 2) 21,2 & 2) 29,9 \\
\hline \multicolumn{3}{|c|}{ Estrutura fora do plano com ligação entre painéis } \\
\hline "ação 1 & "ação 2 & combinação 1 e 2 \\
\hline 1) 4,4 & 1) 22,3 & 1) 31,2 \\
\hline 2) 4,3 & 2) 12,7 & 2) 19,5 \\
\hline 3) 11,7 & 3) 127,5 & 3) 164,7 \\
\hline
\end{tabular}


Com exceção da combinação 1 e 2 para ligações entre painéis, pode-se notar que, para os casos analisados, os esforços transmitidos estão dentro do permitido.

\subsection{Exemplo de estrutura de vários pavimentos}

\subsubsection{Descrição da estrutura e painéis}

Apresenta-se uma aplicação para um caso de vários painéis com vários pavimentos, seguindo a mesma linha anterior. Este exemplo corresponde a uma estrutura realizada em parte de concreto pré-moldado, cujos dados foram cedidos gentilmente pela Reago Indústria e Comércio S. A . Analisam-se esforços e o comportamento do conjunto para um caso de estrutura de vários pavimentos, através do qual se pode ter uma idéia da contribuiç̧ão dos painéis e de sua influência nos esforços de pilares.

A estrutura principal é constituída de pilares pré-moldados engastados na fundação com vigas simplesmente apoiadas, através de pinos. Os painéis de fechamento, dispostos na direção horizontal, são ligados diretamente nos pilares. Neste trabalho é feita a análise de uma parte da estrutura, correspondendo a uma elevação de pilares.

Os painéis de fechamento possuem largura constante de $2500 \mathrm{~mm}$ com os comprimentos indicados na Figura 4.17, possuindo espessura total de $180 \mathrm{~mm}$ sendo 30mm de camada final de acabamento arquitetônico, conforme mostrado na Figura 4.18.
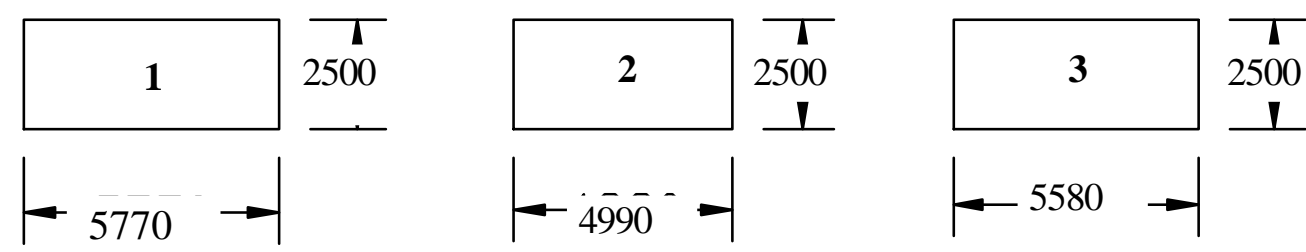

Figura 4.17- Tipos de painéis utilizados ao longo da estrutura (medidas em mm) 


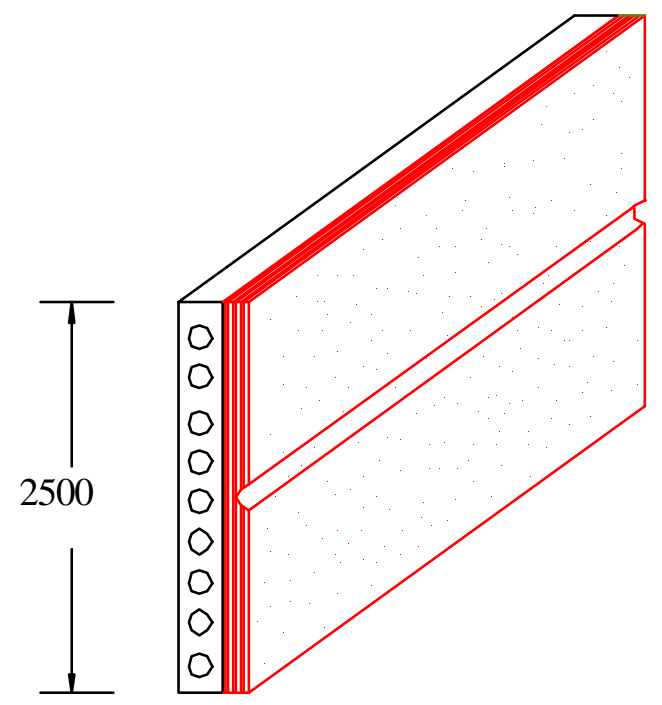

Figura 4.18- Vista do painel de fechamento com o acabamento (dimensões em mm)

Os painéis são dispostos uns sobre os outros mediante apoio de elastômero, e ligados aos pilares através de insertos metálicos, conforme representado na Figura 4.19.

Assim, para as ações verticais, as forças são transmitidas dos painéis superiores para os inferiores e do primeiro painel para a parte inferior dos pilares, mediante consolos, ou diretamente para os blocos de fundação, conforme o caso. De forma independente, as ações horizontais são transmitidas diretamente aos pilares, através de ligações apresentadas na Figura 4.20. A flexibilidade do pino da ligação, com comprimento de 200mm, permite a acomodação dos painéis, frente às variações volumétricas de temperatura, retração e fluência. 

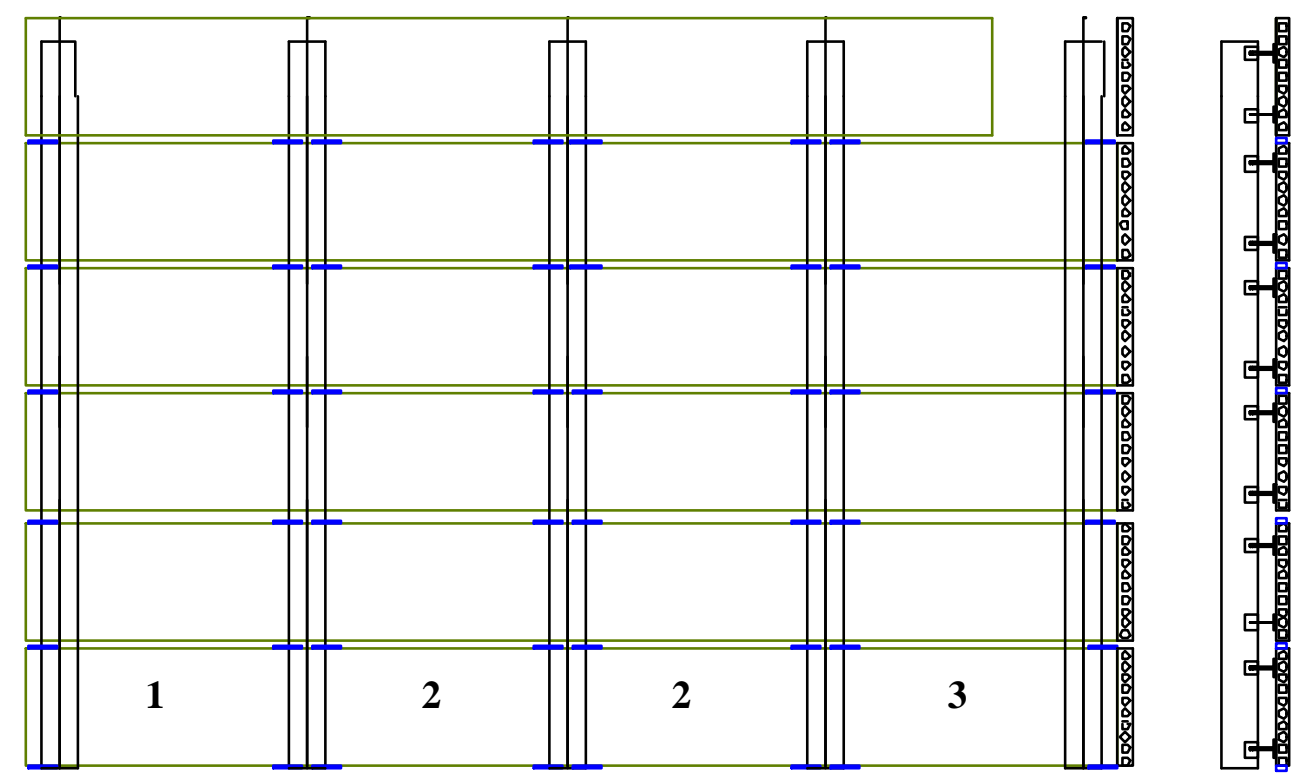

Figura 4.19- Disposição dos painéis na estrutura analisada

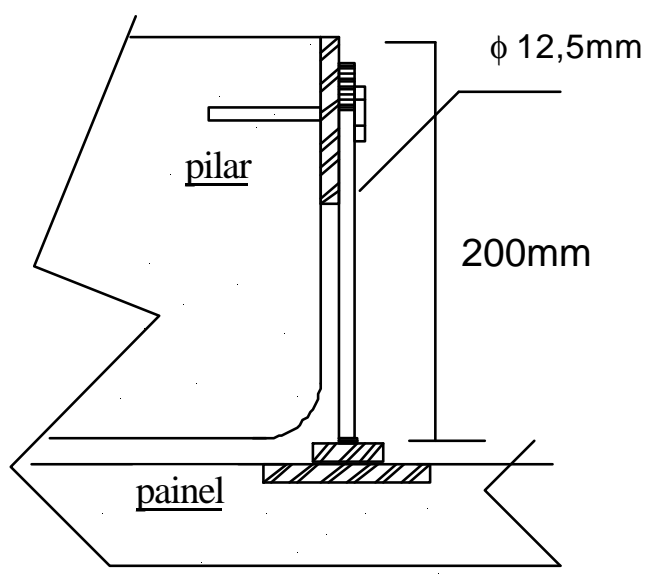

Figura 4.20- Tipo de ligação utilizada para interligar painéis e estrutura principal

Os valores das ações consideradas foram os mesmos adotados no exemplo anterior: o primeiro corresponde ao efeito da ação lateral (vento e frenagem) e o segundo, ao efeito das variações volumétricas (fluência, retração e temperatura).

A parte da estrutura, para os dois carregamentos, foi modelada da seguinte forma: a) pilares como elementos de barra perfeitamente engastados na fundação (Figura 4.21.a)); b) vigas como elementos de barra perfeitamente articulados nos pilares; c) os 
painéis como elementos de casca, dispostos excentricamente em relação ao pórtico formado pelos pilares e vigas (Figura 4.21.b)); d) a ligação dos painéis com o pilares como barra de aço. Dessa forma, resultou um modelo tridimensional formado por elementos de barra e de casca. Os materiais foram considerados com comportamento elástico-linear.

Considerou-se a ligação entre painéis e estrutura principal também por molas com rigidezes vertical e horizontal calculadas de acordo com a eq. 3.1.

$$
\begin{array}{ll}
\mathrm{d}=200 \mathrm{~mm} & \\
\mathrm{E}_{\mathrm{c}}=3130 \mathrm{kN} / \mathrm{cm}^{2} & \lambda_{\tau \mathrm{b}}=0,265 \mathrm{~cm} / \mathrm{kN} \\
\mathrm{E}_{\mathrm{s}}=21000 \mathrm{kN} / \mathrm{cm}^{2} & \mathrm{k}=3,77 \mathrm{kN} / \mathrm{cm} \\
\mathrm{d}_{\mathrm{b}}=12,5 \mathrm{~mm} &
\end{array}
$$

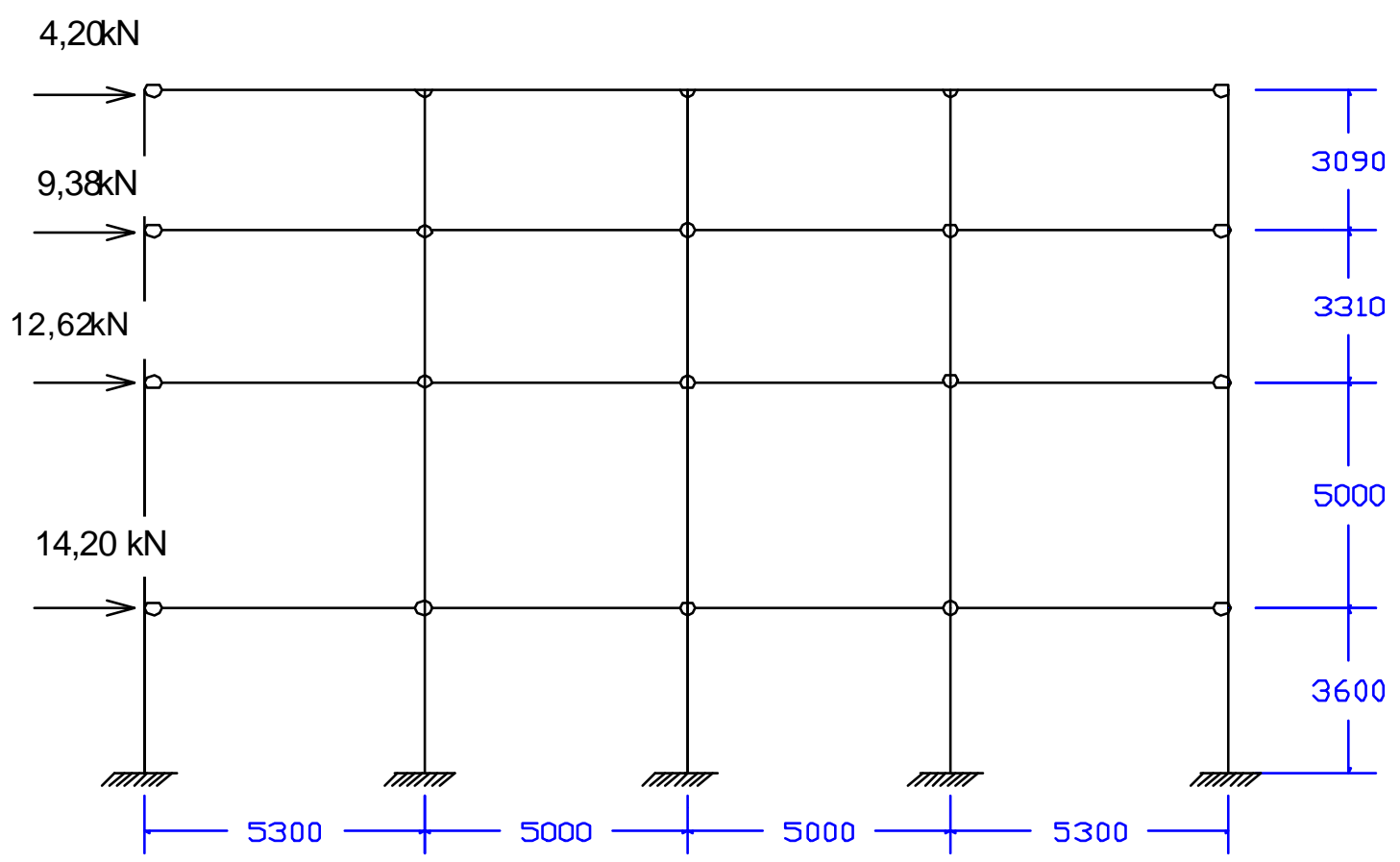

a) Esquema de análise da estrutura

Figura 4.21- Esquemas dos painéis e estrutura (cont.) 


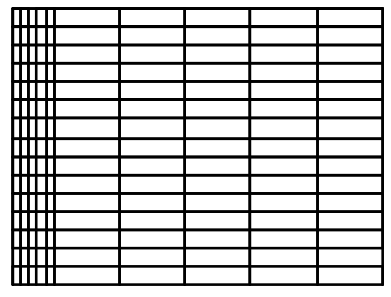

150 elementos

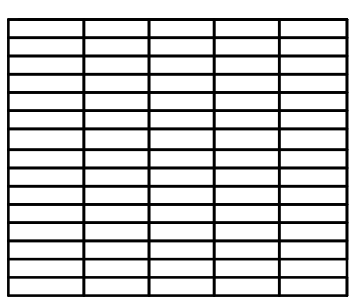

75 elementos

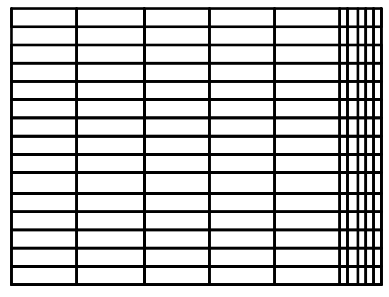

150 elementos

b) Esquema de análise dos painéis

Figura 4.21- Esquemas dos painéis e estrutura (cont.)

Os valores adotados para a resolução do exemplo estão listados a seguir.

Módulo de elasticidade longitudinal do concreto: $\mathrm{E}_{\mathrm{c}}=31,30 \mathrm{GPa}$

$\Rightarrow$ Módulo de elasticidade longitudinal do aço: $\mathrm{E}_{\mathrm{c}}=210 \mathrm{GPa}$

$\Rightarrow$ Coeficiente de Poison do concreto: $v=0,25$

$\Rightarrow$ Coeficiente de Poison do aço: $v=0,3$

$\Rightarrow$ Áreas das seções transversais das vigas $200 \mathrm{mmx} 400 \mathrm{~mm}$ e pilares $600 \mathrm{~mm} 600 \mathrm{~mm}$ :

$\mathrm{A}_{\mathrm{v}}=0,0800 \mathrm{~m} 2 ; \mathrm{Ap}=0,36 \mathrm{~m}^{2}$

$\Rightarrow$ Momentos de inércia das vigas $\left(\mathrm{I}_{\mathrm{v}}\right)$ e pilares $\left(\mathrm{I}_{\mathrm{p}}\right): \mathrm{I}_{\mathrm{v}}=0,0432 \mathrm{~m}^{4} \mathrm{I}_{\mathrm{p}}=0,00521 \mathrm{~m}^{4}$

$\Rightarrow$ Espessura do painel, se considerado maciço: $\mathrm{e}=18 \mathrm{~cm}$

$\Rightarrow$ Carregamento de vento: $\mathrm{q}=0,8 \mathrm{kN} / \mathrm{m}^{2}$

Inicialmente, foi feita uma avaliação do comportamento da estrutura, considerando o pórtico formado pelos pilares e vigas sem a consideração dos painéis. Em seguida, analisou-se o deslocamento no topo para os casos de excentricidade da ligação de 200mm, 50mm e 10mm. Além dos deslocamentos, foram analisados, para as três excentricidades, os esforços nas ligações, bem como as tensões nos painéis devidas às ações laterais e variações volumétricas.

Para a ação 1, adotou-se a ação do vento igual a da Figura 4.21.a).

Para a ação 2 , adotou-se uma variação térmica de $-35^{\circ} \mathrm{C}$, conforme exemplo anterior, a fim de englobar os efeitos da temperatura da atmosfera, retração e fluência. 


\subsubsection{Análise dos deslocamentos}

Para a análise dos deslocamentos, considerou-se a ação de vento incidindo no plano do painel.

Analisou-se a estrutura de vários pavimentos, conforme dito anteriormente, sem os painéis de fechamento, e, em seguida, considerando sua interação com a estrutura principal. Os resultados estão apresentados na Tabela 4.13 que ilustra, para cada análise, uma descrição dos elementos finitos utilizados, bem como seu respectivo deslocamento referente ao topo, para a ação 1 .

Os resultados encontrados mostram que, como seria de esperar, o grau de restrição promovido pelos painéis de fechamento é desprezível, pois o deslocamento horizontal no topo dos pilares praticamente não foi afetado, principalmente em virtude do tipo de ligação escolhida, extremamente deformável.

A Figura 4.22 mostra a variação do deslocamento horizontal no topo do pilar em função do comprimento do pino da ligação, para o carregamento 1 (vento). Observa-se que a redução do comprimento do pino diminui a deformabilidade da ligação, promovendo um enrijecimento da estrutura, frente às ações laterais, o que reflete uma redução no deslocamento no topo do pilar.

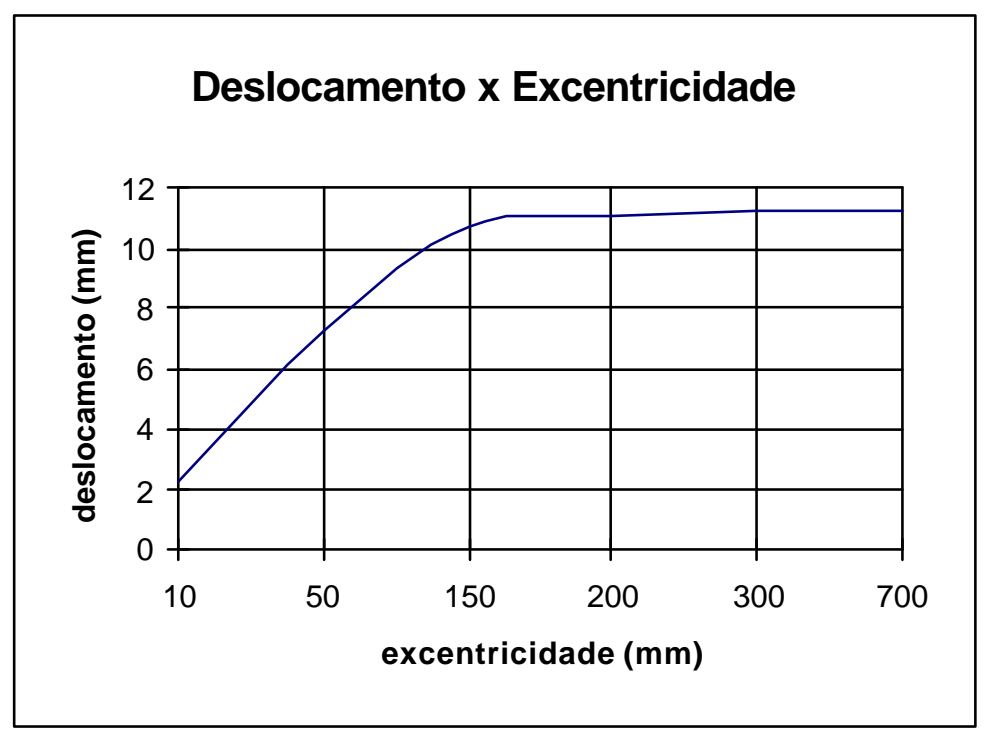

Figura 4.22- Representação da excentricidade x deslocamento 
Tabela 4.13- Deslocamentos no topo do pilar com a descrição dos elementos utilizados para todos os casos

\begin{tabular}{|c|c|c|c|c|c|}
\hline \multirow{2}{*}{\multicolumn{2}{|c|}{ Análises }} & \multirow{3}{*}{\begin{tabular}{|c|}
$\mathbf{a}_{\text {topo }}(\mathbf{m m})$ \\
11,24 \\
\end{tabular}} & \multicolumn{3}{|c|}{ "Descrição } \\
\hline & & & painel & estrutura & ligação \\
\hline pórtico sem o painel & 1 & & - & $\begin{array}{c}\text { BEAM } \\
\text { (viga) }\end{array}$ & - \\
\hline $\begin{array}{l}\text { modelo tridimensional com } \\
\text { painéis dispostos } \\
\text { excentricamente de } 200 \mathrm{~mm}\end{array}$ & 2 & 11,03 & $\begin{array}{c}\text { QSI4 } \\
\text { (casca) }\end{array}$ & $\begin{array}{r}\text { BMS3 } \\
\text { (viga) }\end{array}$ & $\begin{array}{c}\text { BMS3 } \\
\text { (viga) }\end{array}$ \\
\hline $\begin{array}{c}\text { estrutura completa, no plano, } \\
\text { desprezando a deformabilidade } \\
\text { das ligações }\end{array}$ & 3 & 1,05 & $\begin{array}{c}\text { QSI4 } \\
\text { (casca) }\end{array}$ & $\begin{array}{l}\text { BMS3 } \\
\text { (viga) }\end{array}$ & $\begin{array}{c}\text { BMS3 } \\
\text { (viga) }\end{array}$ \\
\hline $\begin{array}{l}\text { estrutura completa, no plano, } \\
\text { com a consideração da } \\
\text { deformabilidade das ligações }\end{array}$ & 4 & 11,03 & $\begin{array}{l}\text { QPM4 } \\
\text { (chapa) }\end{array}$ & $\begin{array}{l}\text { BEAM } \\
\text { (viga) }\end{array}$ & $\begin{array}{l}\text { JNT3 } \\
\text { (mola) }\end{array}$ \\
\hline $\begin{array}{l}\text { modelo tridimensional com } \\
\text { painéis dispostos } \\
\text { excentricamente de } 50 \mathrm{~mm}\end{array}$ & 5 & 7,31 & $\begin{array}{c}\text { QSI4 } \\
\text { (casca) }\end{array}$ & $\begin{array}{l}\text { BMS3 } \\
\text { (viga) }\end{array}$ & $\begin{array}{r}\text { BMS3 } \\
\text { (viga) }\end{array}$ \\
\hline $\begin{array}{l}\text { modelo tridimensional com } \\
\text { painéis dispostos } \\
\text { excentricamente de } 10 \mathrm{~mm}\end{array}$ & 6 & 2,21 & $\begin{array}{c}\text { QSI4 } \\
\text { (casca) }\end{array}$ & $\begin{array}{l}\text { BMS3 } \\
\text { (viga) }\end{array}$ & $\begin{array}{c}\text { BMS3 } \\
\text { (viga) }\end{array}$ \\
\hline
\end{tabular}

Conforme foi visto, variando-se o comprimento do pino, pode-se variar a rigidez da estrutura, cujo efeito pode ser aproveitado fazendo seu redimensionamento de forma a reduzir as dimensões dos pilares, assegurando uma relativa economia de material.

Tomando como referência o deslocamento horizontal no topo do pilar, pode-se reduzir a seção dos pilares de $600 \mathrm{~mm}$ x $600 \mathrm{~mm}$ para $500 \mathrm{~mm}$ x $500 \mathrm{~mm}$ com comprimento 
do pino da ligação de 50mm, ou seja, o deslocamento horizontal no topo do pilar da situação real com pilares de $600 \mathrm{~mm}$ x $600 \mathrm{~mm}$ com comprimento do pino de $200 \mathrm{~m}$ é aproximadamente igual ao de pilares de $500 \mathrm{~mm}$ x $500 \mathrm{~mm}$ com comprimento de pino de $50 \mathrm{~mm}$.

A partir daí, observa-se uma redução do volume de concreto da seção de $600 \mathrm{~mm}$ x $600 \mathrm{~mm}$ para $500 \mathrm{~mm}$ x $500 \mathrm{~mm}$ em torno de $31 \%$, mas deve-se salientar que tal redução implica também no aumento dos esforços nas ligações, o que, em alguns casos, pode inviabilizar o projeto. Deve-se analisar a relação dos custos do volume de concreto e das ligações para cada caso isolado e definir com precisão se a redução acarreta gastos menores.

Pode-se, ainda, com a diminuição da seção do pilar, obter uma redução da armadura utilizada. Portanto tem-se a partir dos resultados:

$$
\begin{aligned}
& \text { Pilar 500mm x 500mm } \\
& \left\{\begin{array}{l}
\mathrm{M}=4520,03 \mathrm{kN} \cdot \mathrm{cm} \\
\mathrm{N}=-8,13 \mathrm{kN}
\end{array}\right. \\
& \mathrm{A}_{\mathrm{s}}=5,75 \mathrm{~cm}^{2} \quad \therefore \quad 8 \phi 10\left(6,40 \mathrm{~cm}^{2}\right) \\
& \rho=\frac{A_{s}}{A_{c}}=\frac{6,4}{2500}=0,00256 \\
& \underline{\text { resulta } \rho=0,256 \%}
\end{aligned}
$$

$$
\begin{gathered}
\text { Pilar 600mm x 600mm } \\
\left\{\begin{array}{l}
\mathrm{M}=5407 \mathrm{kN} \cdot \mathrm{cm} \\
\mathrm{N}=-9,12 \mathrm{kN}
\end{array}\right. \\
A_{\mathrm{s}}=8,28 \mathrm{~cm}^{2} \quad \therefore \quad 8 \phi 12,5\left(10 \mathrm{~cm}^{2}\right) \\
\rho=\frac{\mathrm{A}_{\mathrm{s}}}{\mathrm{A}_{\mathrm{c}}}=\frac{10}{3600}=0,00278 \\
\underline{\text { resulta } \rho=0,278 \%}
\end{gathered}
$$

Portanto percebe-se que a taxa de armadura para ambas as situações é bem próxima. A redução de $31 \%$ no volume de concreto corresponde a uma redução global da ordem de $20 \%$ no custo dos pilares.

$\mathrm{O}$ redimensionamento de uma estrutura ocasiona um projeto que incorpora os painéis de fechamento trabalhando em conjunto com a estrutura principal, ou seja, os mesmos atuando como um elemento estrutural. Dessa maneira, deve-se tomar o cuidado de alterar a disposição desses elementos em futuras reformas, pois poderia acarretar a um esforço adicional na estrutura principal ,não considerado no projeto. 


\subsubsection{Análise de tensões nos painéis e de esforços nas ligações}

A partir dos deslocamentos acima, nota-se que há um enrijecimento adicional da estrutura principal quando se considera a interação dos painéis. Contudo esse enrijecimento acarreta, também, esforços nos painéis e nas ligações, geralmente não analisados.

Utilizando o software LUSAS, foram avaliados os esforços nos painéis e nas ligações desprezando-se ou não o efeito da temperatura, para os seguintes casos:

- CASO 1 - pilar 600mm x600mm com excentricidade na ligação de 200mm;

- CASO 2 - pilar 600mmx600mm com excentricidade na ligação de 50mm;

- CASO 3 - pilar 600mmx600mm com excentricidade na ligação de 10mm;

- CASO 4 - pilar 500mmx500mm com excentricidade na ligação de 50mm;

- CASO 5 - pilar 400mmx400mm com excentricidade na ligação de 10mm.

\subsubsection{Tensões nos painéis}

A seguir, nas figuras 4.22 a 4.24, estão listados os máximos valores das tensões principais nos painéis, para os casos 2 e 4, para ambas as ações. Está incorporada, ainda, no apêndice, a distribuição das tensões principais fornecida pelo software. 


\begin{tabular}{|c|c|c|c|c|c|c|c|}
\hline $\begin{array}{l}2,155 \\
0,792\end{array}$ & $\begin{array}{r}3,516 \\
-0,532\end{array}$ & $\begin{array}{l}-0,567 \\
3,533\end{array}$ & $\begin{array}{l}3,542 \\
-0,569\end{array}$ & $\begin{array}{l}-0,567 \\
3,552\end{array}$ & $\begin{array}{r}3,558 \\
-0,568\end{array}$ & $\begin{array}{l}0,774 \\
4,048\end{array}$ & \\
\hline 2,144 & 3,434 & $-0,5621$ & 3,464 & $-0,560$ & 3,487 & $-0,521$ & 0,994 \\
\hline 0,772 & $-0,528$ & 3,457 & $-0,563$ & 3,482 & $-0,561$ & 3,497 & 2,081 \\
\hline 2,042 & 3,217 & $-0,534$ & 3,250 & $-0,531$ & 3,277 & $-0,493$ & 0,936 \\
\hline 0,72 & $-0,502$ & 3,244 & $-0,535$ & 3,274 & $-0,532$ & 3,293 & 1,968 \\
\hline 1,786 & 2,744 & $-0,465$ & 2,787 & $-0,461$ & 2,816 & 0,426 & 0,805 \\
\hline 0,61 & $=-0,440$ & 1,343 & $-0,465$ & 2,817 & $-0,460$ & 2,836 & $=1,700$ \\
\hline 1,132 & 1,974 & $-0,337$ & 1,994 & $-0,331$ & 1,974 & $-0,305$ & 0,574 \\
\hline 0,447 & $-0,318$ & 2,010 & $-0,334$ & 2,021 & $-0,318$ & 2,028 & 1,213 \\
\hline 0,523 & 0,804 & $-0,133$ & 0,799 & $-0,130$ & 0,797 & $-0,119$ & 0,226 \\
\hline 0,187 & $-0,124$ & 0,816 & $-0,130$ & 0,807 & $-0,128$ & 0,800 & 0,472 \\
\hline
\end{tabular}

Figura 4.22-Valores extremos das tensões principais em $\mathrm{kPa}$ : ação 1, pilares $600 \times 600 \mathrm{~mm}^{2}$, comprimento de pino de $200 \mathrm{~mm}$

\begin{tabular}{|c|c|c|c|c|c|c|c|}
\hline 102,1 & 84,0 & $-13,68$ & 85,32 & $-13,68$ & 86,06 & $-13,60$ & \\
\hline 52,94 & $-12,75$ & 84,92 & $-13,74$ & 85,32 & $-13,80$ & 86,00 & \\
\hline 106,39 & 85,89 & $-14,20$ & 87,0 & $-14,15$ & 87,46 & $-13,07$ & 60,46 \\
\hline 54,15 & $-13,24$ & 86,9 & $-14,23$ & 87,51 & $-14,15$ & 87,29 & 106,4 \\
\hline 108,8 & 86,7 & $-14,46$ & 88,1 & $-14,38$ & 88,8 & $-13,27$ & 61,46 \\
\hline 54,74 & $-13,52$ & 87,98 & $-14,48$ & 88,70 & $-14,40$ & 88,75 & 108,1 \\
\hline 102,54 & 80,7 & $-13,64$ & 82,29 & $-13,54$ & 83,03 & $-12,48$ & 57,55 \\
\hline 50,59 & $-12,80$ & $=82,24$ & $-13,66$ & $=83,01$ & $-13,56$ & 83,08 & $=101,7$ \\
\hline 82,16 & 63,3 & $-10,75$ & 64,22 & $-10,60$ & 64,6 & $-9,72$ & 44,74 \\
\hline 128,4 & $-10,80$ & 64,69 & $-10,70$ & 64,94 & $-10,58$ & 64,74 & 79,17 \\
\hline 35,51 & 28,2 & $-4,63$ & 28,1 & $-4,53$ & 28,03 & $-4,35$ & 19,15 \\
\hline 18,61 & $-4,32$ & 28,69 & $-4,58$ & 28,42 & $-4,53$ & 27,91 & 33,81 \\
\hline
\end{tabular}

Figura 4.23- Valores extremos das tensões principais máximas em $\mathrm{kPa}$ ação 1 pilares $500 \times 500 \mathrm{~mm}^{2}$, comprimento de pino de $50 \mathrm{~mm}$ 


\begin{tabular}{|c|c|c|c|c|c|c|c|}
\hline $\begin{array}{r}480 \\
4670\end{array}$ & $\begin{array}{c}6890 \\
\text { । } \\
690\end{array}$ & $\begin{array}{l}740 \\
730\end{array}$ & $\begin{array}{c}740 \\
730 \\
\end{array}$ & $\begin{array}{l}7120 \\
710\end{array}$ & $\begin{array}{r}730 \\
1 \\
\quad 1 \\
690 \\
\end{array}$ & $\begin{array}{r}730 \\
720 \\
\end{array}$ & \\
\hline 480 & 690 & 720 & & 720 & 720 & 700 & 510 \\
\hline 470 & 690 & 710 & 720 & 720 & 730 & 690 & 480 \\
\hline 480 & 680 & 710 & 710 & 710 & 720 & 670 & 500 \\
\hline 450 & 680 & 700 & 710 & 710 & 700 & 690 & 470 \\
\hline 420 & 600 & 690 & 690 & 690 & 690 & 610 & 440 \\
\hline$=410$ & $=600$ & 690 & $=690$ & $=690$ & $\begin{aligned} & 11 \\
= & 690\end{aligned}$ & $=610$ & $=\begin{array}{r}\text { I } \\
=430\end{array}$ \\
\hline 440 & 680 & 700 & $710^{\prime}$ & 710 & 700 & 680 & 460 \\
\hline$=490$ & $660^{\prime}$ & $=720$ & $=710^{\prime}$ & 710 & 720 & $=670$ & $=510$ \\
\hline 480 & 720 & 740 & 750 & 750 & 740 & 720 & 500 \\
\hline 510 & $710^{\prime}$ & 760 & $750^{\prime}$ & 750 & $\begin{array}{c}11 \\
760\end{array}$ & 710 & $\begin{array}{r}1 \\
530\end{array}$ \\
\hline
\end{tabular}

Figura 4.24- Valores máximos das tensões em kPa; ação 2, pilares 500x500 $\mathrm{mm}^{2}$, comprimento de pino de $50 \mathrm{~mm}$

Pode-se notar na distribuição das tensões principais, que a maior concentração das tensões ocorre nos pontos de ligações.

A tensão de tração, de acordo com a NBR1, é de 2,2 MPa. Pelas figuras exibidas pode-se perceber que a maior tensão de tração encontrada para todos os casos não ultrapassa o valor dado em norma para a situação real.

\subsubsection{Esforços resultantes nas ligações}

Os máximos esforços resultantes, obtidos para os casos 2 e 4 estão ilustrados nas Figuras 4.25 a 4.27. Para o máximo esforço resultante deve-se verificar se o mesmo ultrapassa a capacidade última da ligação. Deve-se salientar que os valores obtidos representam a soma vetorial das duas componentes no plano. Os outros casos podem ser encontrados no apêndice. 
A resistência da ligação é governada pela resistência do pino de aço e pela resistência do concreto junto ao inserto metálico. A resistência característica da ligação medida em ensaio foi de $23 \mathrm{kN}$, indicando que existe elevado nível de segurança na ligação uma vez que os esforços solicitantes são bastante inferiores.

Portanto chega-se, adotando a ligação totalmente engastada, a uma estimativa de sua resistência:

resistência ao cisalhamento:

- $\mathrm{R}_{\mathrm{d}}=\phi_{\mathrm{v}} \cdot 0,75 \cdot \mathrm{A}_{\mathrm{p}} \cdot \mathrm{f}_{\mathrm{u}} \quad \Rightarrow \quad \mathrm{R}_{\mathrm{d}}=0,60 \cdot 0,75 \cdot 1,23 \cdot 41,5=22,97 \mathrm{kN}$

- resistência característica medida em ensaio: $23 \mathrm{kN}$

onde

$\mathrm{R}_{\mathrm{d}}=$ resistência de cálculo

$\phi_{\mathrm{v}}=0,60$

$\mathrm{A}_{\mathrm{p}}=$ área bruta do pino

$\mathrm{f}_{\mathrm{u}}=$ tensão de escoamento do material

A resistência será a menor delas : $22,97 \mathrm{kN}$

resistência à flexão: o máximo momento obtido nas análises é $1,5 \mathrm{kN}$.cm. Portanto tem-se:

$$
\begin{aligned}
& \mathrm{f}=\frac{\mathrm{M}}{\mathrm{Z}} \leq 0,9 \cdot \mathrm{f}_{\mathrm{u}}=37,5 \mathrm{kN} / \mathrm{cm}^{2} \\
& \mathrm{f}=\frac{10}{1,61}=7,89 \mathrm{kN} / \mathrm{cm}^{2} \quad<37,5 \text { OK!!! }
\end{aligned}
$$

onde

$$
\mathrm{f}=\text { tensão à flexão }
$$

$\mathrm{M}=$ momento no pino

$Z=$ momento estático dada por $\pi \cdot r^{3} / 4$

$\mathrm{f}_{\mathrm{u}}=$ tensão de escoamento do material 
Com exceção da ação 2, que eleva bastante os valores dos esforços, pode-se notar que, para os casos analisados, os esforços transmitidos estão dentro do permitidos.Quando se tem comprimento de pino de $50 \mathrm{~mm}$ e pilar de seção $500 \mathrm{~mm} \mathrm{x}$ $500 \mathrm{~mm}$, os esforços ultrapassam o valor limite de $22,97 \mathrm{kN}$, mas ficam bem próximos dele. Para a situação crítica de comprimento de pino de $10 \mathrm{~mm}$, os esforços são extremamente altos.



Figura 4.25- Esforços de cisalhamento em $\mathrm{kN}$ : ação 1, pilares $600 \times 600 \mathrm{~mm}^{2}$, comprimento de pino de $200 \mathrm{~mm}$ 


\begin{tabular}{|c|c|c|c|}
\hline $\begin{array}{l}3,08 \{ }_{3}^{2,98} \\
3,01 \backslash{ }_{3,05}\end{array}$ & $\begin{array}{l}3,04 \backslash{ }_{3,00}^{3,05} \\
2,99 \\
\end{array}$ & $\begin{array}{l}3,05 \backslash \nearrow_{3,02} \\
3,00 \backslash \searrow^{3,06}\end{array}$ & $\begin{array}{l}3,02 \\
3,00\end{array}$ \\
\hline $3,20 \backslash \nearrow_{3,05}$ & $3,15^{\prime}$ & $3,14^{r}$ & 3,13 \\
\hline $3,08 \searrow \searrow 3,16$ & $\searrow 3,16$ & 3,14 & 3,09 \\
\hline $3,27 \backslash \nearrow_{3,08}$ & 3,21 & $3,19^{\nwarrow}$ & 3,18 \\
\hline $3,12 \swarrow$ & $3,10 \swarrow \searrow 3,21$ & 3,12 & 3,14 \\
\hline 3,07 & $3,03^{\top}$ & $3,01^{r}$ & 2,99 \\
\hline 2,89 & 2,90 & 2,92 & 2,93 \\
\hline $2,45^{K}$ & 2,38 & $2,36^{K}$ & 2,33 \\
\hline $2,30 \swarrow$ & 2,28 & $2,29 \swarrow$ & $2,29 k$ \\
\hline $1,07 \backslash \nearrow_{1,00}$ & 1,03 & 1,01 & 1,00 \\
\hline $1,00 \swarrow \searrow 1,03$ & $1,01 \swarrow \searrow 1,02$ & $1,00 \swarrow \searrow 1,00$ & 0,99 ๙ \\
\hline
\end{tabular}

Figura 4.26- Esforços de cisalhamento em $\mathrm{kN}$ : ação 1, pilares $500 \times 500 \mathrm{~mm}^{2}$, comprimento de pino de $50 \mathrm{~mm}$

\begin{tabular}{|c|c|c|}
\hline $20,9 \searrow \begin{array}{l}20,0 \\
20,3\end{array}$ & 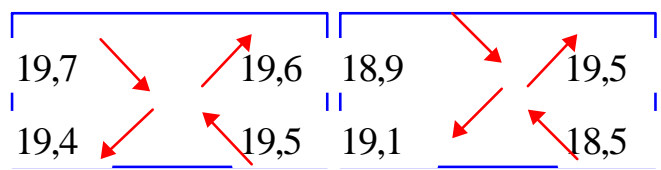 & $\begin{array}{l}20,2 \\
20,2\end{array}$ \\
\hline $\begin{array}{l}20,7 \searrow \begin{array}{l}20,2 \\
20,2\end{array}{ }_{20,4} \\
\end{array}$ & 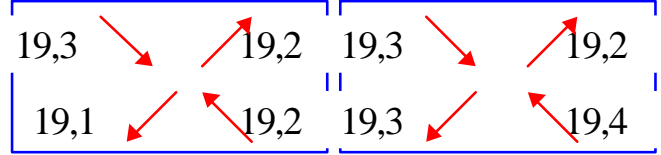 & $\begin{array}{l}20,5 \\
20,2\end{array}$ \\
\hline \begin{tabular}{|l}
$20,8 \searrow>19,8$ \\
19,4 \\
\hdashline 20,2
\end{tabular} & 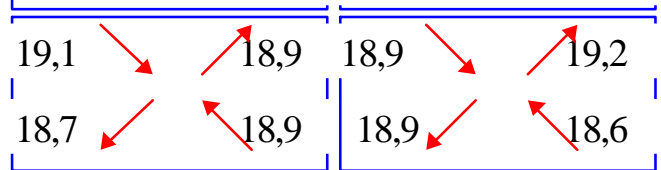 & $\begin{array}{l}19,6 \\
20,2\end{array}$ \\
\hline 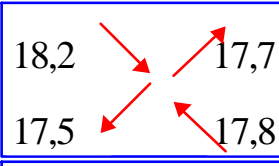 & 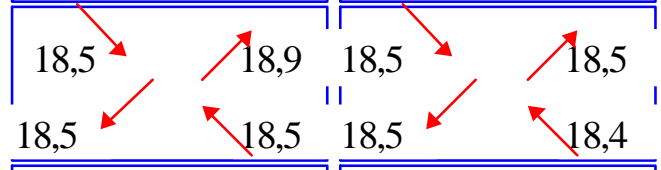 & $\begin{array}{l}17,9 \\
17,9 \\
\end{array}$ \\
\hline $\begin{array}{l}18,5 \searrow \begin{array}{r}20,3 \\
19,4\end{array} \\
21,4\end{array}$ & $\begin{array}{l}18,6 \searrow \begin{array}{ll}19,0 & 19,0 \\
19,4 & \\
19,0 & 19,0\end{array} \\
19\end{array}$ & $\begin{array}{l}18,5 \\
21,4\end{array}$ \\
\hline $20,2 \searrow \frac{21,4}{20,7}$ & 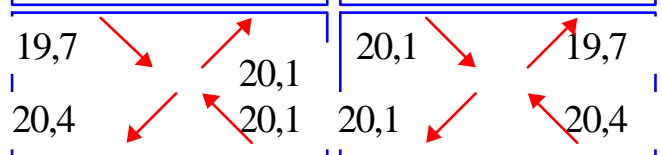 & $\begin{array}{l}21,4 \\
20,7\end{array}$ \\
\hline
\end{tabular}

Figura 4.27- Esforços de cisalhamento em kN; ação 2, pilares 500x500 $\mathrm{mm}^{2}$, comprimento de pino de $50 \mathrm{~mm}$ 
A partir de todos os resultados dos esforços relacionados acima, pode-se construir uma tabela que visualize um resumo dos mesmos. A partir da Tabela 4.14, observa-se que:

$\Rightarrow$ tantos os esforços nas ligações como as tensões principais são aproximadamente iguais, quando se passa de pilares de $600 \mathrm{~mm}$ x $600 \mathrm{~mm}$, com pino de comprimento de $50 \mathrm{~mm}$ e de pilares de $500 \times 500 \mathrm{~mm}$, com pino de comprimento $50 \mathrm{~mm}$. Assim, podem ser estendidas as mesmas considerações com relação à resistência da ligação e do dimensionamento dos painéis, que não deve significar sensíveis diferenças nos custos dessas partes;

$\Rightarrow$ os esforços nas ligações aumentam com a redução do comprimento do pino;

$\Rightarrow$ pelos valores indicados na Tabela 4.14, tem-se que os esforços e as tensões principais crescem com a redução do comprimento, de forma diferente nas duas ações. Com a ação 2, o crescimento desses parâmetros é bastante acentuado, devido à variação volumétrica dos painéis; e

$\Rightarrow$ para comprimento de pino de $10 \mathrm{~mm}$, os esforços na ligações são superiores aos valores de resistência, embora as tensões principais indicassem que não haveria dificuldades em dimensionar os painéis para a situação em questão. 


\begin{tabular}{|c|c|c|c|c|c|}
\hline Situação & $\begin{array}{c}\text { Deslocamento } \\
\text { devido às ações } \\
\text { laterais (mm) }\end{array}$ & $\begin{array}{c}\text { esforços nas ligações } \\
\text { sem a temperatura e } \\
\text { retração }(\mathrm{kN})\end{array}$ & $\begin{array}{c}\text { tensões nos painéis sem } \\
\text { a temperatura e } \\
\text { retração } \\
\left(\mathrm{kN} / \mathrm{m}^{2}\right)\end{array}$ & $\begin{array}{c}\text { esforços nas ligações } \\
\text { devido a temperatura e } \\
\text { retração }(\mathrm{kN})\end{array}$ & $\begin{array}{c}\text { tensões nos painéis } \\
\text { devido a temperatura e } \\
\text { retração } \\
\left(\mathrm{kN} / \mathrm{m}^{2}\right)\end{array}$ \\
\hline $\begin{array}{c}\text { pilares } 600 \mathrm{mmx} 600 \mathrm{~mm} \\
\text { ligação e=200mm }\end{array}$ & 11,03 & $\begin{array}{c}\text { plano : } \mathbf{0 , 0 9 8} \\
\text { fora do plano : } \mathbf{0 , 0 9 8}\end{array}$ & $\begin{array}{c}\text { plano : } \mathbf{6 , 5 6} \\
\text { fora do plano : } \mathbf{6 , 5 6}\end{array}$ & $\begin{array}{c}\text { plano : } \mathbf{0 , 3 0} \\
\text { fora do plano : } \mathbf{0 , 4 3}\end{array}$ & $\begin{array}{c}\text { plano :9,75 } \\
\text { fora do plano : 10,85 }\end{array}$ \\
\hline $\begin{array}{c}\text { pilares } 600 \mathrm{~mm} \times 600 \mathrm{~mm} \\
\text { ligação e=50mm }\end{array}$ & 7,31 & 2,30 & 60,45 & 6,80 & 224,86 \\
\hline $\begin{array}{c}\text { pilares } 600 \mathrm{mmx} 600 \mathrm{~mm} \\
\text { ligação e=10mm }\end{array}$ & 2,21 & 5,20 & 214,47 & 45,6 & 1391,15 \\
\hline $\begin{array}{c}\text { pilares } 500 \mathrm{~mm} \times 500 \mathrm{~mm} \\
\text { ligação e }=50 \mathrm{~mm}\end{array}$ & 11,15 & 3,14 & 88,81 & 7,81 & 251,77 \\
\hline $\begin{array}{c}\text { pilares } 400 \mathrm{mmx} 400 \mathrm{~mm} \\
\text { ligação e=10mm }\end{array}$ & 3,02 & 10,1 & 350,54 & - & - \\
\hline
\end{tabular}

Tabela 4.14 - Resumo de tensões, deslocamentos e esforços nas ligações para os casos analisados 


\section{Considerações finais e conclusões}

Em geral, os elementos de fechamento não são considerados no enrijecimento da estrutura; no entanto foi visto que tal efeito é considerável podendo ser incorporado ao projeto. Para estruturas pré-moldadas, mesmo em pequenas alturas, têm-se, em decorrência do tipo de ligação entre elementos, pouca rigidez e significativos efeitos globais de segunda ordem. Nesses casos, os painéis de fechamento desempenham um importante papel no enrijecimento da estrutura principal.

As principais conclusões gerais, a respeito da influência do painel de fechamento, listam-se a seguir:

a) os painéis de fechamento de concreto pré-moldado podem ser incluídos numa estratégia de projeto para resistência da estrutura às ações laterais;

b) a partir da consideração da interação entre painéis de fechamento com a estrutura principal pode-se obter uma redução nas solicitações da estrutura principal, variando a deformabilidade da ligação; 
c) o aumento do enrijecimento da estruturas pelos painéis de fechamento acarreta um aumento nos esforços nas ligações e nas solicitações dos painéis, sendo que os esforços nas ligações são mais críticos;

d) mesmo painéis com aberturas, com menores espessuras, e nervuras contribuem efetivamente no enrijecimento, conforme se mostrou no primeiro exemplo;

e) da análise do painel isolado, nota-se que ocorre uma diferença significativa dos deslocamentos no topo, para as situações do painel no plano, e fora dele;

f) na estrutura de um único pavimento analisada, a consideração de interação possibilita a passagem de situação em que os efeitos globais de segunda ordem são relevantes para aquela em que tais efeitos são desprezíveis. Para a estrutura analisada de vários pavimentos, a consideração de interação resulta em significativas economias de materiais; e

g) mediante a estratégia de projeto de considerar os painéis de fechamento na resistência das ações laterais, podem ser atingidas significativas economias globais, a partir do redimensionamento dos pilares, levando, com isso, a estruturas mais econômicas. No exemplo desenvolvido, esta economia é da ordem de $20 \%$ no custo dos pilares.

Como prolongamento desta pesquisa, pode-se desenvolver tanto um método prático e rápido que incorpore a interação dos painéis sem a utilização de quaisquer recursos computacionais, como avaliar o efeito de enrijecimento, considerando o comportamento nãolinear do concreto. 


\section{REFERÊNCIAS BIBLIOGRÁFICAS}

ASSOCIAÇÃO BRASILEIRA DA CONSTRUÇÃO INDUSTRIALIZADA (1986).

Manual técnico de pré-fabricados de concreto. São Paulo, ABCI/ Projeto.

BELLEI, I. H. (1994). Edifícios industriais em aço. São Paulo, Pini. p.53-76.

BLJUGER, F. E. (1988). Design of precast concrete structures. Chichester, England, Ellis Horwood.

CHARNEY, F. A. ; HARRIS J. R. (1989). The effect of architectural precast concrete cladding on the lateral response of multistory buildings. In: INTERNATIONAL SYMPOSIUM ON ARCHITECTURAL PRECAST CONCRETE CLADDING: ITS CONTRIBUTION TO LATERAL RESISTANCE OF BUIDINGS, Chicago, USA, 8-9 Nov.Proceedings.

EL DEBS, M. K. (1996). Estruturas pré-moldadas de concreto. São Carlos, EESC - USP. ( Notas de aula da disciplina “SET 861 - Estruturas pré-moldadas de concreto") 
FEDERATION INTERNATIONALE DE LA PRECONTRAINTE (1982). The design, manufacture and erection of architectural concrete elements: guide to good practice. FIP

FERREIRA, M. A. (1993). Estudo de deformabilidades de ligações para a análise linear em pórticos planos de elementos pré-moldados de concreto. São Carlos. 166p. Dissertação (Mestrado) - Escola de Engenharia de São Carlos, Universidade de São Paulo.

GAIOTTI, R. ; STAFFORD SMITH, B. (1993). Effect of precast cladding on the wind load response of tall building structures. PCI Journal, v.38, n.2, p. $72-84$.

GAIOTTI, R. ; STAFFORD SMITH, B. (1992). Stiffening of moment-resisting frame by precast concrete cladding. PCI Journal, v.37, n.5, p. 80-92.

GAIOTTI, R. (1990). Interactive Effects of non-structural elements on the behaviour of tall building structures. Ottawa. 360 p. Doctor degree thesis - University of Canadá.

GOODNO, B. J. ; CRAIG, J. I. (1989). Historical overview of studies on contribution of cladding to lateral resistance of buildings. In: INTERNATIONAL SYMPOSIUM ON ARCHITECTURAL PRECAST CONCRETE CLADDING: ITS CONTRIBUTION TO LATERAL RESISTANCE OF BUIDINGS, Chicago, USA, 8-9 Nov.Proceedings.

GOODNO, B. J. ; PALSSON, H. (1986). Analitycal studes of building cladding. Journal of Structural Engineering, v.112, n.4, p. 665-676. 
HENRY, R. M. ; ROLL. F. (1986). Cladding-frame interation. Journal of Structural Engineering, v.112, n.4, p. 815-834.

KONCZ, T. (1975). Manual de la construccion prefabricada. Madrid, Hermann Blume.

LUSAS (1995). Finite element analysis system: user manual, versão 11.0. Kingston upon Thames, UK, FEA - Finite element analysis.

MILLER, C. J. (1972). Analysis of multistory frames with light gauge steel panel infills. Ithaca, School of Civil and Environmental Engineering Cornell Universty, Departament of Sctrutural Engineering. Report nㅜㅜㄴ.

OLIN, J. ; HAKKARAINEN, T.; RAMA, M. (1985). Connections and joints between precast concrete units. Espoo, Julkaisija-Utgivare.

PHILLIPS, W. R.; SHEPPARD, D. A. (1988). Plant-cast precast and prestressed concrete: a design guide. 3. ed. Mcgraw-Hill.

PRESTRESSED/PRECAST CONCRETE INSTITUTE (1988). Design and typical details of connections for precast and prestressed concrete. Chicago, PCI.

PRESTRESSED/PRECAST CONCRETE INTITUTE (1992). PCI design handbook: precast and prestressed concrete. Chicago, PCI.

PRESTRESSED/PRECAST CONCRETE INSTITUTE (1989). PCI manual for structural design and architectural precast concrete. Chicago, PCI. 
PUBAL, Z. (1986). Theory and calculation of frame structures with stiffening walls. Prague, Czechoslovakia, Elsevier.

TAYLOR, H. P. J. (1992). Precast concrete cladding. London, Edward Arnold.

VASCONCELOS, A . C. (1988). O desenvolvimento da pré-fabricação no Brasil. Revista Politécnica, v.200. 


\section{LISTA DE FIGURAS}

FIGURA 1- Valores extremos das tensões principais máximas (S1) e mínimas (S3) para o painel maciço desprezando a estrutura principal; unidades em $\mathrm{kN} / \mathrm{cm} 2$; Exemplo de painel isolado

FIGURA 2- Valores extremos das tensões principais máximas (S1) e mínimas (S3) para o painel maciço com aberturas desprezando a estrutura principal; unidades em $\mathrm{kN} / \mathrm{cm} 2$; Exemplo de painel isolado

FIGURA 3- Valores extremos das tensões principais máximas (S1) e mínimas (S3) para o painel maciço com nervuras e sem aberturas desprezando a estrutura principal; unidades em $\mathrm{kN} / \mathrm{cm} 2$; Exemplo de painel isolado.

FIGURA 4- Valores extremos das tensões principais máximas (S1) e mínimas (S3) para o painel maciço caso da estrutura fora do plano estrutura principal; unidades em $\mathrm{kN} / \mathrm{cm} 2$; Exemplo de painel isolado

FIGURA 5- Valores extremos das tensões principais máximas (S1) e mínimas (S3) para o painel maciço sem nervuras e com aberturas caso da estrutura fora do plano; unidades em $\mathrm{kN} / \mathrm{cm} 2$; Exemplo de painel isolado..... 06

FIGURA 6- Valores extremos das tensões principais máximas (S1) e mínimas (S3) para o painel maciço caso da estrutura no plano; unidades em $\mathrm{kN} / \mathrm{cm} 2$; Exemplo de painel isolado

FIGURA 7- Valores extremos das tensões principais máximas (S1) e mínimas (S3) para o painel maciço com nervuras e caso da estrutura no plano; unidades em $\mathrm{kN} / \mathrm{cm} 2$; Exemplo de painel isolado.

FIGURA 8- Valores extremos das tensões principais máximas (S1) e mínimas (S3) para o painel sem nervuras e com aberturas caso da estrutura no plano; unidades em $\mathrm{kN} / \mathrm{cm} 2$; Exemplo de painel isolado 
FIGURA 9- Valores extremos das tensões principais para a ação 1; caso no plano sem ligações entre painéis; direção y; unidades em kN/cm2; Exemplo de estrutura de um único pavimento .................................... 10

FIGURA 10- Valores extremos das tensões principais para a ação 2; caso no plano sem ligações entre painéis; direção y; unidades em kN/cm2; Exemplo de estrutura de um único pavimento

FIGURA 11- Valores extremos das tensões principais para a ação 1; caso no plano com ligações entre painéis; direção y; unidades em kN/cm2; Exemplo de estrutura de um único pavimento

FIGURA 12- Valores extremos das tensões principais para a ação 2; caso no plano com ligações entre painéis; direção y; unidades em kN/cm2; Exemplo de estrutura de um único pavimento

FIGURA 13- Valores extremos das tensões principais para a ação 1; caso fora do plano com ligações entre painéis; direção y; unidades em kN/cm2; Exemplo de estrutura de um único pavimento

FIGURA 14- Valores extremos das tensões principais para a ação 2 ; caso fora do plano com ligações entre painéis; direção y; unidades em kN/cm2; Exemplo de estrutura de um único pavimento

FIGURA 15- Valores extremos das tensões principais para a ação 1; caso fora do plano sem ligação entre painéis; direção $\mathrm{x}$; unidades em $\mathrm{kN} / \mathrm{cm} 2$; Exemplo de estrutura de um único pavimento

FIGURA 16- Valores extremos das tensões principais para a ação 1; fora do plano; comprimento de pino de $200 \mathrm{~mm}$; pilar de seção $600 \mathrm{~mm}$ x 600mm; unidades em $\mathrm{kN} / \mathrm{cm} 2$; Exemplo de estrutura de vários pavimentos.

FIGURA 17- Valores extremos das tensões principais para a ação 1; caso fora do plano; comprimento de pino de 50mm; pilar de seção 500mm x 500mm; unidades em $\mathrm{kN} / \mathrm{cm} 2$; Exemplo de estrutura de vários pavimentos. 
FIGURA 18- Valores extremos das tensões principais para a ação 2; caso fora do plano; comprimento de pino de 50mm; pilar de seção $500 \mathrm{~mm}$ x 500mm; unidades em kN/cm2; Exemplo de estrutura de vários pavimentos.

FIGURA 19- Valores extremos das tensões principais para a ação 1; caso no plano; comprimento de pino de 50mm; pilar de seção 500mm x 500mm; unidades em kN/cm2; Exemplo de estrutura de vários pavimentos.

FIGURA 20- Valores extremos das tensões principais para a ação 1; caso fora do plano; comprimento de pino de $10 \mathrm{~mm}$; pilar de seção $400 \mathrm{~mm}$ x $400 \mathrm{~mm}$; unidades em kN/cm2; Exemplo de estrutura de vários pavimentos.

FIGURA 21 - Valores extremos das tensões principais para a ação 2; caso fora do plano; comprimento de pino de $10 \mathrm{~mm}$; pilar de seção $400 \mathrm{~mm}$ x 400mm; unidades em $\mathrm{kN} / \mathrm{cm} 2$; Exemplo de estrutura de vários pavimentos.

FIGURA 22- Esforços de cisalhamento em kN: ação 1, pilares $600 \times 600 \mathrm{~mm}^{2}$, comprimento de pino de $50 \mathrm{~mm}$

FIGURA 23- Valores extremos da tensões principais em $\mathrm{kPa}$ : ação 1, pilares $600 \times 600 \mathrm{~mm}^{2}$, comprimento de pino de $50 \mathrm{~mm}$

FIGURA 24- Esforços de cisalhamento em kN: ação 1, pilares $600 \times 600 \mathrm{~mm}^{2}$, comprimento de pino de $10 \mathrm{~mm}$

FIGURA 25- Valores extremos da tensões principais em $\mathrm{kPa}$ : ação 1, pilares $600 \times 600 \mathrm{~mm}^{2}$, comprimento de pino de $10 \mathrm{~mm}$

FIGURA 26- Esforços de cisalhamento em kN: ação 1, pilares $400 \times 400 \mathrm{~mm}^{2}$, comprimento de pino de $10 \mathrm{~mm}$

FIGURA 27- Valores extremos da tensões principais em $\mathrm{kPa}$ : ação 1, pilares $400 \times 400 \mathrm{~mm}^{2}$, comprimento de pino de $10 \mathrm{~mm}$

FIGURA 28- Esforços de cisalhamento em kN: ação 2, pilares $600 \times 600 \mathrm{~mm}^{2}$, comprimento de pino de $50 \mathrm{~mm}$

FIGURA 29- Valores extremos da tensões principais em kPa: ação 2, pilares $600 \times 600 \mathrm{~mm}^{2}$, comprimento de pino de $50 \mathrm{~mm}$ 
FIGURA 30- Esforços de cisalhamento em kN: ação 2, pilares 600x600 mm², comprimento de pino de $10 \mathrm{~mm}$

FIGURA 31 - Valores extremos da tensões principais em $\mathrm{kPa}$ : ação 2, pilares $600 \times 600 \mathrm{~mm}^{2}$, comprimento de pino de $10 \mathrm{~mm}$

FIGURA 32- Esforços de cisalhamento em kN: ação 2, pilares $400 \times 400 \mathrm{~mm}^{2}$, comprimento de pino de $10 \mathrm{~mm}$.

FIGURA 33- Valores extremos da tensões principais em $\mathrm{kPa}$ : ação 2, pilares $400 \times 400 \mathrm{~mm}^{2}$, comprimento de pino de $10 \mathrm{~mm}$ 


\section{APÊNDICE}

Neste apêndice, apresentam-se a distribuição das tensões e os valores extremos das tensões nos painéis e esforços nas ligações decorrentes das ações do vento (ação 1) e variações volumétricas (ação 2), para os três exemplos analisados. As figuras 1 a 8 (representando o painel isolado), 9 a 15 (estrutura de um pavimento) e 16 a 21 (estrutura de vários pavimentos), são obtidas pela saída gráfica do "software" LUSAS. As subsequentes representam os valores extremos de tensões e esforços para os pontos de ligações dos painéis com a estrutura principal. 
CONTOURS OF $S 1$

$$
\text { A }-0.1028 E-01
$$

B $\quad 0.3172 E-02$

C $\quad 0.1662 \mathrm{E}-01$

D $0.3007 E-01$

E $\quad 0.4352 E-01$

F $\quad 0.5697 E-01$

(G) $0.7042 \mathrm{E}-01$

$0.8387 E-01$

$0.9732 E-01$

J $\quad 0.1108$

K $\quad 0.1242$

L $\quad 0.1377$

M $\quad 0.1511$

$N \quad 0.1646$

$0 \quad 0.1780$

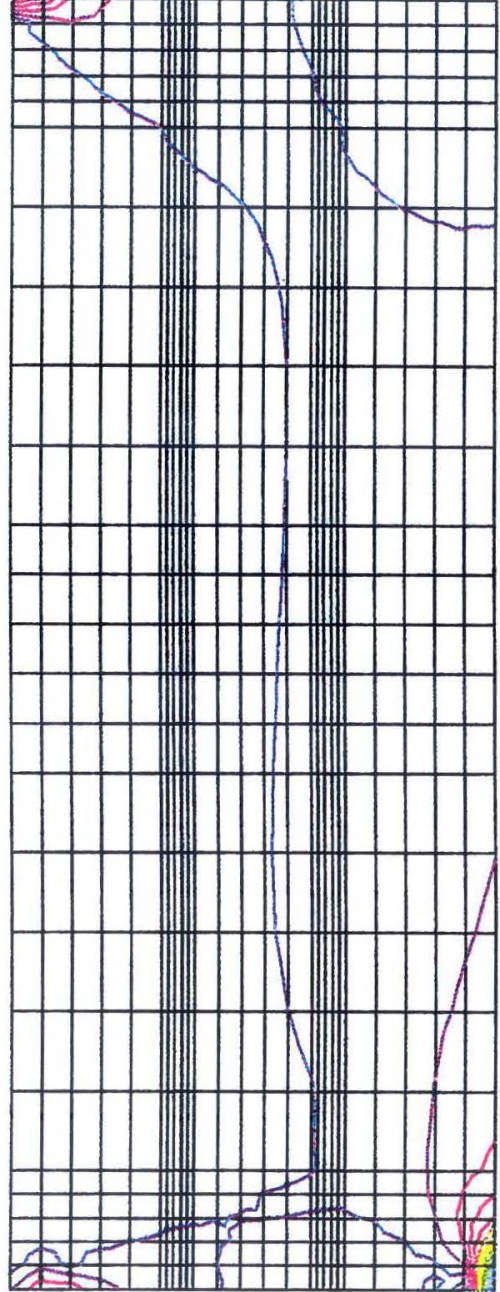

CONTOURS OF S3

A -0.1780

B -0.1646

C -0.1511

D $\quad-0.1377$

E $\quad-0.1242$

$F \quad-0.1108$

$-0.9732 E-01$

$-0.8387 E-01$

$-0.7042 E-01$

J - $0.5697 E-01$

K $\quad-0.4352 E-01$

L $\quad-0.3007 E-01$

$M \quad-0.1662 E-01$

$N \quad-0.3172 E-02$

$0 \quad 0.1028 \mathrm{E}-01$

\begin{tabular}{l}
1 \\
\hline
\end{tabular} C

Figura 1- Valores extremos das tensoes principais maximas (S1) e minimas (S3) para o painel macico desprezando a estrutura principal; unidades em kN/cm2; Exemplo de painel isolado 


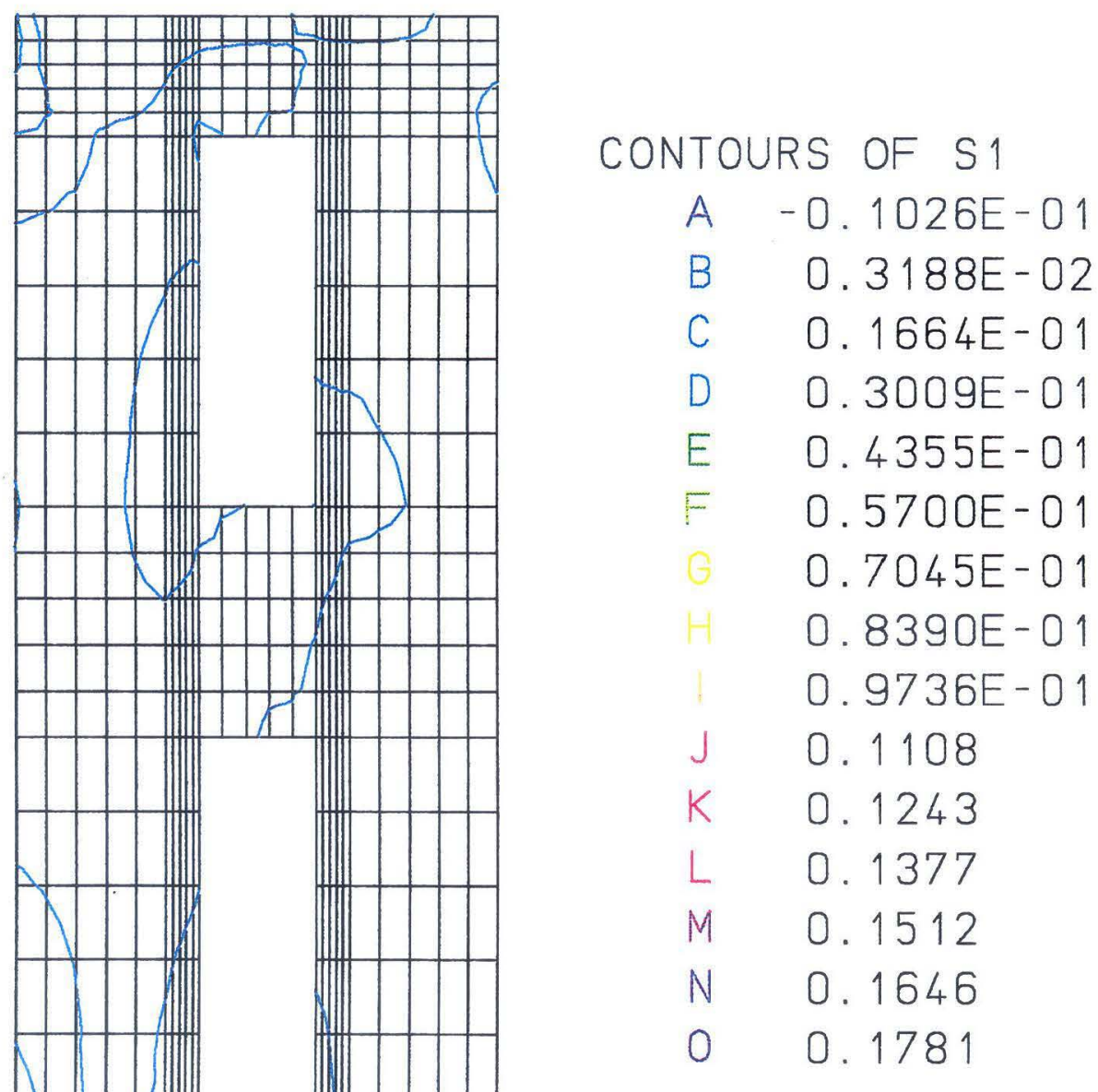

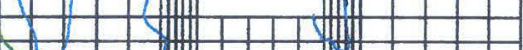

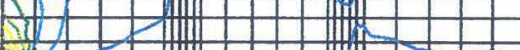
约

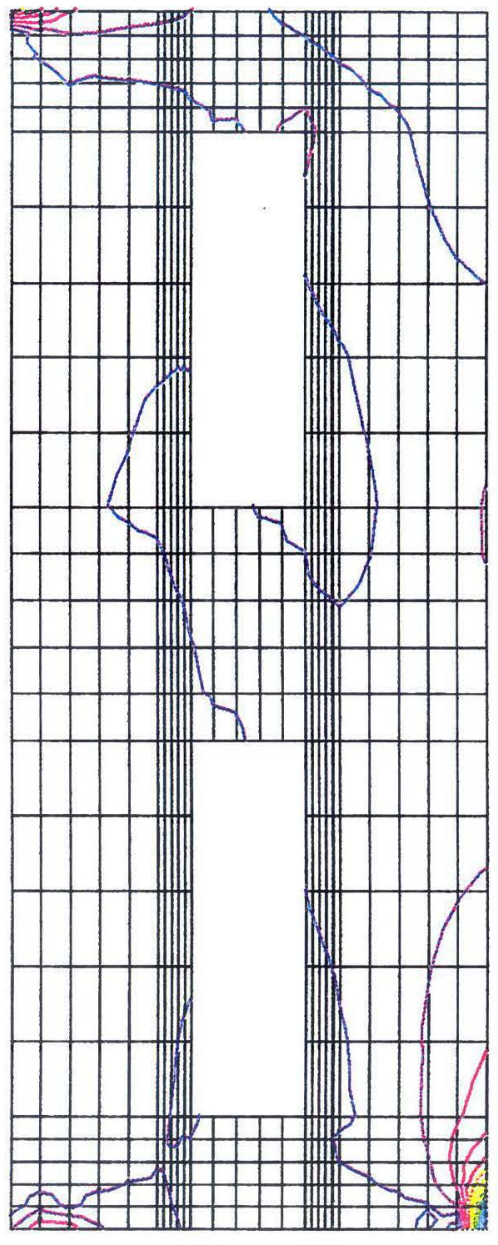

CONTOURS OF 53

$\begin{array}{ll}A & -0.1781 \\ B & -0.1646 \\ C & -0.1512 \\ D & -0.1377 \\ E & -0.1243 \\ F & -0.1108 \\ G & -0.9737 E-01 \\ H & -0.8392 E-01 \\ & -0.7048 E-01 \\ J & -0.5703 E-01 \\ K & -0.4358 E-01 \\ L & -0.3013 E-01 \\ M & -0.1669 E-01 \\ N & -0.3238 E-02 \\ O & 0.1021 E-01\end{array}$

Figura 2- Valores extremos das tensoes principais maximas (S1) e minimas (S3) para o painel macico com aberturas desprezando a estrutura principal; unidades em $\mathrm{kN} / \mathrm{cm} 2$; Exemplo de um painel isolado 


\section{CONTOURS OF $S 1$}

A -0.1028E-01

B $\quad 0.3171 \mathrm{E}-02$

C $0.1662 \mathrm{E}-01$

D $0.3007 E-01$

E $\quad 0.4352 E-01$

$F \quad 0.5697 E-01$

$0.7042 E-01$

$0.8387 E-01$

0. $9732 E-01$

J $\quad 0.1108$

K $\quad 0.1242$

L $\quad 0.1377$

M O. 0.1511

$\mathrm{N} \quad 0.1646$

O 0.1780

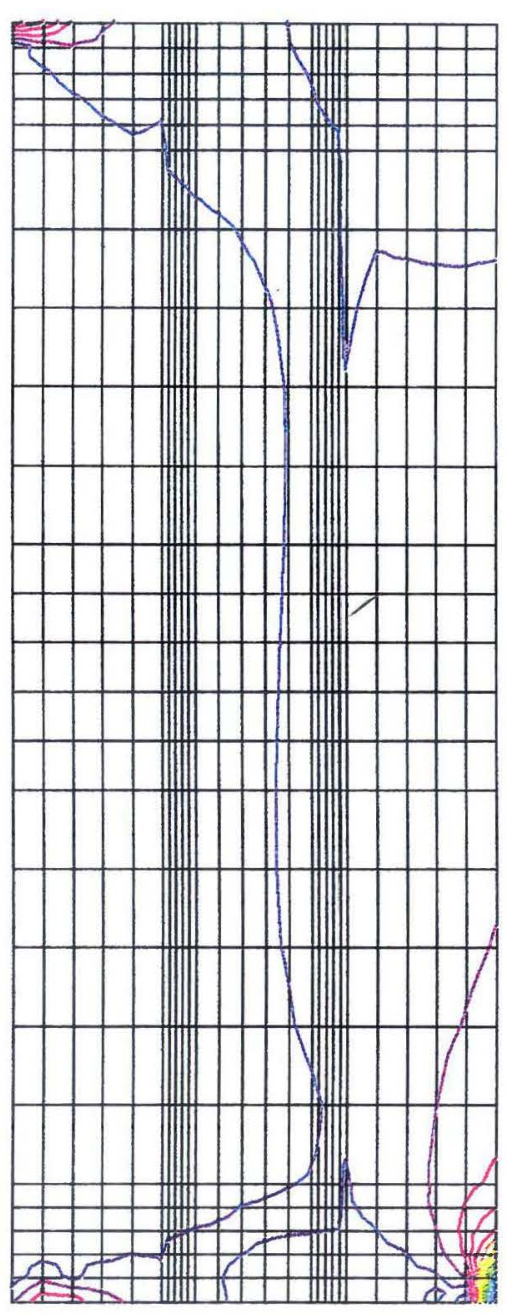

\section{CONTOURS OF S3}

A -0.1780

B -0.1646

C -0.1511

D $\quad-0.1377$

E $\quad-0.1242$

$F \quad-0.1108$

$-0.9732 E-01$

$-0.8387 E-01$

$-0.7042 E-01$

J -0.5697E-01

K - $-0.4352 E-01$

L - - 0.3007E-01

$M$ - $0.1662 E-01$

$N-0.3171 E-02$

O O. 1028E-01

Figura 3-Valores extremos das tensoes principais maximas (S1) e minimas (S3) para o painel com nervuras e sem aberturas desprezando a estrutura principal; unidades em $\mathrm{kN} / \mathrm{cm} 2$; Exemplo de painel isolado 

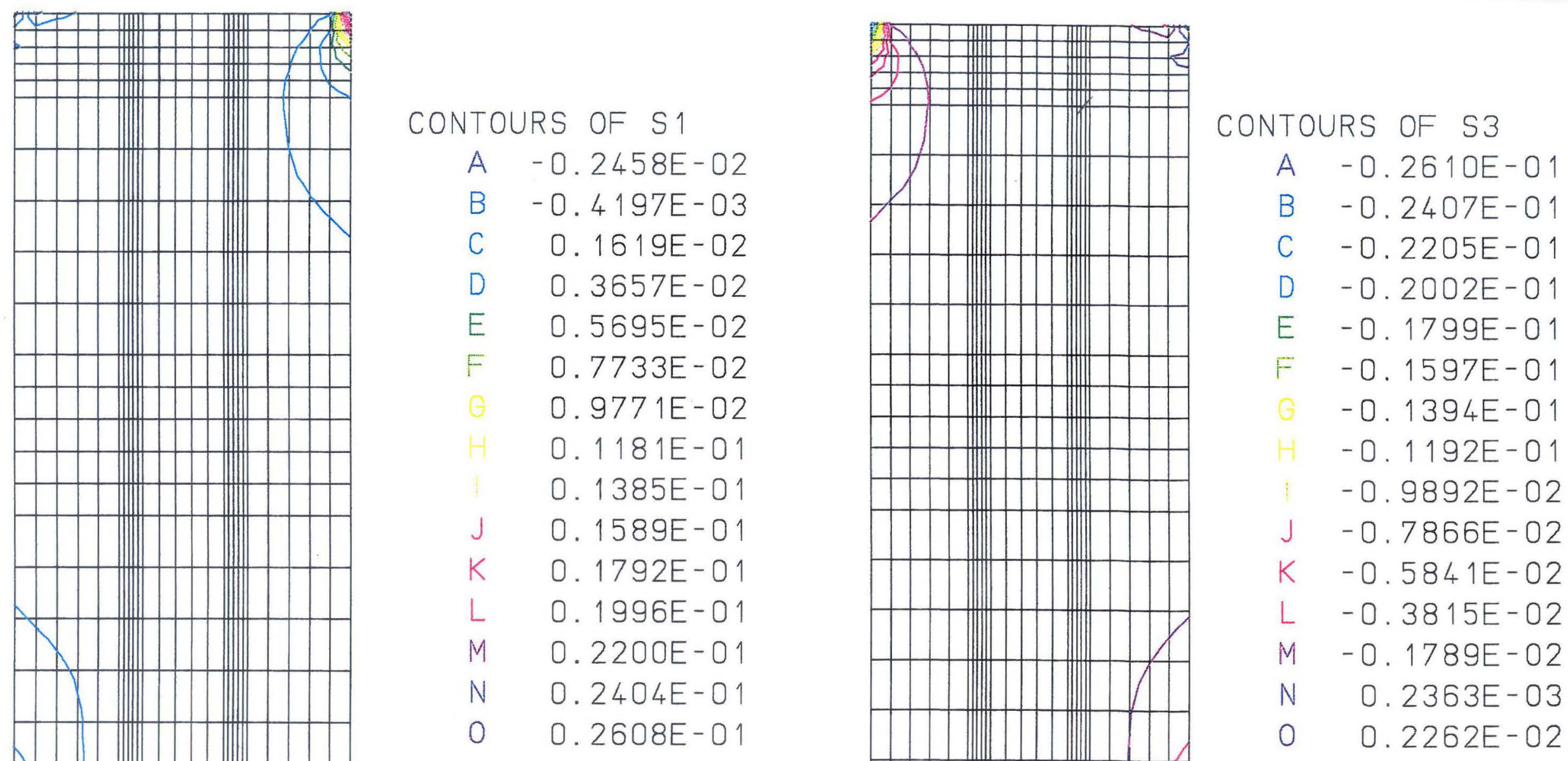

Figura 4- Valores extremos das tensoes principais maximas (S1) e minimas (S3) para o painel macico; caso da estrutura fora do plano; unidades em kN/cm2; Exemplo de painel isolado 
r

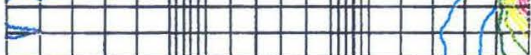

\begin{tabular}{llll}
\hline & & &
\end{tabular}

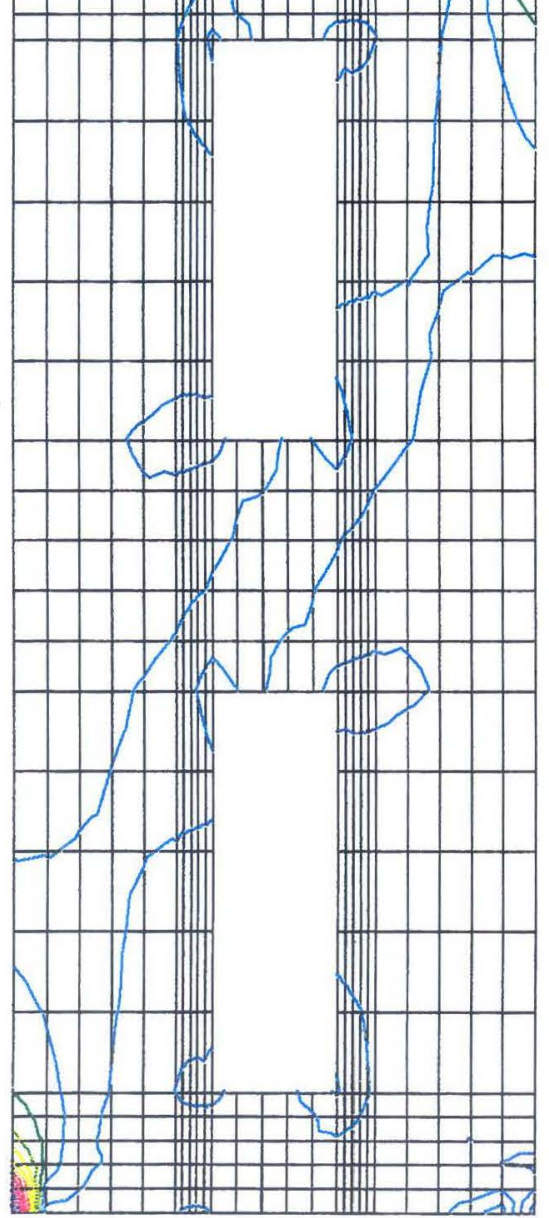

\section{CONTOURS OF S1}

A - $0.2466 E-02$

B $-0.5027 E-03$

C $0.1461 \mathrm{E}-02$

D $0.3425 E-02$

E $\quad 0.5388 E-02$

F $\quad 0.7352 E-02$

$0.9316 E-02$

0. $1128 E-01$

$0.1324 E-01$

J $\quad 0.1521 E-01$

K $\quad 0.1717 E-01$

L $\quad 0.1913 E-01$

M 0.2110E-01

N $0.2306 E-01$

O $0.2503 E-01$

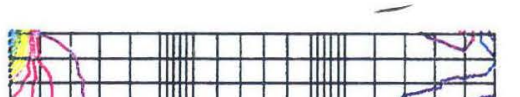

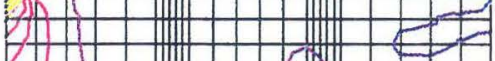

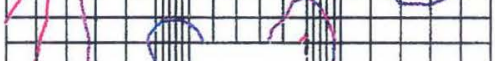

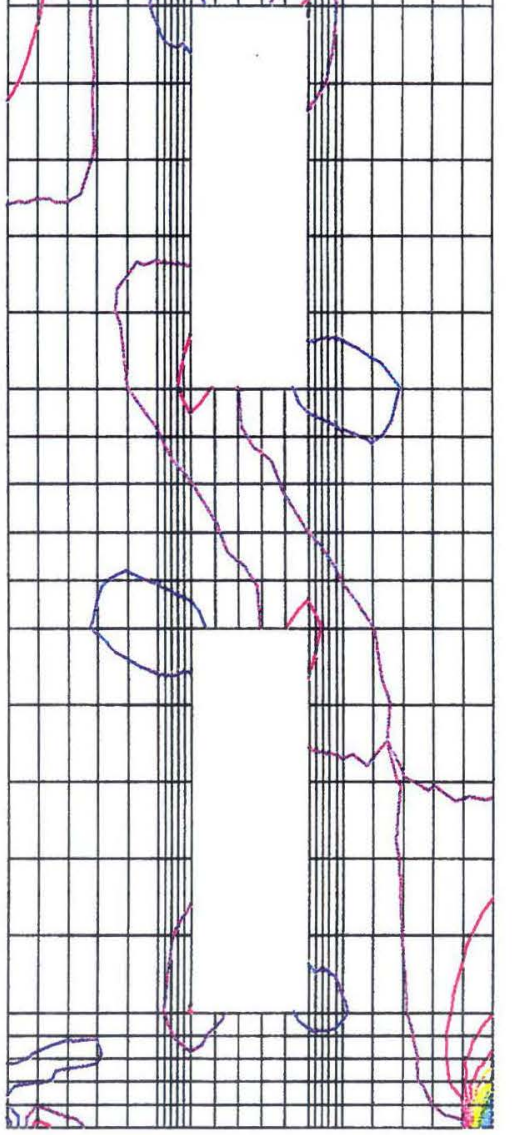

\section{CONTOURS OF 53}

A - $0.2505 E-01$

B -0.2309E-01

C - $0.2114 E-01$

D - $0.1919 E-01$

E - $0.1723 E-01$

$F \quad-0.1528 E-01$

$-0.1333 E-01$

$-0.1138 E-01$

$-0.9423 E-02$

$-0.7470 E-02$

K - $0.5517 E-02$

L $-0.3565 E-02$

$M-0.1612 E-02$

$N \quad 0.3411 E-03$

O 0.2294E-02

Figura 5- Valores extremos das tensoes principais maximas (S1) e minimas (S3) para o painel sem nervuras e com aberturas; caso da estrutura fora do plano; unidades em kN/cm2; Exemplo de painel isolado 


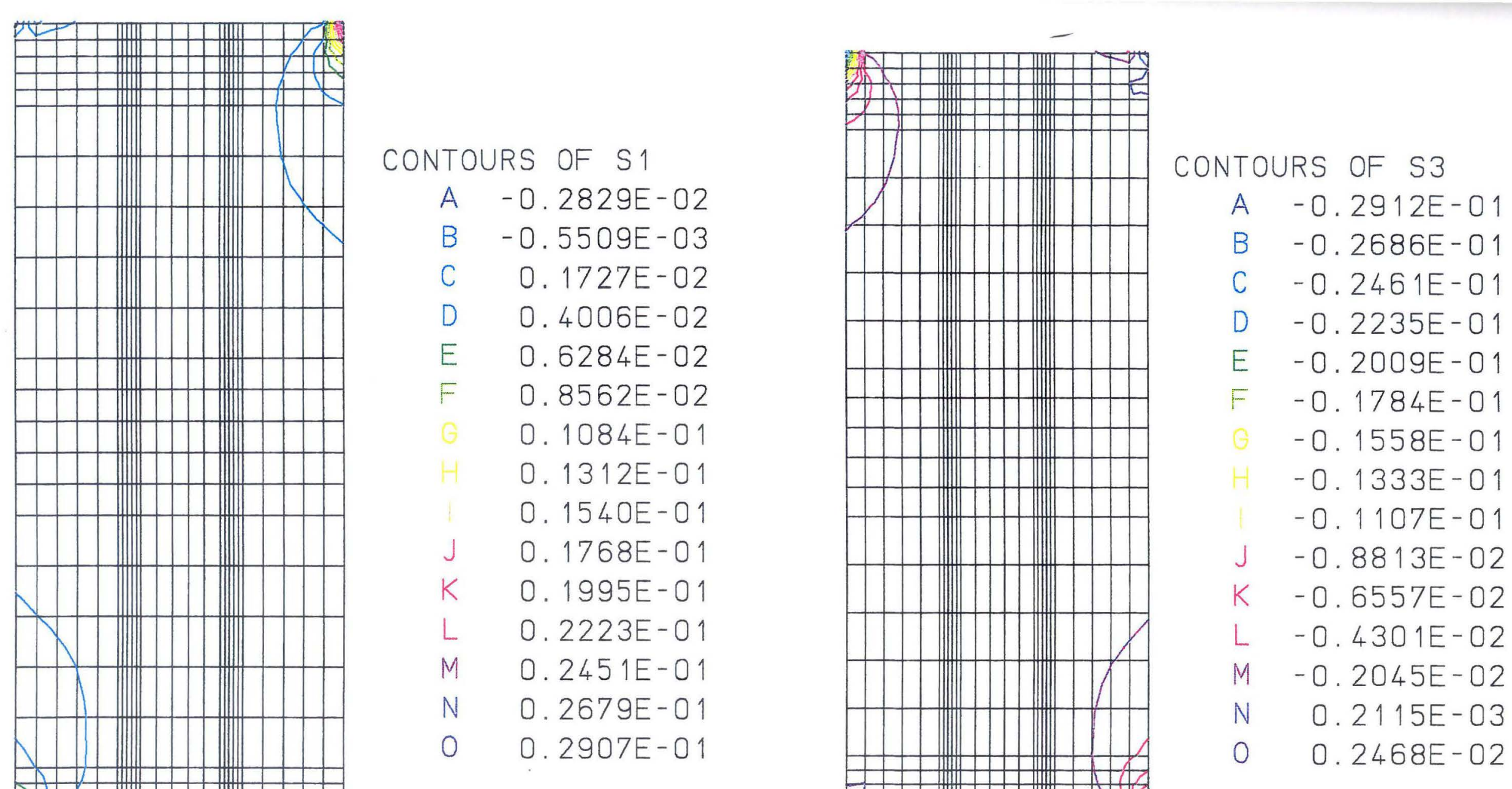

Figura 6- Valores extremos das tensoes principais maximas (S1) e minimas (s3) para o painel macico; caso da estrutura no plano; unidades em kN/cm2; Exemplo de painel isolado 
CONTOURS OF $S 1$

A - $0.5959 E-02$

B -0.1115E-02

C $\quad 0.3728 E-02$

D $0.8572 \mathrm{E}-02$

E $\quad 0.1342 E-01$

F $\quad 0.1826 \mathrm{E}-01$

$0.2310 E-01$

$0.2795 E-01$

$0.3279 E-01$

J $\quad 0.3763 E-01$

K $0.4248 E-01$

L $\quad 0.4732 E-01$

M $\quad 0.5216 E-01$

N $\quad 0.5701 E-01$

O $0.6185 E-01$
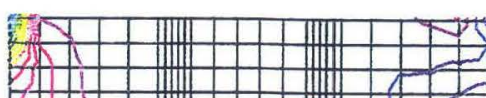

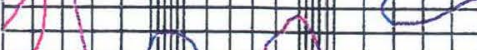

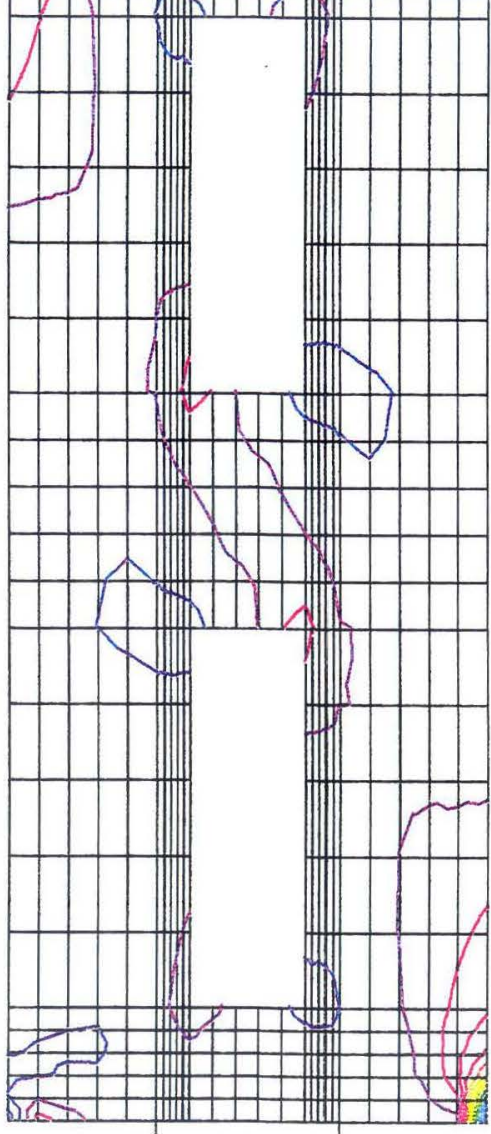

CONTOURS OF S3

A -0.6197E-01

B $-0.5714 E-01$

C $-0.5232 E-01$

D - $0.4750 E-01$

E - $-0.4268 E-01$

$F \quad-0.3785 E-01$

$-0.3303 E-01$

$-0.2821 E-01$

$-0.2339 E-01$

- $0.1856 E-01$

K - $-0.1374 E-01$

L $\quad-0.8918 E-02$

M $\quad-0.4096 E-02$

$\mathrm{N} \quad 0.7269 \mathrm{E}-03$

O $0.5550 E-02$

Figura 7-Valores extremos das tensoes principais maximas (S1) e minimas (S3) para o painel com nervuras e aberturas; caso da estrutura no plano; unidades em $\mathrm{kN} / \mathrm{cm} 2$;

Exemplo de painel isolado 



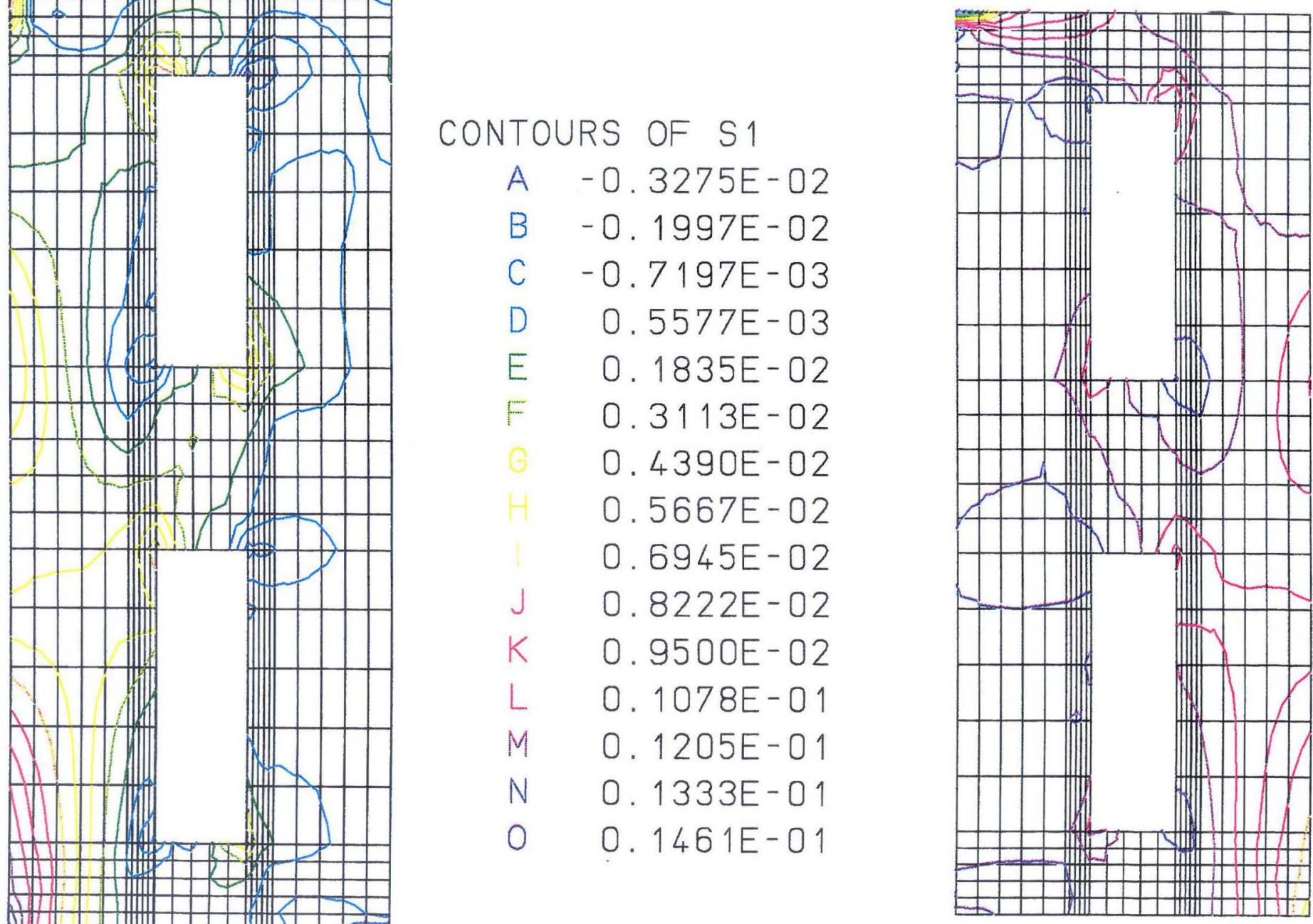

CONTOURS OF S3

A - $0.3014 E-01$

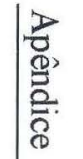

B $-0.2781 E-01$

C $-0.2549 E-01$

D - $0.2316 E-01$

E -0.2084E-01

$F \quad-0.1851 E-01$

$-0.1619 E-01$

$-0.1386 E-01$

- $0.1154 E-01$

$J \quad-0.9214 E-02$

K -0.6889E-02

L - $0.4564 E-02$

$M \quad-0.2239 E-02$

N $0.8557 E-04$

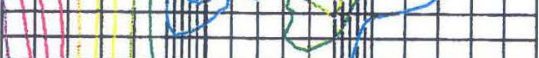

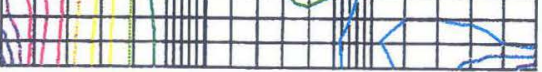

$0.1461 \mathrm{E}-01$

$0 \quad 0.2411 E-02$

Figura 8- Valores extremos das tensoes principais maximas (S1) e minimas (S3) para o painel sem nervuras e com aberturas: caso da estrutura no plano; unidades em $\mathrm{kN} / \mathrm{cm} 2$; Exemplo de painel isolado 




CONTOURS OF S 1

$\begin{array}{ll}A & -0.6318 E-01 \\ B & -0.3918 E-01 \\ C & -0.1518 E-01 \\ D & 0.8829 E-02 \\ E & 0.3283 E-01 \\ F & 0.5684 E-01 \\ G & 0.8084 E-01 \\ H & 0.1048 \\ & 0.1289 \\ J & 0.1529 \\ K & 0.1769 \\ L & 0.2009 \\ M & 0.2249 \\ N & 0.2489 \\ O & 0.2729\end{array}$

Figura 9- Valores extremos das tensoes principais para a acao 1; caso no plano sem ligacoes entre paineis; direcao y; unidades em kN/ cm2, Exemplo de estrutura de um unico pavimento 


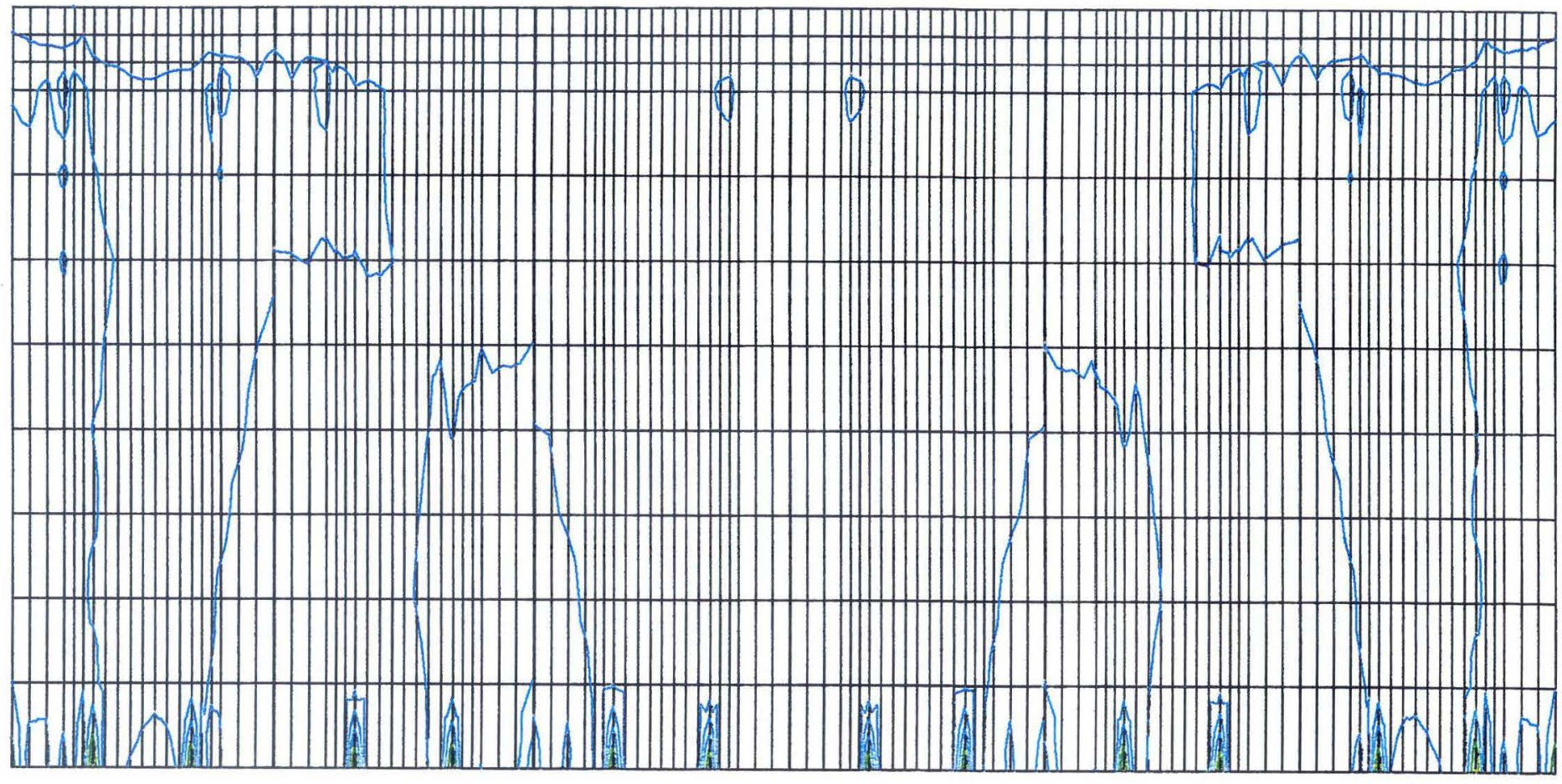

$$
\begin{array}{cl}
\text { CONTOURS OF S1 } \\
\text { A } & -0.2669 \mathrm{E}-01 \\
\text { B } & 0.3440 \mathrm{E}-01 \\
\text { C } & 0.9548 \mathrm{E}-01 \\
\text { D } & 0.1566 \\
\text { E } & 0.2177 \\
\text { F } & 0.2787 \\
\text { G } & 0.3398 \\
H & 0.4009 \\
\text { I } & 0.4620 \\
J & 0.5231 \\
\text { K } & 0.5842 \\
\text { L } & 0.6453 \\
\text { M } & 0.7064 \\
\text { N } & 0.7675 \\
\text { O } & 0.8285
\end{array}
$$

\footnotetext{
Figura 10- Valores extremos das tensoes principais para a acao 2; caso no plano sem ligacoes entre paineis; direcao y: unidades em kN/cm2; Exemplo de estrutura de um unico pavimento
} 


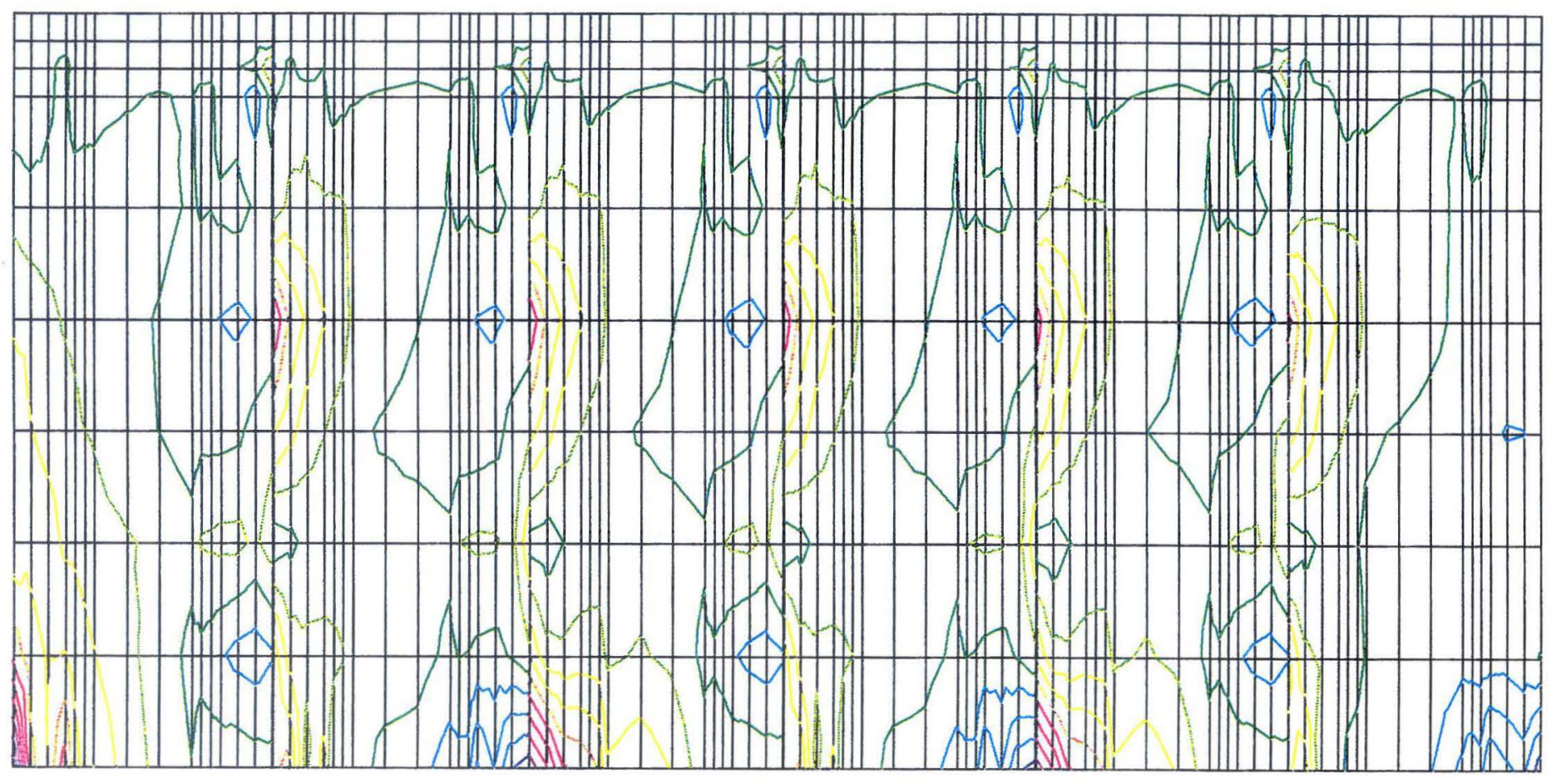

$$
\begin{array}{cc}
\text { CONTOURS OF } S 1 \\
\text { A } & -0.4011 \mathrm{E}-01 \\
\text { B } & -0.2786 \mathrm{E}-01 \\
\text { C } & -0.1561 \mathrm{E}-01 \\
\text { D } & -0.3357 \mathrm{E}-02 \\
\text { E } & 0.8894 \mathrm{E}-02 \\
\text { F } & 0.2115 \mathrm{E}-01 \\
\mathrm{G} & 0.3340 \mathrm{E}-01 \\
\mathrm{H} & 0.4565 \mathrm{E}-01 \\
& 0.5790 \mathrm{E}-01 \\
\mathrm{~J} & 0.7015 \mathrm{E}-01 \\
\mathrm{~K} & 0.8240 \mathrm{E}-01 \\
\mathrm{~L} & 0.9465 \mathrm{E}-01 \\
\mathrm{M} & 0.1069 \\
\mathrm{~N} & 0.1192 \\
\mathrm{O} & 0.1314
\end{array}
$$

Figura 11- Valores extremos das tensoes principais para a acao 1; caso no plano com ligacoes entre paineis; direcao y; unidades em kN/cm2; Exemplo de estrutura de um unico pavimento 


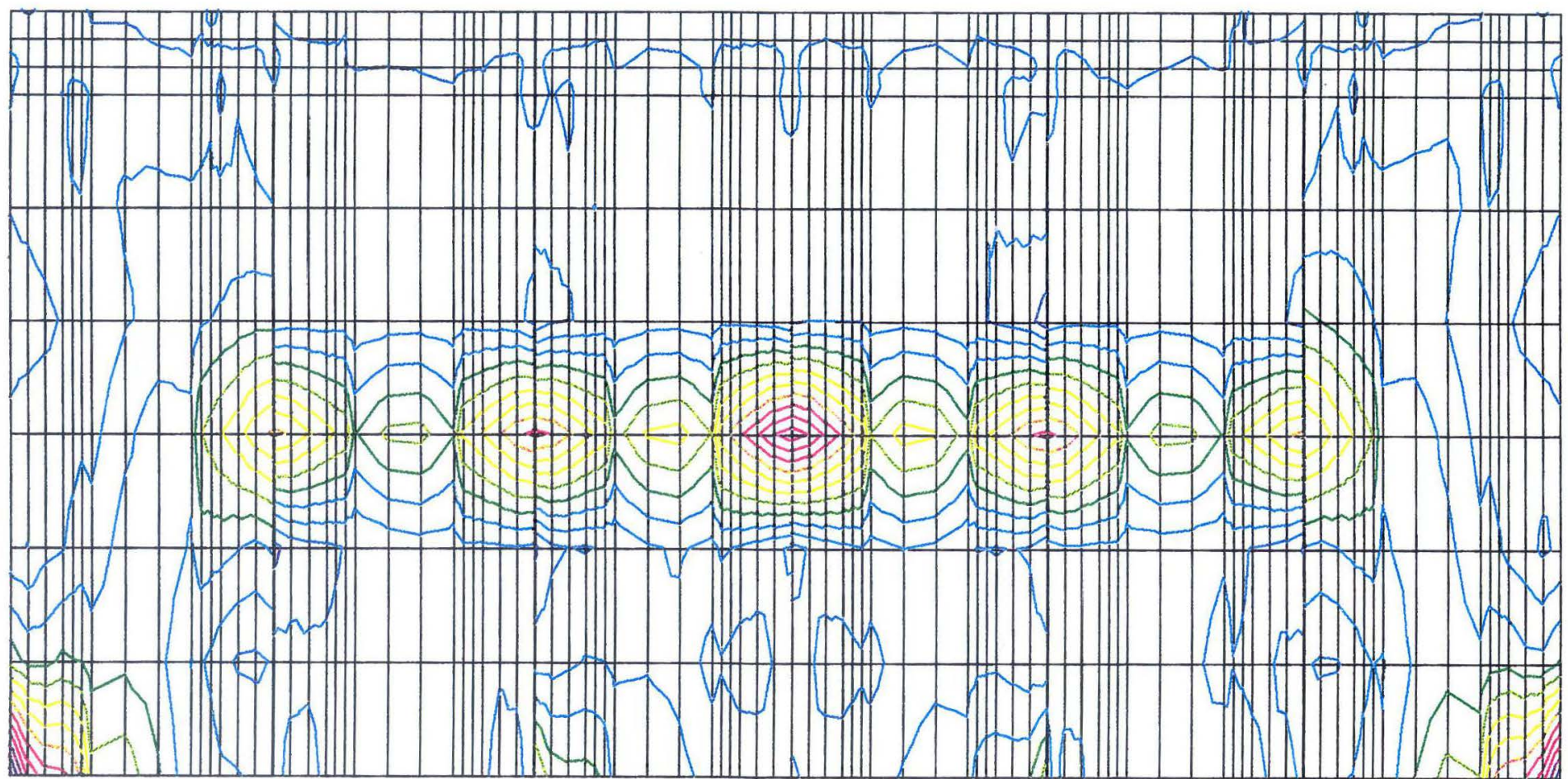

$$
\begin{array}{cl}
\text { CONTOURS OF S } 1 \\
\text { A } & -0.9065 E-0 \\
B & 0.1439 E-0 \\
C & 0.1194 \\
\text { D } & 0.2245 \\
\text { E } & 0.3295 \\
\text { F } & 0.4346 \\
G & 0.5396 \\
H & 0.6446 \\
& 0.7497 \\
J & 0.8547 \\
K & 0.9598 \\
L & 1.065 \\
M & 1.170 \\
N & 1.275 \\
O & 1.380
\end{array}
$$

Figura 12-Valores extremos das tensoes principais para a acao 2; caso no plano com ligacoes entre paineis; direcao y: unidades em kN/cm2; Exemplo de estrutura de um unico pavimento 


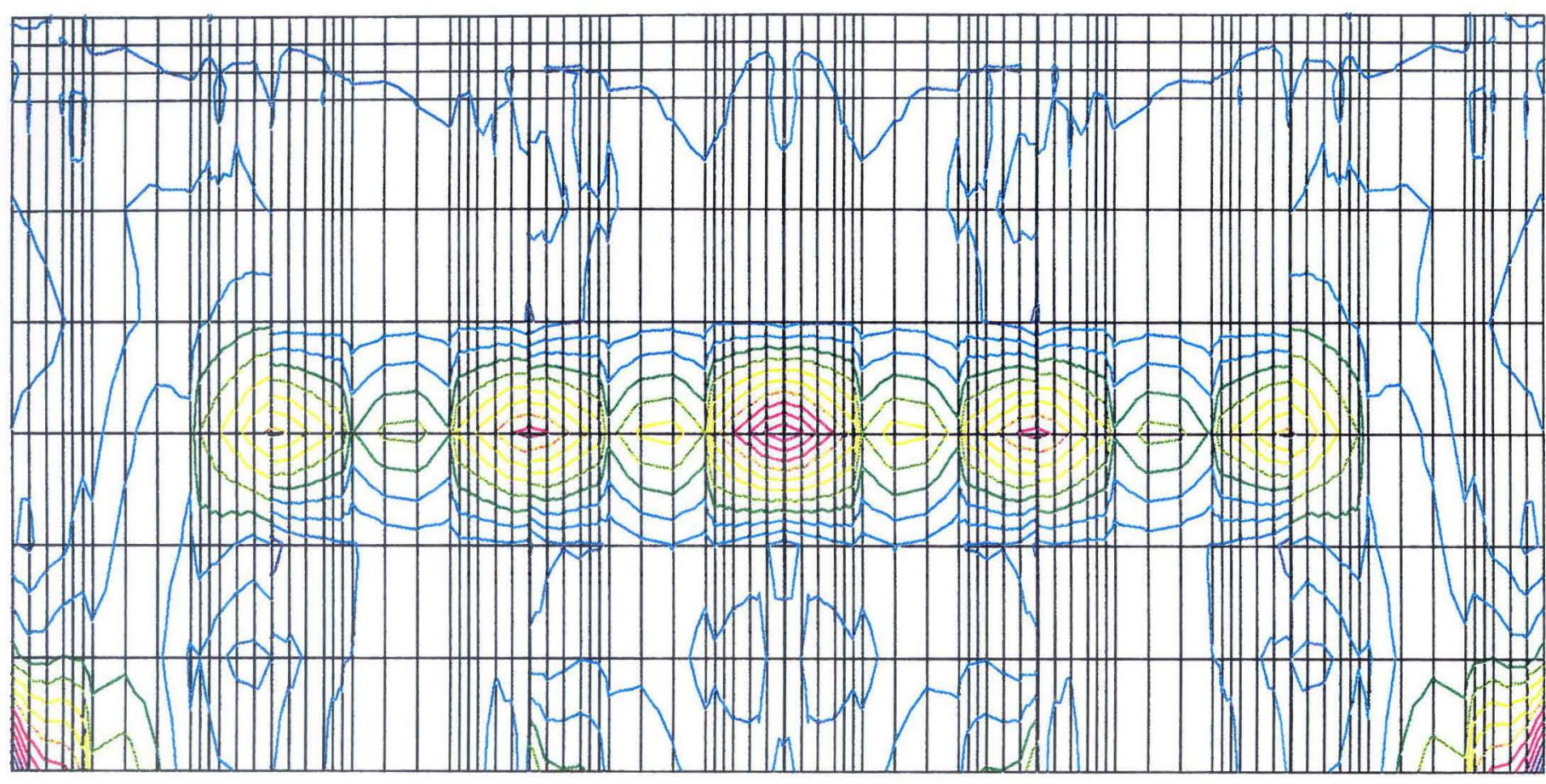

$$
\begin{array}{cl}
\text { CONTOURS OF S1 } \\
\text { A } & -0.7664 E-01 \\
\text { B } & 0.2400 E-01 \\
\text { C } & 0.1246 \\
\text { D } & 0.2253 \\
\text { E } & 0.3259 \\
F & 0.4266 \\
\text { G } & 0.5272 \\
H & 0.6279 \\
& 0.7285 \\
J & 0.8292 \\
\text { K } & 0.9298 \\
\text { L } & 1.030 \\
\text { M } & 1.131 \\
\text { N } & 1.232 \\
O & 1.332
\end{array}
$$

Figura 14- Valores extremos das tensoes principais para acao 2; caso fora do plano com ligacoes entre paineis: direcao y; unidades em kN/cm2; Exemplo de estrutura de um unico pavimento 


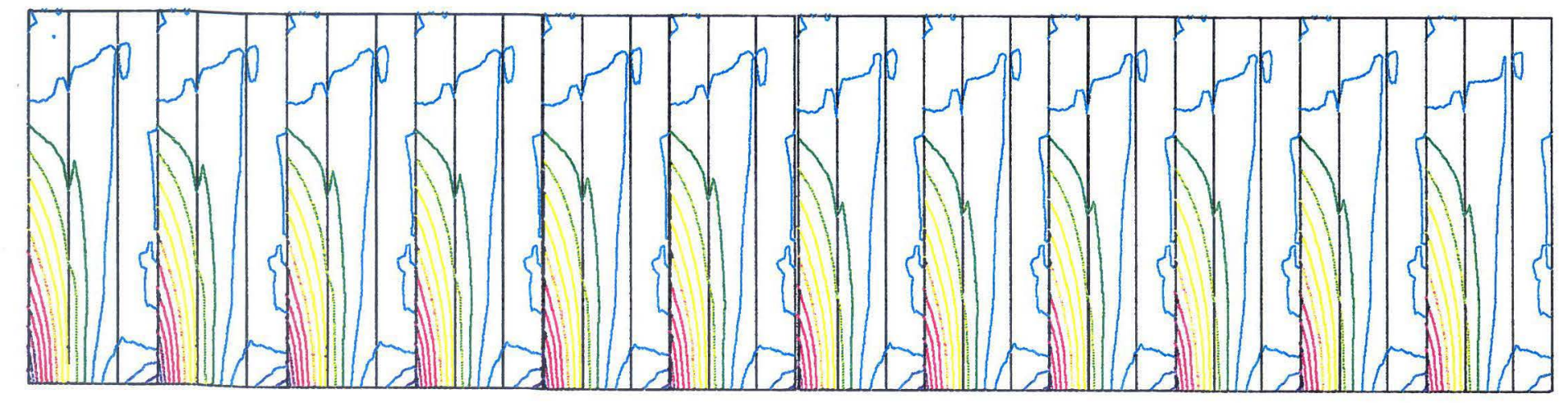

$\begin{array}{cr}\text { CONTOURS OF S1 } \\ \text { A } & -0.1333 E-01 \\ \text { B } & -0.6619 E-02 \\ \text { C } & 0.9183 E-04 \\ \text { D } & 0.6802 E-02 \\ \text { E } & 0.1351 E-01 \\ F & 0.2022 E-01 \\ & 0.2693 E-01 \\ \text { H } & 0.3364 E-01 \\ & 0.4036 E-01 \\ J & 0.4707 E-01 \\ \text { K } & 0.5378 E-01 \\ \text { L } & 0.6049 E-01 \\ \text { M } & 0.6720 E-01 \\ \text { N } & 0.7391 E-01 \\ \text { O } & 0.8062 E-01\end{array}$

Figura 15- Valores extremos das tensoes principais para a acao 1: caso fora do plano sem ligacao entre paineis:

direcao x: unidades em kN/cm2; Exemplo de estrutura de um unico pavimento 


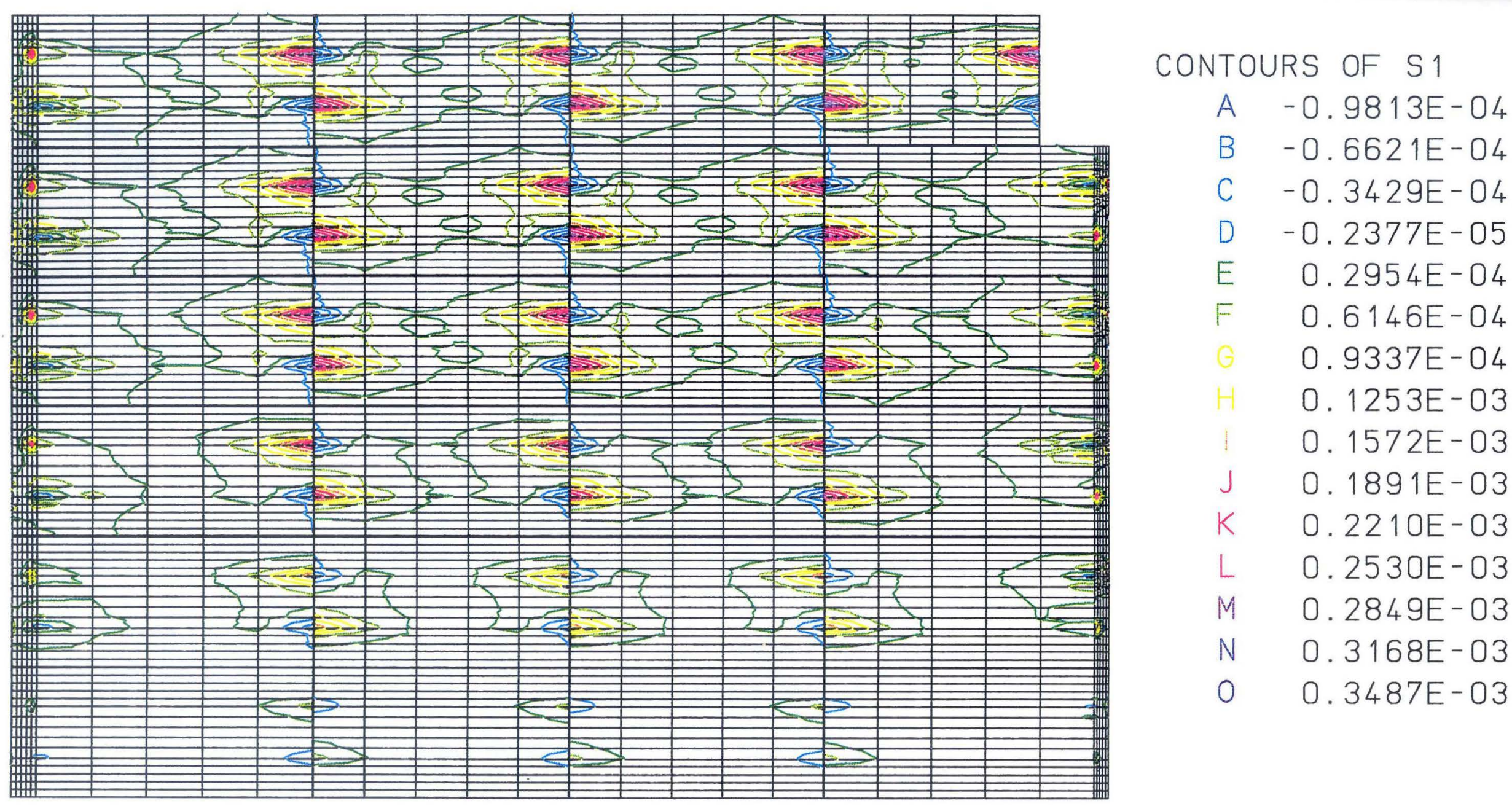

Figura 16-Valores extremos das tensoes principais para a acao 1; fora do plano; comprimento de pino de 200mm; pilar de secao $600 \mathrm{~mm} \times 600 \mathrm{~mm}$; unidades em $\mathrm{kN} / \mathrm{cm} 2$;

Exemplo de estrutura de varios pavimentos 


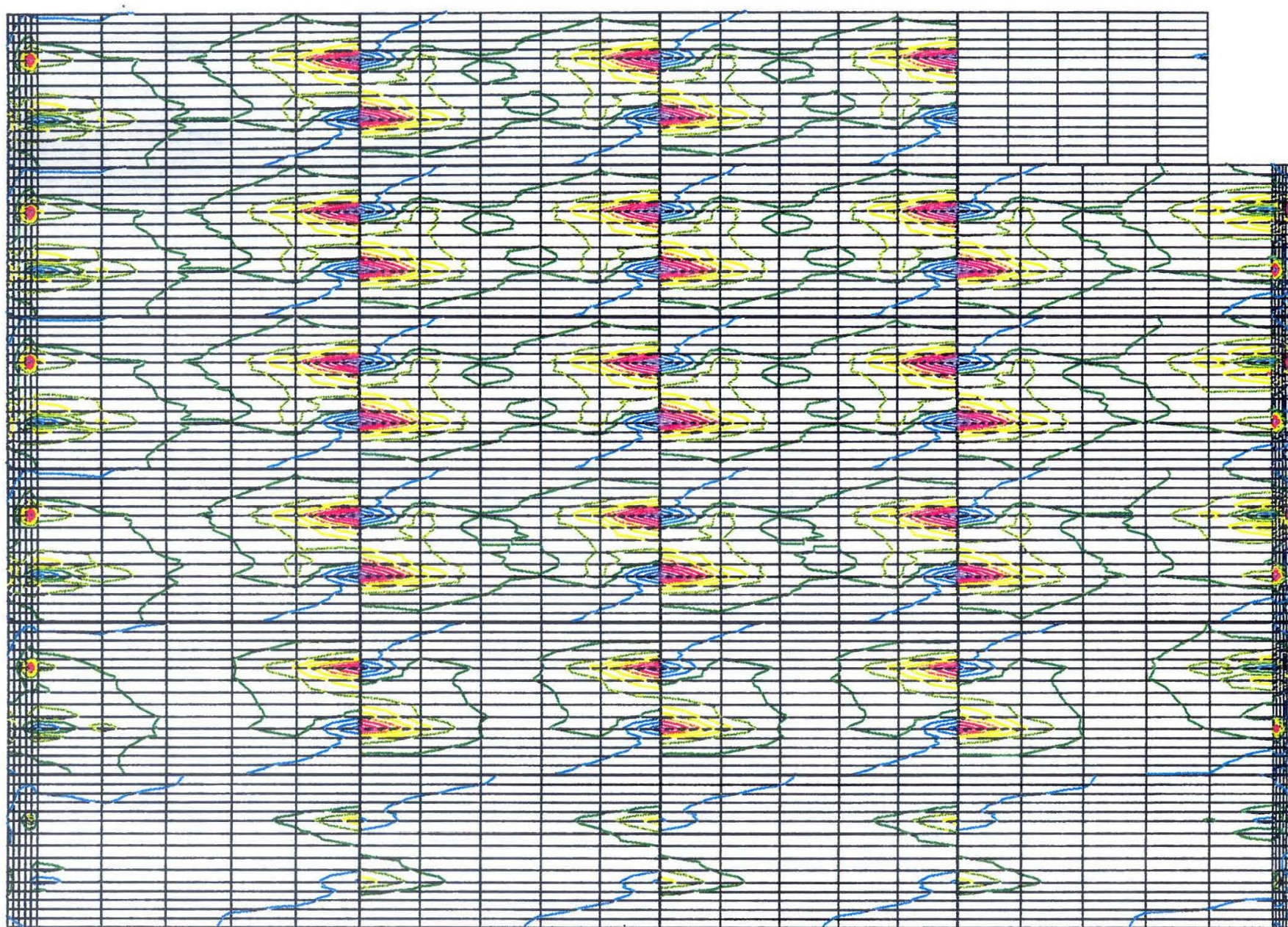

CONTOURS OF S1

A - $0.2017 E-02$

B $-0.1321 E-02$

C $-0.6242 E-03$

D $\quad 0.7217 E-04$

E $\quad 0.7685 E-03$

$F \quad 0.1465 E-02$

G $\quad 0.2161 \mathrm{E}-02$

$0.2858 \mathrm{E}-02$

$0.3554 E-02$

J $0.4250 E-02$

K $0.4947 E-02$

L $\quad 0.5643 E-02$

M 0.6340E-02

N $0.7036 E-02$

O $0.7732 E-02$

Figura 17- Valores extremos das tensoes principais para a acao 1; caso fora do plano; comprimento de pino de $50 \mathrm{~mm}$; pilar de secao $500 \mathrm{~mm} \times 500 \mathrm{~mm}$; unidades em $\mathrm{kN} / \mathrm{cm} 2$;

Exemplo. de estrutura de varios pavimentos 


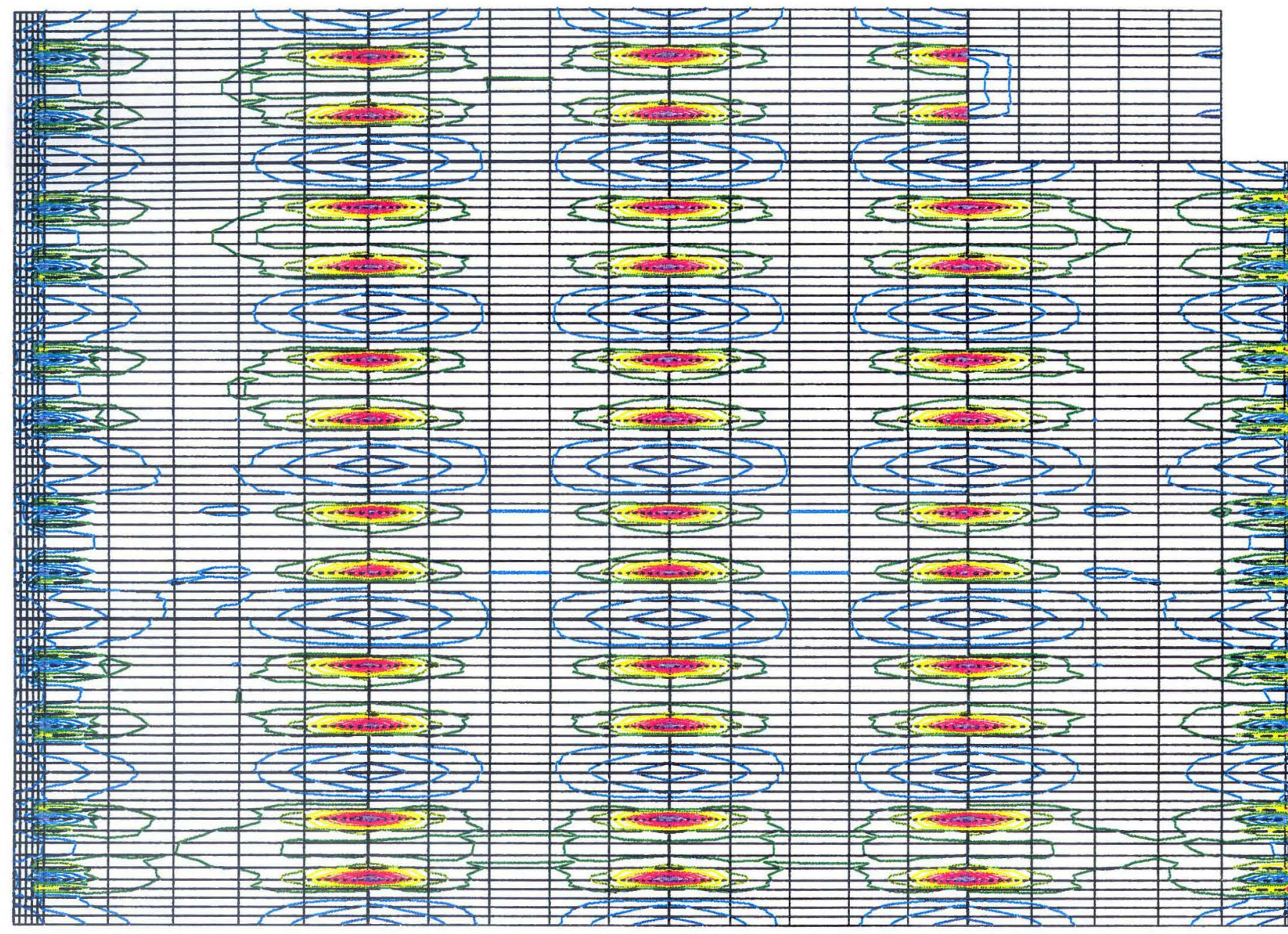

$$
\begin{array}{cc}
\text { CONTOURS OF } S 1 \\
\text { A } & -0.3274 E-03 \\
\text { B } & 0.4672 E-02 \\
\text { C } & 0.9670 E-02 \\
\text { D } & 0.1467 E-01 \\
\text { E } & 0.1967 E-01 \\
F & 0.2467 E-01 \\
G & 0.2967 E-01 \\
H & 0.3466 E-01 \\
& 0.3966 E-01 \\
J & 0.4466 E-01 \\
K & 0.4966 E-01 \\
\text { L } & 0.5466 E-01 \\
M & 0.5966 E-01 \\
N & 0.6466 E-01 \\
\text { O } & 0.6966 E-01
\end{array}
$$

Figura 18- Valores extremos das tensoes principais para a acao 2: caso fora do plano: comprimento de pino de $50 \mathrm{~mm}$; pilar de secao $500 \mathrm{~mm} \times 500 \mathrm{~m}$; unidades em $\mathrm{kN} / \mathrm{cm} 2$; Exemplo de estrutura de varios pavimentos 




CONTOURS OF S1

$\begin{array}{cr}A & -0.2025 E-02 \\ B & -0.1326 E-02 \\ C & -0.6263 E-03 \\ D & 0.7303 E-04 \\ E & 0.7724 E-03 \\ F & 0.1472 E-02 \\ G & 0.2171 E-02 \\ H & 0.2870 E-02 \\ \mid & 0.3570 E-02 \\ J & 0.4269 E-02 \\ K & 0.4968 E-02 \\ L & 0.5668 E-02 \\ M & 0.6367 E-02 \\ N & 0.7066 E-02 \\ O & 0.7766 E-02\end{array}$

Figura 19- Valores extremos das tensoes principais para a acao 1: caso no plano; comprimento de pino de $50 \mathrm{~mm}$; pilar de secao $500 \mathrm{~mm} \times 500 \mathrm{~mm}$; unidades em $\mathrm{kN} / \mathrm{cm} 2$;

Exemplo de estrutura de varios pavimentós 


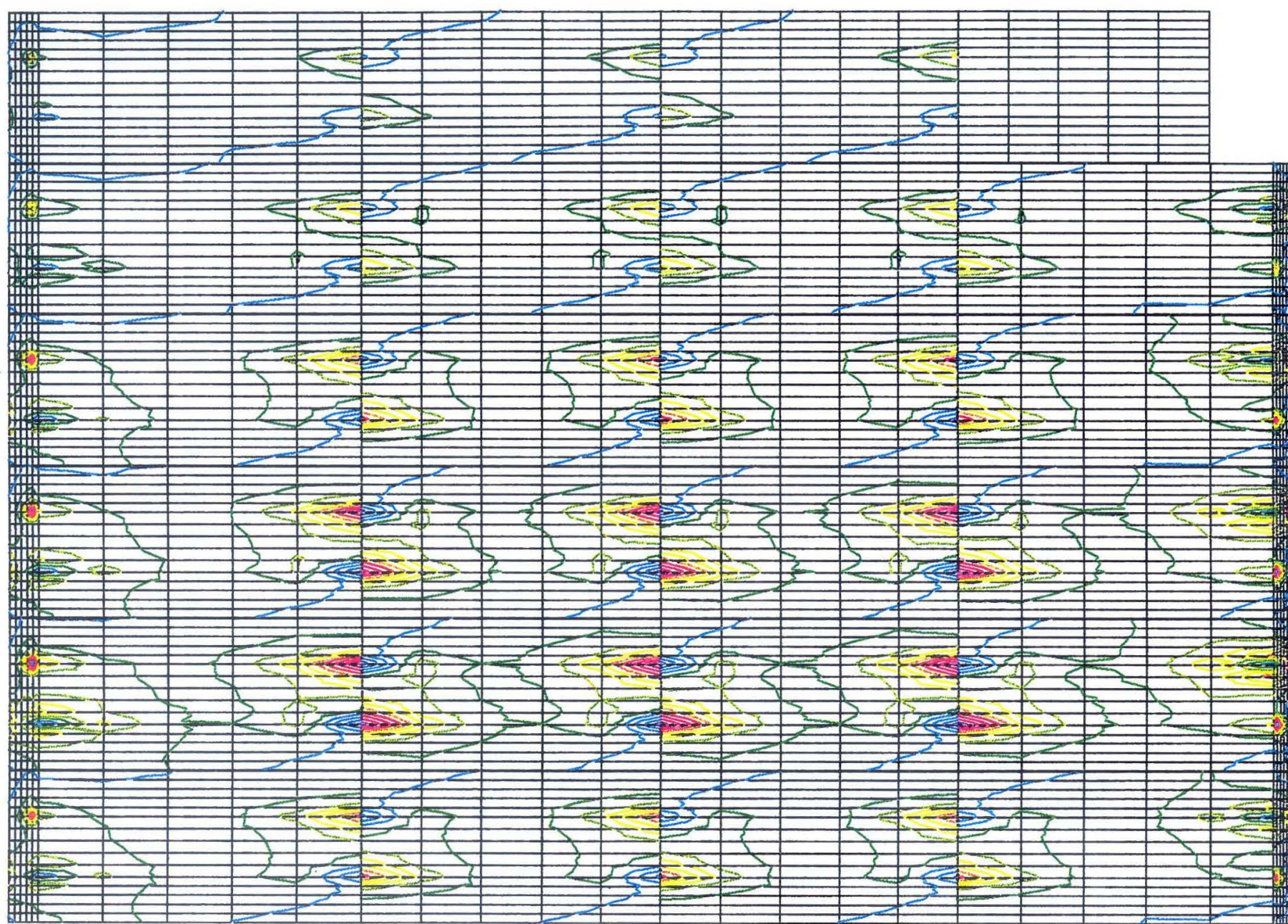

CONTOURS OF $S 1$

A - $0.5685 E-02$

B $-0.3736 E-02$

C -0.1787E-02

D $0.1624 E-03$

E $\quad 0.2112 \mathrm{E}-02$

F $\quad 0.4061 \mathrm{E}-02$

$0.6010 E-02$

$0.7959 E-02$

$0.9908 E-02$

J $\quad 0.1186 E-01$

K $\quad 0.1381 E-01$

L $\quad 0.1576 E-01$

$M \quad 0.1771 E-01$

$N \quad 0.1965 E-01$

O $0.2160 E-01$

Figura 20- Valores extremos das tensoes principais para a acao 1; caso fora do plano; comprimento de pino de 10mm; pilar de secao $400 \mathrm{~mm} \times 400 \mathrm{~m}$; unidades em kN/cm2 Exemplo de estrutura de varios pavimentos 


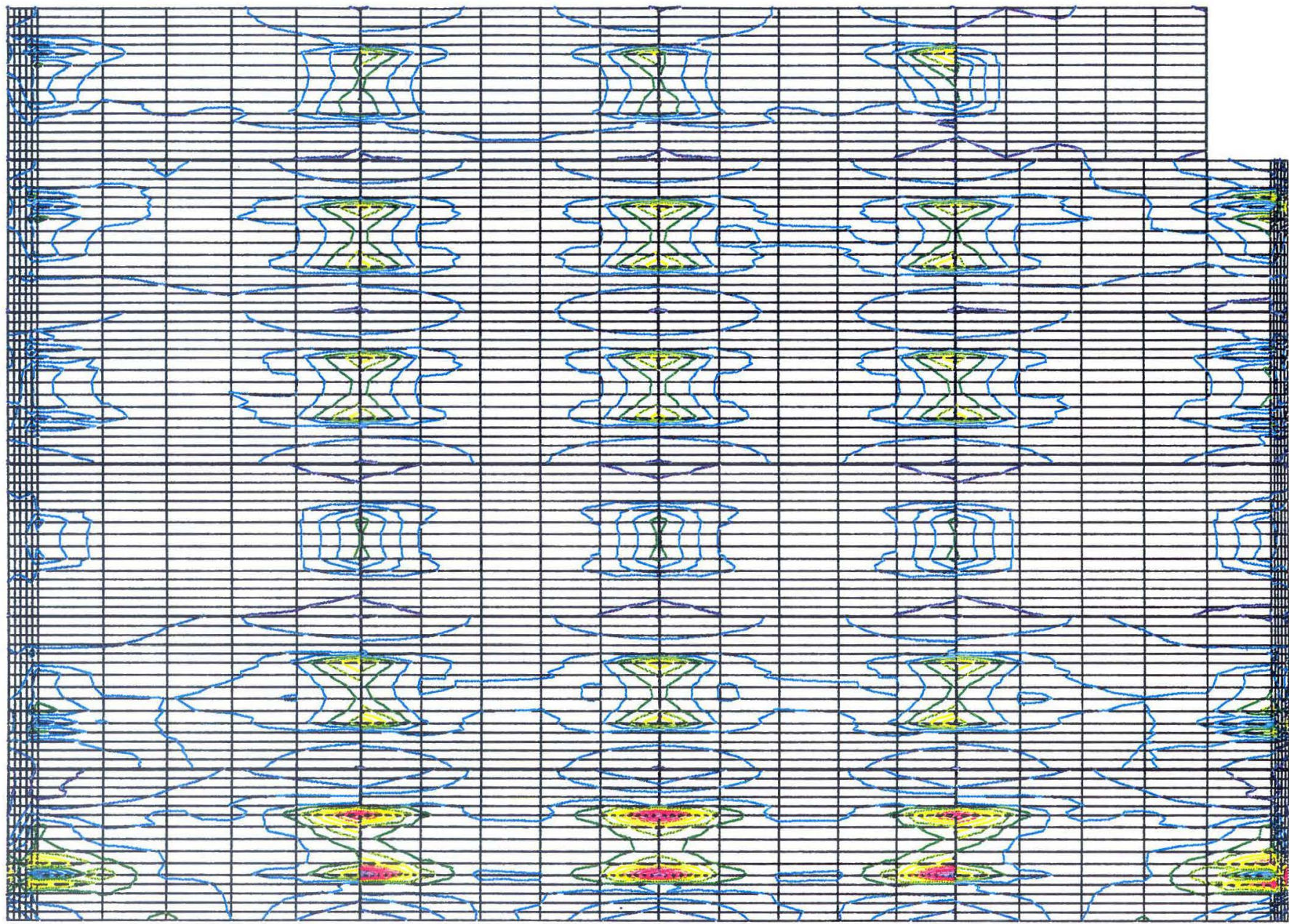

$\begin{array}{cl}\text { CONTOURS OF S } 1 \\ \text { A } & 0.6320 \mathrm{E}-02 \\ \text { B } & 0.1200 \\ \text { C } & 0.2337 \\ \text { D } & 0.3473 \\ \text { E } & 0.4610 \\ F & 0.5747 \\ \text { G } & 0.6883 \\ H & 0.8020 \\ & 0.9157 \\ J & 1.029 \\ \text { K } & 1.143 \\ \text { L } & 1.257 \\ \text { M } & 1.370 \\ \text { N } & 1.484 \\ \text { O } & 1.598\end{array}$

Figura 21 - Valores extremos das tensoes principais para a acao 2; caso fora do plano; comprimento de pino de 10mm: pilar de secao de $400 \mathrm{~mm} \times 400 \mathrm{~mm}$; unidades em $\mathrm{kN} / \mathrm{cm} 2$; Exemplo de estrutura de varios pavimentos 


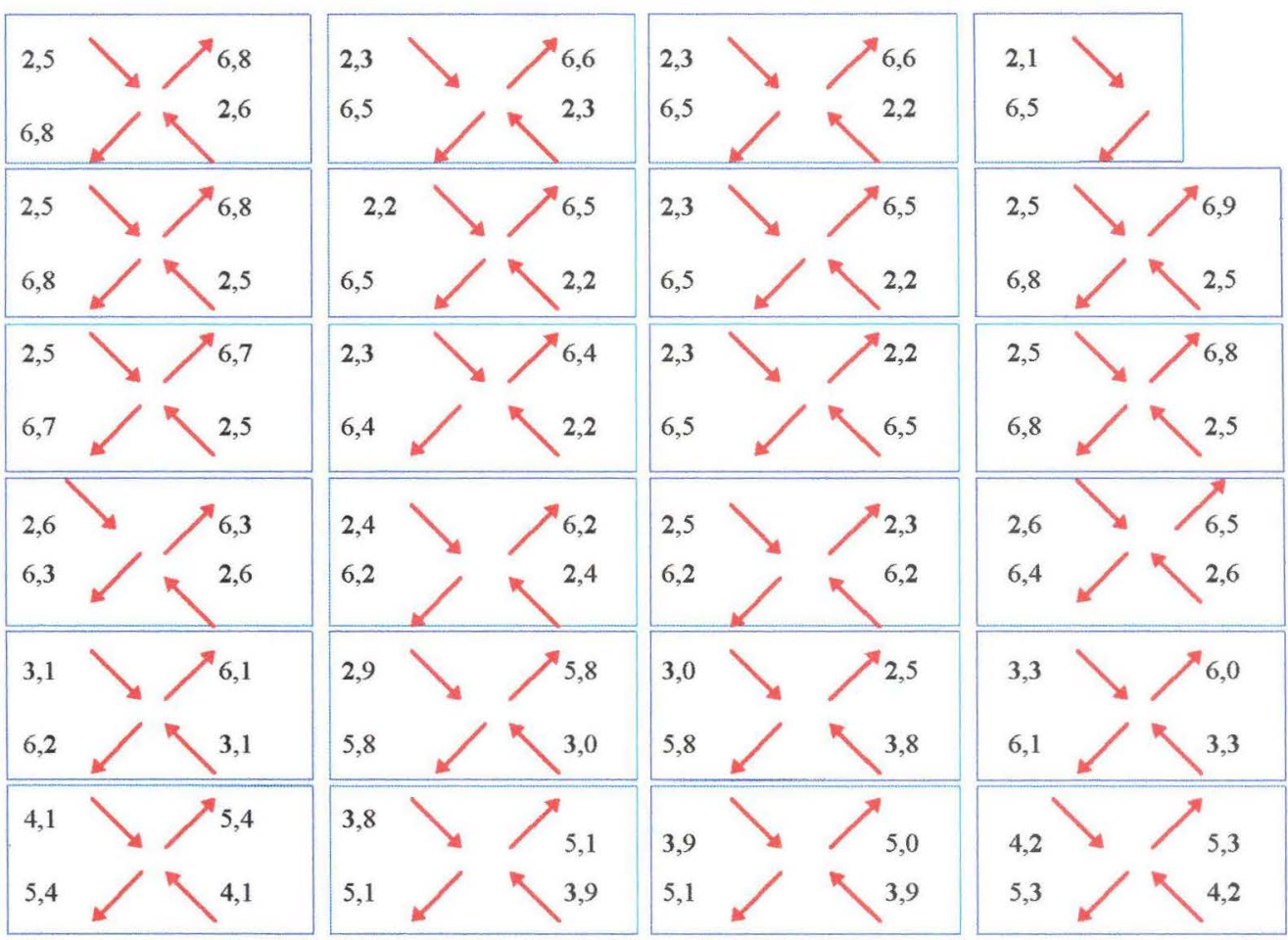

Figura 22- Esforços de cisalhamento em $\mathrm{kN}$ : ação 1, pilares $600 \times 600 \mathrm{~mm}^{2}$, comprimento de pino de $50 \mathrm{~mm}$

\begin{tabular}{|c|c|c|c|c|c|c|c|}
\hline 72,31 & 58,78 & $-9,66$ & 59,836 & $-9,65$ & 60,453 & 9,70 & \\
\hline 36,94 & 3,61 & 59,50 & $-9,72$ & 60,00 & $-9,73$ & 59,58 & \\
\hline 68,62 & 58,52 & $-9,84$ & 59,53 & $-9,79$ & 60,025 & $-9,03$ & 17,14 \\
\hline 36,82 & $-9,21$ & 59,33 & $-9,87$ & 59,94 & $-9,981$ & 60,10 & 23,78 \\
\hline 73,39 & 56,79 & $-9,70$ & 57,88 & $-9,62$ & 58,55 & $-8,86$ & 16,73 \\
\hline 35,76 & $-9,10$ & 57,75 & $-9,73$ & 58,48 & $-9,64$ & 58,74 & 23,31 \\
\hline 66,97 & 50,57 & $-8,82$ & 51,79 & $-8,71$ & 52,51 & $-7,99$ & 15,02 \\
\hline 31,64 & $-8,32$ & 51,81 & $-8,83$ & 52,54 & $-8,72$ & 52,79 & 21,04 \\
\hline 51,95 & 38,11 & $-6,69$ & 38,79 & $-6,54$ & 39,19 & $-5,97$ & 11,18 \\
\hline 24,41 & $-6,31$ & 39,25 & $-6,63$ & 39,50 & $-6,51$ & 39,45 & 15,66 \\
\hline 21,59 & 16,45 & $-2,86$ & 16,36 & $-2,67$ & 16,30 & $-2,43$ & 18,36 \\
\hline 10,8 & $-2,58$ & 16,86 & $-2,70$ & 16,61 & $-2,65$ & 16,31 & 6,36 \\
\hline
\end{tabular}

Figura 23-Valores extremos das tensões principais em $\mathrm{kPa}$ : ação 1, pilares $600 \times 600 \mathrm{~mm}^{2}$, comprimento de pino de $50 \mathrm{~mm}$ 

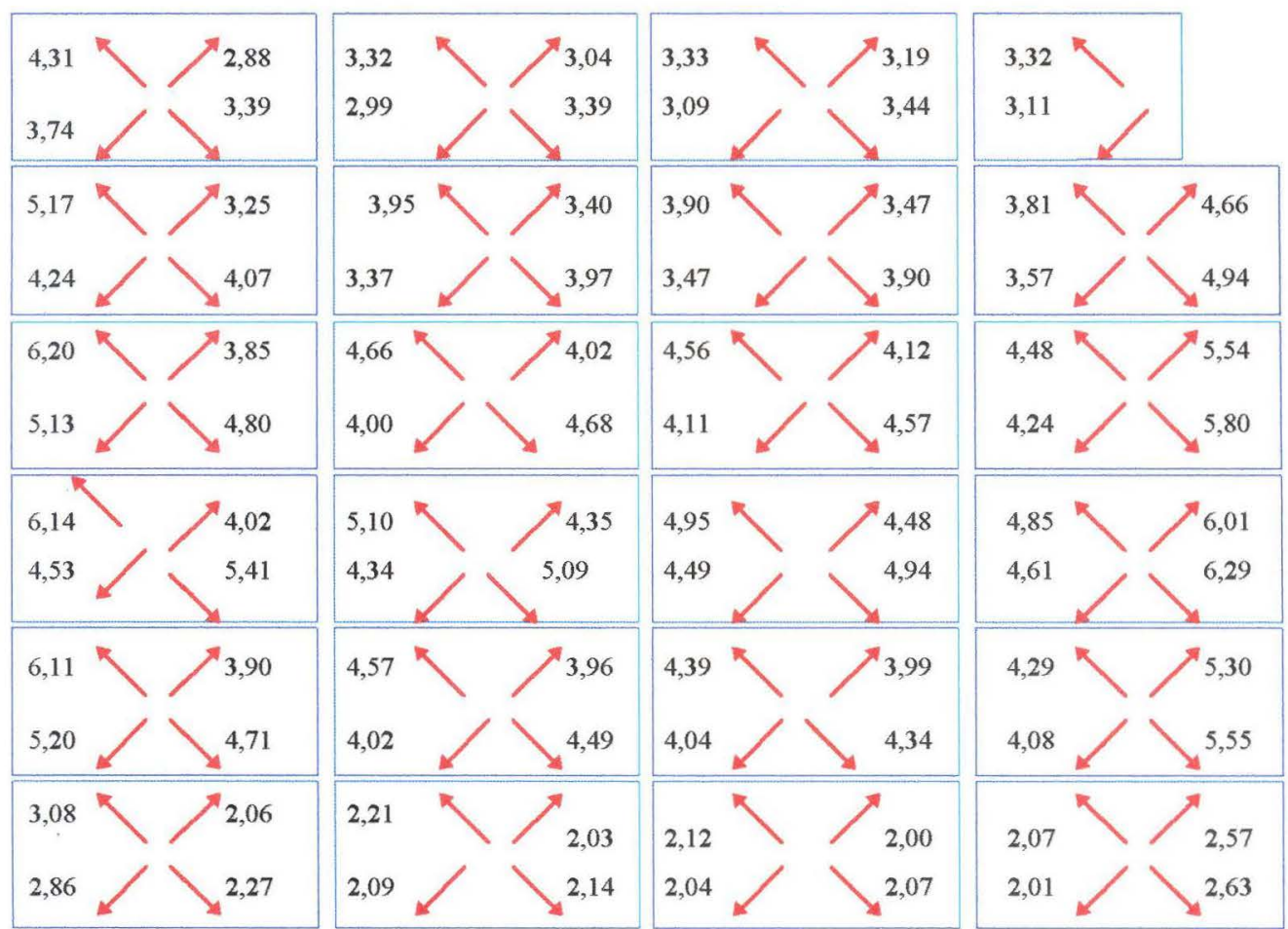

Figura 24-Esforços máximos em $\mathrm{kPa}$ : ação 1, pilares $600 \mathrm{x} 00 \mathrm{~mm}^{2}$, comprimento de pino de $10 \mathrm{~mm}$

\begin{tabular}{|c|c|c|c|c|c|c|c|}
\hline 149,98 & 89,51 & $-16,74$ & 95,80 & $-16,67$ & 101,50 & $-16,50$ & \\
\hline 65,20 & $-15,95$ & 92,83 & $-17,37$ & 96,56 & $-17,56$ & 97,02 & \\
\hline 181,79 & 99,89 & $-20,09$ & 105,71 & $-20,00$ & 108,47 & $-17,73$ & 90,23 \\
\hline 73,16 & $-18,70$ & 104,50 & $-20,29$ & 108,43 & $-19,87$ & 111,78 & 173,24 \\
\hline 219,00 & 118,16 & $-23,78$ & 127,88 & $-23,23$ & 129,22 & $-20,85$ & 107,25 \\
\hline 89,12 & $-22,50$ & 123,95 & $-23,84$ & 128,95 & $-23,26$ & 133,03 & 202,90 \\
\hline 214,47 & 123,73 & $-26,22$ & 134,82 & $-25,06$ & 140,41 & $-22,51$ & 116,45 \\
\hline 77,09 & $-25,89$ & 134,89 & $-26,09$ & 140,67 & $-25,09$ & 144,41 & 219,92 \\
\hline 214,81 & 120,11 & $-23,26$ & 122,67 & $-22,30$ & 125,14 & $-20,12$ & 102,58 \\
\hline 90,80 & $-22,06$ & 126,15 & $-22,76$ & 127,36 & $-22,04$ & 127,83 & 193,74 \\
\hline 107,66 & 63,70 & $-11,27$ & 63,55 & $-10,74$ & 62,97 & $-9,61$ & 49,73 \\
\hline 50,71 & $-10,53$ & 66,82 & $-10,70$ & 65,13 & $-10,40$ & 63,58 & 91,40 \\
\hline
\end{tabular}

Figura 25-Valores extremos das tensões principais em $\mathrm{kPa}$ : ação 1 , pilares $600 \times 600 \mathrm{~mm}^{2}$, comprimento de pino de $10 \mathrm{~mm}$ 


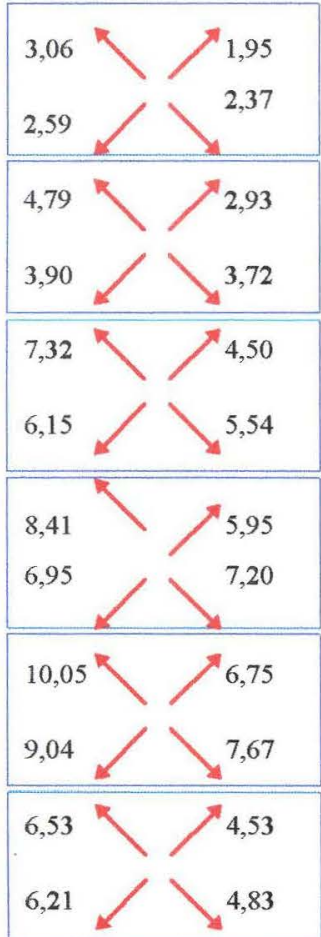

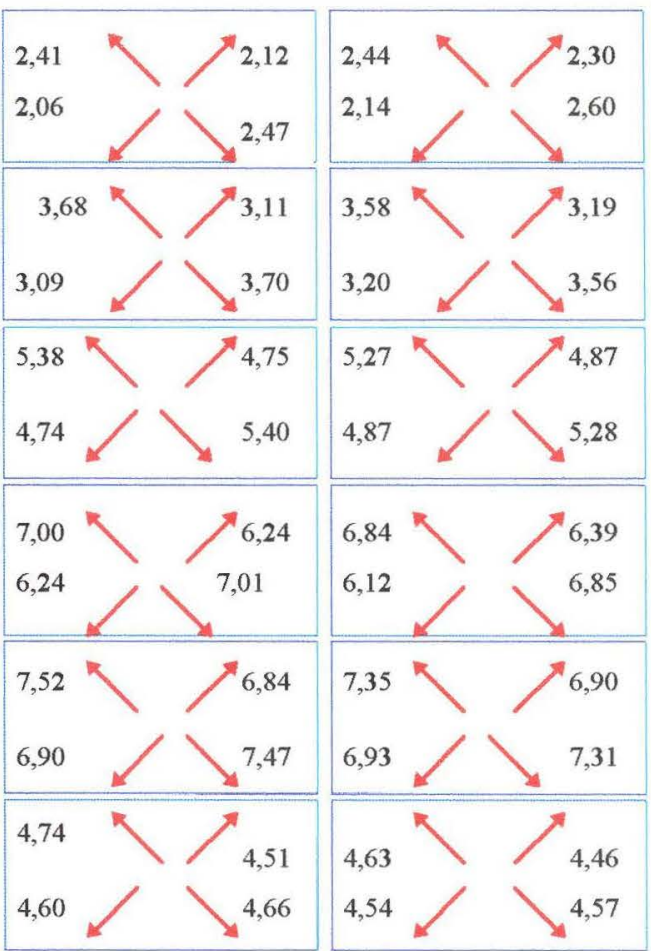

\begin{tabular}{|l|l|l|}
\hline & \\
\hline
\end{tabular}

Figura 26-Esforços máximos em $\mathrm{kPa}$ : ação 1, pilares $400 \times 400 \mathrm{~mm}^{2}$, comprimento de pino de $10 \mathrm{~mm}$

\begin{tabular}{|c|c|c|c|c|c|c|c|}
\hline 107,32 & 60,41 & $-12,19$ & 66,43 & $-12,18$ & 73,07 & $-12,18$ & \\
\hline 45,03 & $-11,14$ & 63,51 & $-12,71$ & 65,59 & $-13,45$ & 66,00 & \\
\hline 169,43 & 89,90 & $-18,87$ & 96,42 & $-18,27$ & 99,25 & $-16,20$ & 81,74 \\
\hline 67,62 & $-17,48$ & 95,39 & $-18,80$ & 100,23 & $-18,10$ & 101,08 & 157,20 \\
\hline 258,91 & 137,58 & $-27,30$ & 148,37 & $-26,60$ & 153,44 & $-23,45$ & 129,90 \\
\hline 107,35 & $-26,00$ & 147,49 & $-27,61$ & 153,02 & $-26,74$ & 157,10 & 237,23 \\
\hline 290,24 & 184,86 & 35,58 & 195,00 & $-34,65$ & 201,47 & $-30,46$ & 170,48 \\
\hline 120,14 & $-34,22$ & 194,54 & $-35,70$ & 201,40 & $-34,65$ & 206,79 & 308,09 \\
\hline 350,54 & 209,29 & $-37,92$ & 214,39 & $-37,28$ & 217,31 & $-33,20$ & 183,00 \\
\hline 158,92 & $-35,85$ & 216,94 & $-37,78$ & 219,23 & $-36,89$ & 222,00 & 337,52 \\
\hline 226,38 & 140,77 & $-23,81$ & 142,15 & $-23,16$ & 141,37 & $-21,03$ & 113,79 \\
\hline 110,23 & $-22,27$ & 146,35 & $-23,31$ & 144,27 & $-23,03$ & 143,33 & 204,86 \\
\hline
\end{tabular}

Figura 27-Valores extremos das tensões principais em $\mathrm{kPa}$ : ação 1, pilares $400 \times 400 \mathrm{~mm}^{2}$, comprimento de pino de $10 \mathrm{~mm}$ 


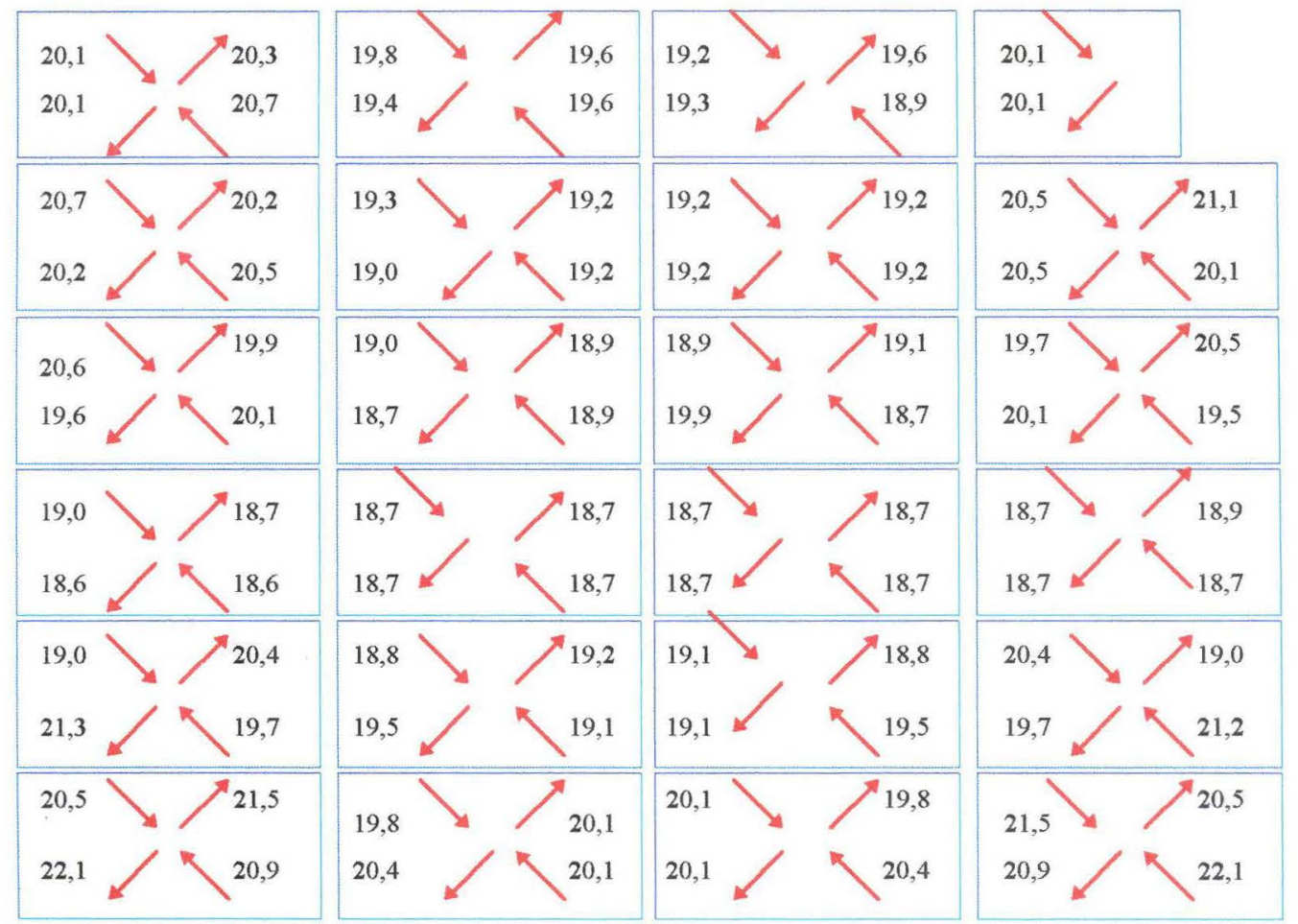

Figura 28- Esforços de cisalhamento em kN; ação 2, pilares $600 \times 600 \mathrm{~mm}^{2}$, comprimento de pino de $50 \mathrm{~mm}$

\begin{tabular}{|c|c|c|c|c|c|c|c|}
\hline 490 & 690 & 740 & 740 & 720 & 730 & 730 & \\
\hline 470 & 700 & 730 & 730 & 720 & 710 & 720 & \\
\hline 480 & 690 & 720 & 720 & 720 & 720 & 700 & 510 \\
\hline 470 & 700 & 710 & 720 & 720 & 720 & 700 & 490 \\
\hline 470 & 680 & 710 & 710 & 710 & 710 & 670 & 500 \\
\hline 460 & 680 & 700 & 710 & 710 & 700 & 680 & 480 \\
\hline 440 & 640 & 700 & 700 & 700 & 700 & 640 & 460 \\
\hline 430 & 630 & 700 & 700 & 700 & 700 & 640 & 450 \\
\hline 450 & 690 & 710 & 710 & 710 & 700 & 690 & 470 \\
\hline 490 & 610 & 730 & 720 & 720 & 730 & 670 & 510 \\
\hline 480 & 730 & 740 & 750 & 750 & 740 & 730 & 500 \\
\hline 510 & 710 & 760 & 750 & 750 & 760 & 710 & 530 \\
\hline
\end{tabular}

Figura 29- Valores máximos das tensões em $\mathrm{kPa}$; ação 2, pilares $600 \times 600 \mathrm{~mm}^{2}$, comprimento de pino de $50 \mathrm{~mm}$ 


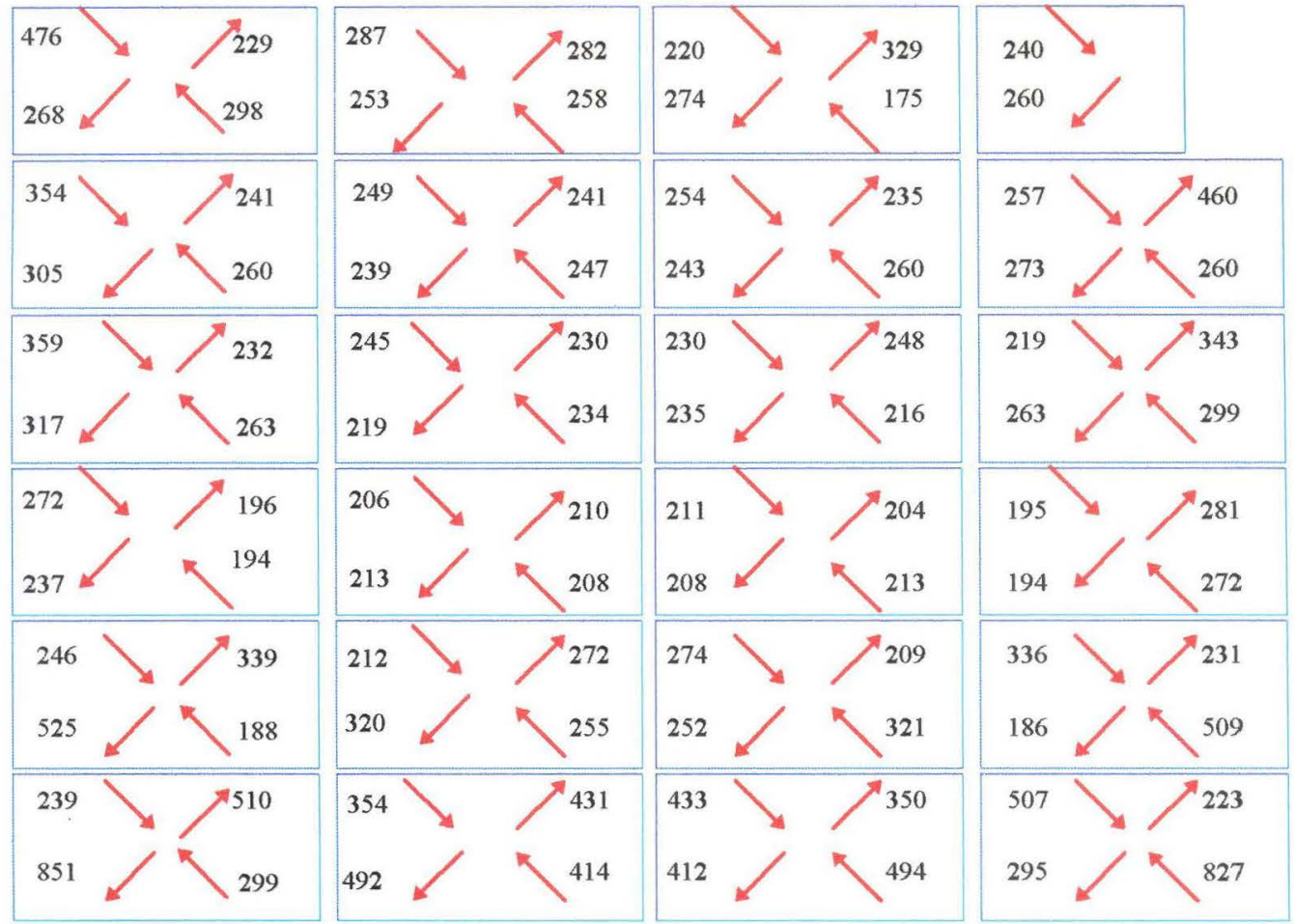

Figura 30- Esforços de cisalhamento em kN; ação 2, pilares $600 \times 600 \mathrm{~mm}^{2}$, comprimento de pino de $10 \mathrm{~mm}$

\begin{tabular}{|c|c|c|c|c|c|c|c|}
\hline 8940 & 7860 & 10740 & 10550 & 8100 & 12080 & 5810 & \\
\hline 5150 & 9780 & 9140 & 9320 & 9490 & 5750 & 1200 & \\
\hline 6900 & 7970 & 8830 & 8510 & 9010 & 8340 & 8990 & 9420 \\
\hline 5480 & 8470 & 7010 & 8720 & 8700 & 9320 & 8880 & 5410 \\
\hline 6420 & 6080 & 8600 & 8000 & 8030 & 8720 & 7040 & 6670 \\
\hline 5630 & 8630 & 7490 & 8060 & 8070 & 7360 & 8650 & 5840 \\
\hline 4940 & 6120 & 6850 & 6700 & 7000 & 6760 & 6070 & 5670 \\
\hline 4840 & 6050 & 7130 & 6950 & 6920 & 7120 & 6020 & 5590 \\
\hline 5030 & 11200 & 7390 & 9660 & 9720 & 7290 & 11100 & 5170 \\
\hline 9870 & 6250 & 11890 & 9570 & 9490 & 11940 & 6190 & 10370 \\
\hline 5390 & 17640 & 14460 & 17000 & 17060 & 14320 & 17570 & 5410 \\
\hline 17000 & 12060 & 19660 & 17130 & 17020 & 19730 & 11880 & 17840 \\
\hline
\end{tabular}

Figura 31- Valores máximos das tensões em $\mathrm{kPa}$; ação 2, pilares $600 \times 600 \mathrm{~mm}^{2}$, comprimento de pino de $10 \mathrm{~mm}$ 


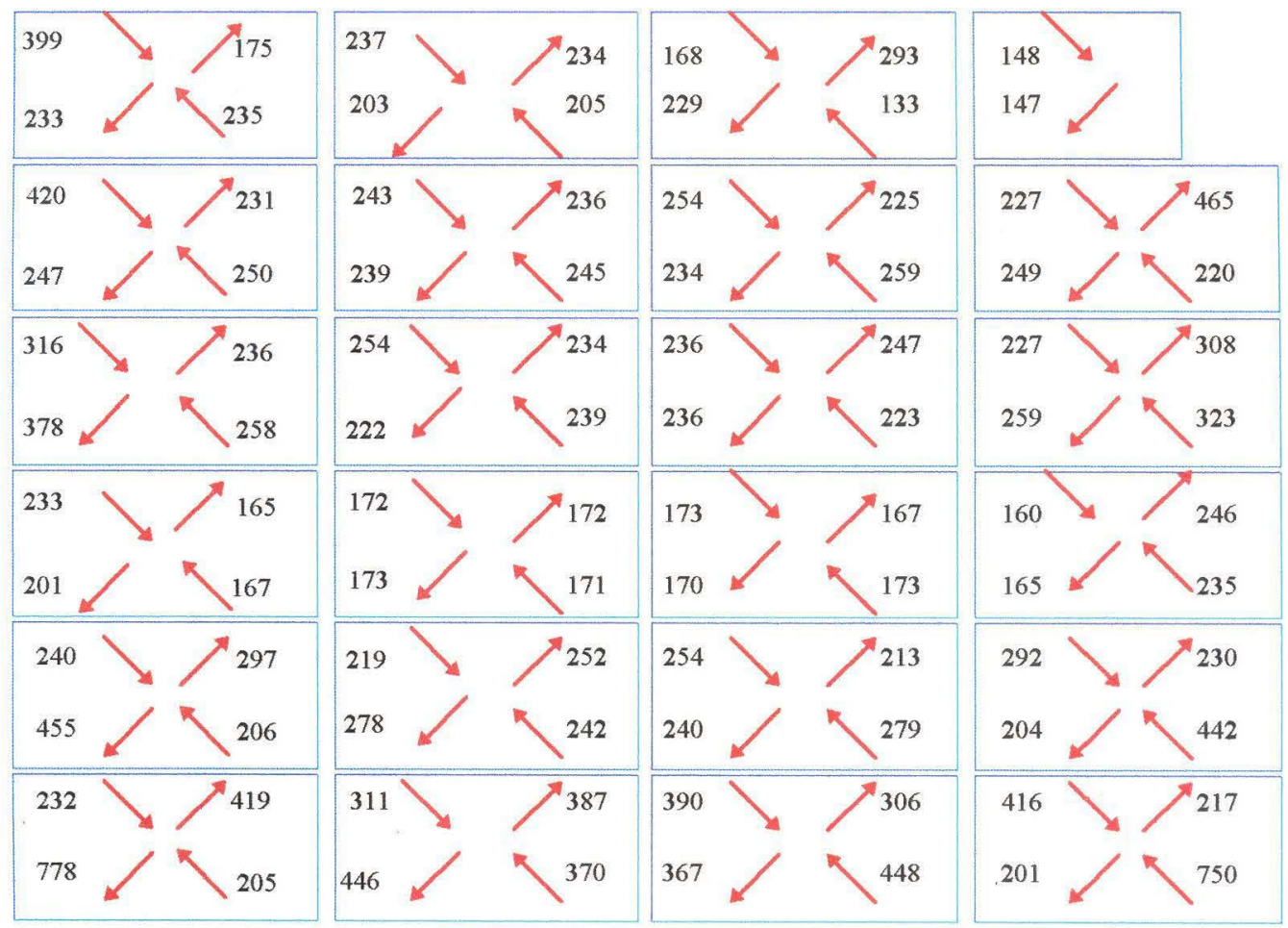

Figura 32- Esforços de cisalhamento em $\mathrm{kN}$; ação 2, pilares $400 \times 400 \mathrm{~mm}^{2}$, comprimento de pino de $10 \mathrm{~mm}$

\begin{tabular}{|c|c|c|c|c|c|c|c|}
\hline 5600 & 5700 & 8600 & 8500 & 5800 & 10500 & 5300 & \\
\hline 4700 & 7400 & 6900 & 7000 & 7600 & 4200 & 5300 & \\
\hline 7900 & 8000 & 8800 & 8600 & 9200 & 8200 & 8000 & 9600 \\
\hline 4700 & 8100 & 8700 & 8900 & 8600 & 9600 & 8000 & 4900 \\
\hline 5700 & 7800 & 9300 & 8500 & 8600 & 9000 & 7500 & 6100 \\
\hline 6120 & 8700 & 7900 & 7300 & 7200 & 8000 & 8800 & 6400 \\
\hline 4400 & 5100 & 5600 & 5600 & 5700 & 5400 & 5000 & 5100 \\
\hline 4300 & 5200 & 5700 & 5600 & 5500 & 5600 & 5100 & 5000 \\
\hline 4600 & 9900 & 7900 & 9100 & 9200 & 7700 & 9700 & 4800 \\
\hline 8600 & 7100 & 10300 & 9100 & 9000 & 10200 & 7100 & 9100 \\
\hline 5400 & 14100 & 12700 & 15200 & 15300 & 12500 & 14000 & 5100 \\
\hline 15300 & 8500 & 17800 & 15300 & 15200 & 17900 & 8300 & 16100 \\
\hline
\end{tabular}

Figura 33- Valores máximos das tensões em $\mathrm{kPa}$; ação 2, pilares $400 \times 400 \mathrm{~mm}^{2}$, comprimento de pino de $10 \mathrm{~mm}$ 